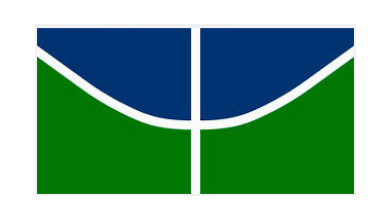

Universidade de Brasília

Instituto de Ciências Exatas

Departamento de Ciência da Computação

\title{
Gerenciamento de Riscos Operacionais em uma Operadora de Planos de Saúde por meio da Aplicação de Técnicas de Deteç̧ão de Anomalias e Análise Multicritério
}

\author{
Tiago Pereira Hillerman
}

\begin{abstract}
Dissertação apresentada como requisito parcial
para conclusão do Mestrado Profissional em Computação Aplicada

Linha de Pesquisa: Gestão de Riscos
\end{abstract}

Orientadora

Prof. ${ }^{\text {a }}$ Dr. ${ }^{\text {a }}$ Ana Carla Bittencourt Reis

Brasília 
Ficha catalográfica elaborada automaticamente, com os dados fornecidos pelo(a) autor(a)

HH652g Hillerman, Tiago Operadora de Planos de Saúde por meio da Aplicação de Técnicas de Detecção de Anomalias e Análise Multicritério / Tiago Hillerman; orientador Ana Carla Reis. -- Brasília, 2016.

$217 \mathrm{p}$.

Dissertação (Mestrado - Mestrado Profissional em Computação Aplicada) -- Universidade de Brasília, 2016.

1. gestão de riscos. 2. detecção de anomalias. 3. análise multicritério. 4. operadora de saúde. 5. mineração de dados. I. Reis, Ana Carla, orient. II. Título. 


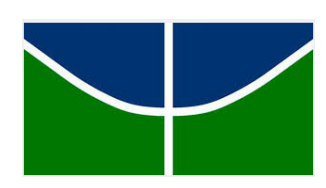

\author{
Universidade de Brasília \\ Instituto de Ciências Exatas \\ Departamento de Ciência da Computação
}

\title{
Gerenciamento de Riscos Operacionais em uma Operadora de Planos de Saúde por meio da Aplicação de Técnicas de Detecção de Anomalias e Análise Multicritério
}

\author{
Tiago Pereira Hillerman
}

\begin{abstract}
Dissertação apresentada como requisito parcial para conclusão do
\end{abstract} Mestrado Profissional em Computação Aplicada

\author{
Prof. ${ }^{\text {a }}$ Dr. ${ }^{\text {a }}$ Ana Carla Bittencourt Reis (Orientadora) \\ $\mathrm{EPR} / \mathrm{UnB}$
}

Prof. Dr. João Carlos Félix Souza

$\mathrm{EPR} / \mathrm{UnB}$
Prof. Dr. Wallace Anacleto Pinheiro Exército Brasileiro - CDS

Prof. Dr. Marcelo Ladeira

Coordenador do Programa de Pós-graduação em Computação Aplicada 


\section{Dedicatória}

Dedico este trabalho à minha família, que sempre me guiou para o caminho correto, e em especial minha esposa Amanda, que com o seu carinho e compreensão, me torna cada dia um homem melhor. 


\section{Agradecimentos}

Agradeço aos meus pais, que me deram todas as condições para realizar o meu potencial.

Ao Sr. Rubens e Sra. Isabel, que me incentivaram ao longo do curso.

À minha esposa Amanda, que esteve do meu lado em cada momento desta jornada.

Minha mais sincera gratidão aos meus colegas de ensino e trabalho e meus professores, em especial à Prof. ${ }^{\text {a }}$ Dr. ${ }^{a}$ Ana Carla Bittencourt Reis, que desde o primeiro momento me apoiou na realização de cada etapa deste projeto. 


\section{Resumo}

No mercado de saúde, o quadro de aumento de despesas médicas se agrava devido a uma convergência de fatores, oriundos de particularidades nos contextos legal, social e econômico. Considerando este cenário, o objetivo deste estudo é a apresentação e aplicação de metodologias qualitativas e quantitativas de análise de riscos em um dos principais processos organizacionais de uma operadora de planos de saúde. Especificamente, o processo avaliado é o de pagamento de contas médicas. Entre os objetivos específicos, buscou-se identificar as melhores práticas referentes à gestão de riscos. Em seguida, é realizado um diagnóstico da metodologia atual de avaliação de riscos existente na organização, com a proposta de integração das técnicas identificadas no decorrer do levantamento bibliográfico. Como resultado, há a proposta de alterações na metodologia atual utilizada na organização, cuja aplicação no processo avaliado resultou na identificação de um conjunto de riscos para tratamento. Entre estes, um dos mais críticos foi o de pagamento de cobranças abusivas em procedimentos assistenciais. Em seguida, são utilizadas técnicas de detecção de anomalias e análise multicritério para o tratamento do risco específico associado às cobranças excessivas de procedimentos assistenciais. Com a aplicação do modelo proposto para tratamento deste risco, foi possível identificar prestadores com indícios de irregularidades em suas cobranças. Considerando a escassez de recursos disponíveis para investigação de entidades suspeitas, foi elaborado um modelo de priorização de investigações, baseado no método de análise multicritério AHP Analytic Hierarchy Process.

Palavras-chave: gestão de riscos, análise multicritério, detecção de anomalias, operadora de saúde 


\section{Abstract}

In the healthcare market, the increasing costs associated with medical expenses are linked to a convergence of factors, arising from peculiarities in legal, social and economic contexts. Considering this scenario, the aim of this study is the presentation and application of qualitative and quantitative methods of risk analysis in one of the main business processes of a health insurance provider. Specifically, we evaluated the medical billings process. Among the specific objectives, we sought to identify the market's best practices related to risk management. This was followed by a diagnosis of the organization's current risk assessment methodology. Based on the review of available literature on the subject, there was a proposed integration of the identified techniques with the current methodology. The application of this new method for the evaluation of the existing risks in the claims processing workflow resulted in a set of risks identified for treatment. Among these, one of the most critical was the one associated with the payment of abusive healthcare service billings submitted by individual providers, related to medical visits and therapy sessions. Therefore, a new model, based on the concepts of anomaly detection, was used in order to analyze the organization's claims data, making it possible to identify a set of providers with evidence of irregularities in their submitted claims. Given the scarcity of resources available for the auditing of suspected entities, a multicriteria analysis model was developed, designed to prioritize these investigations.

Keywords: risk management, multi-criteria analysis, anomaly detection, healthcare service providers 


\section{Sumário}

1 Introdução 2

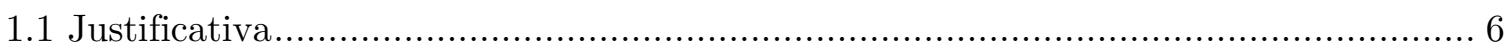

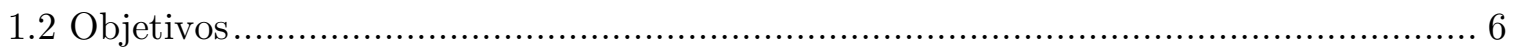

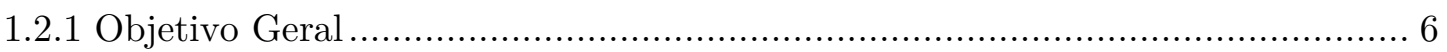

1.2.2 Objetivos Específicos ……………………………………………….... 7

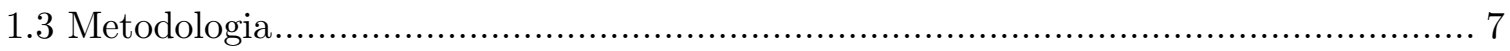

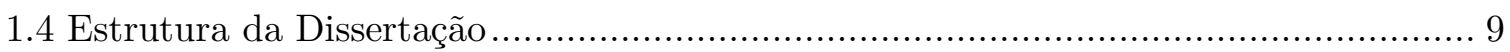

2 Base Conceitual $\quad 12$

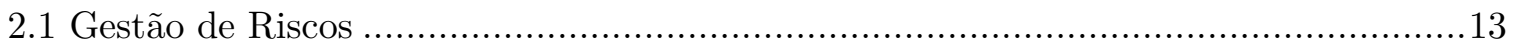

2.1.1 Modelos de Gestão de Riscos ……………………......................................

2.1.1.1 Enterprise Risk Management - ERM …………........................................

2.1.1.2 Gestão de Riscos - ABNT NBR ISO 31.000:2009 ……................................17

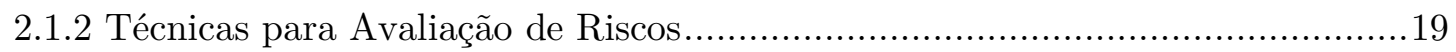

2.1.2.1 Autoavaliação de Riscos e Controles - RCSA ………………………........19

2.1.2.2 Análise de Modos e Efeitos de Falha - FMEA ……….................................23

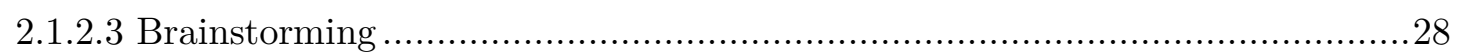

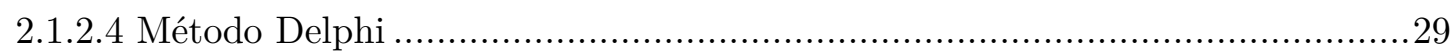

2.2 Deteç̧̃̃o de Anomalias em Conjuntos de Dados......................................................31

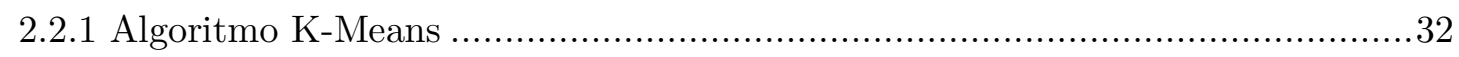

2.2.2 Algoritmo PAM (Partitioning Around Medoids) ............................................. 35

2.2.3 Clustering hierárquico (Hierarchical Clustering) .............................................

2.2.4 Determinando o número de clusters em um conjunto de dados..........................38

2.2.5 Processo Padrão Inter-Indústrias para Mineração de Dados - CRISP-DM........40

2.3 Modelos Multicritério de Apoio a Decisão ……………………………..............42

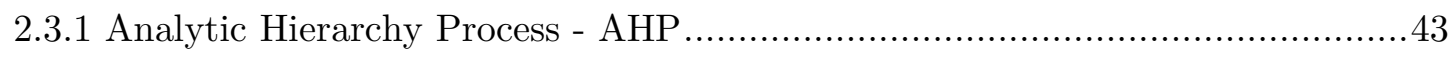

3 Revisão da Literatura

3.1 Gestão de Riscos no Mercado de Saúde ...................................................................

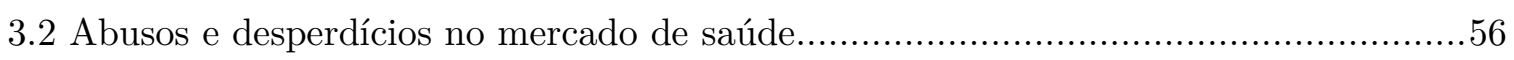

3.3 Aplicação de técnicas qualitativas e quantitativas para gestão de riscos operacionais

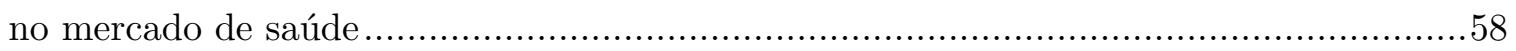

3.3.1 Gestão de riscos por meio da análise qualitativa .............................................58

3.3.2 Gestão de riscos por meio da análise multicritério ..........................................59

3.3.3 Gestão de riscos por meio da detecção de anomalias em bases de dados ...........61 


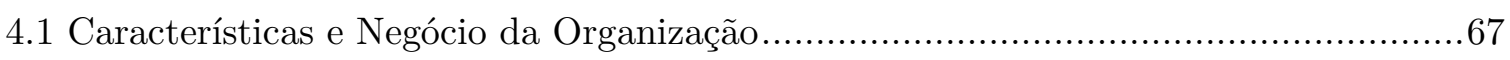

4.2 Processo de Pagamento de Contas Médicas ...........................................................69

4.2.1 Despesas Relacionadas ao Processo de Pagamento de Contas ..........................71

4.3 Contexto da Gestão de Riscos na Organização Avaliada ….....................................75

4.3.1 Metodologia Atual de Gestão de Riscos na Organização Avaliada ...................76

5 Nova Metodologia de Autoavaliação Aplicada ao Processo de Pagamento de Contas Médicas

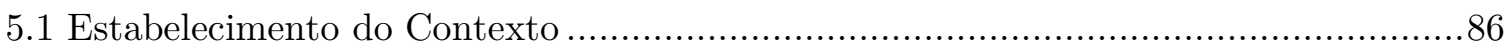

5.2 Avaliação de Riscos - por Atividade ............................................................... 87

5.2.1 Atividade 1 - Recepção, triagem, preparação e distribuição, às equipes de

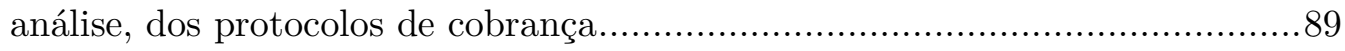

5.2.2 Atividade 2 - Verificação de protocolos digitados importados no sistema. Devolução de documentos com erro à Gerência de Atendimento......................90

5.2.3 Atividade 3 - Envio e recebimento de guias ao Núcleo de Auditoria .................91

5.2.4 Atividade 4 - Efetuar análise de cobranças médico-hospitalares .......................92

5.2.5 Atividade 5 - Envio e recebimento de ocorrências para regularização da área

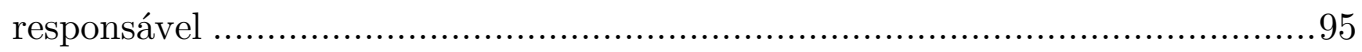

5.2.6 Atividade 6 - Devolução de guias e preparo de correspondência de devolução

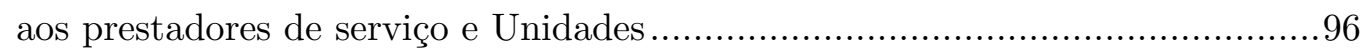

5.2.7 Atividade 7 - Mudança de fase de protocolos processados ............................97

5.2.8 Atividade 8 - Envio de contas processadas à Equipe de Conferência.................97

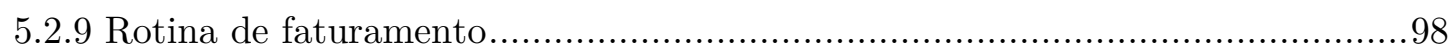

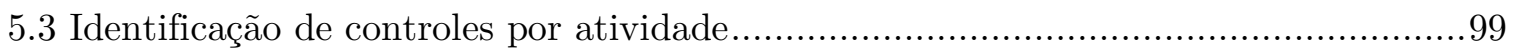

5.4 Consulta aos colaboradores e reanálise pela equipe de autoavaliação........................99

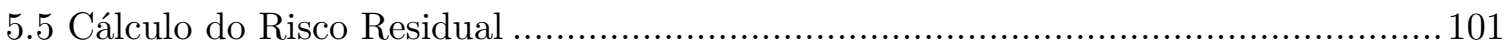

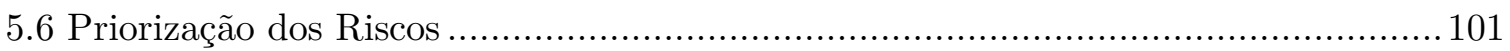

5.6.1 Mensuração do valor de Deteç̧ão, por risco identificado .............................. 101

5.6.2 Cálculo do valor de priorização (RPN) por risco........................................ 102

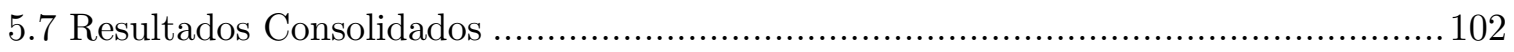

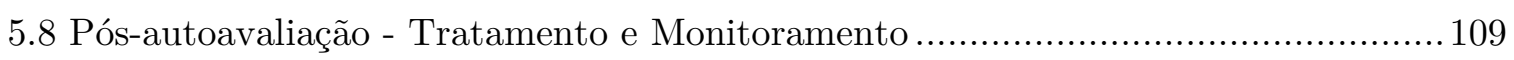

5.9 Resultado - Risco priorizado para análise quantitativa ...................................... 110

6 Modelo para Identificação de Cobranças Excessivas em Consultas Médicas 111

6.1 Entendimento do Negócio - definições iniciais ........................................................ 114

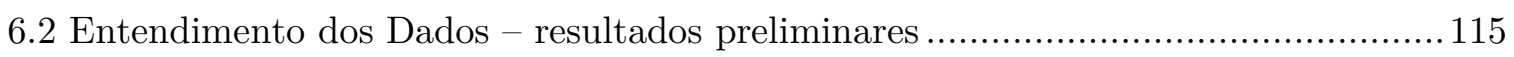

6.3 Entendimento do Negócio - análise do conjunto inicial ........................................ 118

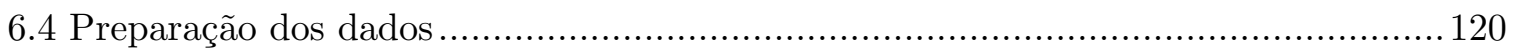

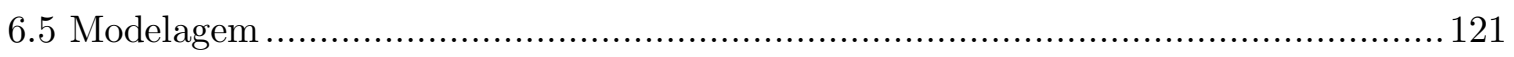

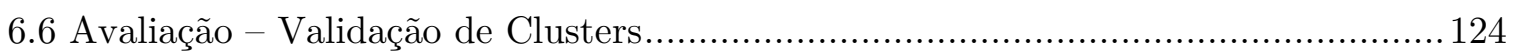


6.7 Implementação e Resultados.

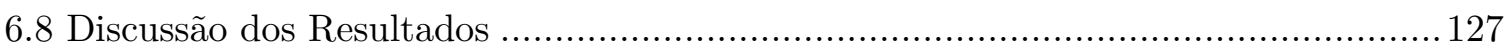

7 Modelo para Identificação de Cobranças Excessivas em Terapias Seriadas 129

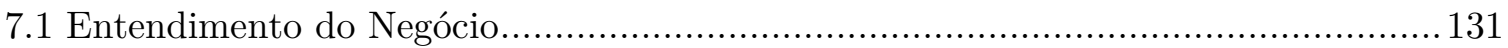

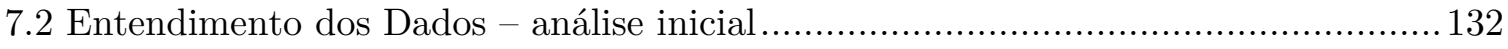

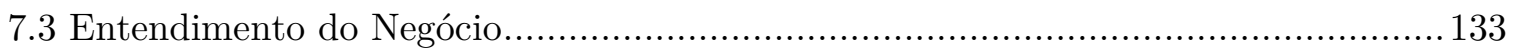

7.4 Entendimento dos Dados - identificação do subconjunto de entidades suspeitas .... 136

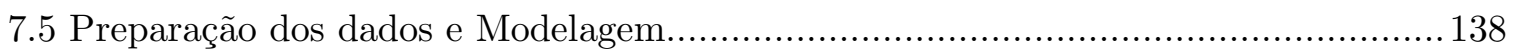

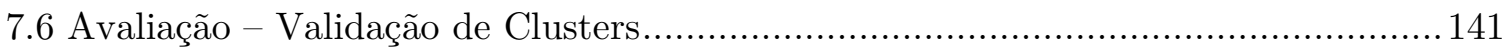

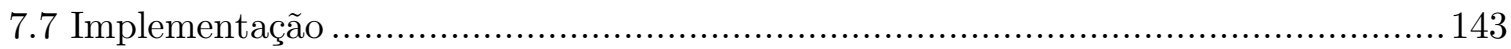

8 Priorização das Investigações com o Método AHP 144

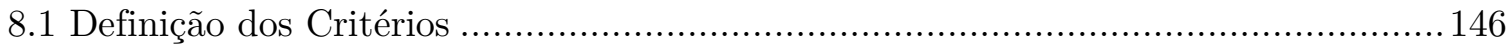

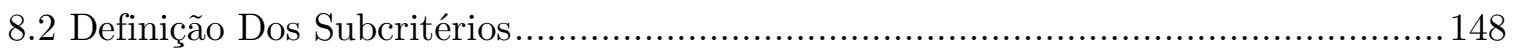

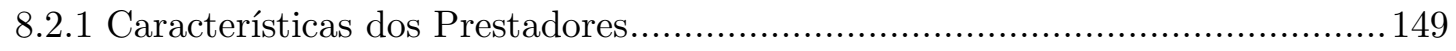

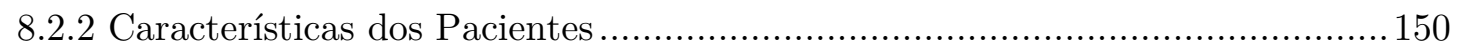

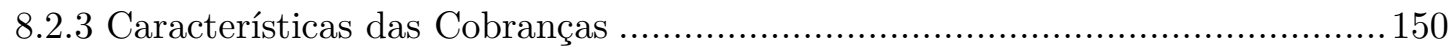

8.3 Resultados Dos Julgamentos, Por Nível Hierárquico ......................................... 151

8.3.1 Resultados dos julgamentos - Critérios em relação ao Objetivo..................... 151

8.3.2 Resultados dos julgamentos - Subcritérios em relação aos Critérios .............. 153

8.3.3 Resultados dos julgamentos - Alternativas por Subcritério........................... 155

8.3.3.1 Características dos Prestadores - Taxa de crescimento das despesas no

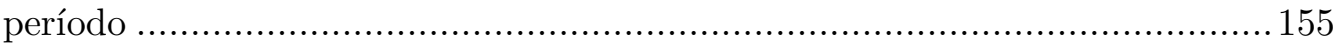

8.3.3.2 Características dos Prestadores - Envolvimento em investigações

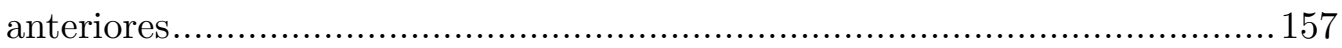

8.3.3.3 Características dos Prestadores - Tempo de credenciamento ............. 158

8.3.3.4 Características dos Pacientes - Percentual de pacientes localizados fora

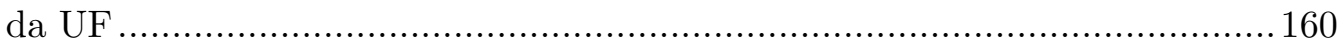

8.3.3.5 Características dos Pacientes - Percentual de pac. jovens ou idosos... 162 8.3.3.6 Características das Cobranças - Percentual de cobranças referentes a

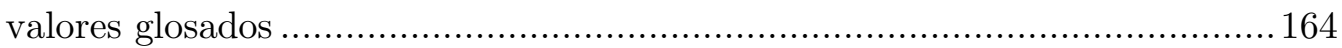

8.3.3.7 Características das Cobranças - Frequência média semanal dos

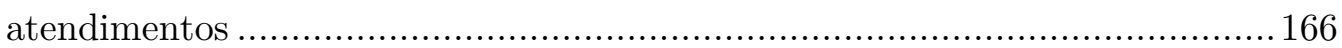

8.3.3.8 Características das Cobranças - Percentual de atendimentos em

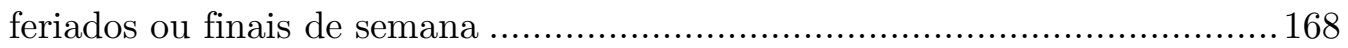

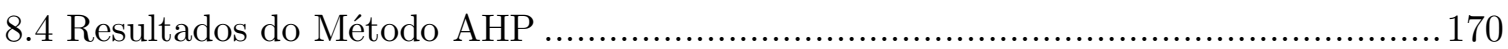

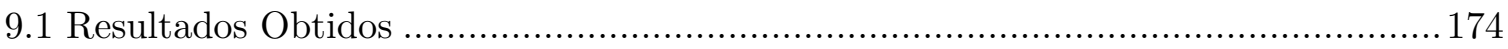

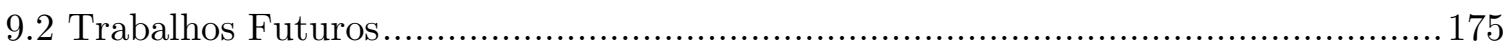


Apêndice I - Fluxograma do Processo de Pagamento de Contas Médicas

Apêndice II - Riscos Identificados no Processo de Pagamento de Contas Médicas - Subprocesso de Análise de Contas Médico-Hospitalares

Apêndice III - Formulário de Levantamento de Riscos 


\section{Lista de Figuras}

$\begin{array}{llr}1.1 & \text { Metodologia de Pesquisa } & 8\end{array}$

$\begin{array}{lll}1.2 & \text { Estrutura da Pesquisa } & 11\end{array}$

$2.1 \quad$ Estrutura da Base Conceitual 12

$\begin{array}{lll}2.2 & \text { Estrutura COSO } & 15\end{array}$

$\begin{array}{lll}2.3 & \text { Estrutura COSO ERM } & 16\end{array}$

$\begin{array}{lll}2.4 & \text { Modelo de gestão de riscos NBR ISO } 31000 & 18\end{array}$

$\begin{array}{lll}2.5 & \text { Escopo das oficinas de autoavaliação } & 20\end{array}$

2.6 Fluxo de avaliação processual do FMEA 25

2.7 Exemplo de clusterização via K-Means 33

2.8 Exemplo de clusterização via o algoritmo PAM 35

2.9 Exemplo de clusterização por meio do Clustering Hierárquico 37

2.10 Exemplo da soma dos erros para diferentes quantidades de clusters 39

2.11 Gráfico o método do "cotovelo" 39

2.12 Diagrama CRISP-DM 40

2.13 Exemplo de hierarquia AHP 44

2.14 Exemplo de cálculo de célula da nova matriz $\quad 47$

2.15 Resultado do cálculo dos pesos dos critérios 49

2.16 Visão geral do modelo AHP - exemplo 50

3.1 Revisão da Literatura 53

3.2 Modelo AHP desenvolvido por Saaty 60

4.1 Etapas do diagnóstico da organização avaliada 66

$\begin{array}{lll}4.2 & \text { Fluxo de prestação de serviços na instituição avaliada. } & 68\end{array}$

$\begin{array}{lll}4.3 & \text { Organograma da instituição avaliada } & 69\end{array}$

4.4 Fluxo interno do pagamento de contas médicas 70

$\begin{array}{lll}4.5 & \text { Gastos assistenciais, por ano, por tipo de procedimento (evento) } & 72\end{array}$

$\begin{array}{lll}4.6 & \text { Despesas por tipo de prestador, por ano } & 72\end{array}$

$\begin{array}{lll}\text { 4.7 } & \text { Quantidade de prestadores, por tipo, por ano } & 73\end{array}$

4.8 Prestadores "Pessoa Física" - despesas por tipo, por ano 74

4.9 Etapas da metodologia atual de riscos e controles da OPS $\quad 77$

4.10 Matriz de Probabilidade vs. Impacto utilizada na MARC 78

4.11 Pontuação por combinação de Criticidade x Impacto 82 
5.1 Proposta de novo fluxo de autoavaliação de riscos e controles 85

5.2 Fluxograma do subprocesso de análise de contas da OPS 88

5.3 Proposta de inclusão da técnica Delphi para a identificação de riscos 100

5.4 Riscos identificados nas atividades de análise de contas médicas 103

6.1 Etapas para criação do modelo de identificação de cobranças 112

$\begin{array}{lll}6.2 & \text { Exemplo de registro de cobrança suspeita } & 118\end{array}$

6.3 Número de clusters (4) definido por meio da técnica do "cotovelo" 121

6.4 Resultados da análise: QTDE_POR_DIA x DIAS_POR_MES 122

6.5 Resultados da análise: QTD_DIA x QTDE_POR_MES 123

7.1 Modelo de análise, por clusterização, de terapias seriadas 130

$\begin{array}{lll}7.2 & \text { Resultados da clusterização - algoritmo K-Means } & 139\end{array}$

$\begin{array}{lll}7.3 & \text { Resultados da clusterização - algoritmo PAM } & 140\end{array}$

$\begin{array}{lll}7.4 & \text { Resultados da clusterização - algoritmo HClust } & 140\end{array}$

$\begin{array}{lll}\text { 8.1 Etapas para construção do modelo AHP } & 145\end{array}$

8.2 Estrutura do modelo AHP - Objetivo e Critérios 146

$\begin{array}{lll}8.3 & \text { Modelo geral AHP } & 148\end{array}$

8.4 Representação gráfica dos pesos do Objetivo e Critérios 152

8.5 Modelo AHP - pesos atribuídos ao Objetivo, Critérios e Subcritérios 154

8.6 Visualização dos pesos para o critério "Característica prestadores" 160

8.7 Visualização dos pesos para o critério "Característica dos pacientes" 164

8.8 Visualização dos pesos para o critério "Característica das cobranças" 170 


\section{Lista de Tabelas}

2.1 Comparativo entre os termos do FMEA e RFMEA 27

2.2 Cálculo do Vetor de Eigen 48

2.3 Julgamentos das alternativas em relação aos critérios 49

2.4 Cálculo de pesos para critério objetivo 49

2.5 Cálculo final para escolha da alternativa 50

2.6 Índices aleatórios calculados por Saaty $\quad 51$

2.7 Exemplo de cálculo de Ymax $\quad 51$

$\begin{array}{lll}5.1 & \text { Classificação dos riscos identificados } & 104\end{array}$

$\begin{array}{lll}6.1 & \text { Atributos considerados na análise } & 116\end{array}$

6.2 Distribuição do campo "Atends por dia" dos prestadores 117

6.3 Resultados da Análise Inicial - Cobranças em consultas 119

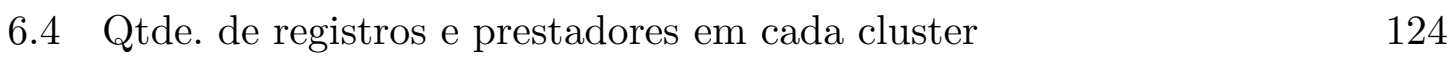

6.5 resultados da clusterização: média e desvio padrão 125

6.6 Matriz de correlação entre as variáveis clusterizadas 125

$\begin{array}{lll}6.7 & \text { Matriz de probabilidade } & 126\end{array}$

7.1 Atributos considerados na análise 133

7.2 Exemplo de possíveis cobranças excessivas em psicoterapia 134

$\begin{array}{lll}7.3 & \text { Resultados dos questionários aplicados aos participantes } & 135\end{array}$

$\begin{array}{lll}7.4 & \text { Resultados da análise inicial } & 136\end{array}$

7.5 Entidades identificadas em cada cluster, por algoritmo 141

$\begin{array}{lll}\text { 7.6 } & \text { Entidades identificadas em cada cluster, por algoritmo } & 142\end{array}$

$\begin{array}{lll}7.7 & \text { Resultados finais da análise de sessões de psicoterapia } & 143\end{array}$

8.1 Pesos resultantes das comparações entre Critérios 152

$\begin{array}{lll}8.2 & \text { Pesos atribuídos aos subcritérios } & 154\end{array}$

8.3 Taxa de crescimento das despesas, por prestador 155

8.4 Tx. de crescimento das despesas - valores de intensidade 156

8.5 Tx. de crescimento das despesas - Comparação de alternativas $\quad 156$

8.6 Tx. de crescimento das despesas - pontuação das alternativas $\quad 156$

8.7 Envolvimento em investigações - comparação de alternativas 157

8.8 Envolvimento em investigações - pontuação das alternativas 158

8.9 Tempo de credenciamento - intensidades para comparação 158

8.10 Tempo de credenciamento - comparação entre alternativas $\quad 159$ 
8.11 Tempo de credenciamento - pesos das alternativas

8.12 Percentual de pacientes localizados fora do Estado - por prestador 160

8.13 Percentual de pacientes localizados fora do Estado - comparações 161

8.14 Percentual de pacientes localizados fora do Estado - pesos 161

8.15 Percentual de pacientes jovens ou idosos - por prestador 162

8.16 Percentual de pacientes jovens ou idosos - intensidades 162

8.17 Percentual de pacientes jovens ou idosos - comparações 163

8.18 Percentual de pacientes jovens ou idosos - pesos por prestador 163

8.19 Percentual de cobranças referentes a valores glosados 165

8.20 Percentual de cobranças referentes a valores glosados - julgamentos 165

8.21 Percentual de cobranças referentes a valores glosados - pesos $\quad 165$

8.22 Frequência média semanal dos atendimentos - por prestador $\quad 166$

8.23 Frequência média semanal dos atendimentos - intensidades $\quad 166$

8.24 Frequência média semanal dos atendimentos - comparações $\quad 167$

8.25 Frequência média semanal dos atendimentos - pesos 167

8.26 Atendimentos em feriados ou finais de semana - por prestador 168

8.27 Atendimentos em feriados ou finais de semana - comparações $\quad 169$

8.28 Atendimentos em feriados ou finais de semana - pesos 169

8.29 Resultados finais do modelo AHP 


\section{Lista de Quadros}

2.1 Formulário Padrão do FMEA 26

2.2 Pseudo-código do algoritmo K-Means 33

2.2 Escala fundamental de Saaty, para comparações par a par 45

2.3 Matriz de comparação entre critérios $\quad 45$

2.4 Matriz de comparação entre critérios, com julgamentos 46

2.5 Conversão, em valores, da matriz de comparação entre critérios $\quad 46$

2.6 Resultados do cálculo da nova matriz de valores 47

$\begin{array}{lll}2.7 & \text { Cálculo final da nova matriz de valores } & 47\end{array}$

2.8 Cálculo do $1^{\mathrm{O}}$ Vetor de Eigen 48

$\begin{array}{lll}4.1 & \text { Formulário Padrão da MARC } & 78\end{array}$

$\begin{array}{lll}4.2 & \text { Categorias de risco na OPS } & 79\end{array}$

4.3 Valores de Nível de Confiança de controles 80

4.4 Pontuação do Nível de Confiança dos controles identificados 81

5.1 Riscos identificados na atividade de recepção e distribuição dos $\begin{array}{ll}\text { protocolos de cobrança } & 89\end{array}$

5.2 Riscos identificados na atividade de verificação e devolução de documentos com erro. $\quad 90$

5.3 Riscos identificados na atividade de envio e recebimento de guias ao $\begin{array}{ll}\text { Núcleo de Auditoria .. } & 91\end{array}$

5.4 Riscos identificados na análise de cobranças médico-hospitalares 93

5.5 Riscos identificados na atividade de envio e recebimento de ocorrências para regularização

5.6 Riscos identificados na atividade de devolução de guias aos $\begin{array}{ll}\text { prestadores e Unidades } & 96\end{array}$

5.7 Riscos identificados na atividade de mudança de fase de $\begin{array}{ll}\text { protocolos processados } & 97\end{array}$

5.8 Riscos identificados na atividade de encaminhamento de guias para Conferência 98

5.9 Quantidade de riscos, por categoria, em cada atividade do processo 105

5.10 Riscos indicados para tratamento, pela nova metodologia 108

5.11 Detalhamento do risco de cobranças abusivas, levantado no decorrer da avaliação

8.1 Escala Saaty para comparações par a par 
8.2 Comparações entre Critérios

152

8.3 Comparação de subcritérios em relação aos Critérios 


\section{Lista de Gráficos}

5.1 Quantidade de riscos identificados, por subcategoria 104

5.2 Quantitativo de riscos inaceitáveis por atividade do processo 106

5.3 Distribuição dos valores de prioridade dos riscos identificados $\quad 106$

5.4 Riscos priorizados - pontuação RPN vs. Riscos Residuais 107

$\begin{array}{lll}5.5 & \text { Riscos priorizados na nova metodologia } & 108\end{array}$ 


\title{
Lista de Abreviaturas e Siglas
}

\author{
AAA American Accounting Association \\ AHP Analytic Hierarchy Process \\ ANS Agência Nacional de Saúde Suplementar \\ BACEN Banco Central do Brasil \\ COSO Comitee of Sponsoring Organizations of the Treadway Commission \\ COSO ERM Enterprise Risk Management - definição do COSO \\ CRISP-DM Cross-Industry Standard Process for Data Mining \\ DEA Data Envelopment Analysis \\ ERM Enterprise Risk Management \\ FMEA Failure Mode and Effects Analysis \\ GCM Gerência de Contas Médicas \\ GRCI Gerência de Riscos e Controles Internos \\ IF Instituição Financeira patrocinadora da OPS \\ IMA Institute of Management Accountants \\ IIA Institute of Internal Auditors \\ MARC Metodologia de Autoavaliação de Riscos e Controles \\ OPME Órteses, próteses, e materiais especiais \\ OPS Operadora de Planos de Saúde \\ RCSA Risk and Control Self-Assessment \\ RPN Risk Priority Number \\ SQL Structured Query Language \\ SUS Sistema Único de Saúde \\ TISS Padrão para Troca de Informações na Saúde Suplementar
}


Parte I 


\section{Capítulo 1}

\section{Introdução}

Existe uma crescente tendência por parte de organizações e órgãos reguladores para a implantação de novos mecanismos de controle, na tentativa de mitigar os riscos presentes nos seus contextos internos e externos. Tratam-se de esforços constantes para o desenvolvimento de soluções para identificação de operações ilícitas e abusos, assim como a redução de ineficiências e desperdícios em processos organizacionais.

O Instituto Brasileiro de Governança Corporativa [47] identifica o risco como sendo um "evento futuro identificado, ao qual é possível associar uma probabilidade de ocorrência", relacionado tanto a perdas quanto oportunidades. Para [47], cabe a todas as áreas de uma organização a responsabilidade de lidar com os riscos inerentes aos seus processos, administrando-os de forma a auxiliar os gestores na tomada de decisões.

Historicamente, é possível verificar que a evolução dos principais modelos de gestão de riscos e implantação de controles foram impulsionados por desenvolvimentos relacionados ao mercado financeiro [17]. Contudo, o gerenciamento de riscos não está relacionado apenas às instituições desta natureza. Os desafios associados às perdas operacionais e ao aumento de despesas são de interesse de instituições de grande porte em vários setores da economia, inclusive na área de seguros de saúde.

No mercado brasileiro, estima-se que, em 2014, $10 \%$ do PIB tenha sido consumido por gastos com saúde [13], sendo que a tendência do aumento do índice de inflação deste setor em 2015, de 18,09\%, foi mais de três vezes superior ao índice de inflação geral do país, conforme dados da consultora [4]. Trata-se de um fato alarmante, pois conforme exposto por [13], na América Latina apenas a Venezuela apresentou uma taxa de crescimento de despesas assistenciais superior à Brasileira. Acrescenta-se a 
isso o fato de que a maior parte dos custos assistenciais (em torno de 60\%) foi absorvido pelo setor privado.

Contudo, este fenômeno não se restringe ao ambiente latino-americano, mas faz parte de uma tendência mundial [97]. A consultora [107] recentemente publicou uma pesquisa ligada à análise de despesas médicas, envolvendo cerca de 170 operadoras de saúde em 58 países, onde constatou que a inflação das despesas de saúde apresentou, entre 2013 e 2014, crescimento duas vezes maior que o índice de inflação geral.

Para as operadoras de planos de saúde que buscam assegurar ações efetivas de atenção à saúde aliada à redução de custos, o foco da gestão de riscos certamente estará voltado à prevenção de eventos que contribuam para o incremento das despesas médicas oriundas da população assistida, ou que afetem negativamente a eficiência da organização no atendimento de seus objetivos, relacionados principalmente à prestação de serviços assistenciais [35].

No mercado de saúde, o quadro de aumento de despesas médicas se agrava devido a uma convergência de fatores, muitas vezes externos às operadoras, pois são oriundos de particularidades dos contextos legal, social e econômico nos quais elas estão inseridas.

No âmbito legal, cabe ressaltar que o principal marco regulatório no mercado de saúde suplementar brasileiro envolveu a aprovação da lei dos Planos de Saúde 9.656/1998 [23], que definiu a ampliação da cobertura assistencial e apresentou novas regras relacionadas ao acompanhamento de preços pelo governo, limitação dos prazos de carência e a obrigatoriedade de ressarcimento ao SUS, sempre que um de seus participantes for atendido em hospital público. No Brasil, a regulamentação do mercado de saúde suplementar é de responsabilidade da Agência Nacional de Saúde Suplementar - ANS, criada por meio da Lei n. 9.961/2000 [24]. Cabe a esta Agência regular, normatizar, controlar e fiscalizar as atividades de saúde suplementar [82]. Neste contexto, [63] avalia que dentre os principais impactos judiciais às operadoras está a crescente concessão de liminares judiciais impetradas pelos participantes, muitas vezes frutos de análises superficiais, feitas pela justiça, dos respectivos pedidos, gerando um consequente aumento nas despesas administrativas e jurídicas das instituições.

No ambiente econômico, são evidentes os efeitos do crescente aumento dos custos assistenciais, que ocorre em patamares muito superiores aos das receitas das organizações. Este impacto é sentido na maior parte das operadoras de mercado, com maior intensidade nas autogestões, especialmente nas que possuem cobertura mais 
ampla, maior quantidade de participantes idosos e abrangência nacional [12] Conforme [98], a elevação dos custos assistenciais é motivada por diversos fatores, como o aumento de preços dos serviços de saúde (ligada, em parte, aos reajustes concedidos aos prestadores de serviços), a ampliação de coberturas e incremento na quantidade de procedimentos realizados (como internações, exames, terapias e consultas) e à incorporação de inovações tecnológicas e novos medicamentos [13].

Visando atender aos desafios atuais e futuros decorrentes das evoluções no contexto social, as organizações buscam incorporar, às suas ações de promoção de saúde, as diretrizes dos modelos de Assistência Integral [78], com enfoque preventivo nas práticas assistenciais e investimentos em sistemas de informação em saúde. Além disso, busca-se encontrar mecanismos racionais de escolha de prestadores (com uma seleção que considere critérios de eficiência, avaliações de qualidade e satisfação dos participantes). Por meio destas e outras medidas, as seguradoras esperam enfrentar futuras tendências do mercado de saúde suplementar, como a estagnação no crescimento do número de participantes e as alterações na legislação dos planos de autogestão que, no mercado brasileiro, são caracterizadas pela crescente interveniência da ANS [82].

Segundo [88], as dificuldades relacionados à criação de controles no fluxo de pagamento de despesas médicas são enfrentados por diversas operadoras de saúde, tanto no setor privado quanto governamental. Isto se dá, em grande parte, ao enorme volume de registros processados, das regras e regulamentos empresariais, e à complexidade dos procedimentos médicos. Para os autores, os analistas das áreas de auditoria de contas encontram-se sobrecarregados com a grande quantidade de informações, e não dispõem de recursos ou técnicas suficientes para a detecção de inconsistências, abusos e erros que resultam em gastos desnecessários, atrasos no pagamento (gerando atritos junto à rede credenciada) e negativas indevidas para a cobertura de procedimentos (resultando, neste caso, em um aumento no índice de insatisfação dos participantes da operadora) [88]. Além disso, conforme exposto por [31], há uma escassez de ferramentas comerciais destinadas ao acompanhamento automatizado do comportamento de prestadores de serviços médicos, o que permitiria às operadoras a identificação tempestiva de atividades anômalas e suspeitas.

Neste contexto, formula-se o problema de pesquisa com o seguinte questionamento: Como realizar o gerenciamento de riscos operacionais no processo de análise de contas médicas de uma operadora de planos de saúde? 
Sendo assim, este estudo busca auxiliar o gerenciamento de riscos nesse processo específico, que está diretamente relacionado ao negócio principal da instituição avaliada, identificada na pesquisa pela sigla 'OPS' (operadora de planos de saúde). Para tanto, o primeiro passo é a revisão do estado da arte relacionado ao tema, com o levantamento de técnicas que auxiliem a identificação de falhas nos processos da organização.

Houve a identificação de oportunidades para a evolução da metodologia atual de análise de riscos utilizada pela entidade, com a proposta de incorporação de uma extensão da técnica FMEA (Failure Mode and Effects Analysis), denominada RFMEA [28], ao modelo existente, construído com base nas diretrizes do Risk and Control Self-Assessment (RCSA, sigla em inglês para Autoavaliação de Riscos e Controles) [80].

Em seguida, a metodologia é utilizada para avaliar o fluxo de análise de contas médico-hospitalares da OPS, identificando-se os principais riscos e controles relacionados à cada atividade do processo.

Ainda no contexto do processo avaliado, e considerando um dos principais riscos apontados - a possibilidade de perdas oriundas de cobranças abusivas de despesas médicas - é realizada uma discussão sobre as principais dificuldades encontradas por empresas neste setor para a mitigação de riscos desta natureza.

A partir destas, propõe-se a criação de modelos quantitativos de controle para o tratamento dos riscos apontados por especialistas da área de negócio. Esta etapa envolve a construção de um modelo automatizado de análise comportamental, que pretende trazer mais agilidade às atividades de auditoria de registros suspeitos de pagamentos de contas médicas. Utilizando a metodologia CRISP-DM (sigla para Cross-Industry Standard Process for Data Mining, ou Processo Padrão InterIndústrias para Mineração de Dados) [32], juntamente com a aplicação de algoritmos de clusterização, é proposto um modelo para análise do comportamento de entidades envolvidas em práticas de cobrança suspeitas. São apresentadas as aplicações deste modelo de análise em dois conjuntos de dados distintos, abrangendo diferentes tipos de procedimentos (consultas em consultório e sessões de psicoterapia), demonstrando como o modelo poderia ser expandido para diferentes tipos de cobranças médicohospitalares.

Por fim, para facilitar a investigação das entidades suspeitas identificadas no modelo de clusterização, é estabelecido um parâmetro de priorização das análises por meio do método de análise multicritério AHP (Analytic Hierarchy Process) [93]. A 
aplicação deste método tem como objetivo a melhoria da eficiência das atividades de investigação, considerando as várias limitações existentes em termos de mão de obra e tempo disponível para a avaliação de prestadores de serviço que apresentam cobranças potencialmente abusivas.

Como contribuição principal, espera-se integrar, ao padrão de gestão de riscos da operadora, um conjunto de práticas que traga maior eficiência no decorrer das atividades de identificação, avaliação, tratamento e monitoramento dos riscos identificados no processo de pagamento de despesas assistenciais.

\section{$1.1 \quad$ Justificativa}

Para [6], processos podem ser definidos como conjuntos sequenciados de atividades, formadas por tarefas necessárias para administrar ou operar uma organização.

O foco desta pesquisa é a construção de um modelo que integre o processo de gestão de riscos com os processos organizacionais de uma operadora de planos de saúde, com ênfase no fluxo de pagamento de contas médicas.

O estudo é justificado devido à necessidade de se manterem atualizadas as metodologias e práticas adotadas pela instituição na sua gestão de riscos. Estas atividades visam atingir e manter um nível adequado de exposição aos diversos fatores que venham a impedir o cumprimento de seus objetivos e a continuidade de seus negócios. Para tanto, busca-se a criação de mecanismos que venham a reduzir a possibilidade de perdas financeiras relacionadas, principalmente, ao processamento de despesas assistenciais.

\section{$1.2 \quad$ Objetivos}

\subsubsection{Objetivo Geral}

O objetivo geral deste projeto de pesquisa é o gerenciamento de riscos operacionais no processo de pagamento de contas médicas de uma operadora de planos de saúde. Para tanto, é realizada a integração de técnicas de detecção de anomalias e métodos de análise multicritério à sua metodologia de avaliação de riscos. 


\subsubsection{Objetivos Específicos}

1. Identificar as melhores práticas referentes à gestão de riscos, por meio do estudo de metodologias, padrões, normas e tecnologias;

2. Realizar um diagnóstico da metodologia atual de gestão de riscos da organização;

3. Propor uma nova metodologia de gestão de riscos, por meio da combinação entre a metodologia existente e as técnicas identificadas por meio do levantamento bibliográfico;

4. Aplicar a metodologia desenvolvida no processo de análise e pagamento de contas médicas, identificando o conjunto de riscos a serem priorizados para tratamento;

5. Propor um modelo para análise quantitativa para tratamento do risco associado a cobranças excessivas de procedimentos assistenciais;

6. Propor um modelo para priorizar as investigações referentes às entidades suspeitas, apontadas pelo modelo de análise quantitativa.

\subsection{Metodologia}

A pesquisa, para [62], é caracterizada como um "procedimento formal, com método de pensamento reflexivo, que requer um tratamento científico e se constitui no caminho para reconhecer a realidade ou para descobrir verdades parciais". Já o método, para essas mesmas autoras, é

"o conjunto das atividades sistemáticas e racionais que, com maior segurança e economia, permite alcançar o objetivo conhecimentos básicos e verdadeiros -, traçando o caminho a ser seguido, detectando erros e auxiliando as decisões do cientista" $[62]$.

Este trabalho considera os fatores e conhecimentos relacionados ao gerenciamento de riscos corporativos à luz de um embasamento normativo e teórico, assim como a elaboração, para a uma organização específica, de um conjunto de propostas para a melhoria de seus controles internos. Por consequência, pode ser 
caracterizado como uma pesquisa de natureza descritiva, que tem como objetivo "analisar, com a maior precisão possível, fatos ou fenômenos em sua natureza e características, procurando observar, registrar e analisar suas relações, conexões e interferências" [71].

A visão geral do estudo é descrita conforme a Figura 1.1:

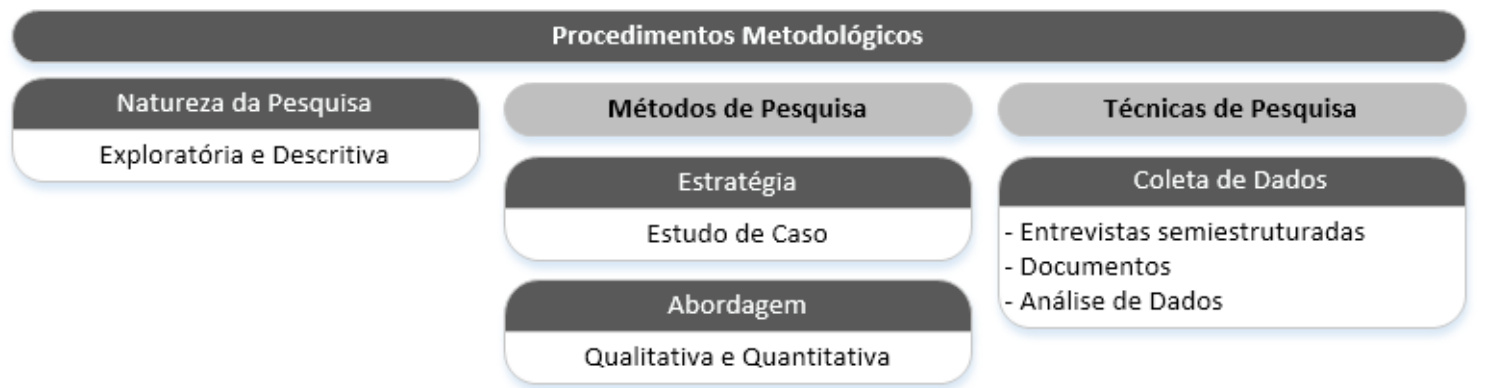

Figura 1.1: Metodologia de Pesquisa

Contudo, o levantamento bibliográfico e apresentação da base conceitual sobre os temas de gestão de riscos corporativos, análise multicritério e detecção de anomalias também deu a este trabalho um caráter exploratório, pois envolveu a análise de técnicas que poderiam ser utilizadas a fim de cumprir os objetivos da pesquisa, o estudo de diferentes autores e pesquisadores, assim como a coleta de informações a respeito dos fenômenos que estão sendo avaliados.

Após a pesquisa bibliográfica, ocorre a fase de levantamento de dados sobre a instituição, que é descrita por [62] como "a análise minuciosa de todas as fontes documentais, que sirvam de suporte à investigação projetada". Esse levantamento foi feito com o auxílio de informações disponíveis no sistema interno da empresa, como estudos anteriores, históricos organizacionais e relatórios.

Quanto à forma de abordagem, o trabalho necessitou de uma pesquisa qualitativa para a etapa de análise de riscos existentes no processo de pagamento de contas médicas. Conforme [96], a investigação qualitativa envolve a coleta de dados, sem o objetivo específico de reduzi-los à números ou avaliá-los estatisticamente. O autor apresenta diversas atividades do "pesquisador qualitativo", entre elas a observação de atividades cotidianas, o envolvimento direto com os indivíduos avaliados e um ponto de vista que considera os fenômenos como um todo, e não apenas suas partes individuais.

Por outro lado, a segunda etapa da pesquisa abordou o estudo de uma base de dados ligados a despesas assistenciais, referentes a um período específico, que vai de 
janeiro a dezembro de 2013. Sendo assim, também foi necessária a realização de uma pesquisa quantitativa, ou seja, uma "busca de resultados precisos, exatos e comprovados por meio de medidas de variáveis preestabelecidas, na qual se procura verificar e explicar sua influência sobre outras variáveis" [71].

Segundo [42], para a avaliação de resultados de uma pesquisa, "torna-se necessário saber como os dados foram obtidos, bem como os procedimentos adotados em sua análise e interpretação". Para a elaboração deste trabalho, a coleta de dados para o estudo qualitativo foi realizada por meio da análise da documentação direta, que [62] consideram como documentos escritos "primários", neste caso compostos por publicações administrativas compilados pelo autor. A análise estrutural foi feita utilizando informações contidas nos normativos internos da empresa, disponíveis na intranet da instituição, que detalham os procedimentos de implantação e gerenciamento de seus processos.

Já o estudo das práticas de cobrança ligadas a despesas assistenciais foi realizado mediante análise de dados extraídos de bancos de dados institucionais, que apresentam as informações sobre despesas médicas referentes ao intervalo de tempo citado anteriormente. Esses dados foram manipulados utilizando o software RStudio [92] e os programas Microsoft Access e Microsoft Excel, versão 2010. Este último serviu para a construção de gráficos informativos, que "objetivam dar ao público ou ao investigador um conhecimento da situação real, atual, do problema estudado" [62].

Conforme a metodologia descrita acima, a próxima seção da pesquisa apresenta os modelos de gestão de riscos, assim como as técnicas e ferramentas utilizadas pelas organizações para mitigar os efeitos de possíveis falhas em seus processos internos.

\subsection{Estrutura da Dissertação}

O presente trabalho foi dividido em três partes. Após a introdução, a primeira parte do trabalho apresenta a base conceitual da pesquisa, composta por conceitos e modelos existentes para a gestão de riscos corporativos e para a detecção de anomalias em conjuntos de dados. Em seguida, a revisão da literatura aborda o tema de gestão de riscos no mercado de saúde, contendo uma breve discussão a respeito dos abusos e desperdícios existentes atualmente neste setor, assim como a identificação de técnicas para detecção de cobranças médicas abusivas e investigação 
de entidades suspeitas. Conclui-se a primeira parte da pesquisa com o diagnóstico da entidade avaliada, contemplando uma breve descrição do seu negócio, sua estrutura organizacional, e do seu processo-chave, introduzindo o contexto atual da gestão de riscos na empresa.

A segunda parte do estudo descreve as propostas de três modelos. O primeiro serve para levantar os riscos existentes no processo avaliado. Esta proposta de metodologia de autoavaliação de riscos e controles, que combina os conceitos atuais de RCSA e RFMEA, é aplicada no processo de pagamento de contas médicas da instituição. Como resultado, é detalhado o conjunto de riscos identificados no processo, sendo um deles - a possibilidade de cobranças assistenciais abusivas apontado como o mais crítico, em decorrência da pontuação obtida após a aplicação da metodologia. Em seguida, é apresentado um modelo para o tratamento deste risco específico, cuja construção teve como base o padrão CRISP-DM e técnicas de detecção de anomalias por meio da clusterização. A construção do modelo é detalhada pelas etapas de entendimento do negócio, preparação dos dados, criação e avaliação dos resultados obtidos. Este modelo é aplicado em dois conjuntos de dados, envolvendo cobranças de consultas médicas e sessões de psicoterapia, ambos identificados como sendo de maior representatividade financeira em relação ao tipo de prestador avaliado (pessoas físicas). Por fim, o terceiro modelo aborda a priorização da análise de entidades suspeitas apontadas pelo modelo de detecção de anomalias. São detalhados os resultados obtidos e as pesquisas em andamento, assim como as propostas de possíveis melhorias no processo de avaliação de riscos da organização, que poderão ser desenvolvidas em trabalhos futuros.

A pesquisa está estruturada conforme o fluxo apresentado na Figura 1.2. 


\section{Problema de Pesquisa}

Como realizar o gerenciamento de riscos operacionais no processo de análise de contas médicas de uma operadora de planos de saúde?

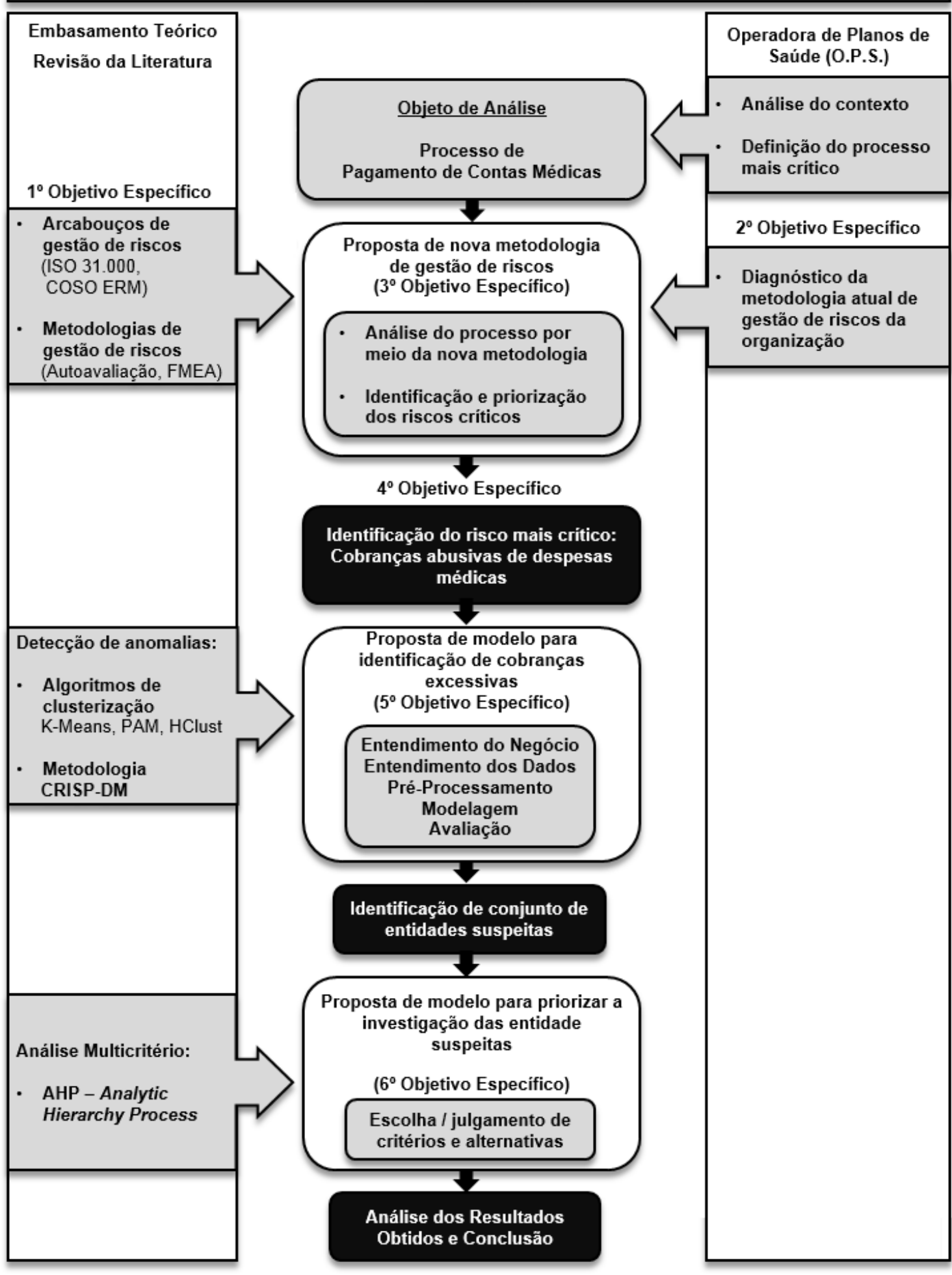

Figura 1.2: Estrutura da Pesquisa 


\section{Capítulo 2}

\section{Base Conceitual}

A construção da base conceitual é realizada por meio da discussão a respeito dos conceitos necessários para o melhor entendimento do modelo proposto, como as definições de risco, gestão de riscos, e de técnicas de avaliação de riscos. Entre estas, destacam-se técnicas qualitativas (Autoavaliação de Riscos, FMEA, Brainstorming e Delphi) e quantitativas (detecção de anomalias em conjuntos de dados e modelos multicritério de apoio a decisão). A Figura 2.1 detalha a estrutura adotada para este Capítulo, apresentando a visão geral dos temas abordados.

\section{Base Conceitual}

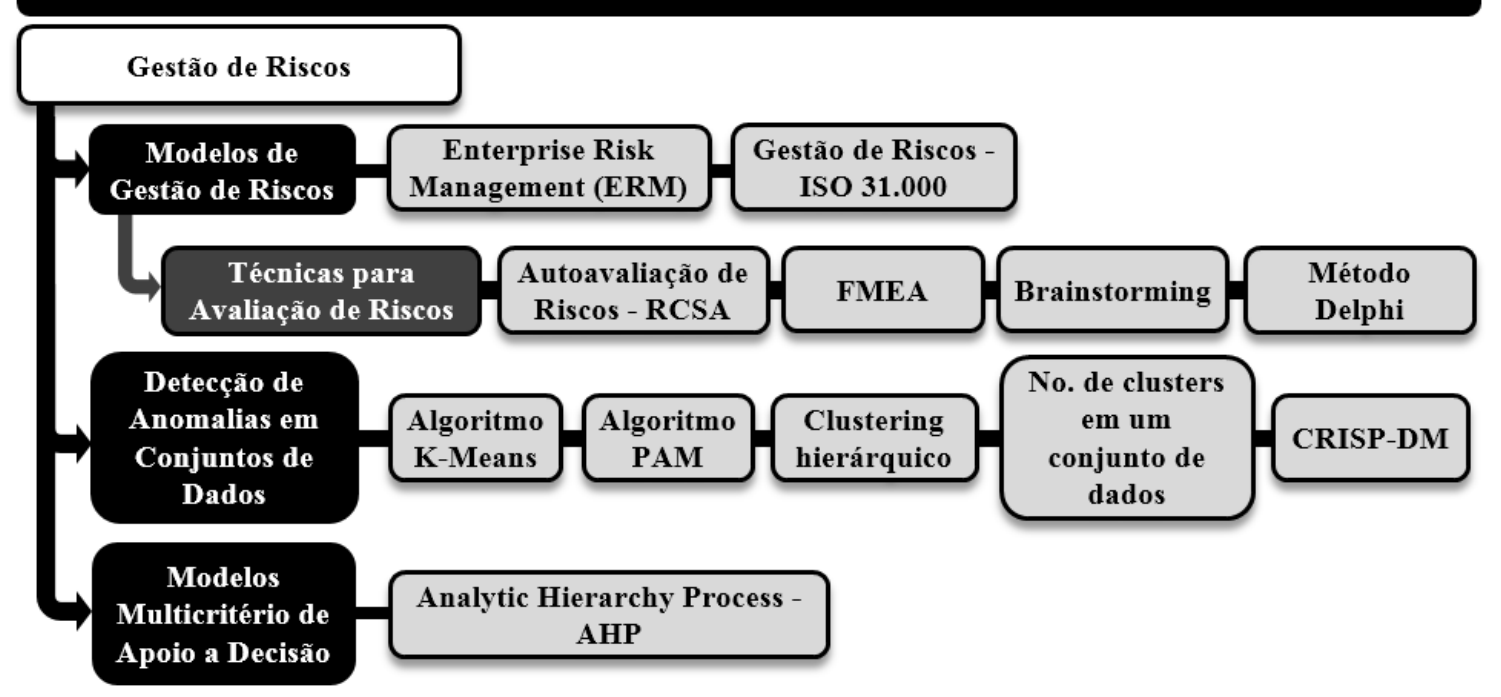

Figura 2.1: Estrutura da Base Conceitual 
Desta forma, o Capítulo inicia-se pela descrição dos principais arcabouços, propostos a partir da década de 80, para a gestão de riscos em ambientes corporativos, entre eles o Enterprise Risk Management (ERM) e a norma ISO 31.000. Em termos de operacionalização destas atividades, são descritas algumas das técnicas mais utilizadas para a avaliação de riscos em projetos ou processos organizacionais, como a autoavaliação de riscos e controles (RCSA), o FMEA, e as técnicas de brainstorming e Delphi.

A segunda parte do Capítulo aborda o uso de ferramentas de detecção de anomalias em conjuntos de dados, com ênfase na aplicação de algoritmos de agrupamento de dados por semelhança, ou clusterização. Entre eles, são avaliados os algoritmos K-Means, PAM e Clustering hierárquico, com a análise de como é definida a quantidade de clusters em um conjunto de dados avaliado. Por fim, esta seção é finalizada com a introdução do modelo padrão adotado para mineração de dados, o CRISP-DM.

A última seção do Capítulo contempla os conceitos relacionados aos modelos multicritério de apoio à decisão, com a descrição em detalhes do AHP - Analytic Hierarchy Process, método escolhido para a construção do modelo específico utilizado neste estudo.

\subsection{Gestão de Riscos}

Para [15], é normal haver uma certa dificuldade em se definir precisamente o conceito de "risco". Todavia, segundo o autor, o risco está intimamente ligado à noção de incerteza, que são os efeitos desconhecidos resultantes de um determinado evento. $\mathrm{O}$ risco, desta forma, está relacionado às consequências negativas ou positivas de um evento ou situação.

Conforme definição da ISO - International Organization for Standardization, o gerenciamento de riscos nas organizações auxilia na melhoria de seu desempenho em um ambiente de incertezas [51]. Inclusive, para este órgão, a própria definição de risco é dada como o "efeito da incerteza sobre os objetivos" de uma entidade, conceito semelhante ao utilizado por [15], que afirma que a essência do gerenciamento de riscos é a "administração das consequências negativas de um futuro incerto".

Segundo os pesquisadores [8], o interesse no gerenciamento de riscos corporativos (ou enterprise risk management - ERM) ganhou enorme força nos 
últimos 20 anos, principalmente devido ao incentivo de órgãos reguladores e agências de classificação, como resultado das crises e escândalos que abalaram o setor financeiro nas últimas décadas. Estes autores enfatizam o papel dos órgãos reguladores em relacionar a análise de controles internos à gestão de riscos, transformando estas atividades em requisitos da governança corporativa.

Os próximos itens abordam os principais arcabouços criados desde a década de 80 para auxiliar os gestores na implantação destas estruturas em seus ambientes corporativos, buscando atender às exigências governamentais e aos anseios de seus clientes e partes interessadas.

\subsubsection{Modelos de Gestão de Riscos}

Nesta seção, são detalhados os conceitos referentes aos principais modelos desenvolvidos ao longo das últimas décadas do século XX para o gerenciamento de riscos corporativos. Estes arcabouços, inicialmente implantados em organizações na área financeira, vêm sendo frequentemente adotadas por organizações também no setor de seguros [57], e servem como base, inclusive, para o modelo atual de gestão de riscos adotado pela OPS, conforme apresentado mais adiante no Capítulo 04.

\subsubsection{Enterprise Risk Management - ERM}

Em 1985, foi criada nos Estados Unidos a National Commission on Fraudulent Financial Reporting (Comissão Nacional sobre Fraudes em Relatórios Financeiros). Seu principal objetivo era o estudo dos fatores que influenciam o surgimento de fraudes organizacionais, presentes muitas vezes em relatórios financeiros e contábeis.

Posteriormente, esta Comissão transformou-se em um Comitê, o COSO Comitee of Sponsoring Organizations of the Treadway Commission (Comitê das Organizações Patrocinadoras da Comissão de Treadway). O Comitê constatou que os controles internos tendem a proporcionar uma garantia razoável (mas nunca absoluta) quanto ao risco [34].

O Comitê é patrocinado por um grupo de entidades não-governamentais, que inclui a American Accounting Association (AAA), o Institute of Management Accountants (IMA) e o Institute of Internal Auditors (IIA). O framework original publicado pela entidade, intitulado Internal Control - Intergrated Framework, foi 
lançado em 1992 e foi desde então adotado por diversas entidades ao redor do mundo, ocorrendo a sua última atualização em 2013. O modelo desenvolvido pelo Comitê se tornou uma referência para organizações que buscam se adequar as crescentes exigências de seus respectivos ambientes regulatórios, principalmente na área financeira. A estrutura proposta pela entidade é apresentada na Figura 2.2:

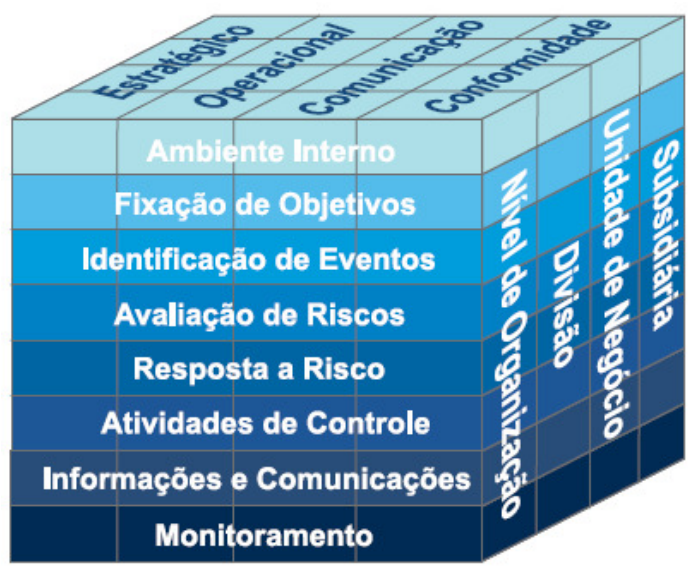

Figura 2.2: Estrutura COSO [34]

Os objetivos (parte superior do cubo) são as definições do que a organização pretende obter ou atingir, no âmbito operacional, de divulgação de resultados (com ênfase no atendimentos aos requisitos de transparência) e de compliance (conformidade) à legislação e normas externas. A estrutura da entidade (lateral do cubo) representa as unidades operacionais e outras estruturas da empresa. Por fim, os componentes principais representem as atividades necessárias para que a entidade atinja seus objetivos. A estrutura do cubo demonstra o relacionamento direto entre estas partes.

Especificamente quanto ao gerenciamento de riscos corporativos, em 2004 o COSO publicou o documento Enterprise Risk Management - Integrated Framework (Gerenciamento de Riscos Corporativos - Estrutura Integrada, ou ERM), onde foi exposto um maior detalhamento do componente de "Avaliação de Riscos" previsto no arcabouço original [34].

Com a publicação do COSO ERM, houve a introdução de técnicas práticas e estudos de casos que poderiam ser utilizados em diversos níveis organizacionais, com o objetivo de aplicar os princípios de gerenciamento de riscos em entidades de diversos portes. Conforme a Figura 2.3, o modelo de ERM do COSO define o fluxo de atividades entre os componentes do gerenciamento de riscos corporativos. 


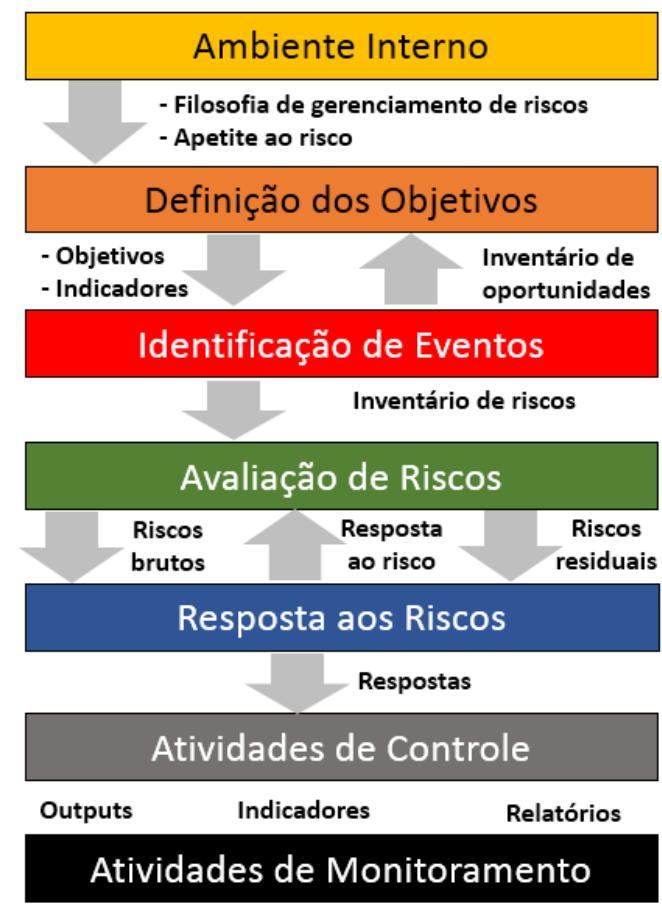

Figura 2.3: Estrutura COSO ERM [34]

Dentre as etapas do diagrama acima, a definição do ambiente interno considera a visão que a instituição possui de si mesma, ou seja, a consciência que existe internamente a respeito da necessidade de se realizar a gestão de riscos. A identificação da "filosofia de gestão de riscos" é o levantamento de crenças e atitudes que caracterizam o modo que a entidade enxerga o risco em todas as suas atividades, desde o nível estratégico até o operacional.

Consequentemente, os objetivos devem ser definidos no nível estratégico, englobando as metas relativas às atividades operacionais, de conformidade, e reporte. A definição dos objetivos é considerada como pré-requisito para que a organização possa realizar as demais etapas de análise de riscos, como a identificação de eventos, avaliação e resposta aos riscos presentes em seu ambiente interno e externo. Auxiliam também na definição do nível de tolerância da empresa a estes eventos.

A próxima etapa, a identificação de eventos, consiste no levantamento, considerando todo o escopo da instituição, de eventos potenciais cuja ocorrência pode afetar os objetivos da entidade, podendo inclusive serem de natureza positiva (oportunidades) ou negativa (ameaças, no sentido de impedir o alcance dos objetivos estabelecidos). Neste último caso, os eventos devem ser avaliados e uma resposta adequada deve ser definida para mitigar seus impactos. 
A etapa de avaliação permite à entidade efetuar a análise, seja por métodos qualitativos e/ou quantitativos, do impacto dos possíveis eventos na realização de seus objetivos processuais. Esta análise deve ser feita sob a ótica de probabilidade de ocorrência e impacto, se possível por meio do agrupamento dos eventos em categorias, considerando os riscos brutos e residuais (cuja criticidade é mensurada considerando o efeito da aplicação de controles existentes).

Após identificados os riscos residuais, a gestão da entidade decide a melhor forma de resposta, ou tratamento dos eventos levantados. As opções incluem aceitar, transferir ou mitigar o risco, sempre com base no seu impacto e probabilidade de ocorrência futura [43]. A mitigação é possibilitada pelas atividades de controle, ou seja, o estabelecimento de políticas e procedimentos que asseguram o cumprimento das medidas adotadas para tratamento dos riscos. Por fim, o monitoramento envolve a avaliação continua do funcionamento dos componentes do ERM.

\subsubsection{Gestão de Riscos - ABNT NBR ISO 31.000:2009}

Em 1995, ocorreu a edição inicial da norma conjunta australiana-neozelandesa AS/NZS 4.360. Logo atraiu a atenção da comunidade internacional, em razão da consciência, na época, da necessidade de se formalizar um processo de gestão voltado para a Governança Corporativa em um ambiente de incertezas.

Este padrão foi substituído em novembro de 2009 pela AS/NZS ISO 31000 [10], que fornece os princípios e padrões a serem considerados no desenvolvimento de metodologias e programas de gerenciamento de riscos. Este padrão passou então a ser considerado uma das principais referências no âmbito da gestão de riscos, por fornecer um guia que poderia ser adotado por todos os tipos de organização, independentemente do seu porte ou área de atuação. O processo de gestão proposto por essa norma pode ser visto na Figura 2.4. 


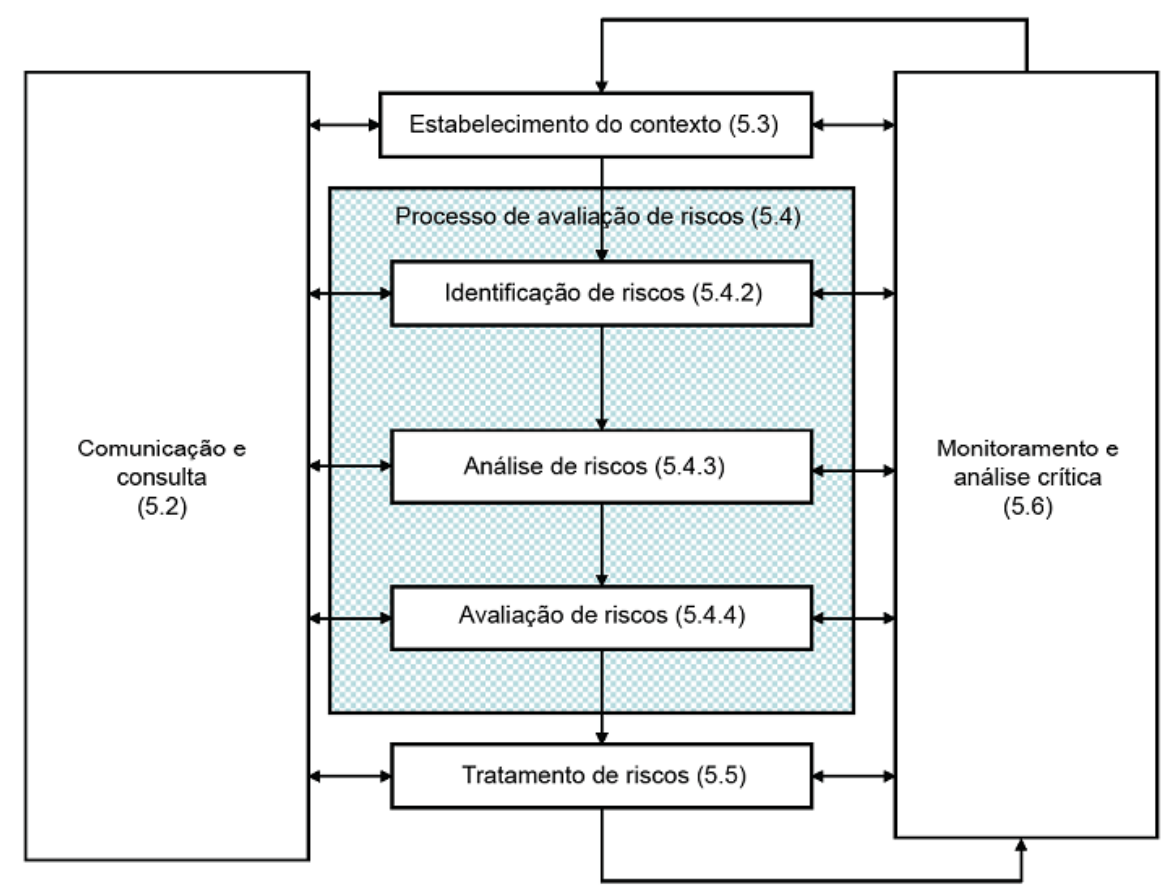

Figura 2.4: Modelo de gestão de riscos NBR ISO 31000 [10]

A visão geral do processo de gestão de riscos da ISO 31000 [10] é composto por elementos que abordam o estabelecimento do contexto, seguida pela identificação, análise, avaliação e tratamento dos riscos, supervisionadas pelas tarefas contínuas de comunicação e monitoramento.

O estabelecimento do contexto envolve a apresentação dos objetivos organizacionais, e como estes são influenciados por fatores internos e externos à organização. A definição do contexto requer uma análise de fatores externos como o ambiente cultural, político e econômico relacionado à instituição, assim como os fatores internos, como o planejamento estratégico de recursos e capacidades.

$\mathrm{Na}$ etapa subsequente, são identificados tanto os riscos como as suas causas e possíveis consequências, assim como os cenários que poderiam ocasionar o surgimento das possibilidades de perda. A análise de riscos considera as probabilidades, impactos e possíveis causas relacionadas aos riscos identificados, no intuito de se estabelecer os riscos "brutos".

$\mathrm{Na}$ fase de avaliação, ocorre a comparação entre o risco bruto e os controles existentes que mitigam seus impactos, com vistas a se definir os riscos inaceitáveis, que serão o foco principal da fase de tratamento. Caso sejam identificados riscos nesta categoria, (sendo o limite de aceitação estabelecido com base nos parâmetros definidos pela própria organização), torna-se necessário o seu tratamento. Os gestores 
podem então optar pela mitigação de riscos por meio da criação de novos controles ou melhoria dos existentes.

As tarefas de comunicação e consulta envolvem o estabelecimento do modo de comunicação com as partes interessadas relacionadas ao processo, sendo o monitoramento e análise compreendidas pela a análise contínua dos controles estabelecidos para mitigação das possibilidades de perda, assim como a metodologia adotada pela entidade para gerenciamento de seus riscos.

\subsubsection{Técnicas para Avaliação de Riscos}

\subsubsection{Autoavaliação de Riscos e Controles - RCSA}

O sucesso na implantação de uma estrutura de gerenciamento de riscos em um ambiente corporativo depende da capacidade que os gestores possuem em extrair informações em todos os níveis e unidades organizacionais. As ferramentas utilizadas na busca destas informações variam de acordo com as necessidades dos gestores e a realidade de cada processo.

Conforme [80], a auditoria interna desempenha o papel de fornecer aos gestores e partes interessadas uma garantia independente em relação ao desempenho das atividades de controle. Contudo, na opinião do mesmo autor, a atuação isolada da auditoria reforça a visão ultrapassada de que a gestão de riscos seria uma atribuição de apenas uma única área. Em contrapartida, uma das melhores formas de obter uma visão mais ampla a respeito da adequação dos controles relacionados à cultura e valores organizacionais é por meio da autoavaliação, realizada preferencialmente pelos colaboradores nos níveis operacionais da organização [80].

Uma das primeiras metodologias de autoavaliação foi desenvolvida por Bruce McCuag, da Gulf Canada, na década de 80 [30]. Na época, essa organização buscou o aumento da produtividade e qualidade de seus negócios por meio da criação de uma metodologia específica, que abrangesse a identificação e aperfeiçoamento dos controles existentes em seus processos internos. O arcabouço criado foi denominado de "Control Self-Assessment", ou Autoavaliação em Controles, também conhecida como autoavaliação de riscos e controles (risk and control self-assessment), ou RCSA.

A RCSA é uma metodologia que busca a revisão dos objetivos de negócio, a identificação dos riscos envolvidos no alcance destes objetivos, e os controles internos 
que foram implantados para mitigação destes riscos [48]. É caracterizada pela análise conjunta realizada por auditores e funcionários de uma unidade de negócio, tornandose atraente justamente por envolver a participação dos indivíduos inseridos diretamente no processo de trabalho.

Conforme [80], não existe um processo padrão que oriente a aplicação da RCSA. Cabe à cada entidade a escolha do melhor formato para aplicação da ferramenta, conforme as suas realidades. Sendo assim, podem existir divergências quanto à periodicidade das avaliações, áreas responsáveis pela condução do processo e ferramentas específicas utilizadas para as etapas de análise e avaliação de riscos. Contudo, existe um consenso [49] em termos das atividades principais que compõem o processo, conforme apresentado na Figura 2.5.

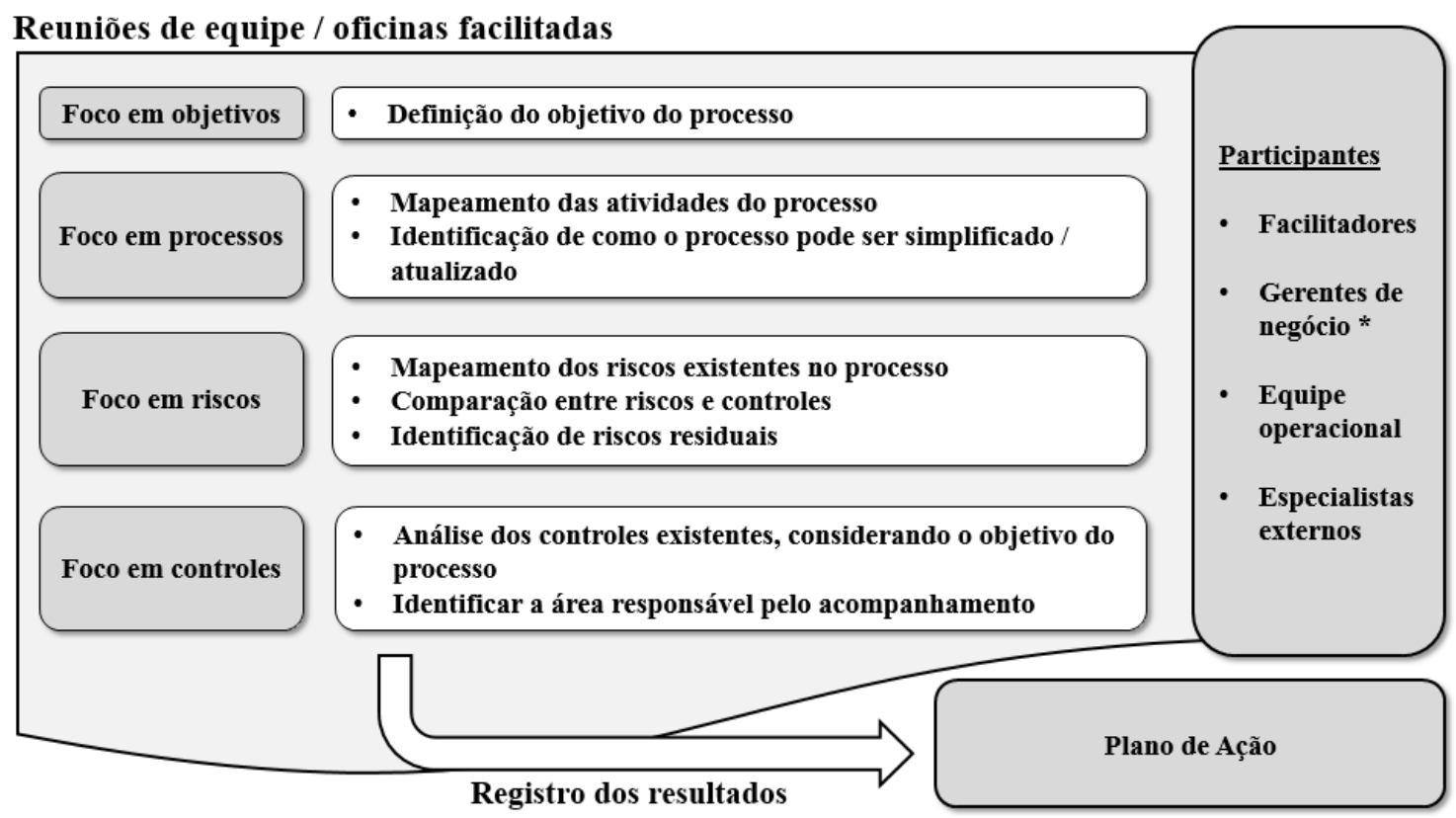

Figura 2.5: Escopo das oficinas de autoavaliação [49]

De forma geral, o RCSA é organizado em torno de "oficinas facilitadas de autoavaliação" (self-assessment workshops), também conhecidas como "reuniões facilitadas de equipe". Estas oficinas envolvem, antes de tudo, a apresentação de como devem ser aplicados os princípios do gerenciamento de riscos dentro da organização, reforçando a cultura de que a gestão de riscos deve envolver a participação de todos os colaboradores [52].

A reunião aborda a discussão de processos específicos, onde os participantes identificam os riscos associados às atividades exercidas e a eficiência dos controles 
existentes para assegurar o cumprimento dos objetivos estabelecidos. Uma das ideias principais desta abordagem é incentivar maior participação e senso de compromisso dos envolvidos na aplicação das melhorias propostas, tendo em vista que eles mesmos foram responsáveis pelo seu desenvolvimento. Sendo assim, evita-se a sensação de que as melhorias estariam sendo impostas por uma área externa à unidade de negócio (como, por exemplo, um órgão de auditoria interna, ou externa). O exercício também provoca maior consciência dos funcionários sobre os reais objetivos do processo, e valoriza o conhecimento que possuem a respeito das atividades exercidas [80].

Conforme a descrição das etapas do workshop dada por [49] no decorrer da metodologia os objetivos do processo são definidos em termos de metas corporativas ou entregas processuais. Todos os riscos e controles posteriormente avaliados serão discutidos à luz deste objetivo, definido no início da oficina.

Os riscos são classificados em tipos: riscos inerentes (sem a consideração do impacto de controles existentes), riscos residuais (onde se considera o impacto dos controles) e eventos (sendo estes os riscos que já se concretizaram, gerando consequências indesejadas). Os controles são classificados como "preventivos" (controles que atuam de forma a evitar a ocorrência de um evento indesejado) e "detectivos" (são aqueles que apontam a ocorrência de em evento após o acontecimento).

Os resultados da avaliação devem ser registrados em formulários, contendo a identificação e descrição dos riscos e seus respectivos controles. Para estes últimos, deve-se registrar as áreas responsáveis pelo seu monitoramento e a sua efetividade na mitigação dos riscos inerentes ao processo. Os riscos residuais são então classificados, definindo se os controles atuais são suficientes para que se enquadrem dentro dos limites definidos como aceitáveis pela organização. Caso negativo, é apontada a necessidade de tomar maiores ações para a mitigação dos impactos negativos.

Por fim, um plano de ação é desenvolvido, com vistas a monitorar as atividades propostas para aperfeiçoamento dos controles identificados. Neste documento, são registrados os responsáveis pela ação, a data prevista para implementação e a categoria esperada do risco residual, após a adoção das medidas propostas.

A equipe deve ser composta por facilitadores (representantes do órgão interno de auditoria interna ou gestão de riscos) e colaboradores da área envolvida no processo. Pode haver a participação pontual, inclusive, de especialistas de outros 
departamentos, que possuam conhecimentos a respeito dos controles que não pertencem à área que está sendo avaliada.

A participação dos indivíduos diretamente inseridos no nível operacional do processo tornou-se um diferencial desta metodologia em relação às práticas tradicionais de auditoria que, segundo os executivos da Gulf Canada, se mostravam ineficientes na detecção de fraudes e ineficiências em unidades de negócios, inclusive em áreas que já haviam sido alvo de investigações anteriores [30].

É aconselhável que o facilitador seja um agente externo ao processo, e que possua experiência em desenvolvimento de sistemas de controle e técnicas de facilitação. Este indivíduo deve fornecer a orientação ao demais participantes quanto ao contexto e os objetivos da oficina, assim como a contribuição esperada de cada um. Neste sentido, é de seu interesse manter um diálogo contínuo entre todas as partes interessadas. O facilitador deve estar acompanhado de um assistente, responsável pelo registro das informações levantadas no decorrer das reuniões.

Conforme [49], a participação dos gestores do processo depende da cultura existente na organização. Evidente que deve haver o seu acompanhamento quanto aos resultados parciais e finais da oficina. Contudo, a presença dos gestores no decorrer das discussões pode inibir a participação dos demais funcionários da área, principalmente quanto ao apontamento de problemas existentes ou a discussão de temas relacionados à política interna da organização.

O Institute of Internal Auditors [48] reforça que a aplicação da RCSA deve ser realizada não em substituição, mas em complemento às atividades rotineiras de auditoria interna. A ferramenta deve servir para ampliar o escopo dos reportes periódicos relacionados aos controles internos, permitindo que os auditores foquem seus esforços em áreas de maior risco, ou que apresentem insuficiência de controles.

Os resultados podem também reforçar um senso de comprometimento na própria área avaliada, uma vez que a responsabilidade pela identificação dos eventos e ações corretivas é transferida para os próprios funcionários. O trabalho em equipe tende também a resultar em uma maior colaboração entre o nível gerencial e as equipes operacionais [30]. A sinergia é obtida principalmente devido ao fato de que os funcionários de nível operacional podem contribuir com uma compreensão mais completa do processo, que dificilmente um auditor externo poderia desenvolver em um curto espaço de tempo. Por este mesmo motivo, menos tempo é gasto com a coleta de informações e validação de atividades [48]. 
O RCSA é considerado como um dos principais componentes de uma estrutura integrada de gerenciamento riscos corporativos, pois permite que uma organização realize a integração de todos os seus esforços de identificação e mitigação de riscos. Por meio desta metodologia, ocorre a transferência da responsabilidade do gerenciamento de riscos para as áreas gestoras dos processos internos, ao tempo que se cria uma linguagem comum de valores em toda a organização [49].

Contudo, conforme [80], a aplicação de processos de análise e avaliação de riscos por meio da autoavaliação só é possível em organizações onde já se possui um certo conhecimento dos diferentes arcabouços de gestão de riscos, havendo o esforço prévio em disseminar uma cultura de riscos e controles em diferentes áreas da empresa. Neste sentido, é ideal que exista uma área específica responsável pela coordenação das atividades, com aval da alta gestão. A implantação das autoavaliações é uma característica de um estágio de maturidade em riscos já caracterizado pela adoção rotineira dos resultados da gestão de riscos na formulação das estratégias da organização.

Por fim, verificou-se que os arcabouços de gestão de riscos e autoavaliação serviram como modelo para a criação da metodologia de auto avaliação da operadora de planos de saúde em análise, e auxiliaram inclusive na elaboração da proposta de melhorias a serem integradas ao modelo existente. Como exemplo, o padrão NBR ISO 31.010 [9], que serve de apoio à norma ISO 31000 [10], contém um conjunto de técnicas sistemáticas para o auxílio no processo de gestão de riscos. Entre estas, encontra-se a técnica de Análise de Modos e Efeito de Falhas (FMEA), Brainstorming e Delphi, cujas etapas foram identificadas como passíveis de serem integradas à metodologia atual da organização, e são descritas nos itens a seguir.

\subsubsection{Análise de Modos e Efeitos de Falha - FMEA}

No período pós-guerra, mesmo antes da formalização dos modelos atuais de gestão de riscos para mitigação de efeitos adversos em ambientes empresariais, as organizações do setor industrial já buscavam atender a necessidade de identificar as falhas processuais em pontos críticos de seus processos, com ênfase naquelas que seriam as mais difíceis de serem detectadas [70].

Em processos industriais, as possíveis falhas tendem a surgir, por exemplo, na transferência de um maquinário, no processo de desenvolvimento ou na fabricação de 
um novo produto [99]. São defeitos que muitas vezes decorrem de atividades prévias na cadeia produtiva, e que podem por sua vez acarretar em outras falhas nas atividades subsequentes.

Para atender à esta demanda, na década de 60 surgiu a primeira versão da metodologia FMEA, sigla em inglês para Análise de Modos e Efeitos de Falha (Failure Modes and Effects Analysis) [70]. Esta metodologia tem como objetivo facilitar a melhoria de processos, identificando os pontos críticos antes das etapas de implementação, focando na prevenção de falhas antes que estas ocorram. No contexto desta ferramenta, todos as possíveis maneiras em que um componente, peça, produto ou processo podem vir a falhar foram denominados de "modos de falha".

Utilizando uma abordagem estruturada, são identificadas as possíveis falhas, e então associados os riscos com causas específicas. Em seguida, listam-se as atividades que servem para mitigar estes riscos. Em contrapartida à uma análise preliminar de risco, aplicada nos estágios iniciais do desenvolvimento de um novo processo, sistema ou operação, o uso do FMEA é mais comumente visto em processos e sistemas já estabelecidos [77].

$\mathrm{Na}$ opinião de [70], o FMEA é um método sistêmico eficiente, que busca avaliar os modos de falha e mitigar seus efeitos indesejados por meio de medidas corretivas, pela análise de um processo dividido em cada uma de suas atividades principais. A Figura 2.6 apresenta o fluxo do processo e suas principais etapas: 


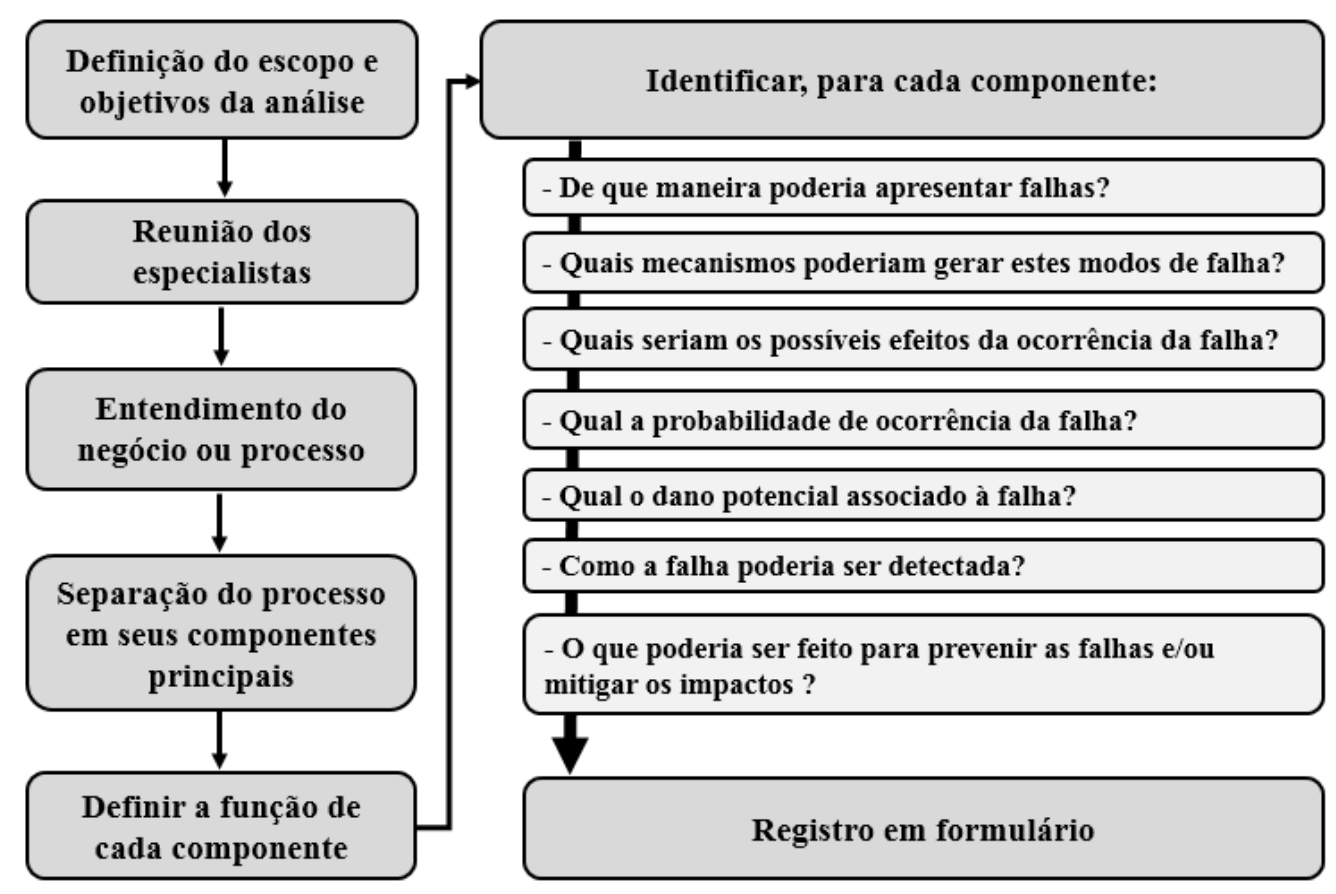

Figura 2.6: Fluxo de avaliação processual do FMEA [77]

A eficiência da ferramenta se reflete não só pelo fato de descrever os pontos de falhas potenciais, mas também quais seriam os efeitos de sua ocorrência [77]

Neste fluxo, descrito por [77], verificam-se as principais etapas da metodologia. Primeiramente, ocorre a definição do foco da avaliação (sistema, produto, processo ou serviço). Deve-se definir se o escopo envolverá uma análise por completo ou em partes.

Em seguida, reúne-se os integrantes da equipe. Em termos de composição da equipe que aplica o FMEA, [99] recomenda que seja composta por um conjunto multidisciplinar de representantes da área de negócio, e nunca por um único indivíduo.

$\mathrm{Na}$ etapa seguinte, no caso de um processo, cria-se um fluxo de atividades, visando facilitar e alinhar o entendimento dos participantes quanto às principais atividades, e como estas se relacionam. Para cada componente, todos os possíveis modos de falha são descritos, juntamente com os controles que devem existir para que estes riscos sejam mitigados.

Os resultados do FMEA são registrados em um documento detalhado, que identifica as diferentes maneiras em que um processo ou produto pode deixar de atingir requisitos críticos de desempenho, conforme o Quadro 2.1: 


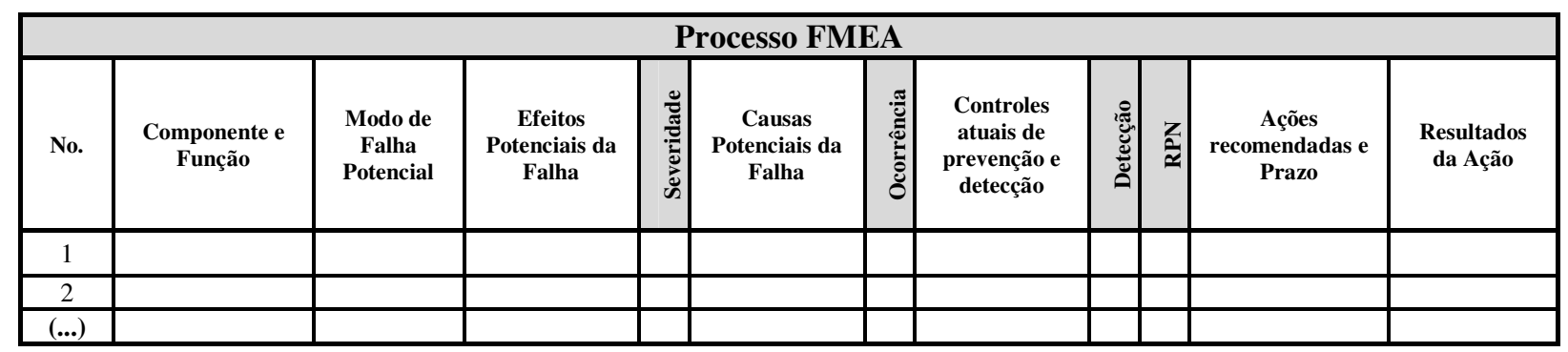

Quadro 2.1: Formulário Padrão do FMEA [70]

Para cada componente (ou atividade) os modos de falha são registrados, de forma a descrever como estas ocorrem, com a especificação de suas causas, como, por exemplo, "cadastro de informação incorreta no formulário digital, devido à falta de treinamento". Já o registro dos efeitos potenciais da falha busca responder à pergunta: "o que acontece quando ocorre a falha?" [99]

Para [99], a essência do FMEA é a identificação de problemas existentes e potenciais, antes que cheguem ao cliente. Sendo assim, há de se esperar que diferentes problemas possuam prioridades distintas. A definição destas prioridades é um dos pontos principais da metodologia.

Neste sentido, o autor apresenta os três fatores que ajudam a definir a prioridade dos modos de falha:

- Severidade $(\mathrm{S})$ : Importância, em termos de efeitos, da falha;

- Ocorrência $(\mathrm{O})$ : Em termos de frequência da falha; e

- Detecção (D): Habilidade de detectar a falha antes que chegue ao cliente.

Para a definição dos valores da cada variável, podem ser utilizadas escalas numéricas qualitativas (com base no comportamento padrão de cada componente, e atribuídas conforme o consenso da equipe de análise) ou qualitativas (seguindo dados históricos, reais) [99]. De forma geral, recomenda-se o uso de uma escala de 0 a 10, considerando a consequência da falha, sua probabilidade e a capacidade de se detectar o problema. A análise pode considerar ocorrências históricas, no mesmo processo ou em processos semelhantes. Especificamente quanto ao valor de Detecção, deve ser considerado que uma falha detectada dentro do fluxo do processo é menos severa do que uma detectada pelo cliente. Quanto mais difícil for sua detecção, maior o valor atribuído a esta variável [9]. 
Os modos de falha identificados são priorizados por meio do valor de priorização do risco (RPN, ou Risk Priority Number) [99], obtido pela multiplicação entre as três variáveis $(\mathrm{RPN}=\mathrm{S} \times \mathrm{O} \times \mathrm{D})$.

No intuito de refinar a análise com foco nos riscos críticos e aprimorar o planejamento de priorização dos riscos identificados, foi proposta a integração do formato atual da metodologia da organização, descrita mais adiante, com a extensão RFMEA, proposta por [28].

Segundo estes autores, o RFMEA é uma modificação do processo, dos produtos e da técnica FMEA. A extensão foi elaborada para uso no ambiente de projetos, com aplicação inicial na indústria eletrônica.

A Tabela 2.1 apresenta os principais alterações realizadas na terminologia FMEA para criação da nova extensão:

\begin{tabular}{ll}
\hline FMEA & RFMEA \\
\hline ID da Falha & ID do Risco \\
Modo de Falha & Descrição do Risco \\
Ocorrência (O) & Probabilidade $(\mathrm{P})$ \\
Severidade (S) & Impacto (I) \\
& $=$ Valor do Risco $(\mathbf{P} \times \mathbf{\text { I }})$ \\
Detecção (D) & Detecção (D) \\
$\mathbf{R P N}=(\mathbf{O} \times \mathbf{S} \mathbf{x} \mathbf{D})$ & $=\mathbf{R P N}(\mathbf{P} \times \mathbf{~} \mathbf{x} \mathbf{D})$ \\
\hline
\end{tabular}

Tabela 2.1: Comparativo entre os termos do FMEA e RFMEA [28]

De forma semelhante ao FMEA, no RFMEA o cálculo do RPN envolve a multiplicação da probabilidade do risco pelo seu valor de impacto, e finalmente pelo "valor de detecção". Nesta adaptação, não é definido um ponto de corte padrão para a priorização dos riscos, devendo ser avaliada a distribuição dos RPN de forma a estabelecer o conjunto daqueles que serão avaliados em primeiro lugar [28].

Os benefícios esperados com o uso do RFMEA incluíram o aumento do foco sobre os riscos iminentes, priorizando o planejamento de contingência para eventos adversos de difícil detecção, o incentivo de uma participação mais ativa da equipe no processo de autoavaliação, e o desenvolvimento de melhores controles para a mitigação de riscos. 


\subsubsection{Brainstorming}

Conforme a ISO 31.010 [9], o brainstorming consiste na coleta de informações e análises gerais, com sua posterior avaliação por mais de um indivíduo. Segundo [86], a técnica envolve o estímulo de discussões abertas por um grupo de indivíduos com conhecimentos a respeito de um determinado tema.

Na opinião de [86], o Brainstorming, embora considerada uma técnica genérica, possui como vantagem o fato de provavelmente ser amplamente conhecida pela maioria dos participantes, e poder ser aplicada em diversas etapas do processo de avaliação de riscos.

A 5 $5^{\text {a }}$ edição do PMBOK [84], esclarece que a técnica pode ser utilizada, principalmente, no levantamento dos riscos de um projeto. O guia recomenda o uso das categorias de risco como pontos de partida para estruturar os tópicos da discussão. Os riscos podem então ser levantados conforme sua classificação. Além da identificação das possíveis falhas no processo, podem ser discutidas também as suas consequências, os critérios para tomada de decisão e as opções de tratamento dos riscos identificados [86].

O PMBOK [84] recomenda que a equipe participante das sessões de brainstorming seja de caráter multidisciplinar, orientadas por um facilitador. A seu critério, o processo pode receber um caráter mais formal, com a definição das regras e objetivos específicos da discussão. A discussão é então direcionada com base em tópicos específicos, com os demais participantes sendo responsáveis pela identificação do maior número possível de questões relacionadas ao tema. Não deve haver espaço para críticas de opiniões alheias [86].

Conforme a ISO 31.010 [9], o ponto forte do brainstorming é o fato de suscitar a imaginação dos membros da equipe, assim como a facilidade de sua condução, e o fato de não haver a necessidade do uso de recursos avançados para sua aplicação. O facilitador é responsável por definir o nível de complexidade e tempo disponível para as discussões.

No entanto, [86] aponta que é justamente esta flexibilidade que torna difícil determinar a real eficiência da técnica, pois não há como avaliar se de fato todas as possíveis lacunas ou pontos de interesse foram identificados. Também existe a tendência dos participantes mais extrovertidos dominarem a discussão. Uma alternativa, neste caso, é o uso de brainstormings envolvendo ambientes mais estruturados, como fóruns de discussão ou salas de chat. Este "brainstorming 
eletrônico" também pode ser útil caso haja um interesse em tornar a discussão anônima, como forma de evitar críticas de caráter pessoal.

\subsubsection{Método Delphi}

Embora a participação de especialistas da área de negócio seja imprescindível na etapa de levantamento de riscos, nem sempre é possível garantir sua contribuição presencial na etapa de análise. Ainda mais difícil é reunir simultaneamente estes indivíduos presencialmente, para que haja a troca de informações necessárias [86].

Conforme a ISO 31.010 [9], a técnica Delphi é um procedimento que busca obter um consenso nas opiniões de um grupo de especialistas. Diferentemente do brainstorming, o método Delphi é caracterizado pela coleta de opiniões individualmente, de forma anônima e em rodadas, sendo os resultados dos levantamentos disponibilizados a todos os participantes no final de cada sessão.

Para [86], a aplicação da técnica Delphi possibilita extrair as opiniões destes especialistas a partir de uma metodologia que, por sua flexibilidade, exige menos esforço em termos de tempo, sem a necessidade dos participantes estarem fisicamente presentes. Ao mesmo tempo, reduz a possibilidade de influenciar as opiniões, pois é aplicada por meio da participação de diversos indivíduos.

A técnica foi batizada com base no antigo oráculo da Grécia antiga, em que um sacerdote emitia as opiniões divinas, que eram então traduzidas por um intérprete. No mundo moderno, os especialistas da área de negócio emitem suas opiniões, e os facilitadores são responsáveis pela interpretação. $\mathrm{O}$ ciclo de questionamentos, respostas e reiterações é repetido várias vezes, até que se alcance um consenso por meio de um "refinamento" das respostas [86].

A ISO 31.010 [9] determina que a técnica Delphi pode ser aplicada em qualquer etapa do processo de gerenciamento de riscos, sempre que for necessário obter o consenso entre um grupo de especialistas. Na sua forma clássica, a Delphi recebe como entradas os questionários, que no contexto da gestão de riscos, podem contemplar áreas específicas de interesse. [86] alerta que deve-se atentar para que as perguntas não influenciem as respostas dos participantes. A cada rodada, o facilitador deve definir os fatores em comum entre as respostas, até que se chegue ao consenso. 
As principais etapas da técnica, conforme [86], são descritas a seguir:

- Identificação e participação dos especialistas: Especialistas são aqueles capazes de fornecer opiniões informadas a respeito do processo e suas etapas. Não precisam necessariamente ser aqueles que lidariam com os efeitos dos riscos apontados. Contudo, devem ter um certo grau de conhecimento a respeito das necessidades da organização.

- Criação do instrumento de avaliação: As perguntas elaboradas devem ser específicas o suficiente para extrair as informações desejadas, e também amplas o suficiente para permitir um certo grau de interpretação.

- Aplicação do instrumento: A forma ideal é que a aplicação do questionário seja feita de forma remota, com tempo suficiente para que os participantes reflitam a respeito de suas respostas.

- Revisão das respostas: Cabe ao facilitador revisar as respostas, identificando pontos e preocupações em comum. Estas devem ser documentadas e reenviadas aos especialistas, para avaliação e revisão. Recomenda-se que esta etapa também seja realizada de forma remota.

- Acolhimento das opiniões e repetição: O processo acima é então repetido quantas vezes o facilitador achar necessário, de forma a eliciar as respostas necessárias para que se tenha uma evolução da discussão.

- Distribuição e aplicação dos dados: Após as rodadas, o facilitador deve emitir a versão final dos resultados, e como estes serão aplicados para a análise do processo.

Considerando que se trata de uma análise qualitativa, a confiabilidade dos resultados é reforçada pela participação de vários indivíduos. Os recursos para a aplicação são mínimos, sendo necessário apenas um bom gerenciamento do tempo entre cada rodada, pois este é o principal recurso consumido pela técnica. Entretanto, conforme [86], o tempo gasto na aplicação é compensado pela qualidade das informações obtidas, o que torna esta técnica, na opinião do autor, em uma das melhores em termos de análise qualitativa.

Além do objetivo de levantar exemplos de técnicas qualitativas de identificação de riscos em processos organizacionais, também foi realizado um levantamento de ferramentas e métodos de avaliação quantitativa, envolvendo a análise de dados 
ligados ao processo avaliado. Entre as descritas a seguir, estão técnicas de detecção de anomalias em conjuntos de dados e de decisão multicritério.

\subsection{Detecção de Anomalias em Conjuntos de Dados}

A detecção de anomalias, conforme descrito por [101], consiste na tentativa de detectar um subconjunto de dados com comportamento consideravelmente diferente de todos os demais no mesmo conjunto. Isso geralmente é realizado por meio da criação de um perfil de comportamento "normal", posteriormente definindo limites e atribuindo uma pontuação para cada entidade, a fim de detectar desvios em relação ao padrão. Esta abordagem atualmente é muito utilizada para estudos de detecção de atividades abusivas e ilegais, como fraudes e lavagem de dinheiro [110].

Uma abordagem muito comum na detecção de anomalias é a clusterização, um método multivariado de aprendizado de máquinas, que divide um conjunto de dados em conjuntos menores de entidades [44].

Para [44], as tarefas de clusterização possuem como principal objetivo avaliar as características referentes à estrutura do conjunto como um todo, principalmente quanto aos subgrupos que possam existir dentro do conjunto. Por meio da clusterização, é possível definir se os dados podem de fato ser separados em subgrupos, e se estes subgrupos possuem características semelhantes, avaliando tanto as entidades em cada agrupamento e os agrupamentos entre si. Também podem ser identificados os pontos mais distantes, ou outliers, que são as entidades que aparentemente não se enquadram em nenhum dos demais grupos.

Conforme [68], uma das principais vantagens da clusterização é a capacidade de avaliar diversas variáveis que apresentam as mesmas características, agrupando-as por semelhança. As classes são criadas a partir dos próprios dados. No contexto do presente estudo, optou-se por esta abordagem pois de fato não existiam "rótulos" iniciais de classificação das entidades (por exemplo, "suspeitas" e "não suspeitas").

A clusterização, é um exemplo de aprendizagem não supervisionada [95], pois não está relacionada à tentativa de predizer algum resultado específico, mas sim de entender os dados, ou seja, de verificar quais são os padrões e comportamentos que existem em um determinado conjunto, e como este está estruturado [68]. 
Neste sentido, a classificação proposta nos dados desta pesquisa estaria enquadrada na categoria de classificação "não supervisionada", visto que não houve uma variável inicial que pudesse ser usada para classificar os dados como "suspeitos" ou "normais" [110].

Em análises desta natureza, vale apontar que deve-se considerar a necessidade de normalizar os dados, para que estes se encontrem em um intervalo fixo, normalmente entre 0 e 1. Uma alternativa, conforme [110] é calcular a média e desvio padrão dos valores dos atributos avaliados, subtraindo então a média de cada valor e dividindo o resultado pelo desvio padrão. O conjunto de valores deverá então possuir uma média de 0 e desvio padrão de 1 . Abaixo, verifica-se um exemplo deste método, fornecido pelo software R Studio [18]:

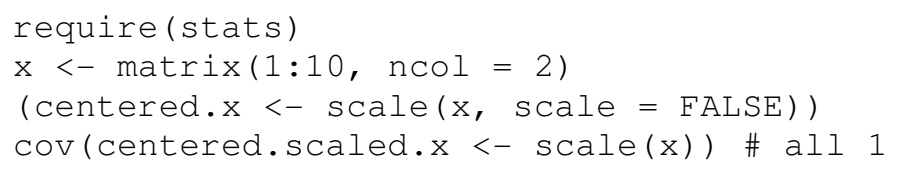

A clusterização, em particular, foi escolhida devido à necessidade de analisar a relação entre os dados e agrupá-los em conjuntos, caso apresentassem um elevado grau de associação. Dentre os algoritmos de agrupamento, foram escolhidos para análise o K-Means, PAM (Partitioning Around Medoids) e Clustering Hierárquico.

\subsubsection{Algoritmo K-Means}

O K-Means é uma técnica proeminente de agrupamento de dados, desenvolvida por Stuart Lloyd em 1957 e refinada por J. Hartigan e A. Wong em 1979 [45]. Atualmente, é considerado uma das técnicas mais populares para as tarefas de análise e mineração de dados [111].

A técnica envolve o agrupamento de entidades em um conjunto de dados em clusters, considerando o número de agrupamentos definido anteriormente pelo analista. Neste método, pressupõe-se que um conjunto de dados pode ser subdividido em diversos agrupamentos, e que existem posições em cada um deles que podem ser consideradas como os "centros" de cada grupo.

Estes pontos virtuais, denominados de "centroides", servem como referência para realizar o agrupamentos, e são calculados conforme a posição média de todos os pontos em cada agrupamento [101]. Os dados relacionados a cada cluster devem estar mais próximos do "centro" de seu próprio grupo do que o centro dos demais. A lógica 
do algoritmo, representada por meio de pseudocódigo elaborado por [95], é apresentado no Quadro 2.2, a seguir:

\section{Algoritmo de clusterização K-Means}

Requer: $K$, número de clusters; $D$, conjunto de dados de $N$ pontos

Garantir: Um conjunto de $K$ clusters

1. Inicialização

2. Repetir

3. $\quad$ Para cada ponto $p$ em $D$ :

4. Encontrar o centroide mais próximo e atribuir $p$ ao cluster correspondente

5. Atualizar os clusters, calculando os novos centroides utilizando as médias dos membros

6. Até que seja atingido o critério de iterações

7. Retornar o resultado da clusterização

Quadro 2.2: Pseudo-código do algoritmo K-Means [95]

A Figura 2.7 exemplifica, de forma gráfica, as etapas do algoritmo considerando um conjunto de dados fictício, com seis elementos e a quantidade de clusters $(\mathrm{K})$ igual a 03 :

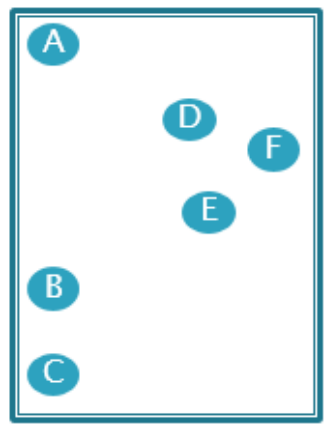

(a) Conjunto inicial de dados

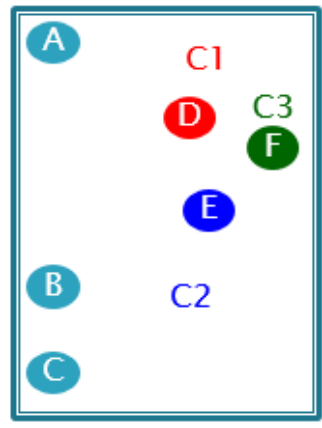

(b) Inserção de centroides iniciais, aleatórios

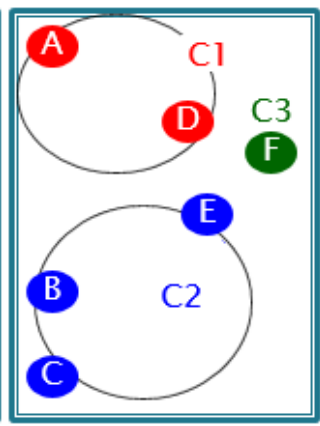

(c) Vinculação de pontos aos centroides mais próximos

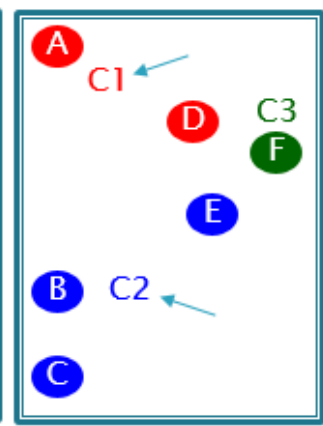

(d) Centroides recalculados, com posiçóes atualizadas

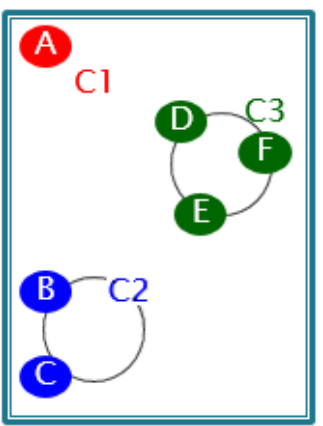

(e) Pontos vinculados aos centroides atualizados

Figura 2.7: Exemplo de clusterização via K-Means [95]

Na Figura 2.7, conforme a etapa (a), inicia-se a aplicação do algoritmo com a definição da quantidade de clusters $K$ e um conjunto de dados individuais $\mathbf{x}_{1} \ldots \mathbf{x}_{n}$.

$\mathrm{Na}$ etapa (b), conforme a quantidade de clusters previamente definida, os centroides iniciais $\mathrm{C}_{1} \cdots \mathrm{C}_{\mathrm{K}}$ são incluídos em posições aleatórias do espaço vetorial. 
Em seguida, conforme a etapa (c), inicia-se uma loop iterativo, com os seguintes passos:

1) Percorrendo o conjunto de dados, cada entidade $\mathrm{Xi}$, é atribuída ao centroide mais próximo $\mathrm{Cj}$, conforme sua distância $\mathrm{D}$ (que pode ser, por exemplo, a distância Euclidiana [103].

\section{$\arg \min D\left(x_{i}, c_{j}\right)$}

2) Conforme a etapa (d), em cada agrupamento $K$, é recalculada a posição dos centroides, conforme a posição média de todas as entidades Xi atribuídas a ele.

$$
c_{j}(a)=\frac{1}{n_{j x_{j} \rightarrow c_{j}}} \sum_{i} x_{i}(a) \quad \text { for } a=1 . . d
$$

Onde (a) pode ser considerado um valor de atributo numérico, calculado para se encontrar a média aritmética.

3) Finalmente, conforme (e), as duas primeiras etapas são então repetidas, até que se atinja a convergência, ou seja, até que nenhuma entidade mude de cluster.

Conforme [101], a utilização do K-Means é vista em diversos contextos. A maioria deles envolve a descoberta de classes dentro de um conjunto de dados, onde não existem classificações, ou rótulos, pré-existentes. Sendo assim, o resultado da aplicação do K-Means é a justamente a substituição de cada entidade por um novo rótulo, um número que representa cada cluster [101].

Um dos motivos citados por [44] para a ampla utilização do algoritmo é sua facilidade de aplicação, o que é refletido no fato de já estar embutido em diversas soluções de mercado. Em termos de complexidade de processamento, caso o número de clusters e a dimensionalidade do espaço forem conhecidos previamente, um problema típico pode ser resolvido com a complexidade $\mathrm{O}\left(\mathrm{n}^{\mathrm{dk}+1} \log \mathrm{n}\right)$, onde $n$ é o número de objetos [44]. Adicionalmente, por se tratar de um algoritmo baseado nos valores médios de cada ponto, e por consequência sensível aos objetos anômalos (outliers), pode ser útil a aplicação de uma etapa inicial de pré-processamento para remover estas distorções [111]. 
Para reduzir este efeito dos outliers sobre o resultado da clusterização, outra alternativa é utilizar um método baseado no uso dos próprios objetos do conjunto como referenciais para agrupamento dos pontos [44]. Um exemplo deste tipo de algoritmo é o PAM, discutido no próximo item.

\subsubsection{Algoritmo PAM (Partitioning Around Medoids)}

Uma alternativa para K-Means é o PAM, ou Partitioning Around Medoids, (partição em torno de medoides) proposto em 1987 por Kaufman e Rousseeuw [56].

Este algoritmo, diferentemente do K-Means, utiliza as entidades já existentes no conjunto de dados como parâmetros de referência para os agrupamentos. Os pontos de referência são denominados "medoides", que servem o mesmo propósito dos "centroides" criados artificialmente pelo K-Means. Sendo assim, os medoides são as entidades que mais se localizam no centro de cada cluster [44].

A Figura 2.8 detalha as etapas do algoritmo, novamente considerando um conjunto de dados com seis elementos e a quantidade de clusters $(\mathrm{K})$ igual a 03 :

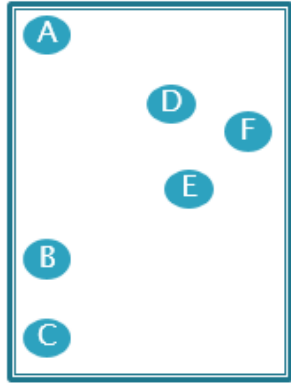

(a) Conjunto inicial de dados

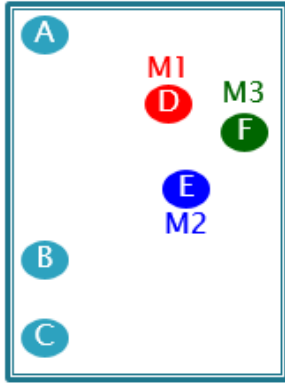

(b) Escolha de pontos aleatórios como
medóides iniciais

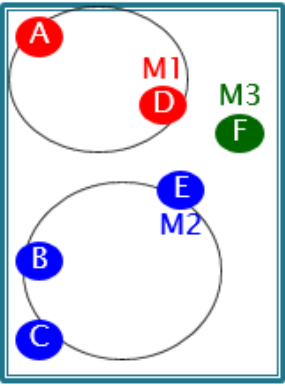

(c) Vinculação de pontos aos medoides mais próximos

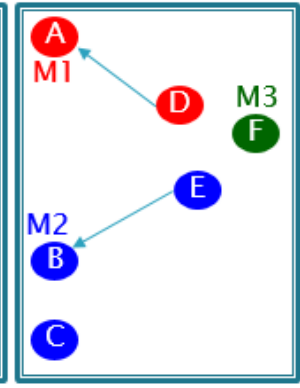

(d) Medoides

recalculados, com posiçóes atualizadas

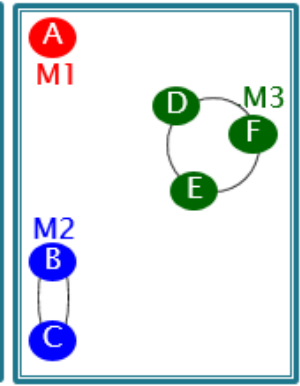

(e) Pontos vinculados aos medoides

Figura 2.8: Exemplo de clusterização via o algoritmo PAM [44]

Assim como no algoritmo K-Means, o método PAM segue um processo iterativo, conforme as etapas abaixo [44]:

1. Conforme o conjunto inicial de dados (etapa 'a'), inicia-se a aplicação do algoritmo pela seleção aleatória dos medoides, que servirão das entidades representativas (etapa 'b'); 
2. Cada ponto é atribuído ao cluster que contém o medoide mais próximo, conforme a etapa 'c' da Figura 10;

3. Após as atribuições, verifica-se a posição dos pontos de cada cluster em comparação ao seu medóide, de forma a avaliar o custo da troca de posições entre o ponto e o medoide existente. O custo, neste caso, é calculado com base na distância entre os pontos, por meio da fórmula:

$$
\operatorname{cost}(x, c)=\sum_{i=1}^{d}\left|x_{i}-c_{i}\right|
$$

onde (x) representa os pontos individuais, (c) representa o medóide, e (d) está relacionada à dimensão do objeto (no caso de um espaço bidimensional, seria igual a '2'). Desta forma, o custo total é a soma das distâncias entre os pontos e o medóide dentro do mesmo cluster.

A alteração de pontos em relação aos clusters, conforme a etapa ' $d$ ' da Figura 10, ocorre caso a soma das distâncias entre os demais pontos e o novo medoide seja inferior à soma em relação ao medoide existente.

4. Após as novas atribuições, o processo se repete até que se satisfaça o critério de convergência (o que normalmente ocorre, quando não se verificam novas atribuições e os medoides permaneçam estáveis).

Este algoritmo possui comportamento semelhante ao K-Means, pois opera por meio da melhoria iterativa da qualidade dos agrupamentos. Na opinião de [44] o PAM tende a ser mais robusto do que o K-Means na presença de outliers, pois o medoide sofre menos influência de pontos distantes do que uma média calculada.

No entanto, a complexidade de cada iteração do algoritmo é $O\left(k(n-k)^{2}\right)$. Para grandes valores de $n$ e $k$, o custo computacional pode tornar-se proibitivo, até mesmo em relação ao K-Means, além do fato de que ambos os métodos requerem que o usuário especifique o número de clusters. Desta forma, assim como o KMeans, é recomendável a aplicação do PAM em conjuntos de dados de pequeno ou médio porte [44]. 


\subsubsection{Clustering hierárquico (Hierarchical Clustering)}

Por último, o Clustering Hierárquico, desenvolvido na década de 80 [110], funciona por meio da fusão sucessiva de valores, com base em uma métrica específica (como a distância euclidiana) até que sejam unidos em um grupo final.

O clustering hierárquico pode ser classificado pelos métodos de "aglomeração" (bottom-up) ou "divisão" (bottom-down). O método por aglomeração inicia pela combinação dos elementos separadamente, agrupando-os conforme as distâncias entre eles. Já o inverso ocorre no método por divisão, em que o conjunto como um todo é separado em conjuntos cada vez menores de elementos, até que todos eles, individualmente, formem seu próprio cluster [44].

Para realizar a aglomeração dos dados, o algoritmo considera primeiramente uma medida de distância entre cada par de clusters, unindo sucessivamente os diferentes agrupamentos conforme sua proximidade com os demais [110]. A Figura 2.9 exemplifica a aplicação do algoritmo.

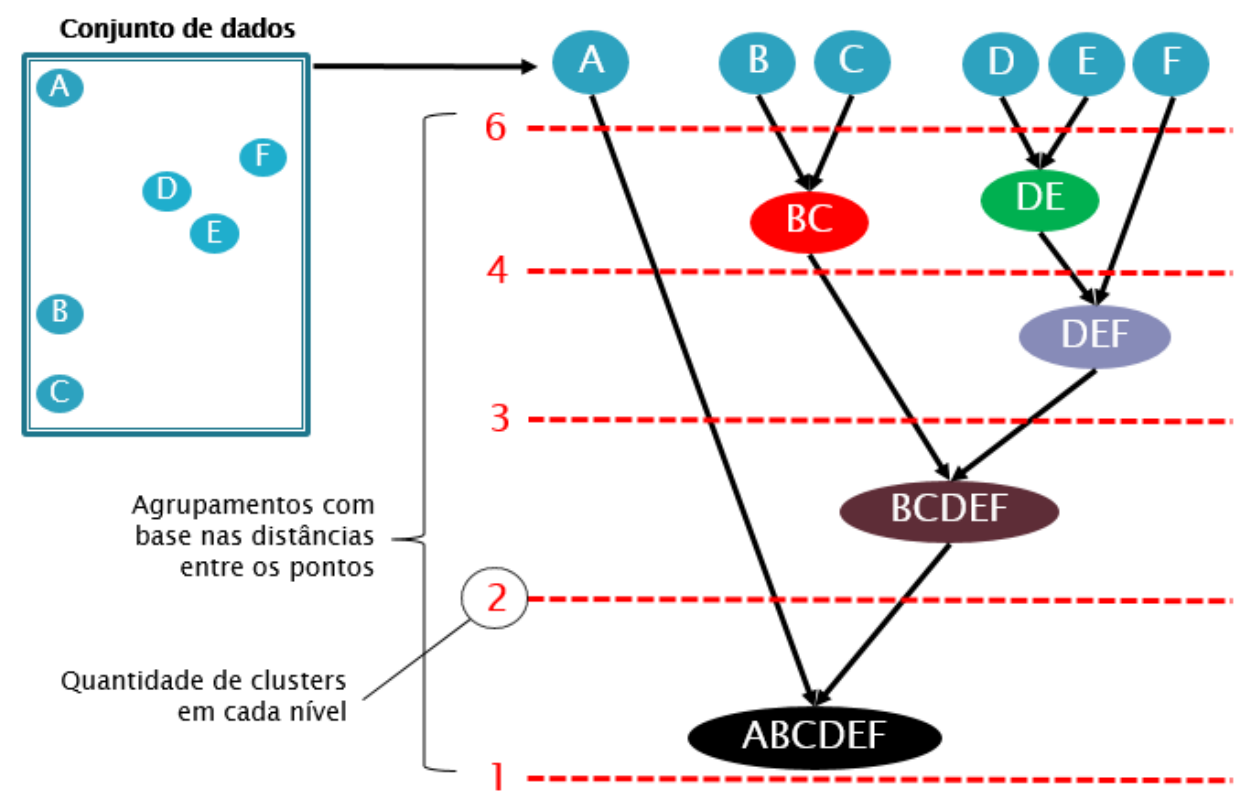

Figura 2.9: Exemplo de clusterização por meio do Clustering Hierárquico [110] 
A divisão sucessiva do conjunto em agrupamentos forma as estruturas denominadas de "dendrogramas". No diagrama que resulta da aplicação do algoritmo, a altura entre cada nódulo pode ser interpretado como o grau de dissimilaridade entre seus "filhos". Esta altura pode ser uma medida útil para determinar o número de clusters dentro do conjunto de dados [110].

Os métodos de clusterização hierárquica podem apresentar dificuldades no tocante à seleção das alternativas de divisão ou fusão dos dados em agrupamentos [44]. Uma escolha mal definida, pelo algoritmo, pode levar a grupos de baixa qualidade. Além disso, os autores enfatizam que métodos deste tipo podem não escalam bem, pois cada decisão de fusão ou divisão requer a análise de muitos objetos ou clusters. Conforme também citado por [44] existem $2^{\mathrm{n}-1}-1$ possíveis maneiras de particionar um conjunto de $n$ objetos em dois subconjuntos exclusivos. Quando $n$ é expressivo, a análise de todas as possibilidades torna-se computacionalmente proibitiva. Entretanto, conforme avaliado por [41], houveram estudos exemplificando como as técnicas de clusterização por hierarquia poderiam ser utilizadas para avaliar conjuntos de dados massivos.

\subsubsection{Determinando o número de clusters em um conjunto de dados}

A tarefa principal no uso dos métodos de clusterização engloba a identificação dos agrupamentos de dados e a atribuição de cada ponto do conjunto a um destes agrupamentos. Um dos principais problemas na clusterização é a definição de um resultado satisfatório, em termos da correta representação dos subconjuntos de dados. Não existe um consenso universal a respeito de um resultado ótimo, em termos da definição da quantidade ideal de clusters $(\mathrm{K})$, principalmente quando a estrutura do conjunto não é previamente conhecida [44].

Sendo assim, uma das medidas que define a eficiência de uma clusterização é a soma das distâncias dos pontos, em cada cluster, em relação ao "centro" do agrupamento. A combinação ideal de clusters pode ser considerada como aquela em que se minimiza a soma destas distâncias [3].

Uma abordagem viável para determinar a quantidade ideal de clusters é o cálculo da soma das distâncias em diversas combinações de número de clusters $\mathrm{K}$ (também conhecida como a "soma dos erros") [3]. Para cada K, haverá uma soma 
que indica a distância entre os pontos e os centros. Entre estas, recomenda-se escolher aquela com o menor resultado [44].

Evidentemente, o "menor" resultado sempre será aquele em que cada cluster é composto por um único ponto. Sendo assim, um método, denominado "método do cotovelo" [105] que consiste em analisar, visualmente, a variação das somas dos quadrados como função do número de clusters. Um exemplo é apresentado na Figura 2.10 .
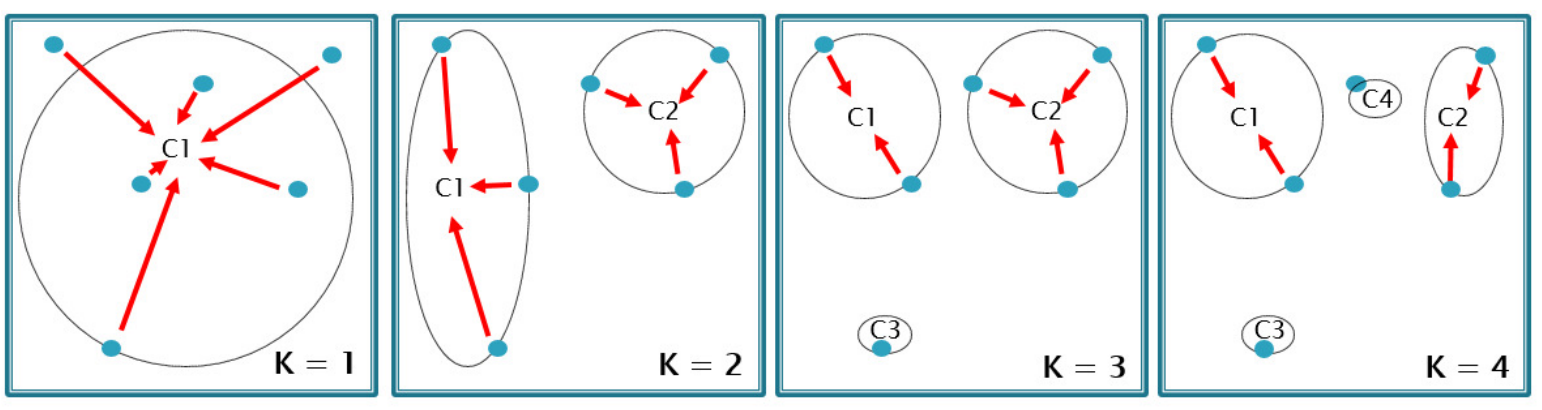

Figura 2.10: Exemplo da soma dos erros para diferentes quantidades de clusters $[3]$

Conforme a Figura 2.10, o número de clusters para as seis entidades poderia ser aumentado até que todos os elementos fossem atribuídos ao seu próprio cluster. É possível realizar uma análise visual da soma dos quadrados para cada combinação de ' $\mathrm{K}$ ' número de clusters, apresentado na Figura 2.11. Esta é a representação do método do "cotovelo", utilizado para estimar a quantidade ideal de clusters:

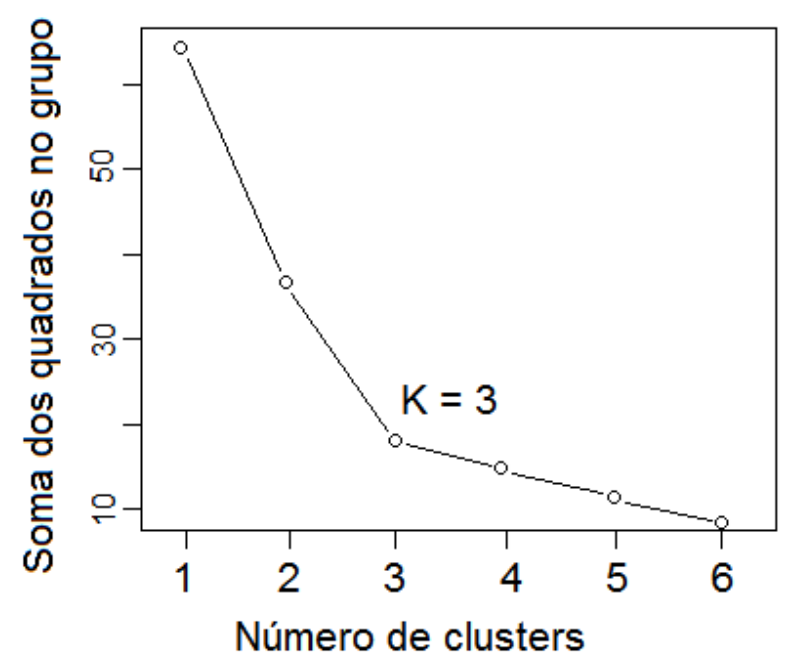

Figura 2.11: Gráfico o método do "cotovelo" [3] 
Após $\mathrm{K}=3$, não é verificada uma variação significativa da soma das distâncias no conjunto. Desta forma, este seria o parâmetro (3 clusters) a ser utilizado na aplicação de um algoritmo de clusterização por partição, como o KMeans ou PAM [60].

\subsubsection{Processo Padrão Inter-Indústrias para Mineração de Dados - CRISP-DM}

Neste estudo, a metodologia Cross Industry Standard Process for Data Mining (Processo Padrão Inter-Indústrias para Mineração de Dados) foi escolhida como ferramenta para estruturar cada etapa do processo de mineração de dados e descoberta de conhecimentos. O CRISP-DM estabelece um padrão para a resolução de problemas relacionados com a mineração de dados [32]. Esta metodologia consiste em vários níveis de abstração, percorrendo desde as tarefas gerais até as mais específicas. Conforme a Figura 2.12, suas fases percorrem as atividades de entendimento do negócio e dos dados avaliados, a preparação destes para a análise, a modelagem e avaliação dos resultados, e a implementação da proposta de análise.

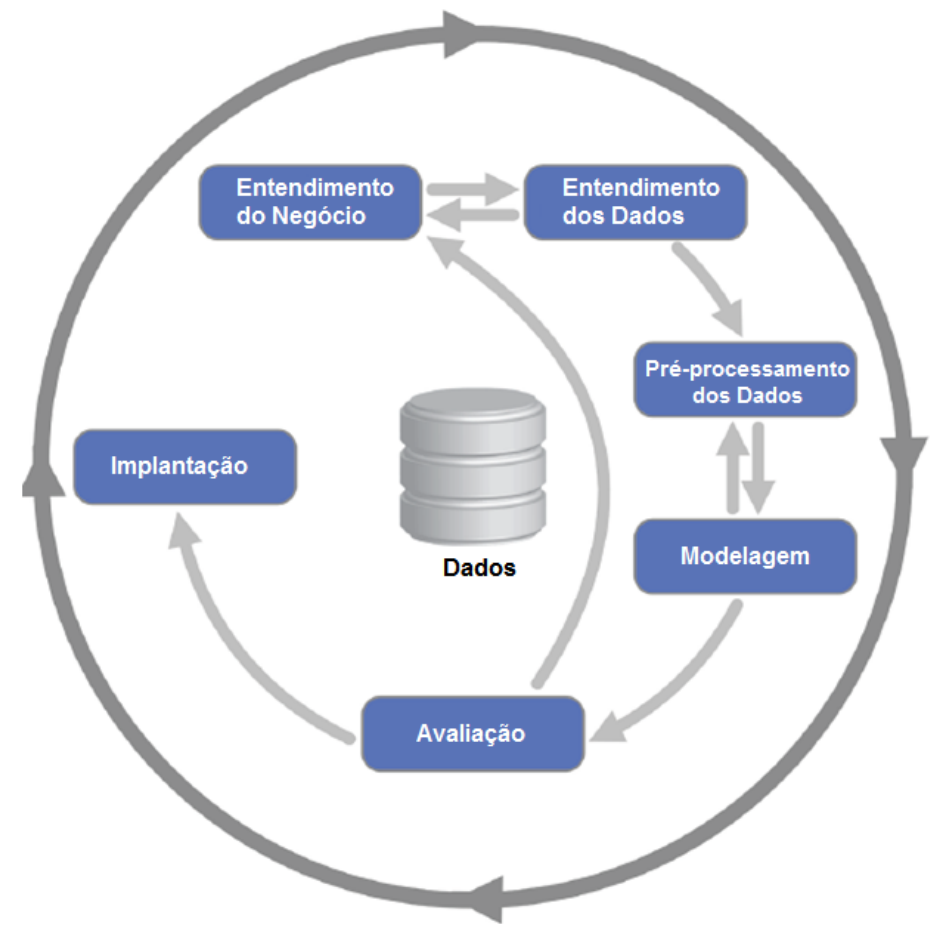

Figura 2.12: Diagrama CRISP-DM [32] 
Na fase de Entendimento do Negócio, procura-se entender os objetivos do negócio e definir os critérios de sucesso do projeto. A ideia é estabelecer as metas do cliente e o tipo de entendimento prévio necessário, a fim de definir o problema específico que precisa ser resolvido.

O próximo passo é composto pelo Entendimento dos Dados, que compreende a seleção e análise do conjunto de dados, para se obter os conhecimentos iniciais por meio de uma análise descritiva. Os dados da estrutura, relações e quaisquer problemas relacionados com a extração e estrutura dos dados são descritos nesta fase.

A etapa de Pré-processamento dos Dados envolve o "ajuste" dos dados, contemplando a seleção de atributos-chave, da formatação, construção e integração dos dados com as ferramentas que serão utilizadas para a sua manipulação. Valores irrelevantes, incorretos e faltantes são tratados nesta fase.

Em seguida, a Modelagem está relacionada à definição dos modelos, parâmetros e planos de teste. As ferramentas escolhidas são então utilizadas para definir os subconjuntos de treinamento, teste e validação.

Na etapa de Avaliação, classes para cada instância são previstas por meio de classificadores, e um índice de sucesso é calculado e validado para todas as instâncias. São definidos os critérios de qualidade e seleção para cada modelo, numa tentativa de alcançar os objetivos de negócio.

Por fim, a Implantação envolve a incorporação do modelo selecionado ao processo de tomada de decisão da organização. São desenvolvidos planos de manutenção e monitoramento, de forma a supervisionar a contínua (e correta) utilização dos resultados do modelo ao longo do tempo. 


\subsection{Modelos Multicritério de Apoio a Decisão}

Conforme a ISO 31.010 [9], a análise multicritério (multi-criteria decision analysis, ou MCDA) envolve o uso de uma gama de critérios para a avaliação objetiva de um conjunto de alternativas, visando a criação de uma ordem de prioridade entre elas.

Para [90], as decisões no ambiente institucional raramente são tomadas por um único indivíduo. Segundo o autor, na maioria dos casos o processo decisório sofre a influência das interações entre as partes interessadas (stakeholders) e seus conflitos de interesse. Como resultado, costuma envolver a listagem das possibilidades, que servem como objetos da decisão considerada. Em seguida, ocorre uma análise das consequências e estimação do valor de cada possibilidade, de forma a compreender as vantagens e desvantagens de cada uma.

Na opinião do autor, para a tomada de decisões envolvendo múltiplos critérios, é necessário haver um conjunto bem definido de alternativas viáveis, um modelo de preferências (estabelecido pelos tomadores de decisão) com uma estrutura racional derivada de um grupo de atributos, e um problema matemático bem definido [89].

De forma semelhante, [50] apontam que as análises desta natureza dependem da definição de um conjunto de opções e critérios (ou medidas de desempenho) para atingir um determinado objetivo. A depender do método utilizado, os critérios podem ser organizados em uma hierarquia, sendo atribuídos pesos a cada um deles conforme sua importância. Em seguida, as opções são avaliadas em relação aos critérios, normalmente por meio de uma matriz.

De acordo com os autores, os métodos de MCDA abordam decisões classificadas em quatro tipos distintos:

a) Problemas de escolha: Em que o objetivo é a seleção de uma única alternativa, ou reduzir um conjunto de opções em um único grupo de "boas" opções;

b) Problemas de classificação: Em que as opções são classificadas em grupos pré-definidos, ou "categorias". O objetivo passa a ser o agrupamento de opções semelhantes, de forma a reduzir o número e opções a serem consideradas para um problema específico. 
c) Problemas de ordenação: em que as opções são ordenadas, das "melhores" para as "piores", por meio de uma pontuação ou comparações par a par.

d) Problemas de descrição: Onde o objetivo é descrever as opções e suas consequências.

Os autores apontam que, em problemas que envolvam as categorias de escolha e ordenação, um dos métodos mais utilizados é o AHP, descrito a seguir.

\subsubsection{Analytic Hierarchy Process - AHP}

O Analytic Hierarchy Process (AHP) surgiu na década de 1970 como um método útil para resolução de problemas relacionados à tomada de decisões complexas, envolvendo múltiplos critérios. Desenvolvido por Thomas Saaty [93], da Universidade da Pensilvânia, a técnica funciona pela decomposição de um problema em critérios hierarquizados, utilizando comparações de pares entre diferentes medidas, com base em opiniões de especialistas ou valores reais. Estas comparações são então convertidas em valores ponderados, de acordo com os critérios predefinidos. Os valores subsequentes demonstram, quantitativamente, a importância relativa de um critério em comparação com todos os outros.

A AHP apresenta como vantagem a possibilidade de unificar pontos de vista distintos, possibilitanto aos tomadores de decisão um critério mais objetivo de escolha entre alternativas.

Conforme [50], o processo abrange três etapas principais. Para fins de ilustração, será tomado como exemplo um proceso de seleção de um fornecedor para uma empresa, semelhante ao estudo realizado por [16]: 
a) Definição do objetivo: Escolha de um fornecedor;

b) Definição dos critérios: Considerando o exemplo acima, os critérios utilizados poderiam ser :

- Pontualidade nos prazos de entrega

- Qualidade dos serviços de assistência técnica

- Experiência de mercado (em anos)

c) Definição de alternativas: Considerando o objetivo acima, seriam os fornecedores a serem escolhidos. No exemplo a seguir, são utilizados as entidades aleatórias Fornecedores "A", "B" e "C".

É importante ressaltar que, na aplicação do método AHP, não é necessário (ou recomendável) considerar o custo envolvido em cada alternativa no primeiro momento. O fator custo-benefício pode ser avaliado após a análise dos demais critérios, de forma a evitar a influência de valores monetários na definição das alternativas.

$\mathrm{Na}$ estrutura clássica do AHP, as três informações (objetivo, critérios e alternativas) são então organizados em um formato hierárquico, conforme a Figura 2.13:

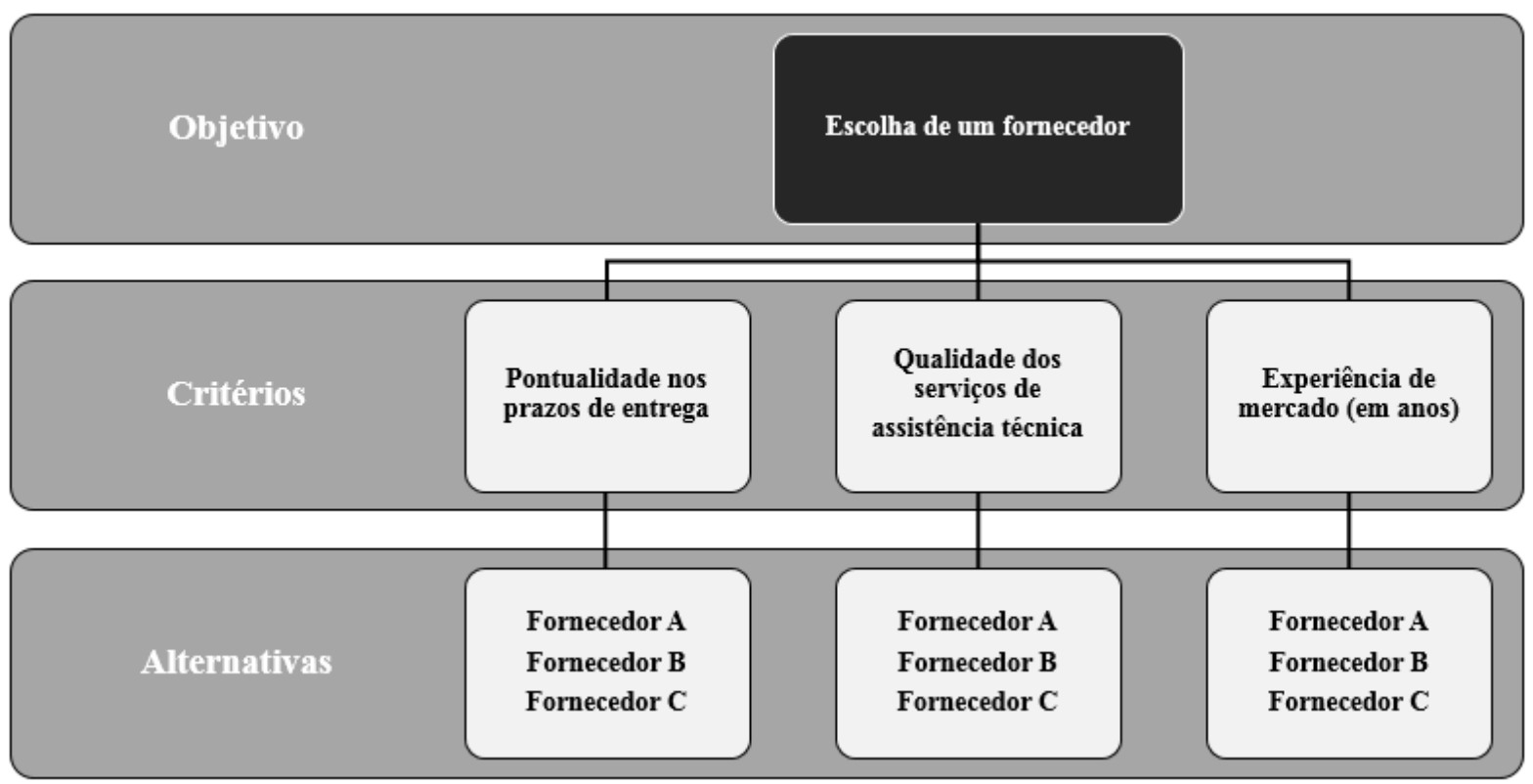

Figura 2.13: Exemplo de hierarquia AHP 
Os avaliadores devem então consolidar as informações, de forma a determinar, par a par, os pesos antre as alternativas. A comparação entre os critérios é feita com base nos julgamentos das partes interessadas, que atribuem valores à cada alternativa, com base em julgamentos objetivos ou subjetivos.

O principal parâmetro utilizado para se chegar a estes valores é a escala fundamental desenvolvida por Saaty [94], que consiste de uma série de valores ímpares, a partir de 1 (de igual importância) a 9 (indicando uma importância relativa extrema de um critério para o outro), conforme o Quadro 2.2:

\begin{tabular}{|c|c|c|}
\hline \multicolumn{3}{|c|}{ Escala Saaty para comparações par a par } \\
\hline $\begin{array}{l}\text { Grau de } \\
\text { importância }\end{array}$ & Conceito & Detalhamento \\
\hline 1 & Importância igual & $\begin{array}{l}\text { Elementos que contribuem igualmente para um mesmo } \\
\text { objetivo }\end{array}$ \\
\hline 3 & Importância moderada & Um elemento é levemente mais importante que o outro \\
\hline 5 & Importância forte & Um elemento é fortemente mais importante que o outro \\
\hline 7 & Importância muito forte & Um elemento é muito mais importante que o outro \\
\hline 9 & Importância extrema & Um elemento é extremamente mais importante. \\
\hline
\end{tabular}

Quadro 2.2: Escala fundamental de Saaty, para comparações par a par [93]

Os critérios e os seus resultados são, então, aplicados na classificação das alternativas escolhidas para análise. Usando a comparação par a par, é possível definir a importância relativa de cada critério em relação aos demais, conforme o Quadro 2.3:

\begin{tabular}{c|c|c|c}
\hline & $\begin{array}{c}\text { Pontualidade } \\
\text { nos prazos de } \\
\text { entrega }\end{array}$ & $\begin{array}{c}\text { Qualidade dos } \\
\text { serviços de } \\
\text { assistência }\end{array}$ & $\begin{array}{c}\text { Experiência } \\
\text { de mercado } \\
\text { (em anos) }\end{array}$ \\
\hline $\begin{array}{c}\text { Pontualidade nos prazos } \\
\text { de entrega }\end{array}$ & & & \\
\hline $\begin{array}{c}\text { Qualidade dos serviços de } \\
\text { assistência }\end{array}$ & & & \\
\hline $\begin{array}{c}\text { Experiência de mercado } \\
\text { (em anos }\end{array}$ & & & \\
\hline
\end{tabular}

Quadro 2.3: Matriz de comparação entre critérios

Utilizando o modelo do Quadro 2.3, os especialistas são questionados a respeito da importância de cada critério em relação aos demais, podendo então responder conforme os exemplos a seguir: 
a) Comparação: "Pontualidade nos prazos de entrega" vs. "Qualidade dos serviços de assistência":

Julgamento: "O critério 'Qualidade dos serviços de assistência' é duas vezes mais importante do que o critério 'Pontualidade nos prazos de entrega"'.

b) Comparação: "Pontualidade nos prazos de entrega" vs. "Experiência de mercado":

Julgamento: "O critério 'Pontualidade nos prazos de entrega' é três vezes mais importante do que o critério "Experiência de mercado"'.

c) Comparação: "Qualidade dos serviços de assistência" vs. "Experiência de mercado":

Julgamento: "O critério 'Qualidade dos serviços de assistência' é quatro vezes mais importante do que o critério 'Experiência de mercado"'.

Os julgamentos são então transcritos conforme o Quadro 2.4, ressaltando que a comparação entre os mesmos elementos deve gerar o resultado igual a ' 1 '.

\begin{tabular}{c|c|c|c}
\hline & $\begin{array}{c}\text { Pontualidade } \\
\text { nos prazos de } \\
\text { entrega }\end{array}$ & $\begin{array}{c}\text { Qualidade dos } \\
\text { serviços de } \\
\text { assistência }\end{array}$ & $\begin{array}{c}\text { Experiência } \\
\text { de mercado } \\
\text { (em anos) }\end{array}$ \\
\hline Pontualidade nos prazos de entrega & $1 / 1$ & $1 / 2$ & $3 / 1$ \\
\hline Qualidade dos serviços de assistência & $2 / 1$ & $1 / 1$ & $4 / 1$ \\
\hline Experiência de mercado (em anos & $1 / 3$ & $1 / 4$ & $1 / 1$ \\
\hline
\end{tabular}

Quadro 2.4: Matriz de comparação entre critérios, com julgamentos

Assim, ambos critérios quantitativos e qualitativos podem ser transformados em escalas numérica e ordinal, facilitando a compreensão dos fatores escolhidos para avaliação, bem como a sua importância relativa em relação ao grupo.

Em seguida, a tranformação da matriz de comparação para uma classificação de critérios é feita pelo cálculo do Vetor de Eigen do conjunto [94]. Este cálculo envolve os passos abaixo:

a) Conversão das frações em valores decimais:

\begin{tabular}{|l|l|l|c|c|c|c|}
\hline $1 / 1$ & $1 / 2$ & $3 / 1$ & \multirow{2}{*}{ Conversão } & 1,0000 & 0,5000 & 3,0000 \\
\cline { 6 - 7 } \cline { 6 - 6 } & $1 / 1$ & $4 / 1$ & 2,0000 & 1,0000 & 4,0000 \\
& $1 / 4$ & $1 / 1$ & & 0,3333 & 0,2500 & 1,0000 \\
\hline
\end{tabular}

Quadro 2.5: Conversão, em valores, da matriz de comparação entre critérios 
Conforme o Quadro 2.5, é realizada a conversão das frações em valores numéricos. Em seguida, a matriz resultante é multiplicada por ela mesma, conforme o Quadro 2.6.

b) Cálculo do resultado da multiplicação da matriz por ela mesma:

\begin{tabular}{|c|c|c|c|c|c|c|c|c|c|c|}
\hline 1,0000 & 0,5000 & 3,0000 & \multirow{3}{*}{$\mathbf{x}$} & 1,0000 & 0,5000 & 3,0000 & \multirow{3}{*}{$=$} & $\mathbf{3 , 0 0 0 0}$ & 1,7500 & 8,0000 \\
\hline 2,0000 & 1,0000 & 4,0000 & & 2,0000 & 1,0000 & 4,0000 & & 5,3 & 0 & 14,0000 \\
\hline 0,3333 & 0,2500 & 1,0000 & & 0,3333 & 0,2500 & 1,0000 & & 1,1666 & 0,6667 & 3,0000 \\
\hline
\end{tabular}

Quadro 2.6: Resultados do cálculo da nova matriz de valores

A Figura 2.14, a seguir, apresenta o exemplo de um dos cálculos realizados para se chegar ao resultado de umas das células da nova matriz:

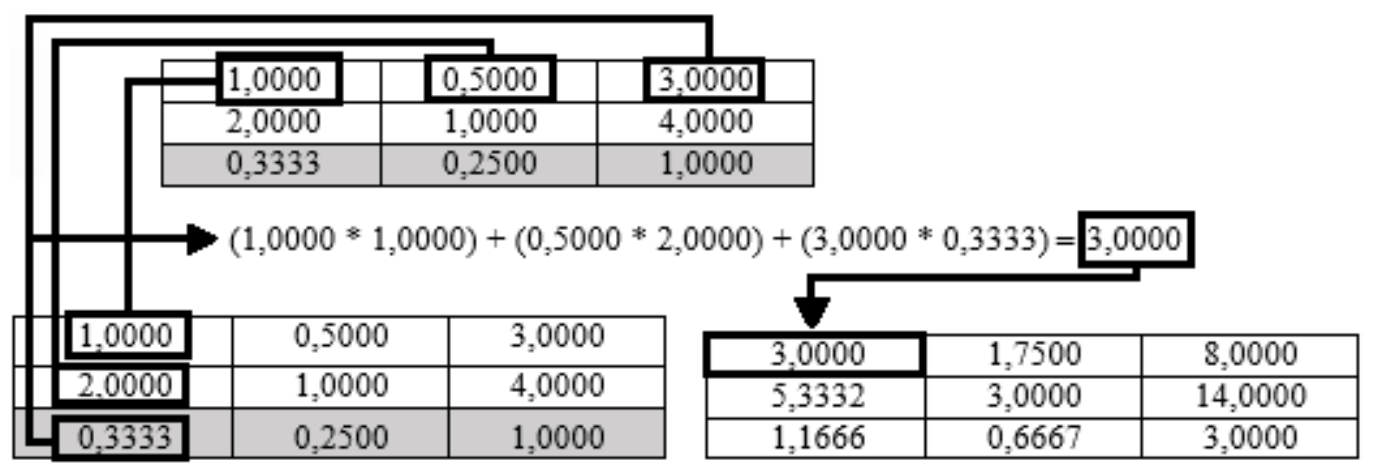

Figura 2.14: Exemplo de cálculo de célula da nova matriz

\section{c) Cálculo do Vetor de Eigen inicial, com base nos valores da nova matriz:}

Após se chegar à matriz resultante da multiplicação anterior, é realizada a soma dos valores em cada linha. A soma da coluna é utilizada para normalizar os resultados.

Passo 1: Soma dos valores de cada linha, e cálculo do resultado final:

\begin{tabular}{c|c|c|c}
\hline \multicolumn{2}{c|}{ Valores da nova matriz } & $\begin{array}{c}\text { Soma das } \\
\text { linhas: }\end{array}$ \\
\hline 3,0000 & 1,7500 & 8,0000 & $\mathbf{1 2 , 7 5 0 0}$ \\
\hline 5,3332 & 3,0000 & 14,0000 & $\mathbf{2 2 , 3 3 3 2}$ \\
\hline 1,1666 & 0,6667 & 3,0000 & $\mathbf{4 , 8 3 3 3}$ \\
\hline & Resultado: & $\mathbf{3 9 , 9 1 6 5}$ \\
\hline
\end{tabular}

Quadro 2.7: Cálculo final da nova matriz de valores 
Passo 2: Normalização dos resultados, dividindo as somas das colunas pelo resultado final:

\begin{tabular}{c|c|c|c}
\hline & $\begin{array}{c}\text { Soma das } \\
\text { colunas: }\end{array}$ & Cálculo & $\begin{array}{c}\text { Resultados } \\
\text { normalizados } \\
\left(\mathbf{1}^{\mathbf{0}} \text { Vetor de Eigen }\right)\end{array}$ \\
\hline (a) & 12,7500 & (a) $/(\mathrm{d}):$ & $\mathbf{0 , 3 1 9 4}$ \\
\hline (b) & 22,3332 & (b) $/($ d): & $\mathbf{0 , 5 5 9 5}$ \\
\hline (c) & 4,8333 & (c) $/($ d): & $\mathbf{0 , 1 2 1 1}$ \\
\hline (d) & 39,9165 & & $\mathbf{1 , 0 0 0 0}$ \\
\hline
\end{tabular}

Quadro 2.8: Cálculo do $1^{\mathrm{o}}$ Vetor de Eigen

Com a normalização dos resultados, chega-se aos valores do $1^{\text {o }}$ Vetor de Eigen.

d) Novos cálculos: Os cálculos referentes às Etapas anteriores b) e c) devem ser repetidos sucessivamente. Desta forma, o próximo passo é a multiplicação da $2^{\text {a }}$ matriz (conforme o Quadro 08) por ela mesma, obtendo-se então os valores da $3^{\mathrm{a}}$ matriz, utilizados para o cálculo do $2^{\mathrm{o}}$ Vetor de Eigen.

Deve-se então comparar os valores do $2^{\mathrm{o}}$ Vetor com os do $1^{\mathrm{o}}$ Vetor. Caso não haja diferença entre ambos (até quatro casas decimais), encerra-se o cálculo. Caso contrário, a $3^{\text {a }}$ matriz deve novamente ser multiplicada por ela mesma, e assim por diante.

Conforme a Tabela 2.2, verifica-se que, no exemplo utilizado, a partir do $3^{\mathrm{o}}$ Vetor de Eigen não são observadas diferenças significativas entre os resultados:

\begin{tabular}{|c|c|c|c|c|c|c|c|c|}
\hline \multicolumn{3}{|c|}{$2^{\mathrm{a}}$ matriz } & $\begin{array}{c}\mathbf{1}^{\mathbf{0}} \\
\text { Vetor } \\
\text { de } \\
\text { Eigen }\end{array}$ & \multicolumn{3}{|c|}{$\begin{array}{c}3^{\mathrm{a}} \text { matriz } \\
\left(2^{\mathrm{a}} \text { matriz ao quadrado }\right)\end{array}$} & \multirow[t]{2}{*}{$\begin{array}{c}2^{\circ} \\
\text { Vetor } \\
\text { de } \\
\text { Eigen } \\
\mathbf{0 , 3 1 9 6} \\
\end{array}$} & \multirow[t]{2}{*}{$\begin{array}{c}\begin{array}{c}\text { Diferença } \\
\text { entre } \mathbf{1}^{\mathbf{0}} \mathbf{e} \\
\mathbf{2}^{\mathbf{o}} \text { Vetor }\end{array} \\
-0,0002\end{array}$} \\
\hline 3,0000 & 1,7500 & 8,0000 & 0,3194 & 27,6653 & 15,8330 & 72,4984 & & \\
\hline 5,3332 & 3,0000 & 14,0000 & 0,5595 & 48,3311 & 27,6662 & 126,6642 & $\mathbf{0 , 5 5 8 4}$ & 0,0011 \\
\hline 1,1666 & 0,6667 & 3,0000 & 0,1211 & 10,5547 & 6,0414 & 27,6653 & 0,1220 & $-0,0009$ \\
\hline \multicolumn{3}{|c|}{$\begin{array}{c}4^{\mathrm{a}} \text { matriz } \\
\left(3^{\mathrm{a}} \text { matriz ao quadrado }\right)\end{array}$} & $\begin{array}{c}3^{\mathbf{o}} \\
\text { Vetor } \\
\text { de } \\
\text { Eigen } \\
\end{array}$ & $\begin{array}{c}\text { Diferença } \\
\text { entre } 3^{\circ} \mathrm{e} \\
2^{\circ} \text { Vetor }\end{array}$ & & & & \\
\hline $2.295,7940$ & $1.314,0555$ & $6.016,8542$ & 0,3196 & 0,0000 & & & & \\
\hline $4.011,1349$ & $2.295,8740$ & $10.512,4476$ & 0,5584 & 0,0000 & & & & \\
\hline 875,9854 & 501,3923 & $2.295,7968$ & 0,1220 & 0,0000 & & & & \\
\hline
\end{tabular}

Tabela 2.2: Cálculo do Vetor de Eigen

O resultado do último cálculo do Vetor de Eigen traz os pesos finais que deverão ser atribuídos a cada critério, conforme a Figura 2.15: 


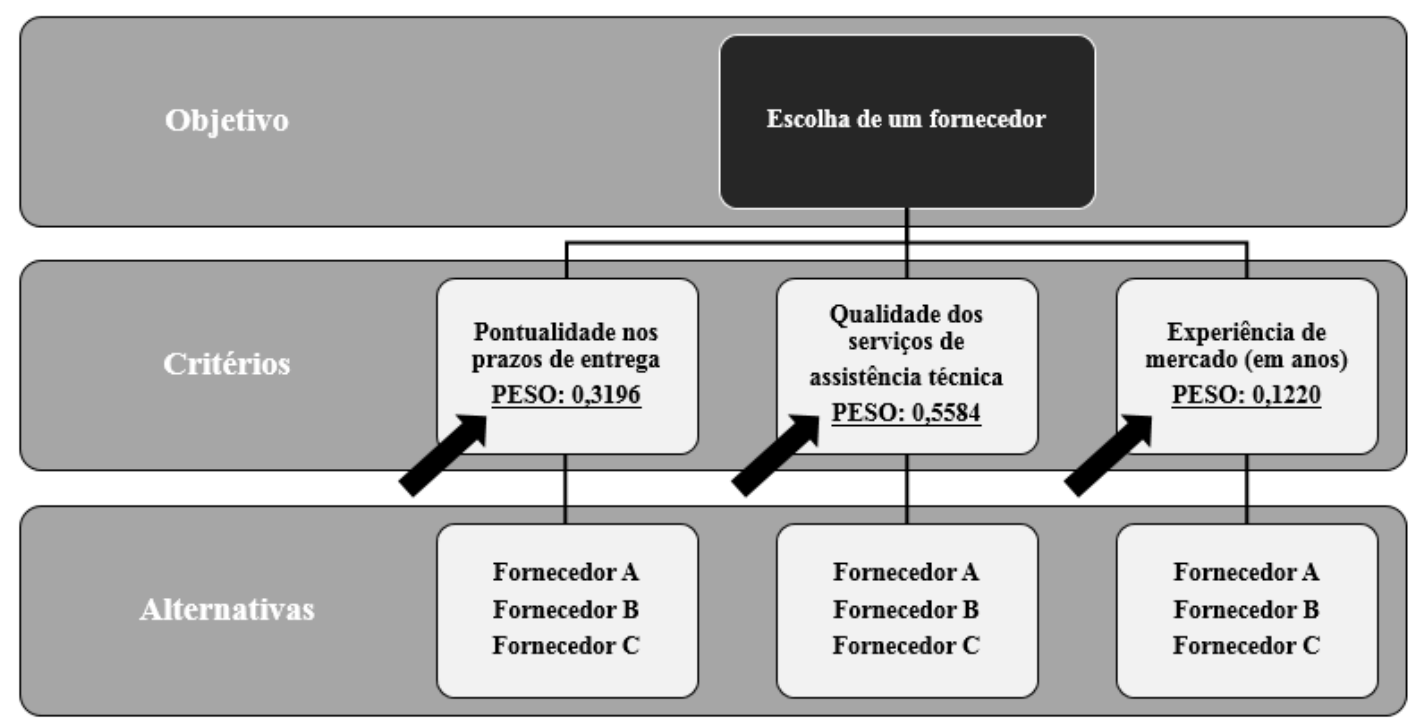

Figura 2.15: Resultado do cálculo dos pesos dos critérios

Para o cálculo do peso das alternativas (Fornecedores) em relação aos critérios, realiza-se o cálculo semelhante ao anterior, conforme a Tabela 2.3. Para cada critério, é feita a comparação entre as alternativas (os julgamentos individuais são fictícios):

\begin{tabular}{|c|c|c|c|c|c|c|c|c|c|c|}
\hline & \multicolumn{10}{|c|}{ Critérios } \\
\hline & \multicolumn{3}{|c|}{$\begin{array}{l}\text { Pontualidade } \\
\text { nos prazos de } \\
\text { entrega }\end{array}$} & \multirow[t]{2}{*}{$\begin{array}{l}\text { Vetor } \\
\text { de } \\
\text { Eigen }\end{array}$} & \multicolumn{3}{|c|}{$\begin{array}{l}\text { Qualidade dos } \\
\text { serviços de } \\
\text { assistência } \\
\text { técnica }\end{array}$} & \multirow[t]{2}{*}{$\begin{array}{l}\text { Vetor } \\
\text { de } \\
\text { Eigen }\end{array}$} & \multirow{2}{*}{$\begin{array}{c}\text { Experiência } \\
\text { de mercado } \\
\text { (em anos) }\end{array}$} & \multirow[t]{2}{*}{ Peso } \\
\hline Fornecedores & $\mathbf{A}$ & B & $\mathbf{C}$ & & $\mathbf{A}$ & B & $\mathbf{C}$ & & & \\
\hline $\mathbf{A}$ & $1 / 1$ & $1 / 2$ & $4 / 1$ & 0,3445 & $1 / 1$ & $2 / 1$ & $2 / 1$ & 0,4836 & 2 & 0,1000 \\
\hline B & $2 / 1$ & $1 / 1$ & $4 / 1$ & 0,5469 & $1 / 2$ & $1 / 1$ & $3 / 1$ & 0,3487 & 8 & 0,4000 \\
\hline $\mathbf{C}$ & $1 / 4$ & $1 / 4$ & $1 / 1$ & 0,1085 & $1 / 2$ & $1 / 3$ & $1 / 1$ & 0,1677 & 10 & 0,5000 \\
\hline
\end{tabular}

Tabela 2.3 - Julgamentos das alternativas em relação aos critérios

Na comparação entre os fornecedores e o critério "Experiência de mercado", verifica-se a capacidade do método em combinar valores subjetivos e objetivos, pois deve-se considerar para este critério apenas um valor único (anos). Neste caso, os valores são normalizados para chegar ao resultado, conforme a Tabela 2.4:

\begin{tabular}{c|c|c}
\hline Fornecedores & $\begin{array}{c}\text { Experiência de } \\
\text { mercado (em anos) }\end{array}$ & Resultado (Peso) \\
\hline A & 2 & $2 / 20=\mathbf{0 , 1 0 0 0}$ \\
\hline B & 8 & $8 / 20=\mathbf{0 , 4 0 0 0}$ \\
\hline C & 10 & $10 / 20=\mathbf{0 , 5 0 0 0}$ \\
\hline TOTAL & 20 & 1,0000 \\
\hline
\end{tabular}

Tabela 2.4: Cálculo de pesos para critério objetivo 
A Figura 2.16 apresenta a hierarquia completa, agora com os pesos de cada critério preenchidos conforme os cálculos par a par:

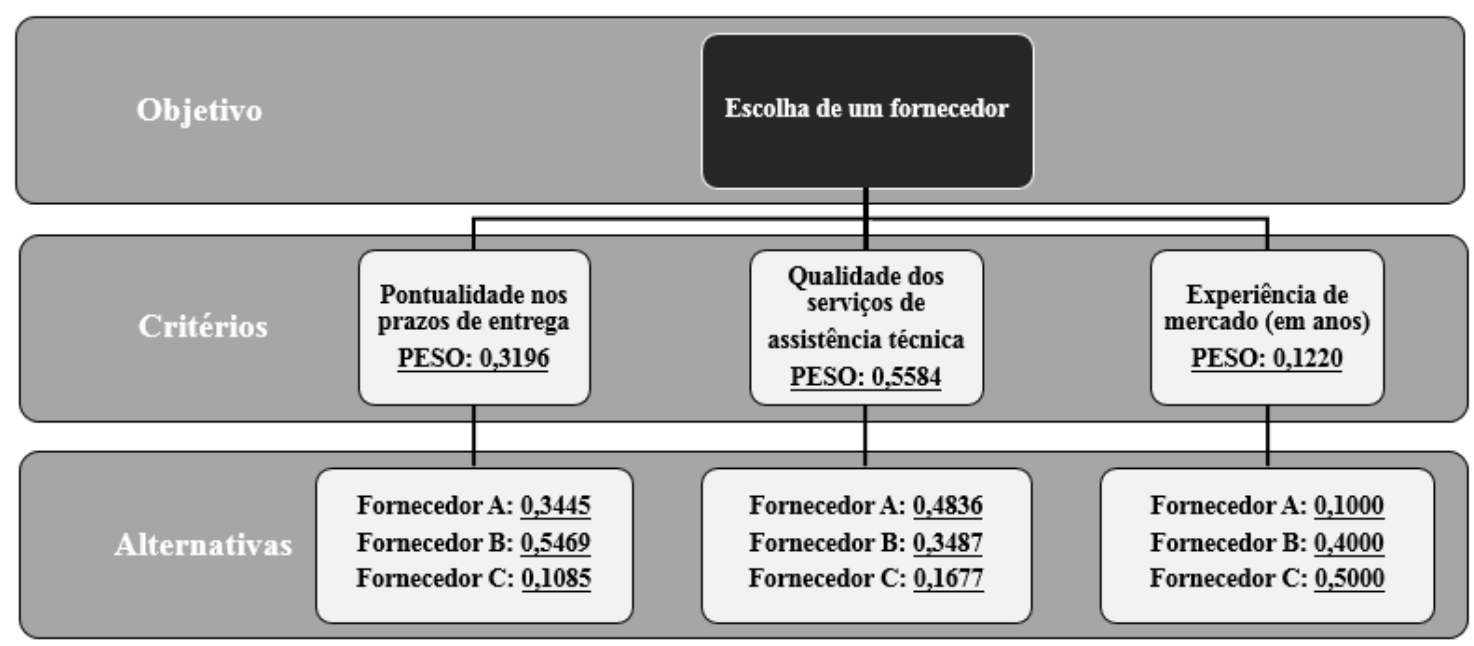

Figura 2.16: Visão geral do modelo AHP - exemplo

O cálculo final para a escolha da alternativa em relação ao objetivo geral envolve a multiplicação da pontuação de cada critério em cada alternativa ( $3^{\text {a }}$ linha da Figura 2.16), pela pontuação geral de cada critério (2a linha da mesma Figura). Este cálculo pode ser visto na Tabela 2.5, onde verifica-se que o Fornecedor B, com pontuação geral de 0,4183, deve ser o escolhido.

\begin{tabular}{|c|c|c|c|c|c|c|c|c|}
\hline & \multicolumn{3}{|c|}{ Critérios } & \multirow{2}{*}{\multicolumn{2}{|c|}{$\begin{array}{c}\text { Pont. } \\
\text { dos } \\
\text { critérios }\end{array}$}} & \multirow{2}{*}{\multicolumn{2}{|c|}{\begin{tabular}{|c} 
Resultado \\
(por \\
Fornecedor)
\end{tabular}}} & \multirow[b]{2}{*}{$\begin{array}{r}\text { Resultado } \\
\text { (cálculo) }\end{array}$} \\
\hline & $\begin{array}{c}\text { Pontualidade } \\
\text { nos prazos } \\
\text { de entrega }\end{array}$ & $\begin{array}{c}\text { Qualidade } \\
\text { dos serviços } \\
\text { de } \\
\text { assistência } \\
\text { técnica }\end{array}$ & $\begin{array}{c}\text { Experiência } \\
\text { de mercado } \\
(\text { em anos })\end{array}$ & & & & & \\
\hline $\begin{array}{c}\text { Fornec. } \\
\text { A }\end{array}$ & 0,3445 & 0,4836 & 0,1000 & \multirow[t]{2}{*}{$X$} & 0,3196 & \multirow[t]{2}{*}{$=$} & 0,3923 & $\begin{array}{c}(0,3445 \times 0,3196)+ \\
(0,4836 \times 0,5584)+ \\
(0,1000 \times 0,1220)\end{array}$ \\
\hline $\begin{array}{c}\text { Fornec. } \\
\text { B }\end{array}$ & 0,5469 & 0,3487 & 0,4000 & & 0,5584 & & $\underline{0,4183}$ & $\begin{array}{c}(0,5469 \times 0,3196)+ \\
(0,3487 \times 0,5584)+ \\
(0,4000 \times 0,1220)\end{array}$ \\
\hline $\begin{array}{c}\text { Fornec. } \\
\text { C }\end{array}$ & 0,1085 & 0,1677 & 0,5000 & & 0,1220 & & 0,1893 & $\begin{array}{c}(0,1085 \times 0,3196)+ \\
(0,1677 \times 0,5584)+ \\
(0,5000 \times 0,1220)\end{array}$ \\
\hline
\end{tabular}

Tabela 2.5: Cálculo final para escolha da alternativa

Devido à liberdade que o método fornece para a classificação dos critérios e alternativas, podem ocorrer inconsistências entre os julgamentos realizados. Como exemplo, para um determinado critério em que o Fornecedor A é julgado ser mais desejável do que o Fornecedor B e este, por sua vez, ser mais desejável que o 
Fornecedor C, seria incoerente um julgamento que definisse que o Fornecedor C é mais desejável que o Fornecedor A.

De forma e estabelecer um parâmetro que determinasse o nível aceitável de inconsistências de acordo com o número de comparações realizadas, Saaty [93] propôs uma "taxa de consistência" (CR, ou Consistency Ratio), conforme a fórmula:

$$
C R=\frac{C I}{R I}
$$

Este indicador é a comparação entre os julgamentos realizados pelos avaliadores, (indicado pela índice de consistência CI (Consistency Index) e julgamentos aleatórios, calculados pelo próprio autor para matrizes de diferentes tamanhos, indicado por RI (random index), ou índices aleatórios.

O RI varia de acordo com o número de critérios avaliados (n), conforme a Tabela 2.6, a seguir:

\begin{tabular}{c|c|c|c|c|c|c|c|c|c|c}
\hline $\mathbf{n}$ & $\mathbf{1}$ & $\mathbf{2}$ & $\mathbf{3}$ & $\mathbf{4}$ & $\mathbf{5}$ & $\mathbf{6}$ & $\mathbf{7}$ & $\mathbf{8}$ & $\mathbf{9}$ & $\mathbf{1 0}$ \\
\hline $\mathbf{R I}$ & 0,00 & 0,00 & 0,58 & 0,90 & 1,12 & 1,24 & 1,32 & 1,41 & 1,45 & 1,49 \\
\hline
\end{tabular}

Tabela 2.6: Índices aleatórios calculados por Saaty [93]

Já o índice de consistência (CI) é calculado com base na fórmula a seguir:

$$
C I=\frac{\lambda_{\operatorname{Max}}-n}{n-1}
$$

Para o cálculo de $\lambda_{M a x}$, é realizada a multiplicação da matriz de comparação pelo seu Vetor de Eigen. Este resultado é então dividido pelo Vetor de Eigen, calculando-se, por fim, a média final do resultado. Para ilustrar este cálculo, pode-se tomar como exemplo a primeira comparação realizada entre os critérios do exemplo

\begin{tabular}{|c|c|c|c|c|c|c|c|c|c|}
\hline \multicolumn{3}{|c|}{$\begin{array}{l}\text { Julgamentos } \\
\text { iniciais }\end{array}$} & \multicolumn{3}{|c|}{$\begin{array}{c}\text { Conversão: } \\
\text { Matriz de comparação }\end{array}$} & \multirow{2}{*}{$\begin{array}{c}\begin{array}{c}\text { Vetor de } \\
\text { Eigen }\end{array} \\
0,3194\end{array}$} & \multirow{2}{*}{$\begin{array}{c}\begin{array}{c}\text { Matriz } \\
\mathbf{x} \\
\text { Vetor de } \\
\text { Eigen }\end{array} \\
0,9624\end{array}$} & \multirow{2}{*}{$\begin{array}{c}\begin{array}{c}\text { Divisão } \\
\text { pelo } \\
\text { Vetor de } \\
\text { Eigen }\end{array} \\
3,0131 \\
\end{array}$} & \multirow{2}{*}{$\begin{array}{c}\text { Média } \\
\text { dos } \\
\text { resultados } \\
(\lambda \text { max }) \\
\end{array}$} \\
\hline $1 / 1$ & $1 / 2$ & $3 / 1$ & 1,0000 & 0,5000 & 3,0000 & & & & \\
\hline $2 / 1$ & $1 / 1$ & $4 / 1$ & 2,0000 & 1,0000 & 4,0000 & 0,5594 & 1,6826 & 3,0075 & $\underline{\mathbf{3 , 0 1 8 3}}$ \\
\hline $1 / 3$ & $1 / 4$ & $1 / 1$ & 0,3333 & 0,2500 & 1,0000 & 0,1210 & 0,3674 & 3,0345 & \\
\hline
\end{tabular}
anterior, conforme a Tabela 2.7 .

Tabela 2.7: Exemplo de cálculo de $\lambda \max$ 
No exemplo acima, o índice de consistência (CI) é dado por $((3,0183)-3) /(3-1)$, ou 0,009 . Se $n=3$, então o índice aleatório (RI) correspondente é 0,58. Desta forma, a taxa de consistência (CR) é igual a 0,009/0,58 =0,016, ou 1,6\%.

Saaty [93] sugere que um conjunto de decisões pode ser considerado "confiável" se a taxa de consistência permanecer abaixo de 0,1 , ou $10 \%$. Na visão do autor, taxas muito acima deste parâmetro aproximam-se demasiadamente de resultados aleatórios, o que indica que os julgamentos iniciais carecem de revisão.

O método tem visto aplicações em diversos setores. Um destes estudos teve como objetivo aumentar a qualidade da seleção e avaliação de fornecedores pelo uso do AHP, no contexto da fabricação de automóveis [113]. Também na indústria automobilística, o AHP foi utilizado para identificar as unidades de negócio mais críticas de uma organização [100]. Tem sido utilizada também na seleção de funcionários [59], gestão de cadeias de fornecimento [11], e até mesmo para avaliar a eficiência do desempenho de aeroportos [61].

O Capítulo 03 apresenta a revisão da literatura, com a análise de algumas aplicações reais desta e outras técnicas de análise quantitativa e qualitativa para o gerenciamento de riscos no ambiente de saúde. 


\section{Capítulo 3}

\section{Revisão da Literatura}

Este Capítulo contempla a revisão da literatura, iniciando-se com a apresentação de um panorama geral dos esforços aplicados por empresas da área de seguros em saúde para a implementação de estruturas corporativas de gestão de riscos. São detalhadas as principais dificuldades enfrentadas por organizações desta natureza, decorrentes de comportamentos abusivos e inconsistências em cobranças médico-hospitalares. Esta análise é complementada com dados estatísticos ligados ao mercado internacional e brasileiro, demonstrando a magnitude das despesas relacionadas ao pagamento de procedimentos desnecessários, serviços não prestados, e cobranças inconsistentes.

Como forma de identificar e mitigar os riscos operacionais presentes neste ambiente, a última parte do Capítulo contém uma discussão a respeito do uso de técnicas qualitativas e quantitativas para gestão de riscos operacionais no mercado de saúde. Estes esforços envolvem a aplicação de análises qualitativas, modelos multicritério e métodos de detecção de anomalias em bases de dados.

Sendo assim, como forma de visualizar a estrutura geral do capítulo, a Figura 3.1 detalha os itens abordados para a realização da revisão da literatura.

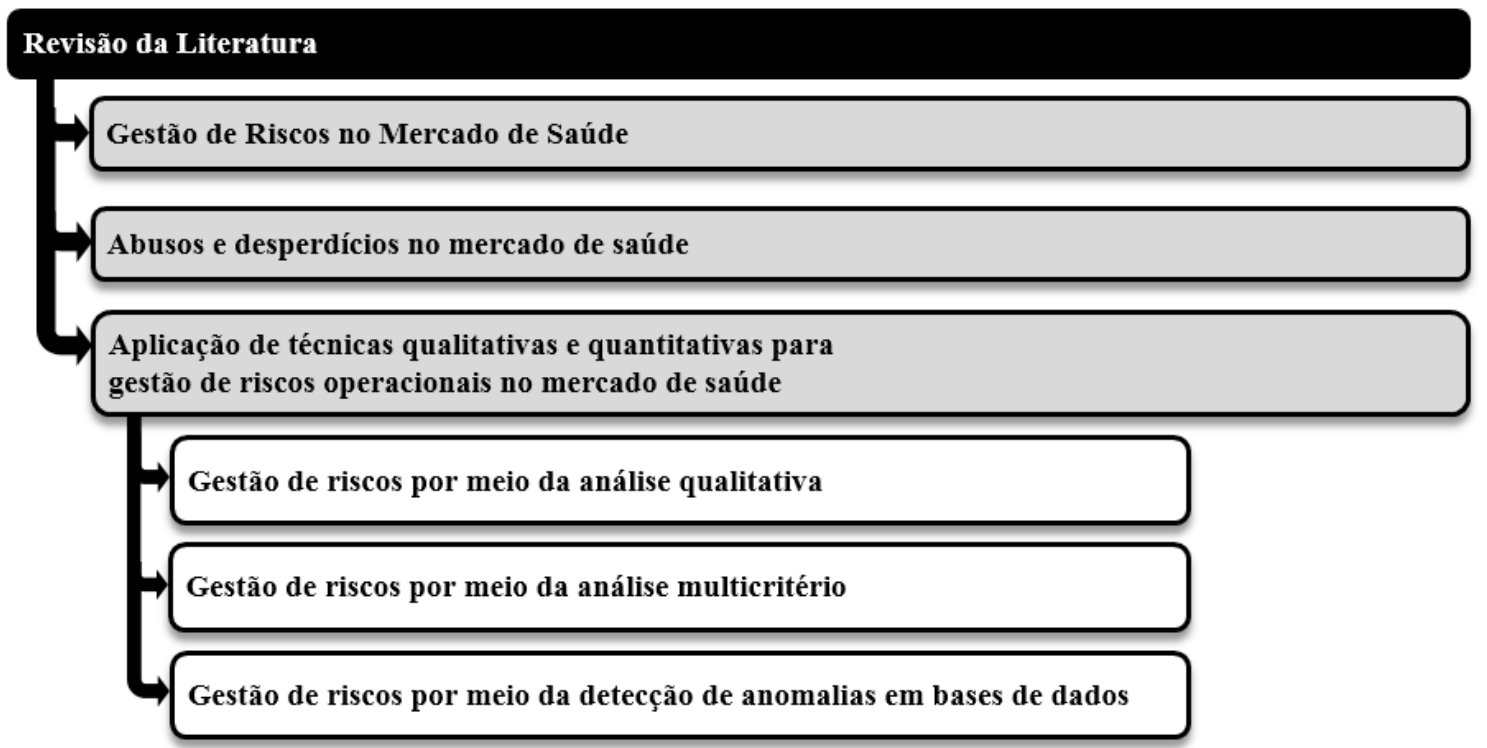

Figura 3.1: Revisão da Literatura 


\subsection{Gestão de Riscos no Mercado de Saúde}

Para [81], a gestão eficaz de riscos é um elemento essencial da administração bemsucedida de projetos e processos organizacionais. Realizada adequadamente, ela auxilia os gestores na criação de medidas para mitigação tanto dos riscos conhecidos quanto dos imprevistos em projetos e processos, independentemente de sua natureza. Conforme [86], a incapacidade de realizar a gestão de risco eficaz pode causar diversos impactos inesperados, como descontrole orçamentário e de prazos previstos em cronograma, impossibilitando o alcance de metas críticas de um projeto ou processo organizacional.

Em uma pesquisa da agência Stand and Poor's, foi apresentado um sumário das causas principais de insolvência das empresas do ramo de seguros em saúde, onde se verificam fatores importantes como o déficit de reservas, gastos com sinistros e fraudes [26].

São evidentes os esforços para o aprimoramento e aplicação de técnicas de gerenciamento de riscos no âmbito das organizações no mercado de saúde. Diversos estudos já foram realizados no sentido de avaliar a percepção de seguradoras a respeito das categorias de risco aplicáveis aos seus negócios.

Em um estudo realizado em parceria com a Universidade de St. Gallen, a consultora Deloitte realçou a crescente importância da gestão de riscos operacionais em empresas da área de seguros [57]. Seu trabalho buscou identificar os fatores-chave para a introdução do gerenciamento de riscos nestas organizações, a visão que as empresas do ramo possuem a respeito do tema, e o estado atual da estrutura de gerenciamento em seguradores europeias de grande porte (a maioria apresentando sinistros anuais acima de 100 milhões de Euros). Como resultado, foi verificado que a maioria das organizações buscou a implantação de uma estrutura integrada como consequência de alterações regulatórias, e que poucas conseguiram até então evoluir sua gestão de riscos além da definição de políticas internas.

Um levantamento geral realizado por [91] investigou o estado atual das atividades de gerenciamento de riscos corporativos em operadoras de saúde norteamericanas. Seu estudo envolveu a preparação e aplicação de um questionário a uma seleção de cerca de 20 especialistas que trabalharam na área de seguros em saúde. Buscou-se avaliar a presença, nas organizações em que os participantes estavam inseridos, de uma estrutura integrada de gerenciamento de riscos e, caso positivo, quais os riscos são considerados nas suas avaliações. Entre suas conclusões, o autor 
cita a realidade de que a maioria ainda está em processo de adequação às práticas de gerenciamento de riscos corporativos. Em grande parte dos casos avaliados, ainda se vê a gestão de riscos centralizada em uma única dependência corporativa, sem um fluxo geral de coleta de dados para tomada de decisões a nível estratégico. Para este autor, nestas empresas, os riscos identificados como "críticos" ainda estão frequentemente associados ao âmbito legal e político, dada uma certa importância também aos fatores relacionados à segurança da informação e rotatividade de funcionários.

$\mathrm{Na}$ comunidade europeia, os pesquisadores espanhóis [106] recentemente abordaram a importância do gerenciamento de riscos nas operadoras de planos de saúde, especialmente à luz das alterações regulatórias que entraram em vigor nos países da União Europeia. Seu trabalho abordou algumas metodologias de levantamento e análise de riscos operacionais, com ênfase nas diretrizes da COSO ERM [36] e Solvency II, que trata dos requisitos mínimos de capital para mitigação do risco de insolvência em organizações da área de seguros [87]. As organizações que se adequam a ambientes de incerteza, na visão dos autores, são aquelas que possuem maior chance de sucesso, devido ao cultivo de uma cultura interna de adaptação e à aceitação de mudanças, que resultam diretamente no fomento da inovação.

Em outro exemplo, [15] apresentam exemplos de fatores relevantes a serem considerados por empresas deste ramo, em termos de riscos associados à gestão atuarial de sinistros, alterações no ambiente regulatório e o crescente uso da internet, pelos participantes, para realização de pesquisas para a comparação de custos e benefícios associados às entidades que oferecem este tipo de serviço.

Os estudos de [88] apresentaram os principais riscos levantados por operadoras de grande porte norte-americanas, mostrando que estavam associados à negação de reajustes de procedimentos por agências regulatórias e às incertezas ligadas às novas regras do Affordable Care Act de 2010, que poderiam resultar em uma possível perda de representatividade de mercado.

Aliados aos esforços de adequação às novas realidades do ambiente regulatório e aos desafios oriundos de avanços tecnológicos, foi verificado também uma crescente preocupação para o tratamento de ameaças ligadas a desperdícios e abusos no mercado de saúde, conforme apresentado no item a seguir. 


\subsection{Abusos e desperdícios no mercado de saúde}

Os tipos mais comuns de abusos na área de saúde têm sido detalhados e agrupados por diversas publicações, citando como exemplo os estudos de [104], [38] e [65]. Os principais estão relacionados a cobranças por serviços não prestados ou equipamentos não fornecidos, assim como a realização de procedimentos médicos desnecessários [20]. Também verifica-se a existência de solicitações separadas de reembolso para itens de um procedimento contratado como pacote, prática denominada de "unbundling" [104], cobranças excessivas com base em alterações de formulários de solicitação [20], uso indevido de dados de participantes e o fornecimento de códigos incorretos de procedimentos, substituindo um código correto por outro semelhante, porém com um custo associado maior [38].

Por se tratar de uma tendência mundial, o crescente aumento da incidência de desperdícios e abuso na área de saúde tem sido amplamente estudado por entidades públicas e privadas, principalmente no exterior, onde diversas estimativas já foram levantadas referentes ao custo anual de despesas médicas relacionadas a cobranças abusivas e inconsistentes.

No mercado europeu, a European Healthcare Fraud ES Corruption Network (Rede Europeia de Corrupção e Fraude em Saúde) estimou, no seu relatório de 2011 [40], que o percentual de perdas associado a práticas abusivas e de desperdício representou, em média, $8 \%$ das despesas, em um grupo de países que incluiu o Reino Unido, França e Estados Unidos, o que representa um aumento de $30 \%$ após a recessão de 2008.

Nos Estados Unidos, estima-se que $30 \%$ dos custos totais de saúde está relacionado a desperdícios e práticas suspeitas [66]. Em 2012, o ex-chefe da agência norte-americana CMS (United States' Centers for Medicare and Medicaid Services, ou Centro de Serviços para Medicaid e Medicare) estimou que as cobranças abusivas na área de saúde representaram cerca de 98 bilhões de dólares referentes às despesas com os principais programas governamentais dos Estados Unidos, o Medicare e Medicaid. Isto representou cerca de $10 \%$ do total das despesas médicas no período, para aquele país [102], percentual semelhante ao apresentado por [73], que cita estimativas do FBI (Federal Bureau of Investigation), e por [19].

Também nos EUA, a NHCAA (Associação Nacional Contra Fraudes em Serviços de Saúde, ou National Health Care Anti-Fraud Association) projetou que os abusos no sistema de saúde podem alcançar, anualmente, o patamar de centenas de 
bilhões de dólares [74]. Tamanha é a magnitude dos desperdícios no sistema de saúde norte-americano que seu Departamento de Saúde e Serviços Humanos (HHS) lançou esforços significativos para o uso de tecnologias avançadas, como a análise preditiva de dados, para combater e prevenir atividades abusivas [75].

Na América Latina, o Brasil representa o maior mercado de saúde. Em 2009, a União, Estados, e municípios direcionaram cerca de $\mathrm{R} \$ 80$ bilhões ao Sistema Único de Saúde (SUS), enquanto o setor privado contribuiu com aproximadamente $\mathrm{R} \$ 90$ bilhões, conforme dados da consultora Pricewaterhousecoopers [85]. Entretanto, aparentemente os investimentos massivos na área não geraram resultados eficientes, pois em 2014 o país posicionou-se em penúltimo lugar em termos de eficiência nos serviços de saúde, em um estudo realizado por [22], onde se avaliaram 48 países com um PIB per capita maior que US\$ 5.000, considerando critérios ponderados como expectativa de vida e gastos assistenciais gerais e per capita. Neste mercado, nos últimos dez anos, os custos de saúde no Brasil têm sofrido um aumento muito superior aos índices oficiais de inflação, conforme exposto por [13].

Ao longo da década anterior, segundo [69], estima-se que a porcentagem de gastos abusivos no mercado de seguros do país, de forma geral, tenha ficado entre 10 e $15 \%$ do total das despesas. Embora não tenham sido localizados dados específicos quanto ao mercado de saúde brasileiro [13], este percentual é semelhante aos índices de desperdícios já levantados em outros países, como visto por exemplo em [40].

O estudo da literatura evidencia a crescente preocupação das empresas do ramo de seguros para mitigação de ameaças internas e externas, que possam impactar seus objetivos e resultados. No próximos itens, será feita uma apresentação das técnicas qualitativas e quantitativas utilizadas para tratamento das inconsistências que venham a ser detectadas no decorrer da análise dos processos organizacionais. 


\subsection{Aplicação de técnicas qualitativas e quantitativas para gestão de riscos operacionais no mercado de saúde}

Nos itens a seguir, são discutidas as aplicações da ferramenta FMEA e do método AHP para a gestão de riscos qualitativos em organizações voltadas à área de saúde. Em seguida, apresentam-se as aplicações das técnicas de detecção de anomalias e mineração de dados para o tratamento de riscos existentes neste mesmo contexto.

\subsubsection{Gestão de riscos por meio da análise qualitativa}

Em termos de aplicações na área de saúde, observa-se que a maioria das implementações da ferramenta FMEA está voltada à redução de riscos associados à segurança dos participantes. O uso de uma variação do FMEA foi vista na seleção de estratégias de manutenção para equipamentos médicos, como incubadores e aparelhos de tomografia [53]. Neste caso, o Fuzzy Failure Modes and Effect Analysis (FFMEA) considerou fatores de avaliação de risco e conjuntos de variáveis como "idade" e "utilização" para gerar uma pontuação ligada a uma estratégia de manutenção específica.

No âmbito na análise de processos na área médica, houve a implementação da técnica também na análise de riscos clínicos em ambientes cirúrgicos [108], resultando em uma evolução no estado da arte para o gerenciamento de riscos, possibilitando uma análise dos fatores que afetam a segurança de pacientes internados. O contexto do estudo envolveu a identificação de riscos na aplicação de medicamentos em um ambiente clínico, e o objetivo final dos pesquisadores foi a proposta de um modelo que auxiliasse no estabelecimento de metas de segurança, e possibilitasse a avaliação da melhoria do desempenho da segurança de seus processos. Os autores levantaram as características dos modelos de análise de falhas mais utilizados, que se baseiam em análises retrospectivas, e propuseram um novo modelo, denominado CREA (Clinical Risk and Error Analysis, ou Análise de Riscos e Erros Clínicos). Nesta nova técnica, observa-se como diferencial o uso de dados estatísticos levantados especificamente para o tipo de processo avaliado, o que auxiliou na definição dos valores de probabilidade atribuídos aos riscos identificados. 
Caixeiro [27] realizou um levantamento geral da aplicação do FMEA para a prospecção de riscos e prevenção de eventos adversos por hospitais em processo de acreditação. O autor identificou que o FMEA é amplamente utilizado para a prospecção de riscos à segurança dos pacientes, nos hospitais brasileiros que se submetem ao processo de avaliação externa junto ao Consórcio Brasileiro de Acreditação. Foram aplicados questionários a um conjunto de quase 50 hospitais, no intuito de verificar, no tocante à aplicação da técnica, as barreiras superadas e as condições existentes em cada entidade. Como resultado da pesquisa, foi observado que metade das entidades avaliadas aplicaram alguma variação da técnica internamente. As principais ferramentas utilizadas, em mais de $90 \%$ dos casos, foram o Brainstorming e a elaboração de fluxogramas.

Em outro estudo, pesquisadores norte-americanos do VA National Center for Patient Safety (Centro Nacional de Segurança de Pacientes, do Departamento de Assuntos de Veteranos) apresentaram uma alteração significativa nas definições de probabilidade e impacto ao desenvolverem uma adaptação do FMEA denominada HFMEA (Healthcare Failure Mode and Effect Analysis), para uso específico na área de saúde [36]. Neste modelo, uma equipe multidisciplinar de avaliadores efetua a análise proativa de processos com o uso de fluxogramas de atividade, aliada a uma matriz de pontuação e árvores de decisão para o levantamento de possíveis vulnerabilidades. A árvore de decisão é estruturada em torno de perguntas referentes à existência de pontos fracos, controles e possibilidade de detecção das falhas.

\subsubsection{Gestão de riscos por meio da análise multicritério}

Quanto às aplicações do AHP para aumentar a eficiência de projetos de auditoria, um estudo realizado por [58] combinou o AHP e a programação por metas (Goal Programming) para alocar, de forma mais eficiente, os esforços de auditoria entre os projetos concorrentes. Os autores concluíram que a principal vantagem dessa abordagem foi poder justificar, com base em métricas de risco, a inclusão ou exclusão de projetos nos planos de auditoria de sua organização.

O AHP também foi utilizado para classificar fatores de risco por ordem de intensidade, facilitando a avaliação da fraude em processos gerenciais [37]. No estudo, os autores buscaram analisar pontos de atenção, ou red flags, de diferentes importâncias. Tratam-se de fatores pessoais, negociais e econômicos tradicionalmente 
considerados pelos auditores para o planejamento de um projeto de auditoria. A seguir, são identificadas as seguintes classes de red flags existentes no modelo considerado pelos autores, com alguns exemplos dos principais fatores, em cada categoria, que propiciam comportamentos fora do padrão:

- Fatores condicionais: Relacionados às condições existentes na organização, que facilitam a ocorrência de fraudes. Exemplos: ausência de controles, transações difíceis de serem auditadas, clientes recentes, crescimento acelerado e existência de conflitos de interesse;

- Fatores motivacionais: Fatores que motivam a ocorrência de comportamentos abusivos, como a diminuição de receitas e remuneração baseada em resultados;

- Fatores de atitude: Relacionados a atitudes e valores que incentivam os indivíduos a cometerem atos ilícitos. Exemplos: ênfase em resultados, histórico de ocorrências inconsistentes, conflitos de interesse, atitude desrespeitosa quanto aos esforços da auditoria.

Para aplicação do AHP nesse contexto, os autores agruparam estes e outros fatores em uma hierarquia, conforme a Figura 3.2:

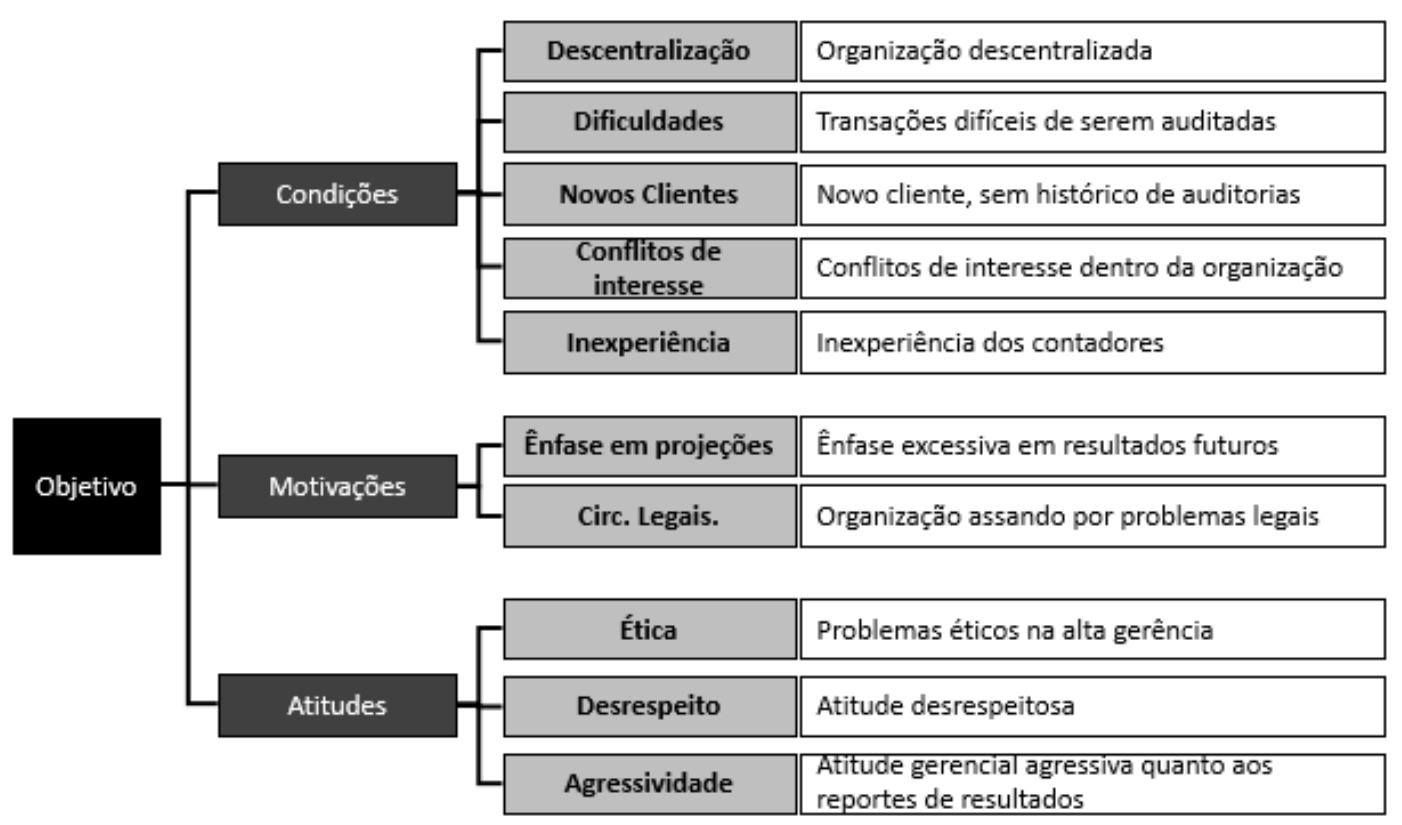

Figura 3.2: Modelo AHP desenvolvido por [37] 
Aplicada por meio do software Expert Choice [39], o modelo abordou apenas a comparação dos critérios, sem aplicação para análise de alternativas reais. Contudo, a técnica mostrou-se flexível em termos de permitir que os auditores pudessem personalizar seus modelos de acordo com o objeto de investigação. A análise apontou que a dificuldade em auditar os registros existentes é o principal fator que deve ser considerado no planejamento de um projeto de auditoria.

Mais recentemente, a técnica tem sido aplicada a fim de se direcionar, de forma mais eficiente, os esforços de unidades de investigação para os casos classificados como sendo de maior criticidade para uma empresa [29]. Neste estudo específico, foram considerados como fatores: o acesso às informações para realizar a auditoria; o nível organizacional dos funcionários envolvidos; o impacto financeiro potencial; a natureza das atividades ilícitas (atividades ilegais, antiéticas, ou ambas); a deficiência de controles; existência de histórico anterior de comportamento indevido; o acesso aos registros relacionados à ocorrência; e o grau de acessibilidade aos indivíduos envolvidos.

Juntamente com as medidas na esfera governamental, o universo acadêmico e o setor privado também apresentaram estudos promissores, que visam identificar a ocorrência de inconsistências e abusos, dos quais alguns exemplos são apresentados a seguir.

\subsubsection{Gestão de riscos por meio da detecção de anomalias em bases de dados}

Joudaki et al. [55], detalhou vários exemplos de publicações que apresentaram métodos diversos para a descoberta de conhecimento com dados assistenciais. São detalhados mais de vinte pesquisas realizadas entre 1997 e 2013, onde foram utilizados conceitos de mineração de dados, detecção de anomalias e abordagens não supervisionadas para a detecção de abusos e inconsistências em cobranças de serviços assistenciais. Em mais da metade dos casos, foram criados modelos utilizando algoritmos de clusterização e técnicas de detecção de outliers.

Como exemplo inicial, pode-se citar o estudo de [79], que aplicaram dois métodos distintos de clusterização para um grande conjunto de dados de despesas assistenciais, a fim de comparar o seu desempenho na detecção de cobranças suspeitas. No estudo, os autores abordam a seleção de variáveis para clusterização, a 
definição do número de clusters, o desempenho de cada algoritmo aplicado (em termos de processamento), e a eficiência dos clusters por meio de uma abordagem supervisionada, com base em conjunto pré-existente de entidades suspeitas. A escolha do cluster a ser investigado é realizada com base em consultas realizadas junto aos especialistas de negócio.

$\mathrm{Hu}$ et al. [46] apresentaram um estudo semelhante, descrevendo um sistema de identificação de usuários com utilização excessiva de serviços de saúde, por meio do "hot spotting" - ou seja, o agrupamento de comportamentos semelhantes por região geográfica. O método dos autores consistiu em segmentar uma população de pacientes em grupos com comportamentos semelhantes, caracterizados pela quantidade de consultas, separadas por tipo (por exemplo, consultas envolvendo clínicos gerais, especialistas, ou exames). As variáveis consideradas, por paciente, foram o número de diferentes tipos de consulta e a quantidade de consultas em cada tipo. O algoritmo aplicado foi o clustering hierárquico, com o número de clusters definido subjetivamente após revisão por especialistas. Os clusters foram avaliadas individualmente em termos de número de pacientes agrupados, custo médio por paciente, e idade média. O resultado da análise revelou agrupamentos de usuários com alto índice de utilização de serviços assistenciais, que poderiam ser priorizados para acompanhamento.

Nesta mesma linha, [73] apresentou dois modelos baseados em dados geográficos, para detectar possíveis desvios no sistema assistencial norte-americano Medicare, ambos usando bancos de dados não supervisionados. O primeiro modelo foi baseado em algoritmos de clusterização, agrupando códigos de endereçamento postal (Códigos ZIP, equivalentes aos CEPs utilizados no Brasil) conforme as características socioeconômicas de cada área. O segundo avaliou a distância percorrida pelos pacientes na busca de serviços médicos, com o objetivo de identificar métricas de risco relacionadas a distâncias "impraticáveis". As variáveis utilizadas no primeiro modelo foram os identificadores e prestadores e beneficiários, valores pagos, e códigos postais das entidades. São aplicados algoritmos de clusterização para agrupar regiões por código postal e modelos de regressão para identificar as regiões estatisticamente mais relevantes. Por meio do modelo, foi possível isolar os casos de prestadores que possuíam um maior percentual de pacientes que, supostamente, percorreram grandes distâncias para serem atendidos. Este resultado facilitaria o apontamento de casos possivelmente ligados ao roubo de identidade, onde os dados de beneficiários são utilizados para a cobrança de serviços fictícios. 
Em [65], observou-se o uso de diferentes tipos de abordagens para a detecção de inconsistências nas cobranças de serviços médicos, tais como a abordagem supervisionada (utilizando dados rotulados), a abordagem não supervisionada, e um método híbrido, onde dados supervisionados são utilizados para melhorar o desempenho de uma abordagem não supervisionada. No modelo proposto pelos autores, que também foi baseado nas distâncias entre beneficiários e pacientes, o diferencial foi o uso de dados extraídos da base de cobranças do governo norte americano, o Center for Medicare and Medicaid Services, com mais de 12 milhões de registros. As cobranças foram filtradas conforme os tipos mais comuns de diagnóstico (por exemplo, pneumonia e septicemia).

Foi vista também a criação de um sistema de detecção baseado em um comitê de redes neurais (MLP) para entidades suspeitas, utilizado por [76]. Os autores basearam o estudo em um banco de 169 cobranças com histórico de abusos, e outro grupo de cobranças rejeitadas devido a inconsistências. Segundo os autores, a abordagem gerou uma melhora significativa nos índices de detecção de cobranças abusivas na operadora de planos de saúde que foi objeto do estudo.

Em outro estudo, um algoritmo de detecção de comunidades foi utilizado por [33] para apontar fraudes relacionadas à conivência médica, que pode ocorrer entre médicos de clínicas gerais e os especialistas indicados por eles. O tipo de conluio investigado envolve o encaminhamento de pacientes, por um clínico geral, a apenas um ou dois especialistas, independente das reais necessidades do beneficiário. Em vários casos, pode haver a transferência dos dados cadastrais do indivíduo, que são utilizados para fabricação de atendimentos inexistentes. Este tipo de fraude normalmente é de difícil detecção, ao menos que os indivíduos sejam entrevistados individualmente. Neste sentido, foram verificados os vínculos existentes entre os dois tipos de entidade (clínicos gerais e especialistas), apontando os prestadores especialistas com alto número de encaminhamentos recebidos, que foram em seguida priorizados para análise.

Outro tipo de investigação, proposto por [5], focou na detecção de fraudes relacionadas à prescrição de medicamentos. O modelo comportamental não supervisionado proposto nesse trabalho busca consolidar, em grupos distintos, os tipos de medicamentos mais propensos a cobranças abusivas. São considerados como variáveis de análise, entre outras, o identificador do medicamento, preço unitário, código da receita médica e o diagnóstico da doença. Inicialmente, é verificada a correlação entre cada variável, e as relações mais fortes são filtradas com base em um 
limite definido pelo usuário. Segundo os autores, o modelo pode ser expandido para outros tipos de procedimentos, inclusive diagnósticos (como exames de raios-x, tomografias e biópsias).

Chandola et al. [31] abordaram a crescente necessidade do uso de dados em massa (big data) para atender às necessidades do sistema de saúde suplementar, principalmente nos EUA. Para eles, a mineração e análise de dados é de interesse especial para operadoras de planos de saúde, tanto na esfera privada quanto pública. Conforme informado pelos autores, este tema tem sido pouco explorado na comunidade de especialistas em mineração de dados. O trabalho apresentou dois objetivos principais: Apresentar e relacionar o conceito de "big data" às cobranças de serviços de saúde, e em seguida descrever as ferramentas e desafios encontrados na análise deste tipo de dados em massa, utilizando técnicas de estado da arte, como a construção de redes sociais, mineração de textos e análise temporal. Os autores buscaram demonstrar como cada um dos métodos pode ser aproveitado para entender o domínio de despesas de saúde, com o objetivo final de melhorar a eficiência dos atendimentos e reduzir a possibilidade de perdas relacionadas às fraudes, desperdícios e abusos. Foram utilizados três metodologias distintas de análise de dados e textos para identificar prestadores fraudulentos. Em primeiro lugar, a transformação de dados de beneficiários e prestadores em documentos possibilitou o uso de ferramentas sofisticadas de análise de texto. Em seguida, o estudo do relacionamento entre prestadores, na forma de uma rede social, mostrou a importância de se avaliar a proximidade entre prestadores suspeitos no sistema de saúde suplementar. E finalmente, a aplicação de métodos de análise temporal permitiu a detecção prévia de prestadores com características suspeitas antes da efetiva ocorrência da fraude. Por fim, os autores apontam a possiblidade de combinar todas as métricas apresentadas em um único modelo integrado, e ainda a criação de novas metodologias para avaliar, por exemplo, indicadores de saúde associados ao histórico da utilização de serviços por participantes.

Vale ressaltar que o uso da mineração de dados para a detecção de atividades suspeitas não se restringe apenas ao mercado de saúde. Como exemplo, [54] focaram na detecção de fraudes externas por meio de técnicas de clusterização de classes multivariadas, avaliando o processo de compras de uma instituição financeira europeia. Este estudo focou em fraudes internas, com ocorrências relacionadas aos funcionários da própria organização. Os pesquisadores separaram seus dados em três grupos, e determinaram o perfil de risco de cada grupo por meio de uma análise 
descritiva. Considerando que o processo avaliado foi o de compras e contratações, os pesquisadores consideraram variáveis como a quantidade de alterações por ordem de compra, a quantidade de funcionários envolvidos, e as aprovações realizadas em cada ordem. Com a aplicação de um algoritmo de clusterização, cada agrupamento foi avaliado em termos de média e desvio-padrão, na tentativa de identificar aqueles com comportamentos mais distantes dos demais, principalmente em termos de alterações realizadas. Como exemplo, os autores calcularam a probabilidade de que um elemento em dos clusters, considerando a quantidade de mudanças realizadas em ordens de compra, poderia estar presente nos demais. Este tipo de análise possibilitou definir quais entidades (funcionários, neste caso) poderiam ser separados para uma futura investigação. O resultado da análise foi a identificação de diversos casos onde, embora não tenham sido identificados casos de fraude, constatou-se a realização de atividades inconsistentes.

Além da criação de modelos para detecção de comportamentos suspeitos e abusos, percebeu-se também um esforço em avaliar a efetividade da investigação de ocorrências no comportamento das entidades envolvidas.

Em um estudo realizado por [19], foi avaliado o impacto do aumento da fiscalização sobre os hábitos de faturamento e tipos de cuidados fornecidos por prestadores de serviços. Nesse estudo, são avaliados dados referentes a gastos assistenciais por período, dias de internação, evolução da condição de pacientes com doenças mais suscetíveis a cobranças abusivas, e gastos com investigações realizadas. O estudo analisa a relação entre as investigações realizadas e os gastos assistenciais e resultados dos tratamentos realizados. Como conclusão, foi verificado que um aumento na fiscalização, na maioria dos casos, corresponde a uma diminuição nos custos assistenciais da população avaliada, sem prejuízos na qualidade dos atendimentos aos participantes.

Concluída a revisão do estado da arte em termos de aplicações de técnicas de análise qualitativa e quantitativa para gestão de riscos no setor de saúde, a próxima seção apresenta a estrutura e contexto da organização avaliada nesta pesquisa. Mais adiante, é feito o detalhamento de sua atual de gestão de riscos, que foi alvo das melhorias propostas na parte final deste trabalho. 


\section{Capítulo 4}

\section{Diagnóstico da Organização Avaliada}

Neste capítulo é descrita a estrutura geral da organização avaliada, e o detalhamento especificamente do seu processo de gerenciamento de riscos corporativos. Conforme a Figura 4.1, a análise do negócio da organização envolveu a descrição de suas principais características, do fluxo de seus principais processos e uma visão geral da estrutura corporativa, visualizada por meio do organograma.

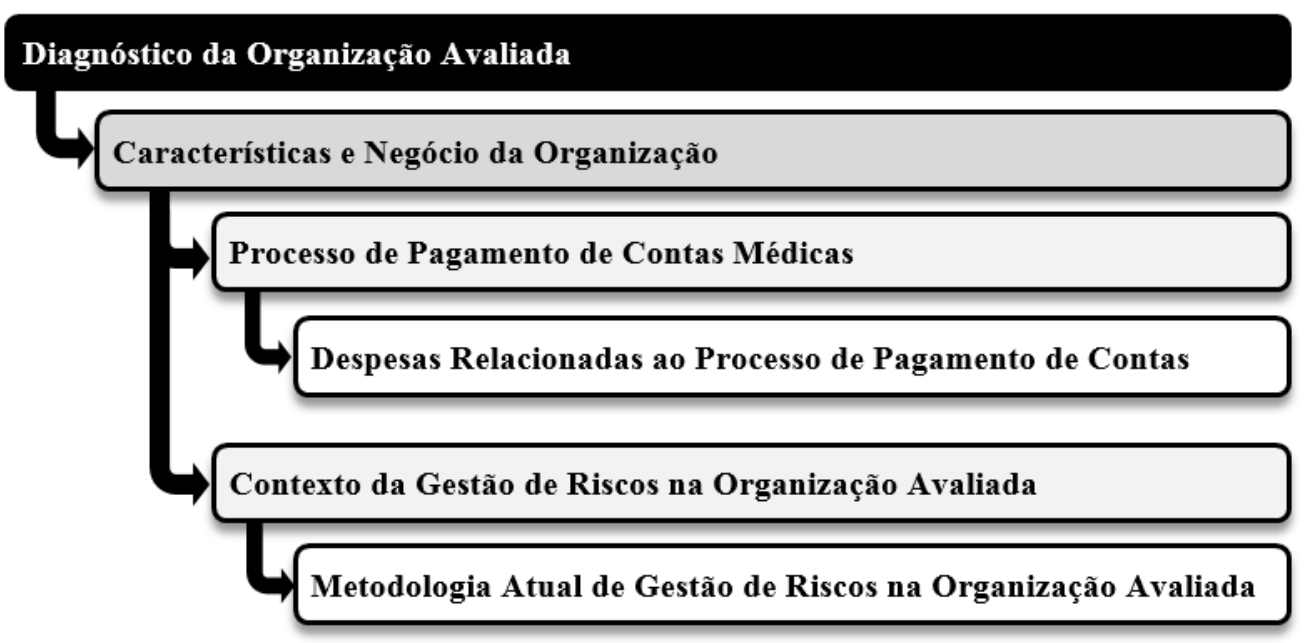

Figura 4.1: Etapas do diagnóstico da organização avaliada

Entre os processos da operadora, o foco de análise foi o fluxo de pagamento de contas médicas, incluindo o delineamento das responsabilidades da área gestora do processo e o desenho do fluxo geral do processo. Esta análise também envolveu o levantamento das despesas assistenciais ligadas a este fluxo, com o detalhamento dos gastos anuais da operadora por tipo de procedimento categoria de prestador de serviço. Ainda nesta seção, é definido o tipo específico de prestador que será avaliado mais adiante, e realizado um levantamento específico de suas despesas. 
A parte final do Capítulo aborda o contexto da gestão de riscos na organização, onde é feita uma descrição geral das características da área de riscos e controles internos da OPS. Finaliza-se pela apresentação da metodologia atual de gestão de riscos desenvolvida pela entidade, pontuando os seus principais aspectos, com a apresentação e descrição do fluxo de suas atividades - estabelecimento do contexto, a identificação, classificação e pontuação de riscos e controles, e a definição dos riscos inaceitáveis.

\subsection{Características e Negócio da Organização}

A entidade avaliada é considerada uma das maiores empresas na modalidade de autogestão em saúde do Brasil, responsável pelo atendimento de cerca de 1 milhão de participantes. Cabe ressaltar que, conforme a Lei 9.656/1998 [23], sistemas de autogestão são aqueles destinados exclusivamente a empregados (ativos, aposentados, pensionistas) participantes de associações, sindicatos, fundações, cooperativas de usuários ou entidades de classes profissionais. Neste caso específico, a OPS foi estruturada para atender as necessidades dos funcionários de uma das maiores instituições financeiras do país, identificada adiante pela sigla 'IF'.

Além da prestação de serviços de voltados à cobertura de gastos com assistência médica, a instituição também desenvolve ações próprias de promoção da saúde, envolvendo a prevenção de doenças e a recuperação de seus participantes. Conforme as pesquisas de satisfação junto aos participantes realizadas pela instituição em anos anteriores, as preocupações de seus participantes estão relacionadas, em primeiro lugar, à ampliação da cobertura assistencial, aliada à manutenção da qualidade nos serviços prestados e à redução nos índices de reajuste das mensalidades. Dentre as principais atividades exercidas por empresas deste tipo, estão as de autorização de procedimentos e ressarcimento de despesas médicas. A Figura 4.2 apresenta uma versão simplificada do fluxo de prestação de serviços da operadora de planos de saúde. 


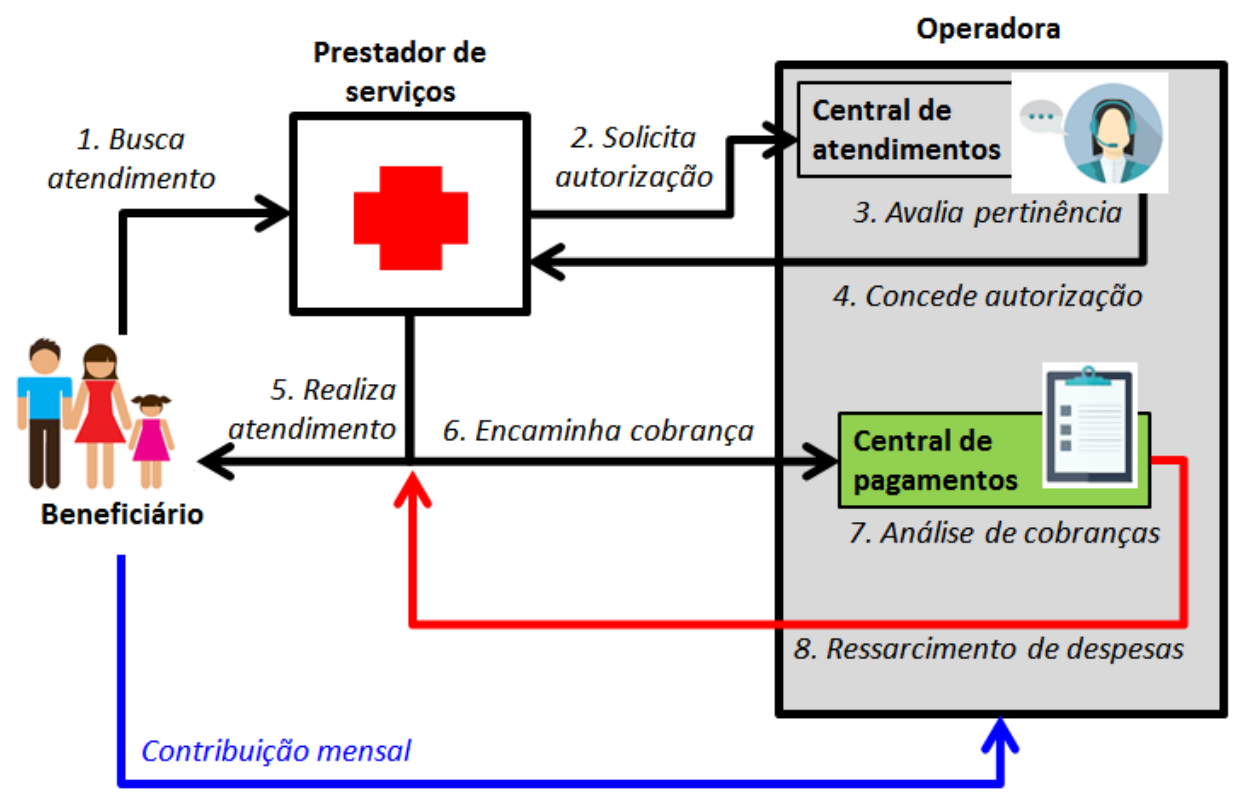

Figura 4.2: Fluxo de prestação de serviços na instituição avaliada.

O fluxo dos negócios na OPS inicia-se pela adesão dos participantes à instituição (composta na sua maioria por funcionários da ativa, aposentados e dependentes da entidade patrocinadora, no caso das autogestões), sendo a contribuição mensal de seus participantes a principal fonte de recursos da empresa. Em contrapartida, os participantes recebem o direito de buscar atendimento médico junto à rede credenciada da instituição (1), que é composta por médicos, clínicas e hospitais, entre outros.

Conforme a complexidade dos procedimentos solicitados, a prestação de serviços é antecedida de uma solicitação de autorização por parte do prestador de serviços médicos (2), encaminhada à central de atendimentos da operadora. Esta área executa a avaliação dos critérios para realização do procedimento (3), considerando uma série de fatores (como existência de cobertura para o procedimento solicitado, necessidade de perícia prévia para realização do procedimento, compatibilidade entre os procedimentos solicitados etc.). Caso o prestador receba a autorização para o atendimento (4), é realizada a prestação de serviços junto ao participante (5).

Periodicamente, as cobranças referentes aos procedimentos realizados em um determinado período são encaminhadas, pelo prestador, à central de pagamentos da operadora (6). Os processos desta área estão sob a gestão de sua gerência de contas médicas. Esta área possui critérios próprios para análise das cobranças, como a comparação entre as características dos procedimentos solicitados na autorização e os 
posteriormente cobrados. Após esta análise final, é gerada uma rotina de ressarcimento (8) das despesas médicas ao prestador de serviços.

Tanto a complexidade quanto o volume financeiro relacionado a cada um dos processos descritos acima incentivaram a organização na busca de modelos e práticas externas que possibilitassem a identificação, tanto das oportunidades de melhoria, quanto dos possíveis eventos que poderiam impedi-la de atingir seus objetivos (sejam estes de nível estratégico, tático ou operacional).

A Figura 4.3 apresenta o organograma da instituição, destacando-se a área gestora do processo avaliado.

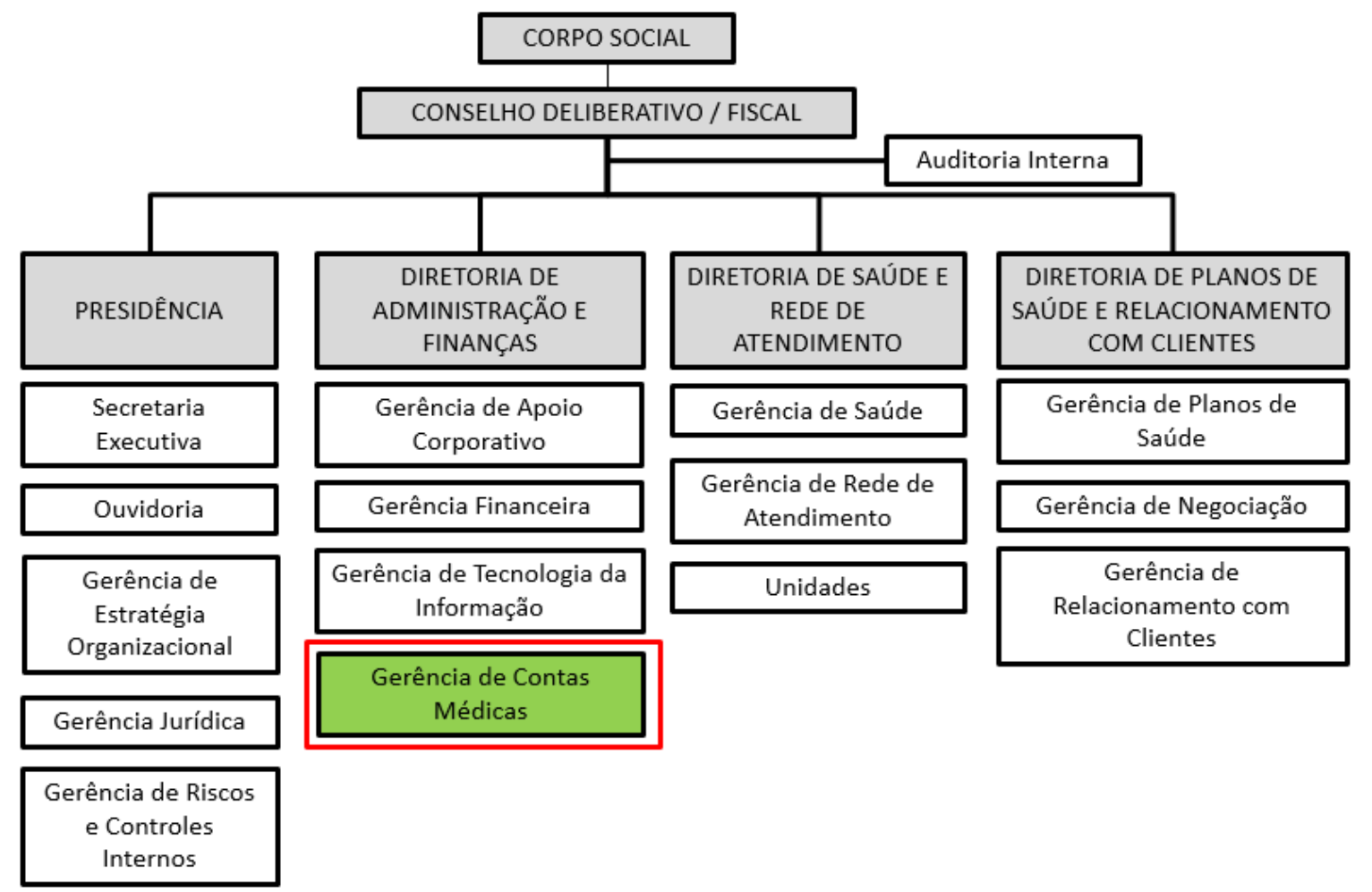

Figura 4.3: Organograma da instituição avaliada

\subsection{Processo de Pagamento de Contas Médicas}

Na organização avaliada, conforme o organograma acima, cabe à Gerência de Contas Médicas (GCM) as funções de recebimento, análise e autorização dos pagamentos referentes às despesas assistenciais encaminhadas pelos prestadores da rede credenciada (e também dos próprios participantes, na modalidade de reembolso).

A área encontra-se subordinada à Diretoria de Administração e Finanças, que é responsável, conforme o Regimento Interno da instituição, pela coordenação das 
Gerências de Apoio Corporativo, Contas Médicas, Financeira e Tecnologia da Informação.

Entre as atribuições desta área constam também a gestão das políticas de análise e pagamento de despesas assistenciais. Isto inclui a proposta de melhorias nos processos e sistemas de pagamento, no intuito de atingir o aumento na eficiência de sua área, como forma de reduzir o risco de perdas e evitar impactos relevantes à Instituição.

Neste sentido, cabe à GCM a identificação de falhas recorrentes do processo de análise de contas, assim como a apuração de situações de perda financeira e de imagem na sua área de atuação. Para este fim, a área é orientada a realizar, periodicamente, testes de conformidade e autoavaliações de riscos nos processos sob sua responsabilidade.

A visão geral da estrutura interna e do fluxograma dos processos da área são apresentados na Figura 4.4:

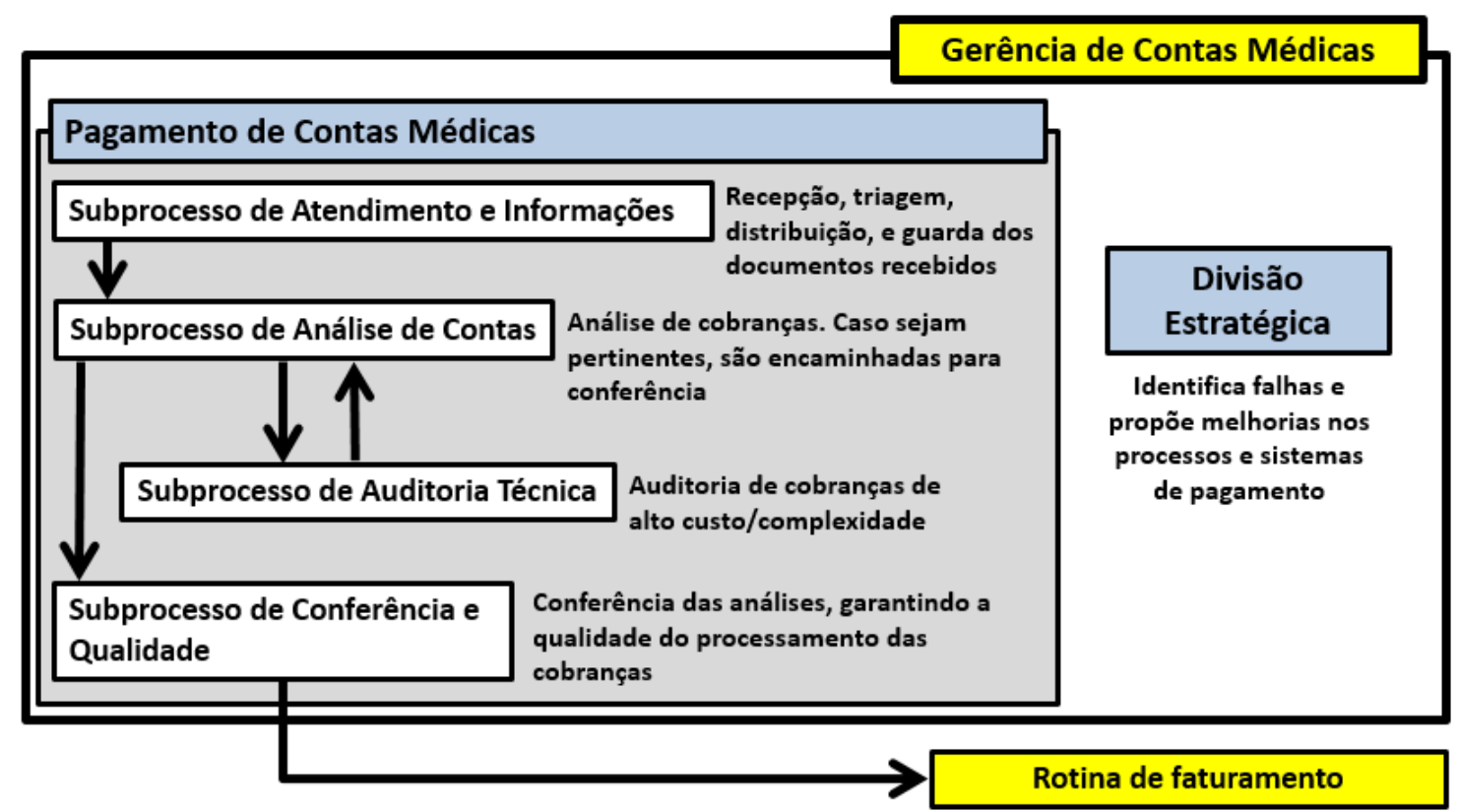

Figura 4.4: Fluxo interno do pagamento de contas médicas

O fluxo de atividades no processo de pagamentos de contas médicas (apresentado com maiores detalhes no Apêndice I) inicia-se pelo protocolo e triagem da documentação física de cobrança, conforme a natureza do documento (meio físico ou eletrônico) e origem (rede credenciada ou de participantes que solicitam o reembolso direto dos atendimentos realizados). 
As cobranças são distribuídas às equipes de análise, organizadas de acordo com a região de atendimento, tipo de procedimento e porte do prestador. Como exemplo, existem equipes específicas de análise de registros oriundos de regiões com maior volume financeiro envolvido, outras responsáveis pelas cobranças de prestadores "estratégicos" (normalmente hospitais ou outras instituições com maior representatividade financeira) e, ainda, equipes especializadas na análise de cobranças por tipo de procedimento.

Para as contas que se enquadram em parâmetros pré-definidos de complexidade ou valor (por exemplo, relacionados a internações ou procedimentos de quimioterapia ou transplante), ou que apresentam cobranças de medicamentos e materiais de alto custo, existe a etapa adicional de Auditoria Técnica, realizada pelos médicos e enfermeiros do Núcleo de Auditoria. Na auditoria da contas médicas, são observadas as regras constantes dos documentos normativos específicos, por tipo de procedimento.

A etapa final antes do envio da cobrança à rotina de faturamento é a de Conferência, onde são certificadas as ações na etapa de análise, no tocante à manutenção ou reversão de negativas de cobrança (denominadas "glosas"), a conformidade de valores cobrados e das tabelas negociadas junto aos prestadores de serviço, assim como a existência de autorização para materiais e medicamentos de alto custo. No nível estratégico, há uma área específica responsável pelo acompanhamento e pela proposta de alterações nos processos e sistemas de pagamento da área como um todo.

Conforme dados da plataforma de Business Intelligence da entidade, o volume de processamento no ano de 2014 envolveu o pagamento de cerca de 1 milhão de guias por mês, com índice de negativas de cobrança em torno de $10 \%$.

\subsubsection{Despesas Relacionadas ao Processo de Pagamento de Contas}

Conforme consulta realizada na base de dados da organização, cerca de $90 \%$ do total de suas despesas no exercício de 2014 (correspondendo a aproximadamente $\mathrm{R} \$ 3$ bilhões), estava relacionados aos gastos assistenciais (contabilmente definidos como "eventos indenizáveis"). A Figura 4.5 demonstra que a maior parte deste valor está relacionado a procedimentos de diagnóstico e terapia, cirúrgicos, clínicos e de consulta. 


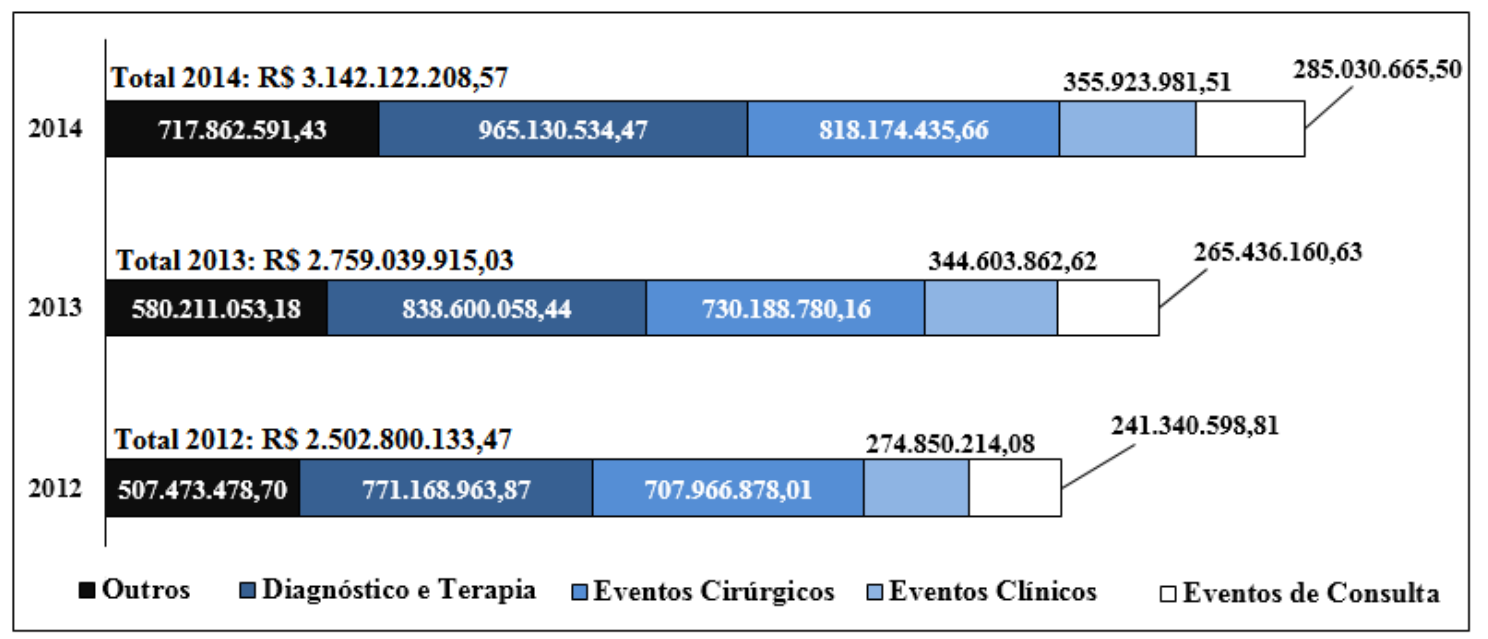

Figura 4.5: Gastos assistenciais, por ano, por tipo de procedimento (evento)

Os gastos descritos na Figura 4.5 são oriundos de serviços prestados por entidades credenciadas junto à OPS. No gráfico da Figura 4.6, é possível visualizar os quantitativos relacionados às despesas por tipo de prestador:

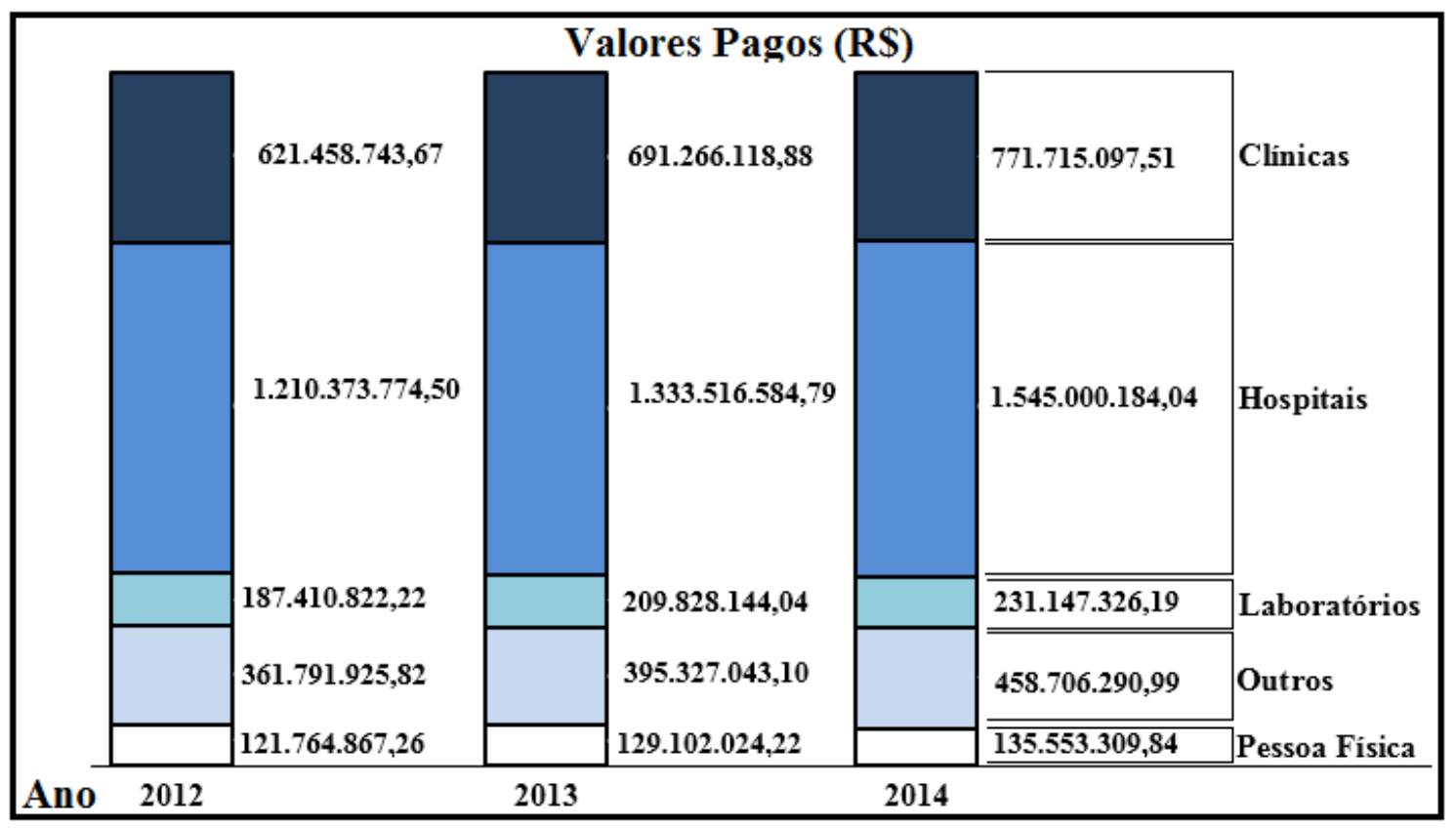

Figura 4.6: Despesas por tipo de prestador, por ano

Em 2014, cerca 50\% das despesas foi proveniente da rede hospitalar da operadora. Outros $30 \%$ estiveram relacionados a pessoas físicas, clínicas e laboratórios. O restante das despesas foi proveniente de outros prestadores, como fornecedores, cooperativas e serviços de remoção.

Estes prestadores compõem uma rede que, conforme a Figura 4.7, contou com mais de 40 mil prestadores em 2014: 


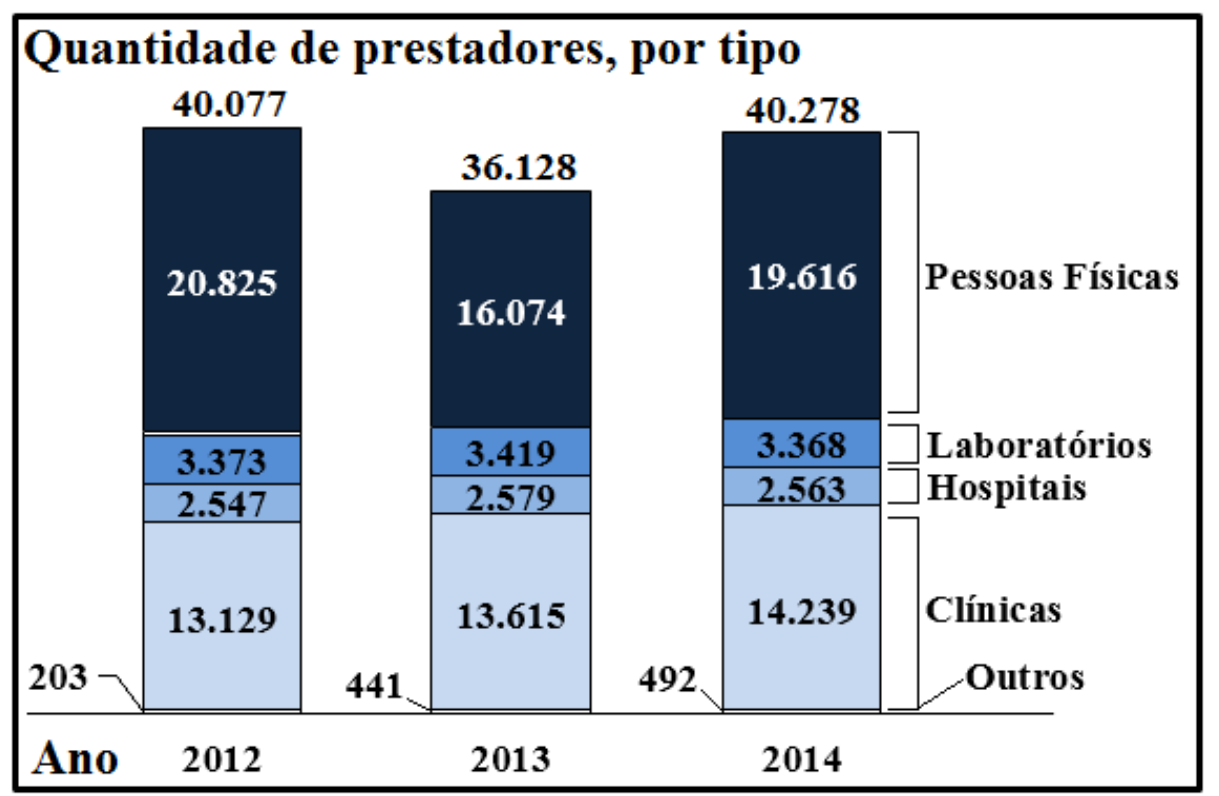

Figura 4.7 - Quantidade de prestadores, por tipo, por ano

De acordo com as Figuras 4.6 e 4.7, apesar de representar, em 2014, 4\% das despesas da OPS, o grupo de entidades do tipo "Pessoa Física" compõe cerca de metade das 40.278 entidades credenciadas naquele período (19.616 prestadores, aproximadamente $48 \%$ do total). Sendo assim, este grupo de entidades foi o escolhido para análise neste estudo, em decorrência tanto de sua representatividade na rede credenciada, quanto pela disponibilidade dos dados de cobrança relacionados a esta categoria, e a ausência de controles para a investigação das cobranças de prestadores desta natureza.

Verifica-se no gráfico da Figura 4.8 a distribuição das despesas para este tipo de prestador, por tipo de procedimento. 


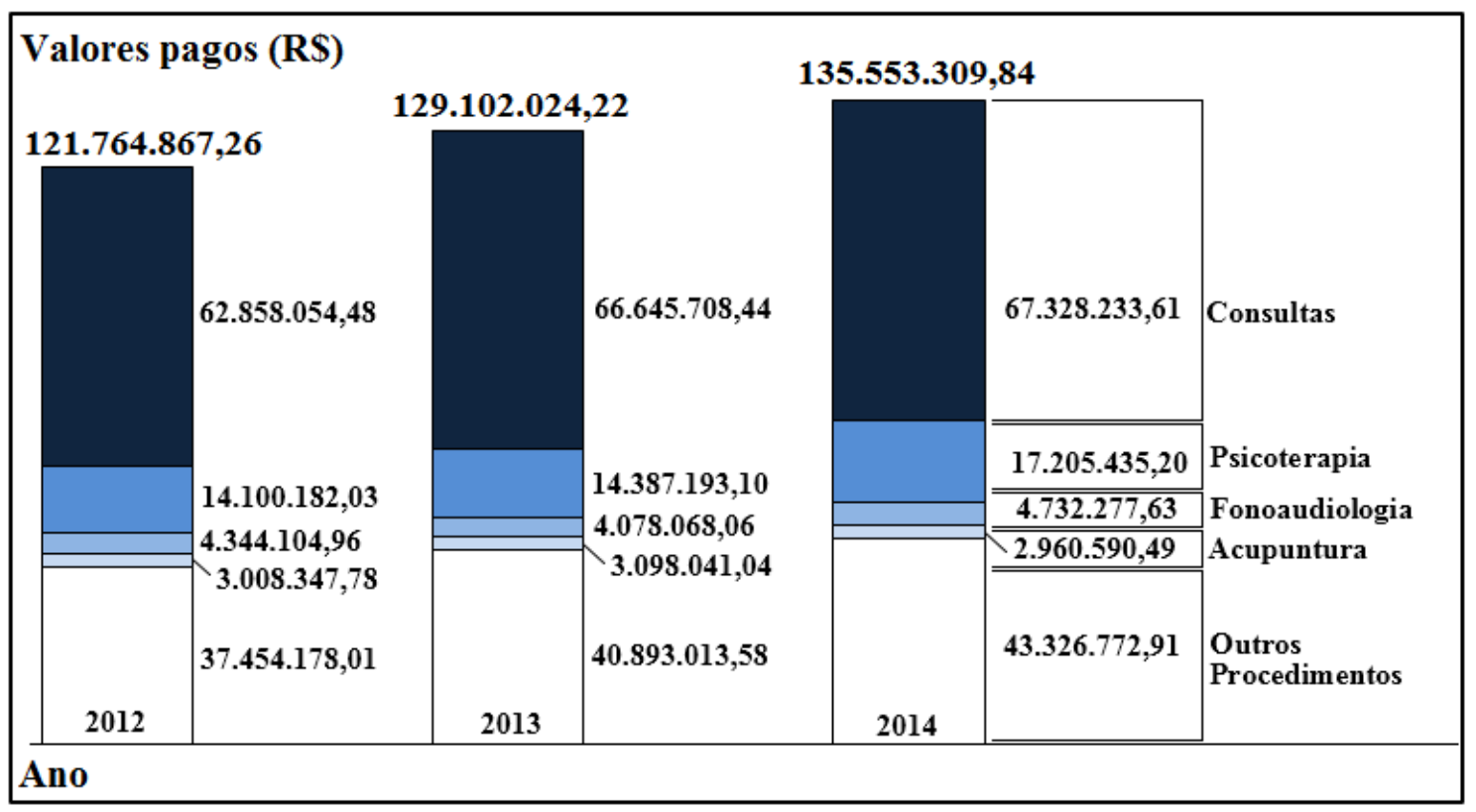

Figura 4.8: Prestadores "Pessoa Física" - despesas por tipo, por ano

Em termos de tipo de procedimento, o comportamento das despesas para Pessoas Físicas manteve-se quase estável entre 2012 e 2014. No período, em torno de $50 \%$ dos gastos esteve relacionado a procedimentos de consulta. Em seguida, outros $20 \%$ estiveram ligados a procedimentos de terapia seriada (psicoterapia, fonoaudiologia e acupuntura). Juntos, estes grupos agrupam em torno de $70 \%$ das despesas no intervalo avaliado. Os outros $30 \%$ estão pulverizados entre mais de 1.000 eventos cirúrgicos, clínicos e diagnósticos.

$\mathrm{Na}$ busca de gargalos e possíveis falhas operacionais, a aplicação da nova metodologia de autoavaliação de riscos envolve a análise tanto os fluxos organizacionais do processo de pagamento de contas quanto as informações provenientes dos bancos de dados de despesas assistenciais. A análise dos gastos contempla o conjunto de prestadores definido anteriormente (pessoas físicas) e as principais despesas relacionadas a este grupo (consultas e tratamentos seriados), na tentativa de identificar possíveis desvios referentes a cobranças indevidas.

Sendo assim, a análise do processo de pagamento de contas médicas sob a ótica de riscos e suficiência de controles se justifica devido à sua criticidade para a entidade, e a importância de se identificar as possibilidades de perda associadas a ineficiências administrativas, falhas de sistema e eventos internos ou externos à empresa, assim como a criação de novos controles (ou a melhoria dos existentes) de forma a mitigar o impacto negativo dos riscos existentes. 


\subsection{Contexto da Gestão de Riscos na Organização Avaliada}

A instituição reconhece que as tarefas de gerenciamento de riscos, controles internos e conformidade não podem ser vistas como atribuições exclusivas à alta administração ou a uma única dependência. São atividades que devem ser previstas a nível organizacional, por todas as partes envolvidas.

Com isso, os normativos da empresa determinam que a responsabilidade pelo gerenciamento de riscos e pelos controles internos e conformidade é de cada gestor, dentro de seu âmbito de atuação. Considera-se como obrigação de todos os funcionários a busca pela identificação e implementação de ações de controle, com vistas à mitigação dos riscos existentes. Por sua vez, os membros da Diretoria Executiva têm como responsabilidade avaliar constantemente todos os riscos da organização, inclusive aqueles considerados aceitáveis ou de baixa significância, pois sua natureza ou nível pode mudar com o tempo. Também devem assegurar que sejam tomadas as medidas adequadas para o tratamento dos riscos não aceitáveis.

Todavia, os órgãos colegiados da organização buscaram propiciar à entidade um gerenciamento mais efetivo das atividades relacionadas à gestão de riscos e conformidade com a estruturação de uma área específica, denominada Gerência de Riscos e Controles Internos (GRCI). Entendeu-se que a implantação desta nova Gerência contribuiria para a melhora da imagem e da reputação da empresa, assim como incentivaria um maior compromisso e responsabilidade por parte de seus gestores.

Entre as responsabilidades fixadas pelo Conselho Deliberativo da instituição para a GRCI estão a formulação de políticas de controles internos e de conformidade, que envolvem o desenvolvimento, implementação e acompanhamento dos mecanismos de controles internos e conformidade de seus processos e produtos. Cabe à GRCI o estabelecimento de pontos de controle nos processos internos, de forma a minimizar a exposição aos riscos identificados. Para tanto, o conjunto de funções estabelecido para a área inclui o desenvolvimento de metodologias de apuração dos níveis de conformidade, suficiência de controles internos e de identificação de riscos.

Quanto às atividades de monitoramento, cabe também à GRCI a divulgação de informações à Diretoria Executiva e aos Conselhos Deliberativo e Fiscal sobre o nível de conformidade apurado na Sede e Órgãos Regionais, acompanhadas do grau 
de criticidade referente às não conformidades identificadas, apontando inclusive a necessidade de alterações em normas, controles e procedimentos vigentes.

Entre suas atividades relacionadas à gestão de riscos, a principal ferramenta é a "Metodologia de Autoavaliação de Riscos e Controles" (MARC). Ela é composta por um conjunto de ferramentas reunidas pela área para auxiliar na identificação de riscos e controles existentes nos procedimentos internos da entidade.

\subsubsection{Metodologia Atual de Gestão de Riscos na Organização Avaliada}

A MARC é uma metodologia de uso corporativo na OPS, que tem por objetivo identificar e avaliar os riscos e controles inerentes aos processos, produtos e serviços da instituição. Ela é dividida em 03 macrofases, com tempo total de aplicação estimado em 14 dias úteis. A Metodologia requer que haja a participação em tempo integral de, no mínimo, dois facilitadores da GRCI com domínio do conteúdo, bem como gestores, executores e intervenientes da área gestora do processo avaliado. Verifica-se o resumo da metodologia no fluxo a seguir, na Figura 4.9. 


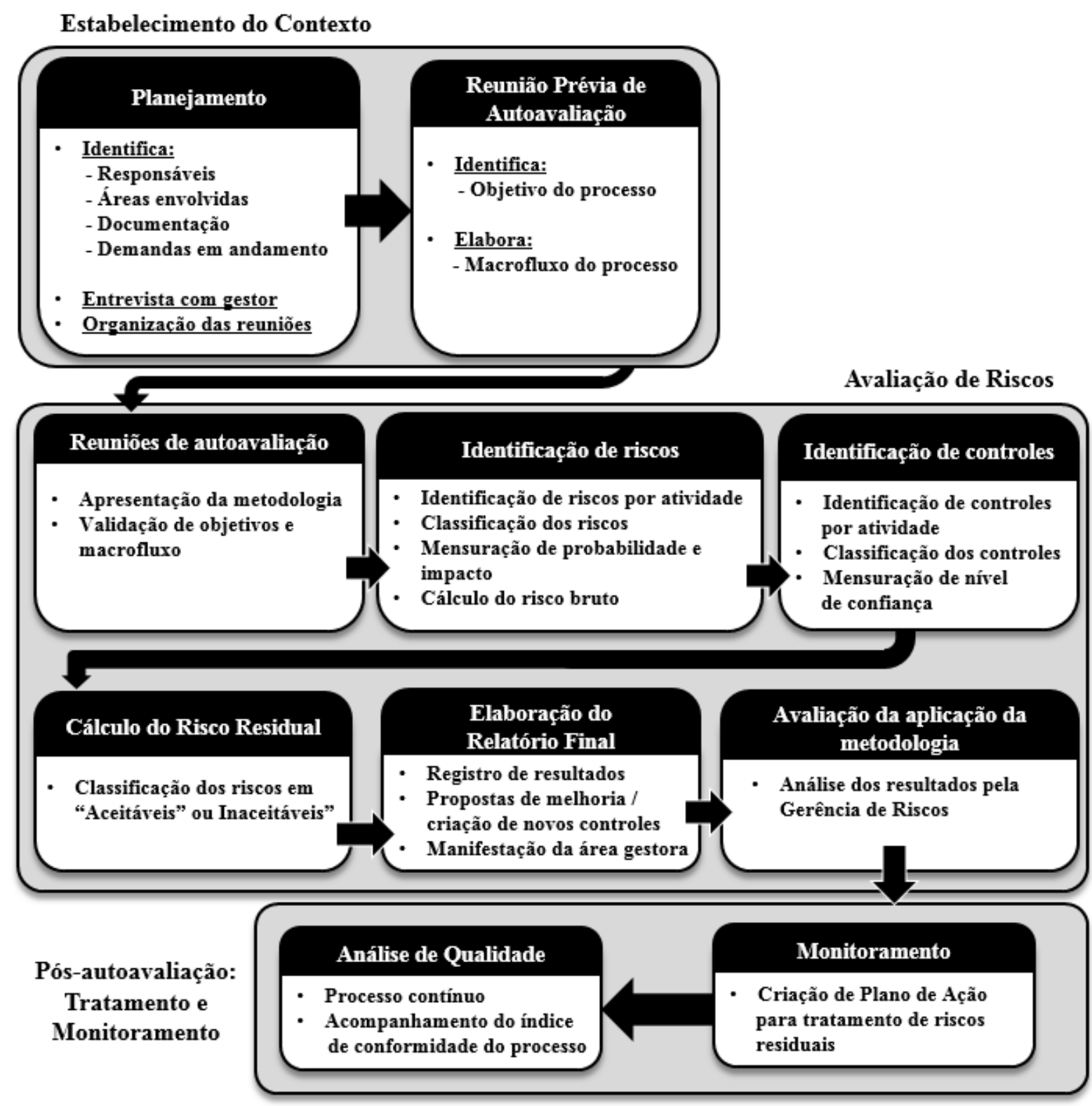

Figura 4.9: Etapas da metodologia atual de autoavaliação de riscos e controles da OPS

O estabelecimento do contexto contempla a primeira etapa, denominada de "Planejamento", em que os facilitadores da Gerência de Riscos, juntamente com o gestor e analistas da área gestora do processo, buscam o conhecimento prévio do fluxo processual ser avaliado, por meio da análise de seus principais fatores (como objetivos, responsáveis e prazos, entre outros). Esta fase é seguida pela etapa de "Reuniões Prévias", onde são identificadas, por meio das técnicas de entrevistas e brainstorming, as atividades e o objetivo do processo. A terceira etapa, envolvendo as atividades de avaliação de riscos, inicia-se com as "Reuniões de Autoavaliação", em que os facilitadores orientam os participantes da área gestora sobre os conceitos e 
a dinâmica da metodologia. Em seguida, os representantes da área gestora, com auxílio da Gerência de Riscos, descrevem e classificam todos os riscos e controles identificados em cada atividade do processo. A principal técnica é a de brainstorming, utilizada nos moldes da descrição apresentada na NBR ISO 31.010 [9].

O registro das informações atualmente é realizado em formulários Word ou planilhas Excel, seguindo o modelo apresentado no Quadro 4.1:

\begin{tabular}{|c|c|c|c|c|c|c|c|c|}
\hline No. & $\begin{array}{c}\text { Riscos } \\
\text { Vinculados à } \\
\text { Atividade }\end{array}$ & $\begin{array}{c}\text { Categoria de } \\
\text { Risco }\end{array}$ & 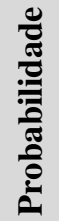 & 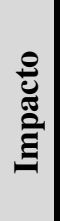 & 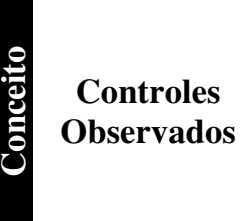 & $\begin{array}{l}\text { Categorias } \\
\text { de Controle }\end{array}$ & 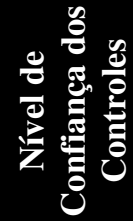 & $\begin{array}{c}\text { Risco } \\
\text { Residual }\end{array}$ \\
\hline 1 & & & & & & & & \\
\hline 2 & & & & & & & & \\
\hline$(\ldots)$ & & & & & & & & \\
\hline
\end{tabular}

Quadro 4.1: Formulário Padrão da MARC

Para definição do valor inicial dos riscos identificados (denominado "risco bruto") utiliza-se a matriz de Probabilidade vs. Impacto, apresentada na Figura 4.10:

\begin{tabular}{|c|c|c|c|c|c|}
\hline \multicolumn{6}{|c|}{ PROBABILIDADE x IMPACTO (ANÁLISE QUALITATIVA) } \\
\hline & Irrelevante (1) & Baixo (2) & Médio (3) & Alto (4) & Extremo (5) \\
\hline Quase certa (5) & Moderado & Alto & Alto & Extremo & Extremo \\
\hline Provável (4) & Baixo & Moderado & Alto & Alto & Extremo \\
\hline Moderada (3) & Baixo & Baixo & Moderado & Alto & Alto \\
\hline Eventual & Insignificante & Baixo & Baixo & Moderado & Alto \\
\hline Improvável (1) & Insignificante & Insignificante & Baixo & Baixo & Moderado \\
\hline
\end{tabular}

Figura 4.10: Matriz de Probabilidade vs. Impacto utilizada na MARC

O conceito do "Risco Bruto" é o resultado do valor da Probabilidade (P) multiplicado pelo valor do Impacto (I), ambos pontuados em uma escala de 1 a 5 . Para atribuição do valor de probabilidade, considera-se o histórico de ocorrências anteriores e os indícios de que o evento voltará a ocorrer no futuro. Já o impacto é medido com base na combinação entre as perdas financeiras e o possível desgaste da imagem da organização. Ambas as atribuições são realizadas de forma subjetiva, após discussão e consenso obtido entre os facilitadores e demais membros da equipe. 
Após a identificação dos riscos por atividade do processo e atribuição dos valores iniciais de probabilidade e impacto, ocorre a classificação dos riscos em categorias e subcategorias pré-definidas, conforme o Quadro 4.2, a seguir:

\begin{tabular}{|c|c|}
\hline Categoria & Descrição - "Possibilidade de perdas decorrentes..." \\
\hline Risco de Mercado & ...de mudanças no comportamento do mercado de saúde. \\
\hline Risco Financeiro & $\begin{array}{l}\text {...de mudanças no comportamento das taxas de juros e câmbio, nos preços de ações e } \\
\text { de commodities e no descasamento entre taxas/preços, prazos e moedas/índices. }\end{array}$ \\
\hline Risco de Crédito & $\begin{array}{l}\text {...da possibilidade de perdas resultantes da incerteza quanto ao recebimento de um } \\
\text { valor contratado, contraparte de um contrato ou emissor de um título. }\end{array}$ \\
\hline Risco de Liquidez & $\begin{array}{l}\text {...da falta de recursos necessários ao cumprimento de uma ou mais obrigações em } \\
\text { função dos descasamentos de compromissos financeiros e aplicações, bem como, de } \\
\text { falta de controle sobre as receitas operacionais. }\end{array}$ \\
\hline Risco Legal & $\begin{array}{l}\text {...da inobservância de dispositivos legais ou regulamentares, da mudança da } \\
\text { legislação ou de alterações na jurisprudência aplicáveis aos negócios da organização. }\end{array}$ \\
\hline Risco de Conjuntura & $\begin{array}{l}\text {...de mudanças: verificadas nas condições políticas, culturais, sociais, econômicas ou } \\
\text { financeiras do próprio país ou de outros países. }\end{array}$ \\
\hline Risco de Imagem & $\begin{array}{l}\text {...de a Instituição ter seu nome desgastado junto ao mercado ou autoridade em razão } \\
\text { de publicidade negativa, verdadeira ou não. }\end{array}$ \\
\hline Risco Operacional & $\begin{array}{l}\text {... de falhas ou fraudes provenientes de pessoas, de processos, de tecnologia ou de } \\
\text { eventos externos. }\end{array}$ \\
\hline
\end{tabular}

Quadro 4.2: Categorias de risco na OPS

As categorias são descritas pela OPS conforme os conceitos da Agência Nacional de Saúde Suplementar (ANS) e Banco Central do Brasil (BACEN) (que, por sua vez, se baseou nas diretrizes do Comitê de Basileia) e na metodologia herdada da IF.

Entre estas categorias, destaca-se a de Riscos Operacionais, descritos pela organização como os resultantes de "falhas ou fraudes provenientes de pessoas, de processos, de tecnologia ou de eventos externos". O conceito está em consonância com a definição da ANS [25], conforme disposto no documento ANS IN/DIOPE 14, de 27/12/2007:

"Risco Operacional compreendem os demais riscos enfrentados pela Operadora de Planos de Saúde, relacionados aos procedimentos internos tais como: risco de perda resultante de inadequações ou falhas em processos internos, pessoas e sistemas, ou seja, é qualquer possibilidade de perda originada por falhas na estrutura organizacional, seja ela oriunda de sistemas, procedimentos, recursos humanos ou tecnológicos ou então, pela perda dos valores éticos e corporativos que unem os diferentes elementos." 
O BACEN [14] complementa a definição da ANS na sua Resolução 3.380/2008, que definiu o risco operacional como proveniente também de eventos externos, além dos fatores internos da organização. Incluem-se nos eventos internos e externos, inclusive, as possíveis ocorrências de fraudes internas e externas, seguindo o exemplo de outras seguradoras que similarmente ampliaram o escopo da categoria para incluir este tipo de risco [67].

Quanto às subcategorias inclusas no conjunto de riscos operacionais, as falhas humanas podem ser decorrentes de equívoco, inobservância de normas ou concentração de serviços em poucas pessoas. Também podem resultar de comportamentos fraudulentos, associados à adulteração ou descumprimento de controles, normas, e ao desvio de valores. As falhas de processos estão relacionadas principalmente ao incorreto desenvolvimento ou à inadequação de normas, à disponibilização de relatórios incorretos ou inadequados ou à inexistência de controles. Já as possibilidades de perda decorrentes de falhas de sistema englobam a possível indisponibilidade, falhas na confiabilidade das informações, ou decisão incorreta em relação à plataforma de desenvolvimento dos sistemas.

Em seguida, a metodologia prevê a identificação, pontuação e classificação dos controles existentes em cada atividade. "Controles" são definidos como instrumentos que permitem minimizar ou controlar possíveis riscos, assegurando, com determinado grau de confiança, o alcance dos objetivos estabelecidos para o processo.

A pontuação dos controles, que resulta em um valor denominado de "Nível de Confiança" (NC), é baseada em categorias pré-estabelecidas, agrupadas por características de tipo, operacionalização, normatização e evidência, conforme o Quadro 4.3, a seguir:

\begin{tabular}{|l|c|l|c|l|c|}
\hline TIPO & Pontuação & Operacionalização & Pontuação & $\begin{array}{l}\text { Normatização / } \\
\text { Evidências }\end{array}$ & Pontuação \\
\hline Corretivo & 0,5 & Manual & 0,5 & Normatizado & 0,5 \\
\hline Detectivo & 1 & Automatizado & 1 & Evidenciado & 0,5 \\
\hline Preventivo & 2 & Automático & 2 & & \\
\hline
\end{tabular}

Quadro 4.3: Valores de Nível de Confiança de controles

A OPS caracteriza um controle como "corretivo" caso sirva como base para correção das causas de problemas numa atividade, após a ocorrência das falhas. Controles "detectivos" detectam algum problema durante a atividade, sem impedir que ele ocorra. Já os "preventivos" são aqueles que servem para impedir a ocorrência 
de problemas durante a atividade. Conforme seu tipo, o controle recebe uma pontuação de 0,5, 1 ou 2 pontos.

Em termos de operacionalização, um controle pode ser classificado como "automático" caso ocorra por meio de automação e sem a intervenção humana. A classificação de "automatizado" é aplicada aos controles que são acionados por meio da intervenção humana, com o auxílio de automação. Controles "manuais", conforme seu nome implica, ocorrem sem o auxílio de automação. Cada nível de operacionalização também recebe uma pontuação específica, também de 0,5 a 2 pontos.

Por fim, o controle recebe 0,5 ponto caso sua operacionalização esteja normatizada (registrada no sistema de documentação da empresa), e outro 0,5 ponto caso possa ser "evidenciado", ou seja, comprovado por meio de registros de sua execução.

A soma da pontuação de um controle é utilizada para atribuição do seu Nível de Confiança, em uma escala de 1 a 5, conforme o Quadro 4.4 a seguir:

\begin{tabular}{|c|c|c|}
\hline $\begin{array}{c}\text { Soma da } \\
\text { pontuação }\end{array}$ & Nível de Confiança & $\begin{array}{c}\text { Pontuação } \\
\text { NC }\end{array}$ \\
\hline 1 a 1,5 & Irrelevante & 1 \\
\hline 2 a 2,5 & Baixa & 2 \\
\hline 3 a 3,5 & Aceitável & 3 \\
\hline 4 a 4,5 & Satisfatória & 4 \\
\hline Igual a 5 & Alta & 5 \\
\hline
\end{tabular}

Quadro 4.4: Pontuação para definição do Nível de Confiança dos controles identificados

Quanto à classificação dos controles, a instituição considera as categorias de "Controles Básicos" e "Controles Diretos". Controles básicos são aqueles considerados fundamentais para minimização dos riscos, sendo aplicáveis à grande maioria dos processos, produtos ou serviços. Já os controles diretos são estipulados especificamente e/ou diretamente em um determinado tipo de processo, produto ou serviço.

Identificados os riscos e os controles existentes, é verificado o "risco residual" (RR), ou seja, o conceito (criticidade) do risco após a aplicação dos controles existentes. O risco residual é o resultado do risco bruto menos o nível de confiança dos controles existentes $(\mathrm{RR}=\mathrm{RB}-\mathrm{NC})$.

Por fim, utilizando o conceito acima, os riscos residuais são classificados em "Inaceitáveis" ou "Aceitáveis". Conforme a Figura 4.11, o valor máximo resultante da 
multiplicação dos conceitos de probabilidade e impacto é 25, e o maior nível de controle apresenta o valor de 5, independentemente da quantidade de controles existentes (nestes casos, é considerado o nível de confiança do "melhor" controle identificado).

\begin{tabular}{|c|c|c|c|c|c|}
\hline Probabilidade & Irrelevante (1) & Baixo (2) & Médio (3) & Alto (4) & Extremo (5) \\
\hline Quase certa (5) & 5 & 10 & 15 & 20 & 25 \\
\hline Provável (4) & 4 & 8 & 12 & 16 & 20 \\
\hline Moderada (3) & 3 & 6 & 9 & 12 & 15 \\
\hline Eventual (2) & 2 & 4 & 6 & 8 & 10 \\
\hline Improvável (1) & 1 & 2 & 3 & 4 & 5 \\
\hline
\end{tabular}

Figura 4.11: Pontuação por combinação de Criticidade x Impacto

Desta forma, entende-se que riscos residuais com valores acima de 20 teriam que ser automaticamente encaminhados para tratamento. Todavia, a organização considera um limite ainda mais conservador, pois são definidos como "inaceitáveis" os riscos residuais com conceito acima de 7 .

A existência de riscos inaceitáveis indica a necessidade de instituir novos controles ou alterar os existentes. Riscos aceitáveis, por outro lado, não impedem a realização do objetivo definido, porém cabe à área gestora a análise dos controles existentes sob a ótica de custo-benefício, com o objetivo de otimizá-los, se possível.

Após a aplicação da metodologia, os facilitadores consolidam as informações em relatório específico. A última etapa, de Pós autoavaliação, consiste na consolidação das avaliações, onde os participantes avaliam a aplicação da metodologia, elaborando um Plano de Ação para tratamento dos riscos residuais evidenciados.

$\mathrm{Na}$ próxima seção, são apresentados os resultados da avaliação de riscos aplicada ao subprocesso de análise de contas médicas, do processo de pagamento de contas, assim como as vantagens observadas na aplicação do RFMEA para priorização dos riscos críticos dentro do processo. 
Parte II 


\section{Capítulo 5}

\section{Nova Metodologia de Autoavaliação Aplicada ao Processo de Pagamento de \\ Contas Médicas}

Concluído o levantamento bibliográfico e revisão da literatura, e considerando o diagnóstico atual da gestão de riscos na OPS, o objetivo deste capítulo é descrever a proposta de uma nova metodologia de autoavaliação de riscos e controles a ser utilizada na instituição. Em seguida, são apresentados os resultados de sua aplicação, em termos de identificação e priorização dos riscos existentes no processo avaliado.

Este novo modelo busca integrar, à metodologia atual da empresa, os conceitos da técnica Delphi, para a identificação de riscos e controles, e FMEA (e, em especial, a extensão RFMEA elaborada por [28], para auxiliar na priorização dos riscos identificados. O modelo é então aplicado na análise do processo de pagamento de contas médicas da organização, descrito anteriormente no item 4.2.

O fluxo da Figura 5.1 detalha como estes conceitos foram integrados às etapas da metodologia existente de autoavaliação na OPS. 


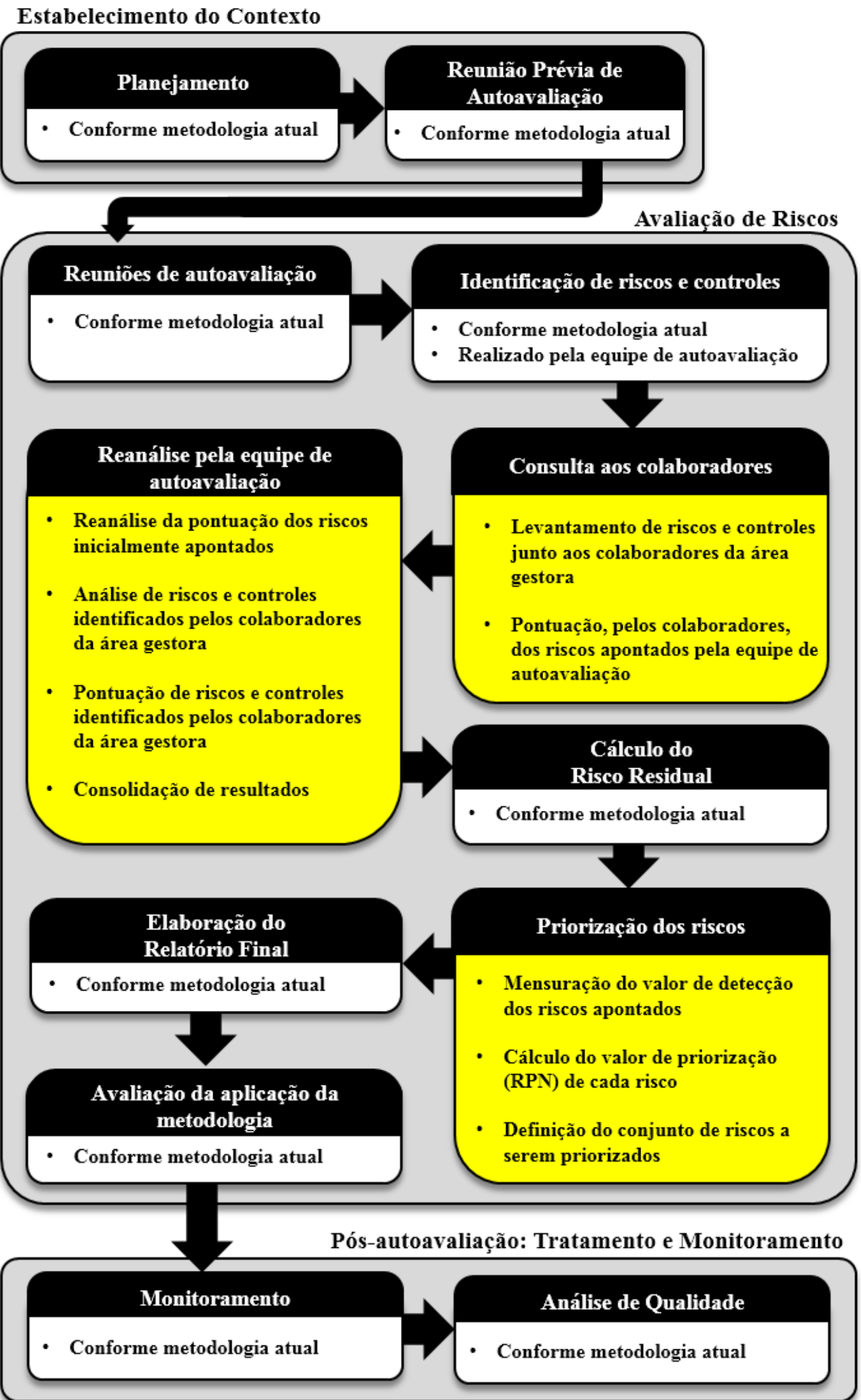

Figura 5.1: Proposta de novo fluxo de autoavaliação de riscos e controles 
Entre as principais alterações no modelo, observa-se que após o mapeamento das atividades do processo e identificação inicial dos riscos e controles pela equipe de autoavaliação, propõe-se uma consulta direta junto aos demais colaboradores da área de negócio, buscando o apoio destes colaboradores para a pontuação dos riscos identificados, assim como o apontamento de novos riscos que não foram levantados inicialmente.

Em seguida, como forma de priorizar o tratamento dos riscos identificados, houve a integração da variável de "Detecção", presente na técnica FMEA, como complemento aos conceitos já utilizados de Probabilidade e Impacto. Conforme visto anteriormente, o RFMEA baseia-se na avaliação tanto do conceito do risco quanto também do valor RPN (valor de prioridade do risco) para encontrar os riscos críticos, que exigem um planejamento imediato de resposta.

\subsection{Estabelecimento do Contexto}

Considerando todas as etapas do processo de pagamento de contas médicas, foi definida que a avaliação sob a ótica de riscos seria realizada no subprocesso de análise de contas. A escolha deste subprocesso ocorreu devido à sua importância dentre as atividades exercidas no decorrer do processo geral de pagamento de contas médicas, considerando o volume financeiro envolvido e os impactos decorrentes de possíveis falhas e atrasos no fluxo de análise. Ocorrências desta natureza, caso não detectadas e tratadas, poderiam gerar possíveis retrabalhos e atrasos de pagamentos, com o subsequente aumento na insatisfação dos clientes externos (como prestadores de serviço e participantes). Por fim, tendo em vista que a aplicação da metodologia só seria possível com o apoio de representantes da área de negócio, um fator importante para escolha do fluxo de análise foi a disponibilidade inicial dos analistas desta área específica para participação na aplicação da metodologia.

Conforme descrito anteriormente, a avaliação do processo baseou-se em entrevistas com representantes da área gestora e na análise dos normativos e instruções relacionados ao processo. O grupo de trabalho contou com a participação de representantes da gerência de contas médicas, com assessoramento dos analistas da Gerência de Riscos da OPS. 


\subsection{Avaliação de Riscos - por Atividade}

Após a validação do macrofluxo e estabelecimento dos objetivos do processo, cada atividade foi avaliada sob a ótica de riscos e suficiência de controles. A avaliação, cujos resultados são descritos a seguir, foi feita considerando os apontamentos dos integrantes da equipe em sessões de discussão, adotando a técnica de Brainstorming, descrita no item 2.1.2.2. Em seguida, foi proposto o encaminhamento das atividades e seus respectivos riscos aos demais colaboradores da área gestora, solicitando suas opiniões a respeito dos riscos apontados por atividade, e a existência de outros riscos não apontados pela equipe de autoavaliação. A equipe, por sua vez, ao receber o retorno dos colaboradores, realizaria a revisão de sua pontuação (considerando a opinião dos colegas) e registraria uma pontuação própria dos novos riscos, caso fossem julgados pertinentes.

A Figura 5.2 apresenta o fluxograma do processo avaliado, elaborado no decorrer da aplicação da metodologia. 


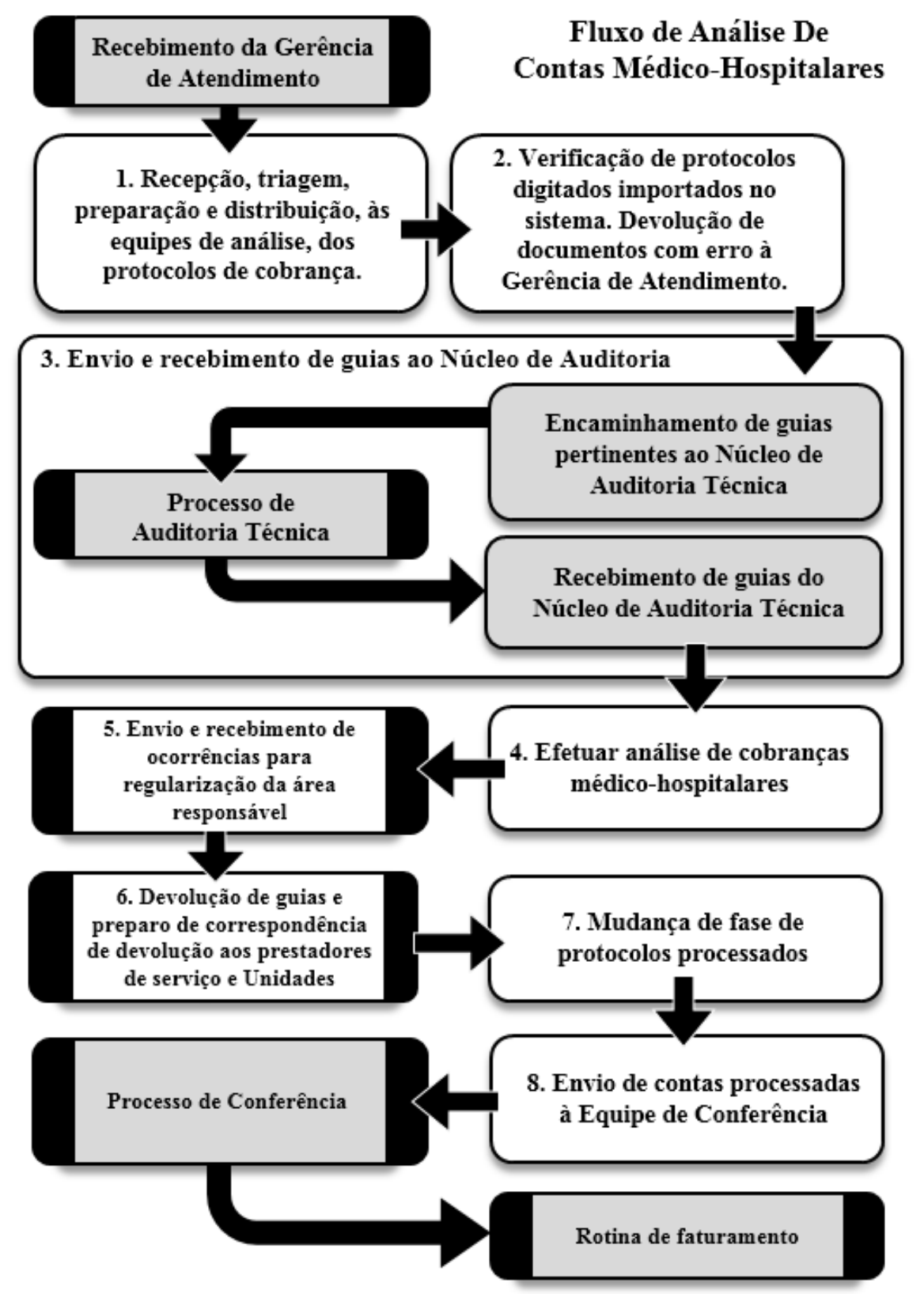

Figura 5.2: Fluxograma do subprocesso de análise de contas da OPS

Nos itens a seguir, descreve-se a relação dos riscos identificados para cada etapa do subprocesso avaliado. 


\subsubsection{Atividade 1 - Recepção, triagem, preparação e distribuição, às equipes de análise, dos protocolos de cobrança}

Conforme descrito no item 4.2, o processo de análise inicia-se pelo recebimento das cobranças distribuídas pela equipe da Gerência de Atendimento, que possui as atribuições de recepção, impostação no sistema, e distribuição dos documentos de contas médicas.

Além do meio físico, o recebimento das cobranças também pode ocorrer eletronicamente, conforme o Padrão obrigatório para Troca de Informações na Saúde Suplementar (TISS), definido pela Resolução Normativa 305 da ANS. As equipes de análise recebem as guias físicas organizadas por data de protocolo de recebimento e, do faturamento eletrônico, organizadas por data de envio. O prazo de pagamento das cobranças, pela OPS aos prestadores de serviço, é de 30 dias corridos após o protocolo na Central de Pagamentos.

O Quadro 5.1 apresenta o resumo dos riscos identificados nesta atividade, já contemplando os valores finais atribuídos para as variáveis de Probabilidade, Impacto (com o cálculo do Risco Bruto) e Detecção:

\begin{tabular}{c|l|c|c|c|c}
\hline No. & Riscos Identificados - Recepção e distribuição dos protocolos de cobrança & P & I & RB & D \\
\hline 01 & $\begin{array}{l}\text { Recebimento de documento físico fracionado, recebimento indevido (trânsito } \\
\text { indevido), não recebimento e não importação do arquivo eletrônico para o sistema } \\
\text { de pagamentos, pela Gerência de Atendimento. }\end{array}$ & 3 & 1 & 3 & 5 \\
\hline 02 & $\begin{array}{l}\text { Acondicionamento dos protocolos oriundos da Gerência de Atendimento com } \\
\text { protocolos e tipos de guias diversos na mesma caixa antes da distribuição aos } \\
\text { analistas. }\end{array}$ & 5 & 2 & 10 & 6 \\
\hline 03 & Recebimento dos protocolos por equipes não responsáveis pelo processamento. & 3 & 1 & 3 & 2 \\
\hline 04 & Sobrecarga do analista, quanto ao volume de guias processadas. & 3 & 1 & 3 & 3 \\
\hline 05 & Perfil inadequado do analista para análise de determinado tipo de guia. & 3 & 4 & 12 & 2 \\
\hline 06 & $\begin{array}{l}\text { Interpretação normativa equivocada, referente ao processo de mudança de fase } \\
\text { (devolução desnecessária do protocolo à Gerência de Atendimento). }\end{array}$ & 5 & 1 & 5 & 3 \\
\hline 07 & $\begin{array}{l}\text { Inclusão/alteração de guias pela equipe de análise, nos protocolos em status de } \\
\text { "digitacãa”. }\end{array}$ & 3 & 4 & 12 & 7 \\
\hline 08 & $\begin{array}{l}\text { Inclusão/alteração de guias, pela equipe de análise, nos protocolos em status de } \\
\text { "análise", ocasionando perda de produção ou pagamento indevido. }\end{array}$ & 3 & 5 & 15 & 7 \\
\hline 09 & Recebimento de guias digitadas de forma incorreta. & 5 & 2 & 10 & 8 \\
\hline
\end{tabular}

Quadro 5.1: Riscos identificados na atividade de recepção e distribuição dos protocolos de cobrança 
Entre os riscos classificados como sendo oriundos de falha humana, destacamse aqueles ligados à sobrecarga dos analistas, no tocante ao volume de guias processadas. A excessiva carga de trabalho pode estar relacionada a diversos tipos de falhas potenciais, como o recebimento de guias incompletas ou digitadas de forma incorreta, o recebimento de protocolos por equipes não responsáveis pelo processamento, ou até mesmo o acondicionamento, em uma mesma caixa, dos protocolos oriundos da Gerência de Atendimento com protocolos diversos.

Uma vez recebido, a depender do status do protocolo, existe a possibilidade de alteração manual dos registros pelo analista de contas. Sendo assim, os riscos identificados estão relacionados à inclusão ou alteração de guias, códigos de procedimento ou itens de custo, ocasionando perdas de produção ou pagamentos indevidos.

\subsubsection{Atividade 2 - Verificação de protocolos digitados importados no sistema. Devolução de documentos com erro à Gerência de Atendimento}

Em seguida, a Gerência de Análise recebe os protocolos e verifica o ocorrência de erros, realizando a devolução de documentos inconsistentes à Gerência de Atendimento. O Quadro 5.2 apresenta o resumo dos riscos identificados nesta atividade:

\begin{tabular}{|c|c|c|c|c|c|}
\hline No. & Riscos Identificados - Verificação e devolução de documentos com erro & $\mathbf{P}$ & I & RB & D \\
\hline 10 & $\begin{array}{l}\text { Devolução das guias para redigitação, interrompendo, dessa forma, a continuidade } \\
\text { da análise. }\end{array}$ & 5 & 2 & 10 & 2 \\
\hline 11 & Extravio das guias devolvidas para a Gerência de Atendimento. & 5 & 3 & 15 & 2 \\
\hline
\end{tabular}

Quadro 5.2: Riscos identificados na atividade de verificação e devolução de documentos com erro

Os riscos apontados nesta atividade estão ligados à devolução indevida e ao extravio de guias encaminhadas à equipe de Atendimento. 


\subsubsection{Atividade 3 - Envio e recebimento de guias ao Núcleo de Auditoria}

Para as guias pertinentes, realiza-se o encaminhamento ao Núcleo de Auditoria Técnica. Esta área é composta por médicos e enfermeiros, e é responsável por verificar a procedência das cobranças realizadas pelos prestadores de serviços (com exceção daqueles que possuem fechamento de contas in loco). Cabe a esta equipe realizar a auditoria nas contas (incluindo materiais, medicamentos, tratamentos e internações) cujos procedimentos se enquadrem em critérios específicos de complexidade e custo. São avaliados os relatórios de auditoria concorrente e autorizações prévias, objetivando a identificação de situações consideradas incomuns e passíveis de avaliação. Por meio de suas atividades, a área auxilia as equipes de análise por meio de uma assessoria técnica, com informações relevantes para o correto pagamento das contas.

As equipes de análise devem encaminhar as guias para o Núcleo de Auditoria em até dois dias depois do recebimento do protocolo físico. Nos casos de ausência de documentação física, as informações são extraídas do sistema de pagamento. A análise técnica do Núcleo de Auditoria é realizada em até três dias úteis. O Quadro 5.3 apresenta o resumo dos riscos identificados nesta atividade:

\begin{tabular}{|c|c|c|c|c|c|}
\hline No. & Riscos Identificados - Envio e recebimento de guias ao Núcleo de Auditoria & $\mathbf{P}$ & $\mathbf{I}$ & $\mathbf{R B}$ & $\mathbf{D}$ \\
\hline 12 & Não recebimento das guias auditadas pela análise. & 3 & 1 & 3 & 2 \\
\hline 13 & $\begin{array}{l}\text { Processamento de Protocolos recebidos da Auditoria sem registro da crítica do } \\
\text { auditor. }\end{array}$ & 3 & 4 & 12 & 2 \\
\hline 14 & $\begin{array}{l}\text { Não observância, pelo analista de contas, dos tipos de atendimentos a serem } \\
\text { encaminhadas para avaliação do núcleo de auditoria técnica. }\end{array}$ & 2 & 4 & 8 & 9 \\
\hline
\end{tabular}

Quadro 5.3: Riscos identificados na atividade de envio e recebimento de guias ao Núcleo de Auditoria

Os riscos referentes ao trânsito de protocolos entre as áreas de Análise e Auditoria estão relacionados à não observância, pelo analista de contas, dos tipos de atendimentos a serem encaminhadas para avaliação do núcleo de auditoria, assim como ao atraso (ou não recebimento) das guias auditadas, e ao processamento de contas recebidos da Auditoria sem registro da crítica do auditor. 


\subsubsection{Atividade 4 - Efetuar análise de cobranças médico- hospitalares}

Considerada a atividade principal dentro do fluxo avaliado, a análise de cobranças consiste em verificar a pertinência técnica e administrativa dos procedimentos cobrados, avaliando a sua conformidade quando comparadas com o contrato firmado junto ao prestador, os registros no sistema de pagamento, e as instruções constantes nos normativos internos da OPS.

Para realização das análises, as equipes são organizadas por Estado (UF), tipo de prestador (hospitais, clínicas, laboratórios e cooperativas, assim como os demais prestadores), e tipo de pagamento (credenciamento e reembolso direto aos participantes). Entre os principais itens a serem verificados, estão a pertinência para o pagamento de órteses, próteses, e materiais especiais (OPME), a adequação dos valores cobrados às tabelas de referência de preços, e a compatibilidade entre as cobranças e os pacotes negociados com os prestadores, conforme o contrato firmado entre as partes.

Para determinados parâmetros, o próprio sistema de pagamentos realiza o apontamento das ocorrências, na forma de glosas (negativas de pagamento). Neste caso, ocorre a avaliação manual do protocolo pelo analista de contas da área, no intuito de manter ou reconsiderar as negativas apontadas. Esta análise considera critérios específicos conforme o tipo de procedimento cobrado. As glosas geradas manualmente são registradas de forma padronizada no sistema de pagamentos, obedecendo uma codificação específica, baseada no padrão TISS, e com registro de justificativa pelo analista. Também ocorre o processamento automático de protocolos de guias de tipos específicos de cobrança, cujo valor esteja abaixo de um limite préestabelecido.

O Quadro 5.4 apresenta o resumo dos riscos identificados nesta atividade. 


\begin{tabular}{|c|c|c|c|c|c|}
\hline No. & Riscos Identificados - Análise de cobranças médico-hospitalares & $\mathbf{P}$ & $\mathbf{I}$ & RB & D \\
\hline 15 & $\begin{array}{l}\text { Falha do analista de contas, oriunda da falta de qualificação, gerando pagamento } \\
\text { indevido. }\end{array}$ & 5 & 5 & 25 & 9 \\
\hline 16 & $\begin{array}{l}\text { Processamento indevido por ausência de impostação e atualização dos dados } \\
\text { cadastrais dos prestadores e beneficiários. }\end{array}$ & 5 & 3 & 15 & 7 \\
\hline 17 & $\begin{array}{l}\text { Processamento das contas médicas com código de evento curinga (genérico), sem } \\
\text { vinculação de autorização. }\end{array}$ & 5 & 4 & 20 & 7 \\
\hline 18 & $\begin{array}{l}\text { Processamento indevido quando da divergência entre os itens (eventos/graus) } \\
\text { autorizados e as anotações no campo observações da autorização. }\end{array}$ & 2 & 3 & 6 & 8 \\
\hline 19 & $\begin{array}{l}\text { Processamento indevido, mediante autorizações com status de "cancelado" no } \\
\text { sistema. }\end{array}$ & 3 & 4 & 12 & 7 \\
\hline 20 & $\begin{array}{l}\text { Processamento indevido de OPME quando da impostação incorreta, ausência de } \\
\text { detalhamento, na autorização, dos materiais/ medicamentos a serem abonados. }\end{array}$ & 3 & 4 & 12 & 7 \\
\hline 21 & $\begin{array}{l}\text { Recebimento de notas fiscais provenientes das Unidades sem a checagem para } \\
\text { pertinência do pagamento, gerando processamento indevido, atraso e retrabalho. }\end{array}$ & 3 & 4 & 12 & 8 \\
\hline 22 & $\begin{array}{l}\text { Ausência de impostações do plano terapêutico nas autorizações de atendimento } \\
\text { domiciliar, gerando atraso de processamento e perda de produtividade. }\end{array}$ & 3 & 4 & 12 & 3 \\
\hline 23 & $\begin{array}{l}\text { Alteração do tipo de guia, de "atendimento ambulatorial" para "internação", com a } \\
\text { mudança indevida das informações originais encaminhadas pelo prestador. }\end{array}$ & 2 & 2 & 4 & 3 \\
\hline 24 & Erro de interpretação, do analista, quanto às informações provenientes da Auditoria. & 3 & 4 & 12 & 9 \\
\hline 25 & $\begin{array}{l}\text { Pagamento de procedimentos na mesma guia, porém contemplados em senhas } \\
\text { distintas, ocasionando a não sensibilização da autorização original. }\end{array}$ & 5 & 4 & 20 & 7 \\
\hline 26 & $\begin{array}{l}\text { Ausência de informativos, ou informações incorretas, que subsidiem o pagamento } \\
\text { diferenciado para determinado participante ou prestador. }\end{array}$ & 3 & 4 & 12 & 7 \\
\hline 27 & $\begin{array}{l}\text { Verificação desnecessária de alertas repetitivos para os eventos da mesma guia, do } \\
\text { mesmo Protocolo. }\end{array}$ & 5 & 4 & 20 & 2 \\
\hline 28 & Processamento das guias sem a análise prévia dos técnicos da Auditoria in loco. & 2 & 4 & 8 & 9 \\
\hline 29 & $\begin{array}{l}\text { Pagamento indevido/duplicado de itens já inclusos nos pacotes negociados com os } \\
\text { prestadores de serviço. }\end{array}$ & 3 & 4 & 12 & 1 \\
\hline 30 & $\begin{array}{l}\text { Pagamento indevido/duplicado de honorários médicos cobrados em duplicidade, } \\
\text { tanto pelo hospital quanto pela equipe médica. }\end{array}$ & 3 & 4 & 12 & 5 \\
\hline 31 & Pagamento em duplicidade de arquivos importados com atendimentos idênticos. & 3 & 4 & 12 & 2 \\
\hline 32 & Não detecção de práticas abusivas de cobrança de serviços médico-hospitalares & 5 & 5 & 25 & 9 \\
\hline
\end{tabular}

Quadro 5.4: Riscos identificados na análise de cobranças médico-hospitalares

Conforme descrito anteriormente, considerando que os apontamentos são identificados para cada prestador individualmente, e que não existe um comparativo automatizado das práticas de cobranças e análises comportamentais entre os prestadores como um todo, um dos principais riscos identificados foi a possibilidade de perdas associadas à não detecção de práticas abusivas de cobrança de serviços médico-hospitalares.

Os demais riscos identificados estão relacionados, de forma geral, à falta de informações que subsidiem uma análise de qualidade, e a não detecção de inconsistências entre a cobrança e os normativos e acordos contratuais.

Entre as possíveis ocorrências, encontra-se a possibilidade de processamento indevido das cobranças, devido à ausência de impostação e atualização dos dados cadastrais dos prestadores e beneficiários. Em termos de negociação contratual, foi 
identificada a possibilidade de pagamentos indevidos ou duplicados de itens já inclusos nos pacotes negociados com os prestadores de serviços. Também foi levantada a hipótese de haver a ausência de informações que subsidiem o pagamento diferenciado para determinado participante ou prestador.

No tocante à distribuição dos protocolos pela análise da equipe, foi identificada a possibilidade de pagamentos em duplicidade, devido à importação de arquivos distintos com atendimentos idênticos. Este cenário também poderia ocorrer caso houvesse a cobrança simultânea de honorários médicos informados pelo hospital e, individualmente, pela equipe médica responsável pelo procedimento.

Especificamente em relação à cobranças de OPMEs, existe uma instrução organizacional de que a análise só deve ocorrer mediante apresentação da nota fiscal do material solicitado. Contudo, como estes documentos são encaminhados pela Unidade responsável pelo participante, foi identificado o risco de recebimento de notas fiscais que não sofreram a verificação prévia quanto à pertinência do pagamento, gerando o processamento indevido, atrasos e retrabalhos.

Dentro do fluxo de análise, existe a definição de que equipes de análise devem observar, além dos critérios técnicos e administrativos, as negociações específicas registradas nas autorizações previamente impostadas no sistema de pagamentos, pela Central de Atendimento e Unidades. Como o registro destas negociações é feito em um campo de texto livre, os riscos ligados às autorizações muitas vezes envolvem o processamento indevido, quando da divergência entre os itens autorizados e as anotações no campo de observações da autorização. Este tipo de anomalia também pode ocorrer no processamento de OPMEs, caso ocorra a impostação incorreta (ou ausência de detalhamento), no registro da autorização, dos materiais/ medicamentos a serem abonados.

Uma outra possibilidade de perda estaria ligada ao processamento indevido de cobranças relacionadas a autorizações com status de "cancelado" no sistema. Outra hipótese relacionada aos registros de autorização seria a ausência de impostações do plano terapêutico nas autorizações vinculadas a certos programas de saúde, gerando atrasos no processamento e perda de produtividade. Como a autorização é muitas vezes gerada antes de se conhecer o conjunto de procedimentos efetivamente necessários para um determinado atendimento, um código de evento "curinga" (genérico) é utilizado para registro da autorização. Este código deve ser substituído manualmente antes do processamento final da guia. Todavia, foi identificada a possibilidade de ocorrer o processamento das contas médicas por meio deste código 
genérico, sem que ocorra a vinculação da autorização original. Também foi identificada a possibilidade de pagamento de procedimentos em uma mesma guia contemplados em autorizações distintas, ocasionando na não sensibilização da autorização original.

No decorrer da análise, cabe ao analista observar os apontamentos realizados nas contas hospitalares que sofrem auditoria in loco, realizada durante a internação do paciente. Neste caso, o principal risco apontado é o de processamento das guias sem a correta verificação das críticas desta natureza, ou a falha de interpretação do analista nas informações provenientes da auditoria.

Os demais riscos levantados no decorrer da autoavaliação estão relacionados à possível falta de qualificação do analista para o desempenho de suas tarefas, ocasionando falhas no processamento de contas e pagamentos indevidos.

\subsubsection{Atividade 5 - Envio e recebimento de ocorrências para regularização da área responsável}

Caso seja identificada alguma irregularidade nas guias de cobrança recepcionadas pelas equipes de análise, cabe à área informar à Unidade jurisdicionante, por e-mail, as distorções entre as cobranças dos prestadores com os registros no sistema e as inconsistências identificadas no cadastro dos prestadores de serviço. O Quadro 5.5 apresenta o resumo dos riscos identificados nesta atividade:

\begin{tabular}{|c|c|c|c|c|c|}
\hline No. & Riscos Identificados - Envio e recebimento de ocorrências para regularização & $\mathbf{P}$ & I & $\mathbf{R B}$ & $\mathbf{D}$ \\
\hline 33 & $\begin{array}{l}\text { Ausência de encaminhamento das inconsistências às áreas responsáveis para devida } \\
\text { regularização. }\end{array}$ & 3 & 3 & 9 & 3 \\
\hline 34 & $\begin{array}{l}\text { Apontamento incompleto e/ou incorreto da necessidade de intervenção da área } \\
\text { responsável. }\end{array}$ & 3 & 3 & 9 & 2 \\
\hline 35 & $\begin{array}{l}\text { Morosidade no recebimento da resolução dos apontamentos, ou não recebimento de } \\
\text { resposta em relação a: cadastro de prestadores e beneficiários / autorização / } \\
\text { parametrização / alertas / tabelas de preços. }\end{array}$ & 3 & 4 & 12 & 2 \\
\hline
\end{tabular}

Quadro 5.5: Riscos identificados na atividade de envio e recebimento de ocorrências

$$
\text { para regularização }
$$

Em termos de riscos identificados, foi verificada a possibilidade de apontamentos incompletos ou incorretos quanto à necessidade de intervenção da área responsável, ou até mesmo a ausência de encaminhamento das inconsistências para a 
devida regularização. Por outro lado, pode também haver morosidade no recebimento da resolução dos apontamentos, ou não recebimento de resposta.

\subsubsection{Atividade 6 - Devolução de guias e preparo de correspondência de devolução aos prestadores de serviço e Unidades}

Compete à área de análise encaminhar para devolução, aos prestadores de serviço, as guias físicas de atendimento que não tiverem o preenchimento adequado dos itens obrigatórios definidos nos normativos internos ou nos acordos contratuais.

Nas situações de devolução de guias passíveis de reapresentação, a área deve especificar o motivo que gerou a devolução e o prazo máximo de reapresentação. Essas informações são geradas automaticamente pelo sistema de pagamentos, e devem ser enviadas ao prestador. A devolução de guias deve acontecer mediante o apontamento de todas as ocorrências na carta de devolução, para evitar nova devolução da mesma guia.

O Quadro 5.6 apresenta o resumo dos riscos identificados nesta atividade.

\begin{tabular}{|c|c|c|c|c|c|}
\hline No. & Riscos Identificados - Devolução de guias aos prestadores e Unidades & $\mathbf{P}$ & $\mathbf{I}$ & $\mathbf{R B}$ & $\mathbf{D}$ \\
\hline 36 & Devolução improcedente das guias. & 3 & 3 & 9 & 2 \\
\hline 37 & $\begin{array}{l}\text { Direcionamento incorreto, das devoluções, para os prestadores de serviços ou } \\
\text { Unidades. }\end{array}$ & 3 & 3 & 9 & 1 \\
\hline 38 & Não efetivação da devolução da documentação física, efetuada somente no sistema. & 3 & 3 & 9 & 3 \\
\hline 39 & Extravio das guias devolvidas. & 2 & 4 & 8 & 3 \\
\hline 40 & Exclusão dos registros dos atendimentos originais extraviados, após a devolução. & 3 & 4 & 12 & 5 \\
\hline 41 & $\begin{array}{l}\text { Devolução inconsistente aos prestadores e Unidades, devido à replicação do motivo } \\
\text { de devolução específico, de uma guia, para todas as demais no mesmo lote. }\end{array}$ & 3 & 4 & 12 & 2 \\
\hline 42 & $\begin{array}{l}\text { Agrupamento dos registros de devolução, na impressão do relatório, para diferentes } \\
\text { Protocolos devolvidos do mesmo prestador, geradas na mesma data. }\end{array}$ & 3 & 4 & 12 & 2 \\
\hline
\end{tabular}

Quadro 5.6: Riscos identificados na atividade de devolução de guias aos prestadores e

\section{Unidades}

Conforme o Quadro 5.6, as falhas neste processo podem estar relacionadas à não efetivação da devolução da documentação física (caso seja efetuada somente no sistema), no extravio das guias devolvidas, e na devolução improcedente. Também foi identificada a possibilidade de direcionamento incorreto das devoluções para os prestadores de serviços ou Unidades. 


\subsubsection{Atividade 7 - Mudança de fase de protocolos processados}

A mudança de fase do protocolo de recebimento, no sistema, envolve a alteração do status das guias de cobrança, possibilitando a visualização do protocolo pela área seguinte dentro do fluxo de processamento de contas. O Quadro 5.7 apresenta o resumo dos riscos identificados nesta atividade:

\begin{tabular}{|c|c|c|c|c|c|}
\hline No. & Riscos Identificados - Mudança de fase de protocolos processados & $\mathbf{P}$ & I & $\mathbf{R B}$ & D \\
\hline 43 & Não observância, pelo analista, das pendências de análise antes da mudança de fase. & 3 & 4 & 12 & 2 \\
\hline 44 & $\begin{array}{l}\text { Envio de Protocolos à equipe de conferência sem a devida realização da mudança } \\
\text { de fase, ocasionando atraso no processamento. }\end{array}$ & 3 & 2 & 6 & 2 \\
\hline 45 & $\begin{array}{l}\text { Não encaminhamento das guias físicas indispensáveis para o processo de } \\
\text { conferência. }\end{array}$ & 2 & 2 & 4 & 1 \\
\hline 46 & $\begin{array}{l}\text { Inobservância de todas as pendências de processamento antes da liberação da } \\
\text { alçada. }\end{array}$ & 5 & 4 & 20 & 2 \\
\hline
\end{tabular}

Quadro 5.7: Riscos identificados na atividade de mudança de fase de protocolos processados

Entre as potenciais falhas apontadas para esta etapa, estão o envio de protocolos à equipe de conferência sem a devida realização da mudança de fase, gerando atrasos no processamento; o não encaminhamento das guias físicas indispensáveis para o processo de conferência; a inobservância de todas as pendências de processamento antes da liberação da alçada; e a não observância, pelo analista de contas, das pendências de análise antes da mudança de fase.

\subsubsection{Atividade 8 - Envio de contas processadas à Equipe de Conferência}

O processo de conferência, de forma geral, possui como objetivo garantir a qualidade do processamento de contas médicas. As principais responsabilidades da Área de Conferência incluem assegurar a conformidade e o cumprimento do prazo de pagamento das cobranças, identificando possíveis divergências e negativas de pagamento registradas de forma indevida.

Este fluxo, que antecipa a etapa final de faturamento, consiste em conferir a pertinência da cobrança, com base nos normativos internos, nos acordos contratuais firmados com o prestador, e nos registros de sistema efetuados pela Unidade jurisdicionante ou Central de Atendimentos. Se for verificada alguma não 
conformidade na guia conferida, a equipe registra a ocorrência no sistema para que a área responsável efetue a regularização. O Quadro 5.8 apresenta o resumo dos riscos identificados nesta atividade:

\begin{tabular}{|c|c|c|c|c|c|}
\hline No. & Riscos Identificados - Encaminhamento de guias para Conferência & $\mathbf{P}$ & $\mathbf{I}$ & $\mathbf{R B}$ & D \\
\hline 47 & Não recebimento das ocorrências em tempo hábil para regularização. & 2 & 2 & 4 & 2 \\
\hline 48 & Recebimento da ocorrência pela equipe indevida. & 2 & 2 & 4 & 1 \\
\hline 49 & Não regularização da ocorrência em tempo hábil do protocolo em questão. & 2 & 2 & 4 & 1 \\
\hline 50 & Não recebimento/devolução de ocorrências provenientes da conferência. & 3 & 3 & 9 & 2 \\
\hline 51 & Não regularização da ocorrência, recepcionada e devolvida à equipe de conferência. & 2 & 3 & 6 & 2 \\
\hline 52 & $\begin{array}{l}\text { Não efetivação da mudança de fase do status de análise para conferência das } \\
\text { ocorrências regularizadas. }\end{array}$ & 3 & 2 & 6 & 2 \\
\hline
\end{tabular}

Quadro 5.8: Riscos identificados na atividade de encaminhamento de guias para Conferência

Os riscos identificados, de forma geral, estão relacionados ao não recebimento, pelas equipes de análise, das ocorrências provenientes da conferência. Existe também a possibilidade de que a ocorrência não sofra a devida regularização, ou que esta não ocorra em tempo hábil, considerando o cronograma de processamento de contas.

\subsubsection{Rotina de faturamento}

Por fim, as guias analisadas são encaminhadas aos detentores das alçadas competentes, para liberação dos pagamentos. A área de Tecnologia da Informação da OPS é responsável pela execução das rotinas de faturamento, enviadas via caixa corporativa, à Coordenação Financeira, e pelo envio de arquivos para pagamento pela instituição financeira competente.

Como este fluxo é externo ao processo de pagamento de contas, não foi incluso no escopo da análise sob a ótica de riscos e controles. 


\subsection{Identificação de controles por atividade}

De forma geral, os controles identificados para as atividades enquadraram-se como sendo do tipo "Direto", ou seja, desenvolvidos especificamente para tratamento dos riscos ligados ao processo avaliado. O Apêndice II detalha os controles individualmente, já considerando a pontuação final referente ao Nível de Confiança, atribuída pelos representantes da área gestora do processo com apoio da equipe facilitadora.

\subsection{Consulta aos colaboradores e reanálise pela equipe de autoavaliação}

Uma das principais alterações propostas no modelo de avaliação de riscos foi a inclusão da etapa de consulta aos demais colaboradores da área gestora, para auxiliar a equipe de autoavaliação na identificação e pontuação dos riscos do processo. Essa alteração foi proposta como forma de mitigar um dos principais pontos fracos relacionados ao uso da técnica de brainstorming na identificação de riscos, que é a incerteza quanto ao levantamento do conjunto total de ocorrências relacionadas a uma determinada atividade.

Por consequência, adotou-se para esta etapa algumas das principais diretrizes da técnica Delphi, descrita anteriormente. O fluxo de envio e recebimento dos formulários é apresentado na Figura 5.3. 


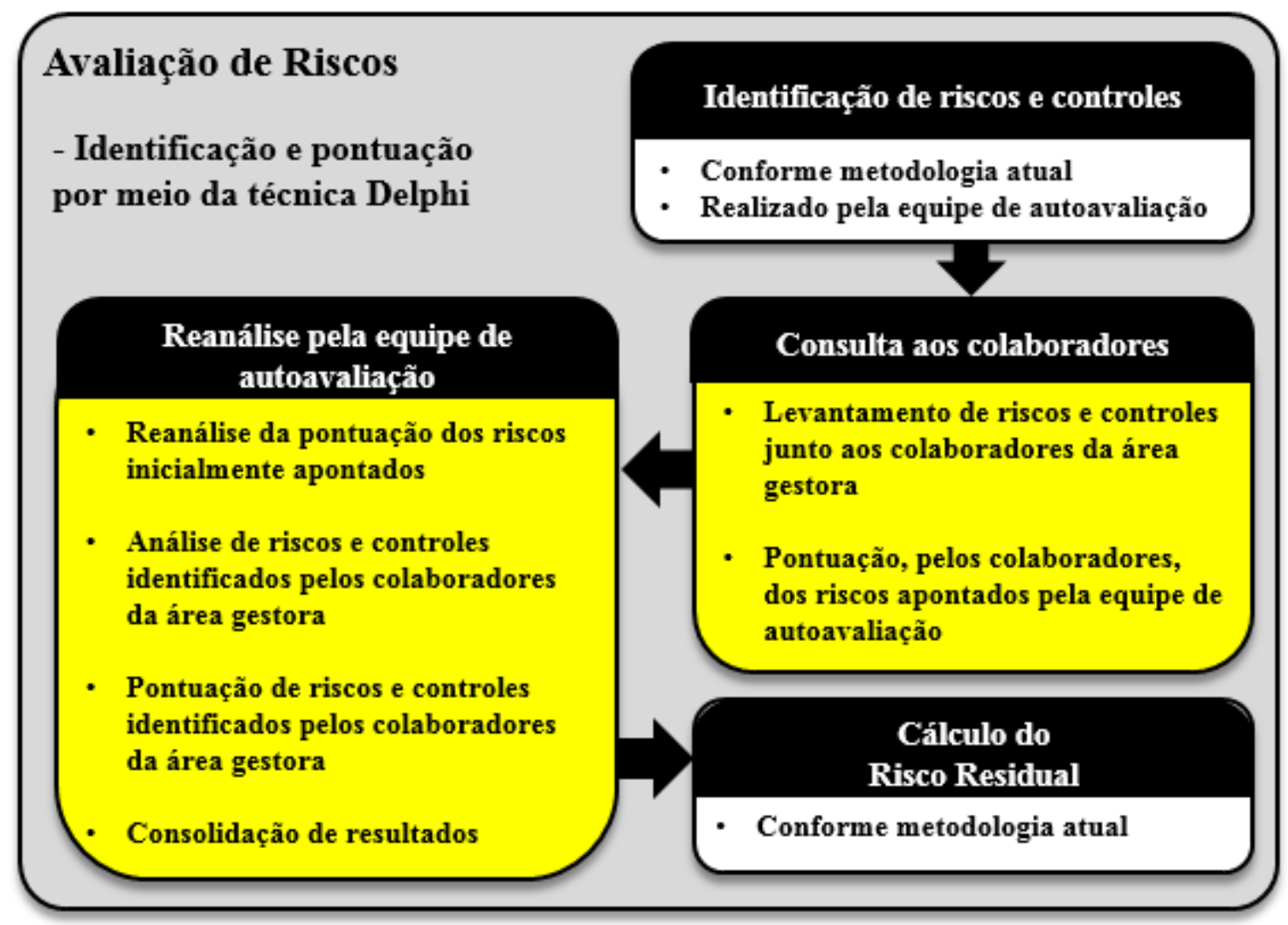

Figura 5.3: Proposta de inclusão da técnica Delphi para a identificação de riscos

A etapa inicial é a identificação dos riscos iniciais pela equipe de autoavaliação. Este conjunto de riscos é classificado e pontuado pela equipe, porém apenas a descrição dos riscos é enviada aos demais colaboradores da área gestora. Estes indivíduos, escolhidos entre a equipe de funcionários da área, recebem a cópia do fluxograma do processo, o conjunto inicial de riscos e as instruções a respeito de sua pontuação na forma de um formulário, cujo modelo consta no Apêndice III. Neste documento, os colaboradores são também incentivados a registrarem suas próprias sugestões a respeito dos riscos existentes do processo, que porventura não foram levantados pela equipe de autoavaliação.

Seguindo as diretrizes do método Delphi, recomenda-se que as informações sejam coletadas de forma anônima, sem identificação dos responsáveis pelos apontamentos. Os formulários são distribuídos por meio de mensagem eletrônica, com cópia oculta. Para garantir o anonimato, recomenda-se que os documentos preenchidos sejam impressos e entregues a um representante da área gestora, que encaminha os formulários a um dos facilitadores integrantes da equipe de autoavaliação.

De posse dos resultados da análise, a equipe de autoavaliação utiliza as novas informações para realizarem uma nova análise da pontuação inicialmente atribuída 
aos riscos identificados, e avaliam a inclusão dos novos riscos informados pelos colaboradores. A depender do nível de complexidade do processo e do tempo disponível para aplicação da metodologia, é realizada uma nova rodada junto à área gestora, desta vez informando a pontuação e o conjunto atualizado de riscos, solicitando a opinião dos indivíduos a respeito da avaliação da equipe.

\subsection{Cálculo do Risco Residual}

Para cada risco, a diferença entre o valor inicial dos Riscos Brutos (RB) e o conceito de Nível de Confiança (NC) dos controles resultou no conceito de Risco Residual (RR). A pontuação definida pela equipe, para cada um dos riscos, está presente no Apêndice II.

Conforme estabelecido pela metodologia da OPS, os riscos com valores residuais acima de 7 são considerados como "inaceitáveis", e devem ser encaminhados para tratamento por meio de Plano de Ação. No entanto, uma das propostas de alteração na metodologia atual prevê a priorização dos riscos com base no valor de RPN, e não do Risco Residual. Os próximos itens detalham a análise que resultou no conjunto final de riscos a serem tratados.

\subsection{Priorização dos Riscos}

\subsubsection{Mensuração do valor de Detecção, por risco identificado}

O parâmetro de Detecção, descrito por [99] e [28], considera a habilidade de se detectar a ocorrência da falha com antecedência suficiente para a tomada de ações de contingência para mitigar seus impactos.

Para a definição do valor referente a este parâmetro, a proposta da nova metodologia consistiu na elaboração de uma escala numérica. Nesta escala, que segue o modelo proposto por [28], considera-se que quanto mais alto o valor, menor a chance de existir um método de detecção que forneça um alerta em tempo hábil.

As categorias criadas para esta medida foram denominadas de "Inexistente" (9 a 10), "Não confiável" (7 a 8), "Ineficiente" (5 a 6), "Confiável" (3 a 4) e "Quase certo" (1 a 2 ).

A atribuição dos valores foi realizada conforme a opinião e experiência dos representantes da área gestora do processo. 


\subsubsection{Cálculo do valor de priorização (RPN) por risco}

Conforme definido no modelo padrão do FMEA [70], o RPN (Risk Priority Number, ou valor de prioridade do risco), é obtido pela multiplicação dos valores de Probabilidade (P), Impacto (I) e Detecção (D), ou seja, RPN $=$ P * I * D.

Sendo assim, uma das alterações propostas para a metodologia atual foi o cálculo do valor do RPN para cada um dos riscos identificados.

Quanto à priorização dos riscos avaliados, optou-se por não definir de antemão um limite específico relacionado aos valores de RPN, que indicasse quais riscos deveriam ser obrigatoriamente verificados. Conforme a sugestão de [28], considerando que a distribuição dos valores de RPN pode variar conforme o processo avaliado, a definição do limite de priorização deverá ocorrer por meio da análise da distribuição destes valores.

\subsection{Resultados Consolidados}

Ao todo, foram levantados 52 riscos associados às atividades do subprocesso de análise de contas médico-hospitalares. A Figura 5.4 detalha o quantitativo de riscos por atividade do processo. 


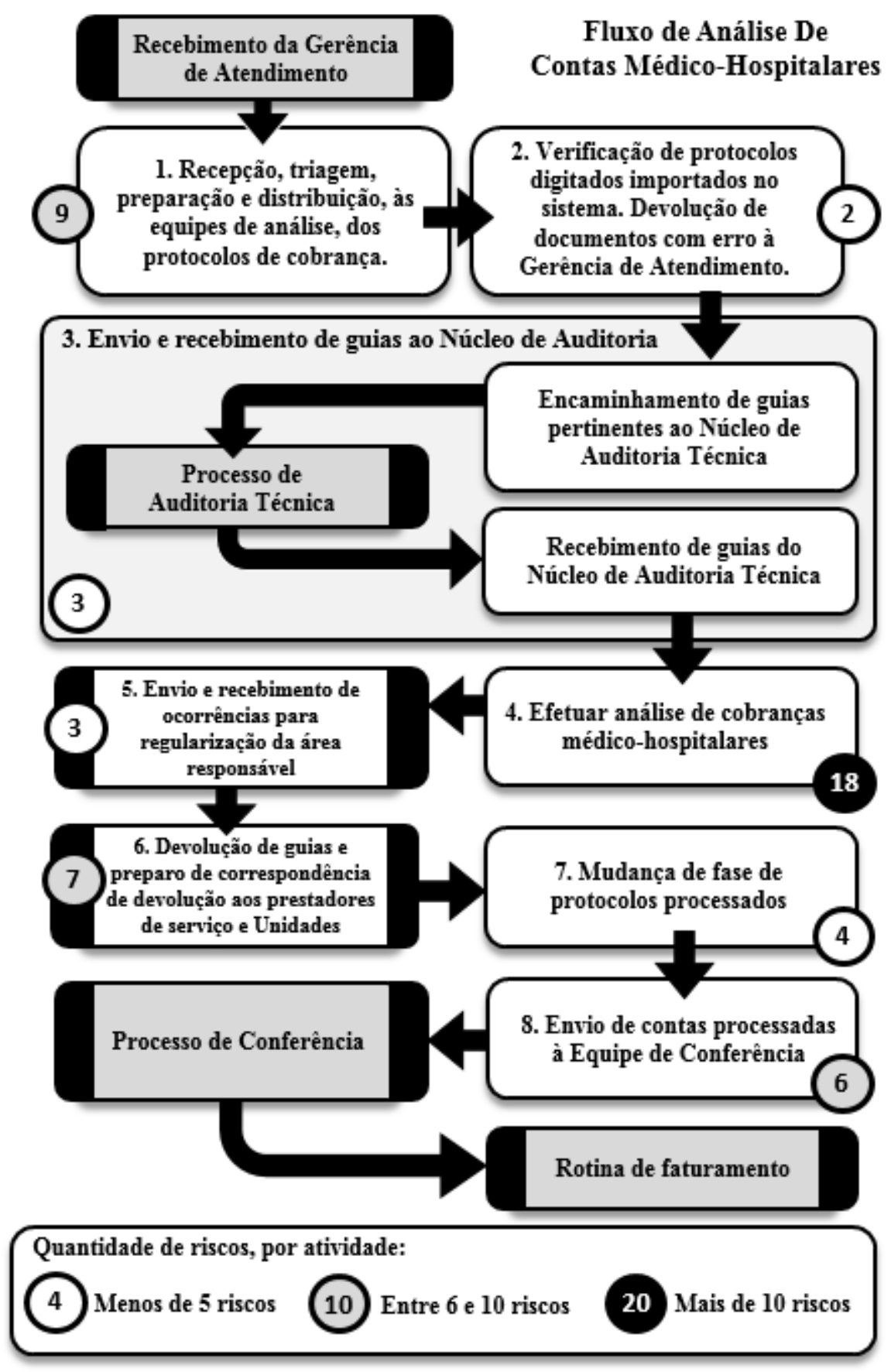

Figura 5.4: Riscos identificados nas atividades do fluxo de análise de contas médicas

Verifica-se que a grande maioria dos riscos está concentrada na Atividade 4, de "Efetuar análise de contas médico-hospitalares", com 18 ocorrências. Em seguida, a Atividade 1, de recepção e distribuição dos protocolos de cobrança às equipes de análise, apresentou 9 riscos. A Atividade 6, de "Devolução de guias aos prestadores e Unidades" apresentou a terceira maior quantidade de riscos, com o total de 7 identificados. A Atividade 8, de envio de contas à equipe de conferência apresentou 6 riscos. As demais etapas do processo apresentaram 5 ou menos riscos por atividade. 
Os riscos identificados, na sua maioria, foram enquadrados na categoria de Riscos Operacionais. Segundo a ANS [25], são riscos provenientes de falhas de pessoas, processos, tecnologia ou de eventos externos. O Gráfico 5.1 exibe o quantitativo de riscos para cada uma destas subcategorias.

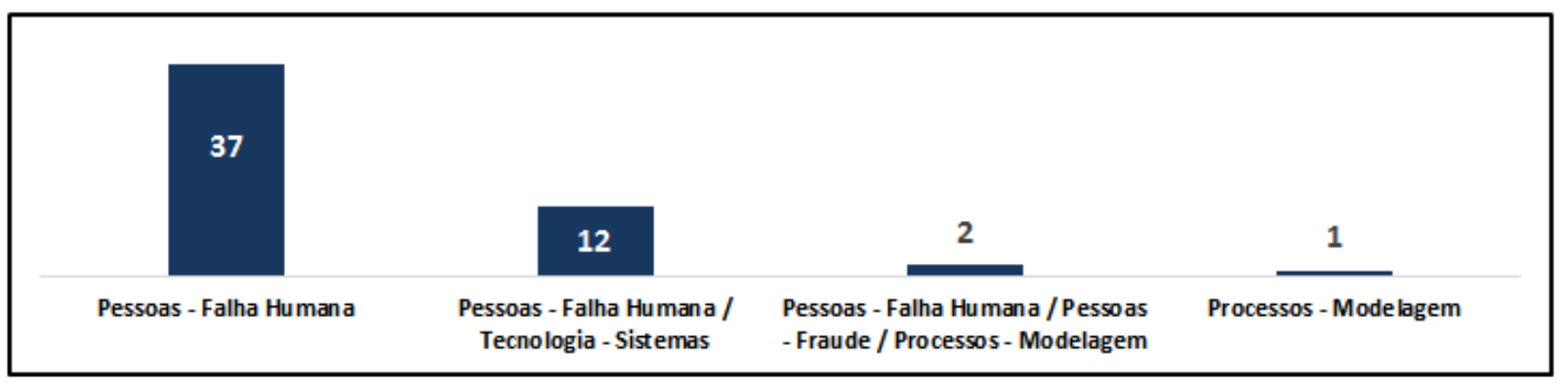

Gráfico 5.1: Quantidade de riscos identificados, por subcategoria

Conforme o Gráfico 5.1, dos 52 riscos apontados, 37 (correspondendo a aproximadamente $71,15 \%$ do total) são atribuídos a potenciais falhas humanas. Outros 12 riscos (cerca de 23\%) podem ser atribuídos a uma combinação de falhas humanas e de tecnologia.

Em seguida, para facilitar a visualização das dificuldades enfrentadas no processo, os riscos foram classificados conforme o seu tipo, conforme a Tabela 5.1. Esta classificação ocorreu mediante consenso entre os membros da equipe.

\begin{tabular}{llc}
\hline Tipo & Qtde. & \% \\
\hline Falha no envio/ recebimento de documentos & 18 & $34,62 \%$ \\
Falhas de análise ou interpretação incorreta & 13 & $25,00 \%$ \\
Registro incorreto/incompleto de informações no sistema & 11 & $21,15 \%$ \\
Falhas de sistema / não detecção de inconsistências & 9 & $17,31 \%$ \\
Acúmulo de tarefas & 1 & $1,92 \%$ \\
\hline Total & $\mathbf{5 2}$ & $\mathbf{1 0 0 \%}$ \\
\hline
\end{tabular}

Tabela 5.1: Classificação dos riscos identificados

Com base nas categorias definidas na Tabela 5.1, o Quadro 5.9 detalha a quantidade de riscos, por categoria, para cada atividade do processo: 


\begin{tabular}{|c|c|c|c|c|c|c|}
\hline Atividades Categorias & $\begin{array}{l}\text { Acúmulo } \\
\text { de tarefas }\end{array}$ & $\begin{array}{c}\text { Falha no envio/ } \\
\text { recebimento de } \\
\text { documentos }\end{array}$ & $\begin{array}{c}\text { Falhas de análise } \\
\text { ou interpretação } \\
\text { incorreta }\end{array}$ & $\begin{array}{l}\text { Falhas de sistema / } \\
\text { não detecção de } \\
\text { inconsistências }\end{array}$ & $\begin{array}{c}\text { Registro incorreto } \\
\text { ou incompleto } \\
\text { de informações } \\
\text { no sistema }\end{array}$ & Total \\
\hline $\begin{array}{l}\text { 1. Recepção, triagem, } \\
\text { preparação e distribuição, } \\
\text { às equipes de análise, dos } \\
\text { protocolos de cobrança. }\end{array}$ & 1 & 4 & 1 & & 3 & 9 \\
\hline $\begin{array}{l}\text { 2. Verificação de protocolos } \\
\text { digitados, importados no } \\
\text { sistema. Devolução de } \\
\text { documentos com erro à } \\
\text { Gerência de Atendimento. }\end{array}$ & & 2 & & & & 2 \\
\hline $\begin{array}{l}\text { 3. Envio e recebimento de } \\
\text { guias ao Núcleo de } \\
\text { Auditoria }\end{array}$ & & 1 & 1 & & 1 & 3 \\
\hline $\begin{array}{l}\text { 4. Análise de cobranças } \\
\text { médico-hospitalares }\end{array}$ & & & 7 & 6 & 5 & 18 \\
\hline $\begin{array}{l}\text { 5. Envio e recebimento de } \\
\text { ocorrências para } \\
\text { regularização da área } \\
\text { responsável. }\end{array}$ & & 1 & & & 2 & 3 \\
\hline \begin{tabular}{|l|} 
6. Devolução de guias e \\
preparo de correspondência \\
de devolução aos \\
prestadores de serviços e \\
Unidades. \\
\end{tabular} & & 5 & & 2 & & 7 \\
\hline $\begin{array}{l}\text { 7. Mudança de fase de } \\
\text { protocolos processados }\end{array}$ & & 2 & 1 & 1 & & 4 \\
\hline $\begin{array}{l}\text { 8. Envio de contas } \\
\text { processadas à Equipe de } \\
\text { Conferência. }\end{array}$ & & 3 & 3 & & & 6 \\
\hline TOTAL & 1 & 18 & 13 & 9 & 11 & 52 \\
\hline
\end{tabular}

Quadro 5.9: Quantidade de riscos, por categoria, em cada atividade do processo

No Quadro 5.9, verifica-se que na Atividade 01, de análise de cobranças médico-hospitalares, a maior parte dos riscos está vinculada à análise incorreta, falhas de sistema e erros de registro de informações. Também destaca-se a Atividade 7, de devolução de guias, com riscos preponderantemente ligados a falhas de envio e recebimento de documentos.

No intuito de identificar as atividades que poderiam apresentar uma maior incidência de gargalos dentro do subprocesso de análise de contas, apresenta-se no Gráfico 5.2 o quantitativo de riscos inaceitáveis para cada atividade: 


\begin{tabular}{|l|l|}
\hline \multirow{2}{*}{$\begin{array}{l}\text { 1. Recepção, triagem, preparação e distribuição, às equipes de } \\
\text { análise, dos protoco los de cobrança. }\end{array}$} & 5 \\
\cline { 2 - 2 } $\begin{array}{l}\text { 2. Verificação de protocolos digitados importados no sistema. } \\
\text { Devolução de documentos com erro à Gerência de Atendimento. }\end{array}$ & 2 \\
\hline 3. Envio e recebimento de guias ao Núcleo de Auditoria & 1 \\
\hline 4. Efetuar análise de cobranças médico-hospitalares & 2 \\
\hline $\begin{array}{l}\text { 5. Envio e recebimento de ocorrências para regularização da área } \\
\text { responsável. }\end{array}$ & 3 \\
\hline $\begin{array}{l}\text { 6. Devolução de guias e preparo de correspondência de devolução } \\
\text { aos prestadores de serviço e Unidades }\end{array}$ & 2 \\
\hline $\begin{array}{l}\text { 7. Mudança de fase de protocolos processados } \\
\end{array}$ & \\
\hline
\end{tabular}

Gráfico 5.2 - Quantitativo de riscos inaceitáveis identificados por atividade do processo

Esta análise confirma a criticidade da atividade de análise de contas médicohospitalares, que contém 15 riscos inaceitáveis, representando cerca e $83 \%$ dos 18 riscos levantados na etapa. A primeira atividade, de recepção e distribuição de protocolos às equipes de análise, manteve-se em segundo lugar também em termos de riscos inaceitáveis, com 5 riscos levantados nesta categoria. As demais atividades apresentaram 3 ou menos riscos inaceitáveis, sendo que a Atividade 8 (envio de contas processadas à equipe de conferência) não apresentou riscos com esta classificação.

A análise concluiu-se pela definição do conceito final de priorização (RPN) por risco identificado, multiplicando os conceitos de Probabilidade, Impacto e Detecção. O Gráfico 5.3 apresenta a distribuição dos valores de RPN, considerando o conjunto total de riscos levantados no decorrer da avaliação.

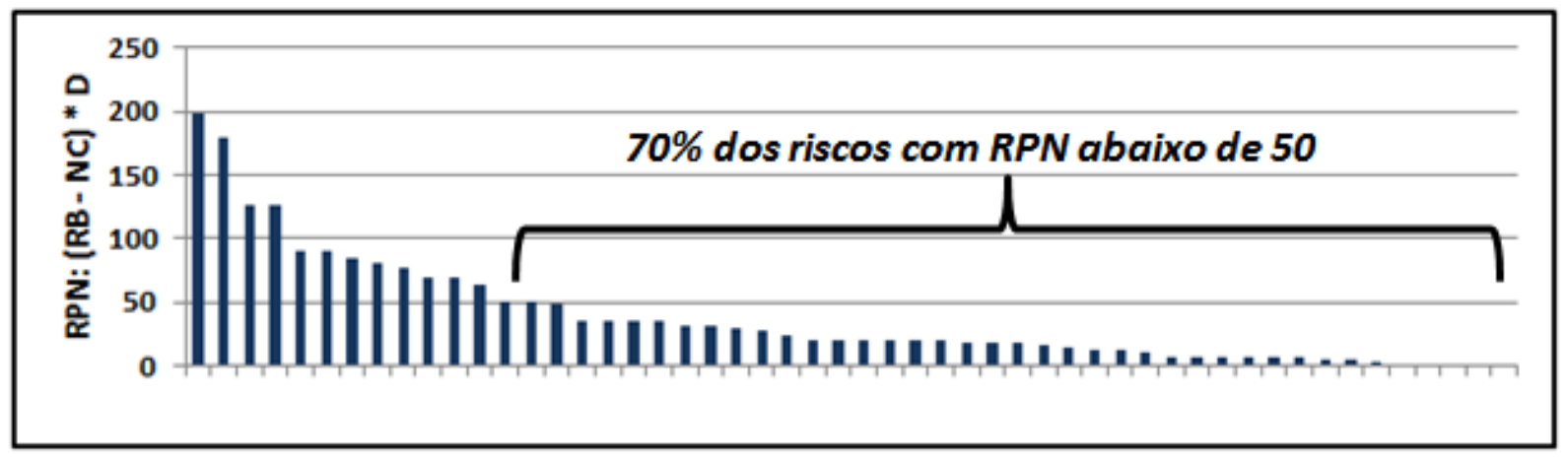

Gráfico 5.3 - Distribuição dos valores de prioridade (RPN) dos riscos identificados 
Conforme destacado no gráfico, aproximadamente $70 \%$ dos riscos (37 de 52) possuem valores de prioridade abaixo de 50. Sendo assim, partindo de um consenso entre os facilitadores e representantes da área gestora, este valor foi definido como ponto de corte para escolha dos riscos a serem priorizados para análise.

A título de comparação, o Gráfico 5.4 apresenta a visão geral dos riscos, conforme a pontuação final do RPN e dos riscos residuais, utilizando um modelo semelhante ao apresentado por [28].

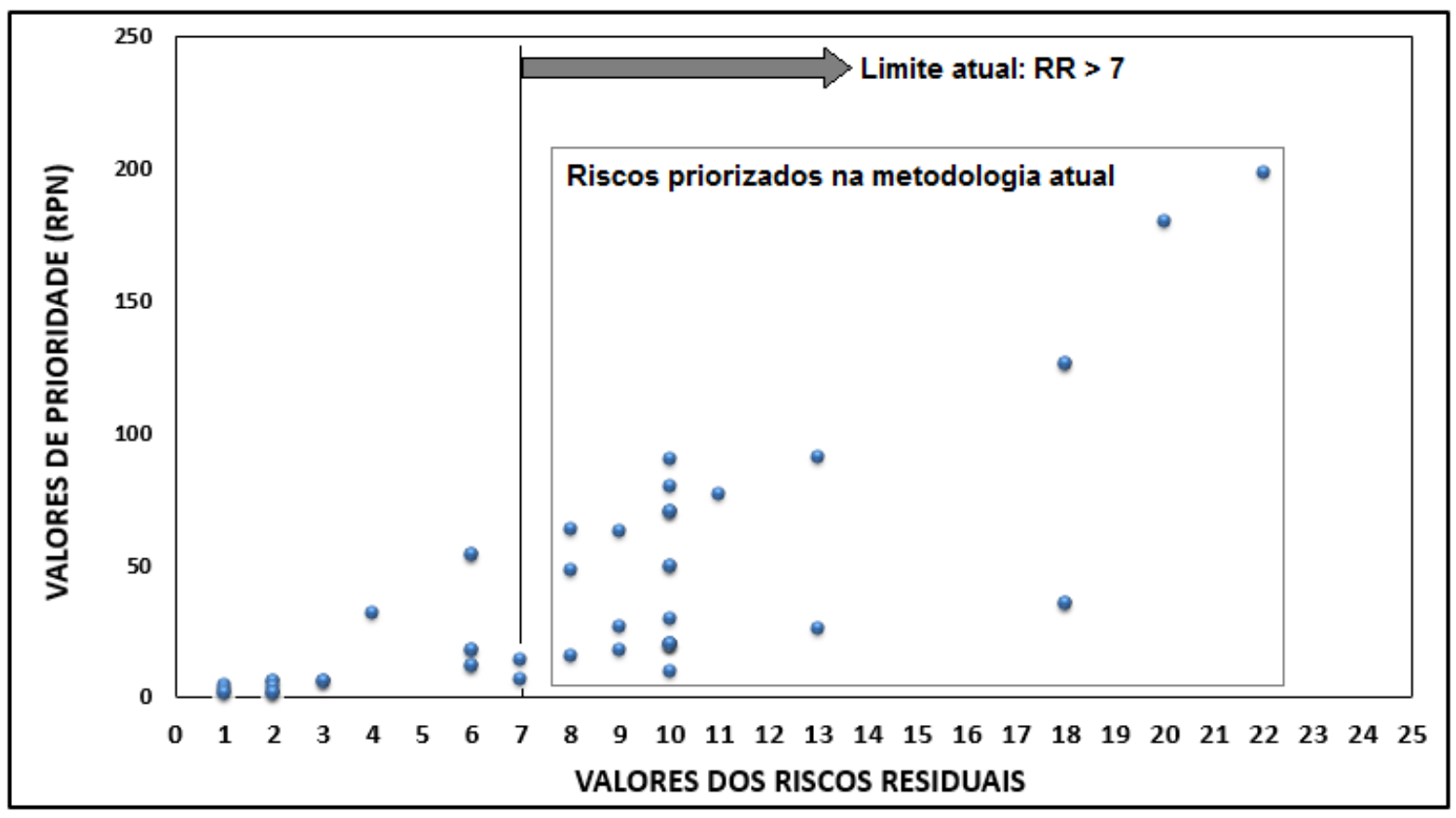

Gráfico 5.4: Riscos priorizados pela metodologia atual - pontuação RPN vs. Riscos Residuais

De acordo com o limite estabelecido na metodologia de autoavaliação atual, 30 dos 52 riscos deveriam ser priorizados para análise, pois apresentam o valor de Risco Residual acima de 7 .

No entanto, considerando o novo limite baseado no valor de RPN, ocorre uma redução na quantidade de riscos priorizados, conforme o Gráfico 5.5. 


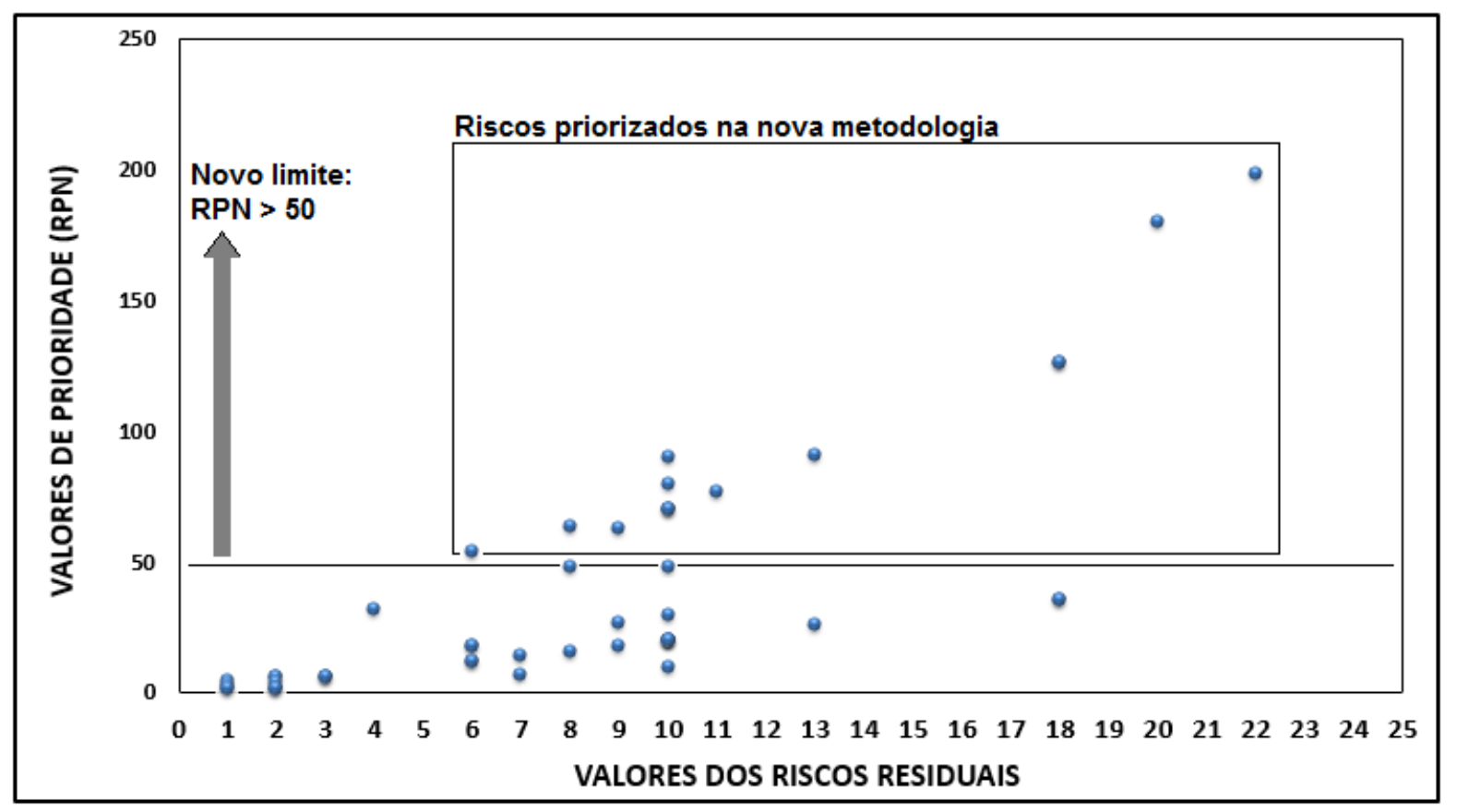

Gráfico 5.5: Riscos priorizados na nova metodologia - pontuação RPN vs. Riscos Residuais

Enquanto a metodologia anterior indicaria 30 riscos como passíveis de investigação, o novo modelo indicou que, destes, apenas 15 deveriam ser priorizados. Este resultado enfatiza a importância de tratamento dos riscos iminentes, que, além de possuírem uma alta criticidade, seriam mais difíceis de serem detectados. Vale mencionar o caso de dois riscos específicos, detalhados no Quadro 5.10.

\begin{tabular}{|c|c|c|c|c|c|c|c|c|c|c|c|}
\hline \multicolumn{12}{|c|}{ Processo RFMEA } \\
\hline Atividade & Risco Identificado & Categoria & 2 & - & $\approx$ & $\begin{array}{c}\text { Controles } \\
\text { Identificados }\end{array}$ & $\begin{array}{c}\text { Categorias } \\
\text { dos } \\
\text { Controles }\end{array}$ & z & $\stackrel{\varkappa}{\simeq}$ & a & $\underset{\underline{z}}{z}$ \\
\hline $\begin{array}{l}\text { 3. Envio e } \\
\text { recebimento } \\
\text { de guias ao } \\
\text { Núcleo de } \\
\text { Auditoria }\end{array}$ & $\begin{array}{l}\text { Não observância, pelo } \\
\text { analista de contas, dos } \\
\text { tipos de atendimentos a } \\
\text { serem encaminhadas para } \\
\text { avaliação do núcleo de } \\
\text { auditoria técnica. }\end{array}$ & $\begin{array}{l}\text { Pessoas - } \\
\text { Falha } \\
\text { Humana }\end{array}$ & 2 & 4 & 8 & $\begin{array}{l}\text { Critérios para } \\
\text { avaliação dos } \\
\text { tipos de } \\
\text { atendimentos } \\
\text { pelo núcleo de } \\
\text { auditoria } \\
\text { técnica }\end{array}$ & $\begin{array}{l}\text { Controle } \\
\text { Direto }\end{array}$ & 2 & 6 & 9 & 54 \\
\hline $\begin{array}{c}\text { 4. Efetuar } \\
\text { análise de } \\
\text { cobranças } \\
\text { médico- } \\
\text { hospitalares }\end{array}$ & $\begin{array}{l}\text { Processamento das guias } \\
\text { sem a crítica da Auditoria } \\
\text { in loco }\end{array}$ & $\begin{array}{l}\text { Pessoas - } \\
\text { Falha } \\
\text { Humana }\end{array}$ & 2 & 4 & 8 & $\begin{array}{l}\text { Atividade de } \\
\text { conferência de } \\
\text { contas médicas }\end{array}$ & $\begin{array}{l}\text { Controle } \\
\text { Básico }\end{array}$ & 2 & 6 & 9 & 54 \\
\hline
\end{tabular}

Quadro 5.10: Riscos indicados para tratamento, pela nova metodologia

Com a introdução do RPN, estes dois riscos, que antes eram considerados aceitáveis, passaram a ser indicados para tratamento, devido ao curto tempo de resposta disponível, evidenciado pelo seu valor de Detecção. 


\section{Monitoramento}

O resultado da análise foi encaminhado para avaliação da área gestora, que realizou os ajustes finais na documentação e retornou a versão final do relatório, contendo os resultados apresentados anteriormente. Conforme a metodologia, o tratamento dos riscos é realizado com a elaboração de um plano de ação para mitigar os riscos definidos como "inaceitáveis" no decorrer da avaliação, cabendo à área a definição de estratégias adicionais para evitar, transferir ou aceitar os riscos, conforme indicado por [43].

Entre as principais medidas de controle propostas pela área gestora, registradas no plano de ação que resultou da aplicação da metodologia, consta a definição de treinamentos periódicos, considerando as atividades desempenhadas pelos colaboradores. Estas atividades incluem a orientação as equipes responsáveis por cada etapa do processo, quanto à importância do cumprimento das instruções normativas da instituição.

O novo conjunto de controles abrangeu também a proposta de alterações de sistema, como a criação de grupos de segurança e a definição de acessos específicos a determinados campos e formulários, considerando o cargo e vínculo empregatício dos colaboradores envolvidos no processo de análise. Também foram propostas novas parametrizações com vistas a automatizar as etapas relacionadas à mudança de status de análise. Foi indicada a necessidade de geração de alertas para recebimento de cobranças em duplicidade e a inserção de controles de segregação de função, para evitar a alteração indevida de registros de sistema. Por fim, foi proposta a criação de relatórios automáticos de acompanhamento para assegurar o funcionamento e a eficácia das alterações, após sua entrada em produção.

Em uma futura análise do mesmo processo, ou seja, após nova aplicação da metodologia, a eficiência das medidas adotadas será evidenciada pela nova avaliação dos riscos identificados anteriormente, com o subsequente recálculo dos valores de risco residual e de prioridade. Na nova rodada, poderão ser propostas alterações nos controles instituídos inicialmente, ou a inclusão de novos controles visando a redução da probabilidade de ocorrência dos riscos e melhorias na detecção dos riscos iniciais. 


\subsection{Resultado - Risco priorizado para análise}

\section{quantitativa}

Após a avaliação do subprocesso análise de contas, foi identificado o risco de perdas associadas à cobrança excessiva de procedimentos médicos. O Quadro 5.11, abaixo, detalha as informações a respeito do risco específico levantado:

\begin{tabular}{|c|c|c|c|c|c|c|c|c|c|c|c|}
\hline \multicolumn{12}{|c|}{ Processo RFMEA } \\
\hline Atividade & $\begin{array}{c}\text { Risco } \\
\text { Identificado }\end{array}$ & Categoria & 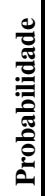 & 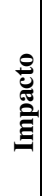 & 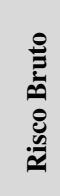 & $\begin{array}{c}\text { Controles } \\
\text { Identificados }\end{array}$ & $\begin{array}{l}\text { Categorias dos } \\
\text { Controles }\end{array}$ & 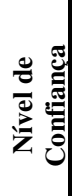 & 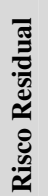 & 总 & 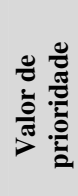 \\
\hline $\begin{array}{c}\text { Efetuar } \\
\text { análise das } \\
\text { cobranças } \\
\text { médico- } \\
\text { hospitalares }\end{array}$ & $\begin{array}{c}\text { Não detecção } \\
\text { de práticas } \\
\text { abusivas de } \\
\text { cobrança de } \\
\text { serviços } \\
\text { médico- } \\
\text { hospitalares }\end{array}$ & $\begin{array}{l}\text { Pessoas - } \\
\text { Falha } \\
\text { Humana / } \\
\text { Tecnologia - } \\
\text { Sistemas }\end{array}$ & 5 & 5 & 25 & $\begin{array}{c}\text { Relatórios } \\
\text { parametrizados e } \\
\text { apontamentos de } \\
\text { sistema }\end{array}$ & Controle Direto & 5 & 20 & 9 & 180 \\
\hline
\end{tabular}

Quadro 5.11: Detalhamento do risco de cobranças abusivas, levantado no decorrer da

$$
\text { avaliação }
$$

$\mathrm{Na}$ visão da área gestora, a probabilidade de perdas é exacerbada pela falta de controles automatizados ligados à avaliação comportamental das práticas de cobrança dos prestadores de serviços médico-hospitalares.

Nos próximos capítulos, são descritas as etapas para a construção deste modelo, os resultados obtidos e os próximos passos para o seu aprimoramento e aplicação em outros contextos que envolvam a análise comportamental de procedimentos médico-hospitalares. 


\section{Capítulo 6}

\section{Modelo para Identificação de Cobranças Excessivas em Consultas Médicas}

Conforme visto no capítulo anterior, a aplicação da metodologia de autoavaliação de riscos resultou no apontamento do risco crítico relacionado à não detecção de práticas abusivas de cobranças médico-hospitalares.

Devido ao fato de existir a possibilidade de análise dos gastos assistenciais, por meio da extração de dados da base de despesas da organização, este risco específico foi escolhido para tratamento por meio de técnicas de detecção de anomalias.

A oportunidade de avaliar os dados referentes às despesas assistenciais permitiu a construção de um modelo para o estudo de um tipo específico de prática abusiva que, a depender do seu resultado, poderia ser expandido para diversos outros tipos de procedimentos pagos pela operadora.

Para elaboração do modelo de tratamento do risco identificado, foi utilizado o arcabouço proposto pela metodologia CRISP-DM. A Figura 6.1 apresenta o passo a passo para sua construção. 


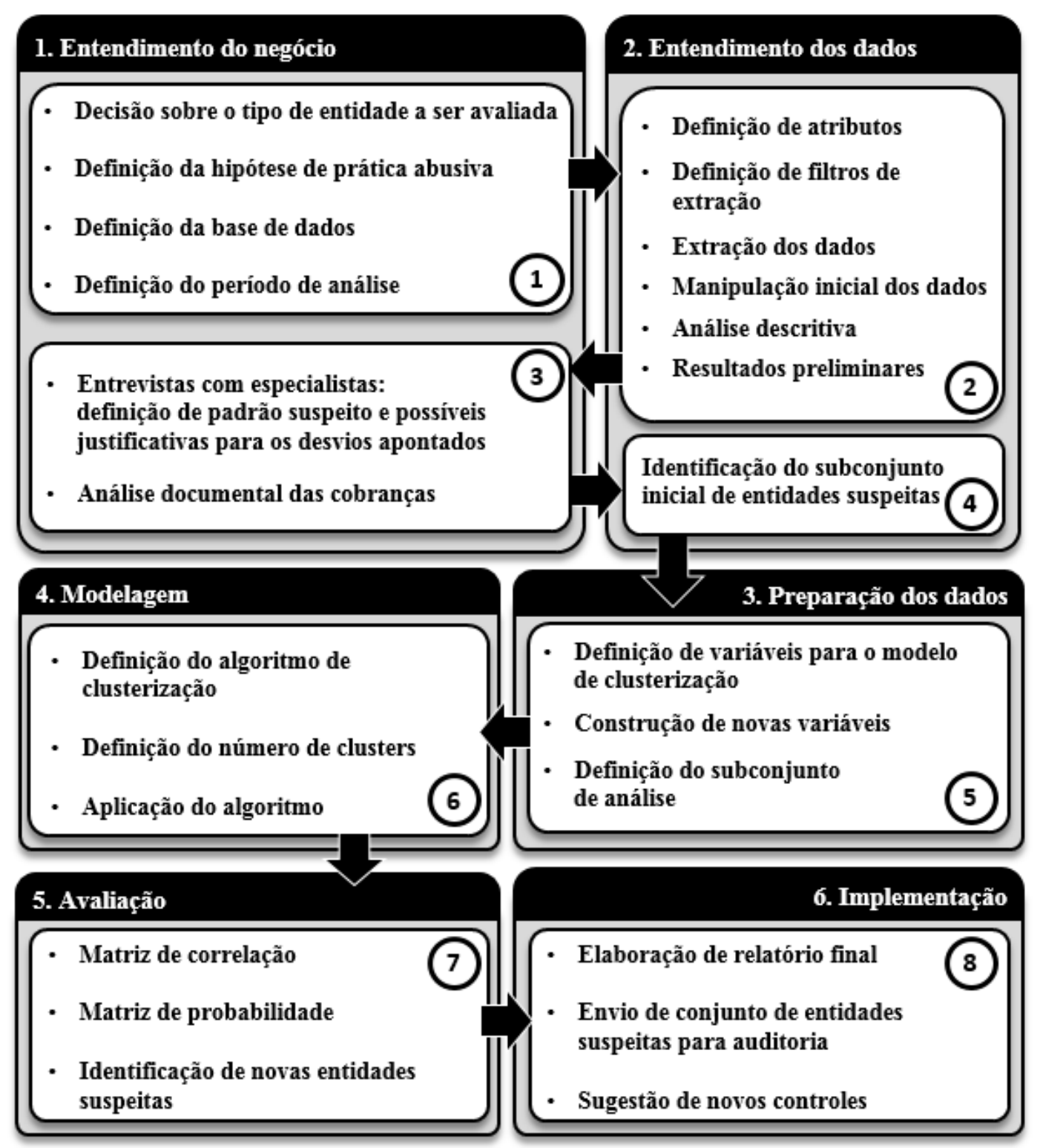

Figura 6.1: Etapas para criação do modelo de identificação de cobranças abusivas

A etapa de Entendimento do Negócio (etapa 1) abrange as atividades de definição da categoria de prestador e tipo especifico de inconsistência (prática abusiva) a serem investigados. Consequentemente, define-se a base de dados que contém as informações relevantes e o período de análise do estudo.

Em seguida, o Entendimento dos Dados (etapa 2) envolve a escolha dos atributos e filtros para a extração dos dados. A manipulação inicial está relacionada à descoberta dos primeiros conhecimentos específicos referentes aos dados analisados. Uma análise descritiva das cobranças resulta em um conjunto inicial de entidades 
suspeitas, que é encaminhado para análise técnica, encerrando a primeira parte desta atividade.

A investigação mais profunda das primeiras anomalias identificadas é feita por meio da consulta aos especialistas da área de saúde da OPS, de forma a definir o padrão suspeito de cobranças. É feita uma confirmação dos casos iniciais com a análise das cobranças físicas, pela área de pagamento de contas. Este esforço resulta no primeiro conjunto de entidades cujo comportamento anômalo foi confirmado (etapa 4).

Os conhecimentos obtidos na primeira fase da investigação são então utilizados para a construção do modelo baseado no uso de algoritmos de clusterização. Neste modelo, o objetivo é que o apontamento de prestadores suspeitos seja feito de forma automática, sem a necessidade de definir um limite de cobranças ou da consulta junto aos especialistas da área de saúde.

A preparação necessária para a construção do novo modelo abrange a manipulação dos dados (etapa 5) para construção das novas variáveis para clusterização. Dentre o conjunto de dados inicias, é definido um subgrupo de análise, contendo os registros com as maiores quantidades de cobrança.

$\mathrm{Na}$ atividade de Modelagem (etapa 6), define-se o algoritmo de clusterização a ser aplicado no subconjunto de dados definido na atividade anterior. Após o agrupamento dos registros pelo algoritmo, a etapa de Avaliação dos Resultados (etapa 7) envolve a verificação da correlação entre as variáveis em cada cluster, e o cálculo da probabilidade de que os dados do cluster priorizado para análise poderiam estar presentes nos demais agrupamentos.

$\mathrm{Na}$ atividade final, de Implementação, são compilados os resultados finais da análise, e sugeridos novos controles para a análise periódica e contínua, pela área gestora do processo, da hipótese de cobranças abusivas definida no estudo (etapa 8).

A seguir, apresenta-se a descrição detalhada de cada uma das atividades apontadas nos itens anteriores. 


\subsection{Entendimento do Negócio - definições iniciais}

Conforme visto na apresentação do processo de pagamento da OPS, dentre as atribuições da sua área de pagamento de contas encontra-se a avaliação de cobranças inconsistentes ou suspeitas. O processo envolve a recepção, análise e aprovação de cobranças (guias) apresentadas pelos prestadores de serviços que atendem a seus participantes. Estes prestadores podem ser classificados como instituições (pessoas jurídicas, como hospitais, laboratórios ou clínicas) ou pessoas físicas (médicos independentes e outros profissionais de saúde).

As cobranças, apresentadas por meio eletrônico ou físico, são primeiramente analisadas por um sistema de pagamento automatizado. Se uma inconsistência específica, pré-definida, for detectada (por exemplo, uma incompatibilidade entre o procedimento e o sexo do participante), o próprio sistema gera uma negação automática, que é então enviada para a validação manual, dependendo do custo do procedimento. Estas negativas de pagamento (ou glosas) podem ser revertidas ou mantidas, gerando uma negativa total ou parcial do valor cobrado pelo prestador de serviços.

No decorrer da revisão da literatura (item 3.3.3) foram verificadas diversas métricas passíveis de serem utilizadas na detecção de cobranças médicas inconsistentes. Dentre o conjunto de práticas abusivas encontra-se o cenário definido como "dia impossível", detalhado por [73]. São casos onde um prestador de serviços apresenta cobranças que, quando analisadas cuidadosamente, demonstram uma quantidade de serviços prestados superior ao limite máximo plausível dentro de um intervalo de 24 horas.

Por um lado, os prestadores de serviços de saúde classificados como "instituições", tais como hospitais e seus serviços relacionados, tipicamente possuem um quadro de profissionais suficiente para atender um alto número de participantes em um único dia. Por outro, os prestadores do tipo "pessoa física", tais como médicos e outros especialistas, possuem, em tese, limitações inerentes que impedem o atendimento de um grande número de participantes em um período de 24 horas.

Embora a operadora possua travas automáticas em seu sistema para o apontamento de cobranças excessivas decorrentes de um único paciente na mesma data, foi verificada a inexistência de controles parametrizados para avaliação da 
quantidade de diferentes indivíduos atendidos por um único prestador em uma determinada data. Isto ocorre devido ao fato de que as instituições (pessoas jurídicas) normalmente são capazes de atender dezenas ou centenas de participantes por dia. Estas entidades costumam ser o principal alvo das investigações, devido ao maior volume de despesas. Subsequentemente, menos ênfase é dada na investigação de prestadores individuais (pessoas físicas). A possibilidade da existência dessa lacuna foi um dos fatores que motivou a investigação deste tipo de prestador.

Outro fator que motivou a escolha de prestadores do tipo "pessoa física", como objeto do estudo, foi o fato de serem o maior grupo de prestadores dentro da rede credenciada da operadora, conforme verificado anteriormente, no item 4.2.1. Neste grupo, as despesas com consultas apresentam o maior valor envolvido. Por este motivo, este tipo de procedimento foi priorizado para análise.

Sendo assim, a segunda etapa deste estudo propõe apresentar um modelo para a análise comportamental de práticas de cobrança de prestadores do tipo "pessoa física", envolvendo consultas em consultório. Foram considerados os registros referentes a um período de 12 meses, especificamente entre janeiro e dezembro de 2013. Optou-se por avaliar este intervalo devido à possibilidade de extração dos dados do período junto à base de despesas assistenciais da organização.

\subsection{Entendimento dos Dados - resultados preliminares}

$\mathrm{Na}$ fase inicial de extração dos dados, optou-se pelos registros de cobrança dos prestadores sinalizadas como "pessoa física", devido aos motivos expostos no item anterior. Também foram selecionadas as entidades que apresentaram suas cobranças por meio do sistema de autorização eletrônica da organização. Esta ferramenta é utilizada para aprovar procedimentos médicos mais simples, e possui um registro de transações que permite verificar a data e hora exata do envio do pedido de autorização para cada procedimento.

Os dados extraídos consistiram em aproximadamente 1 milhão de registros de pagamento, envolvendo 12.758 prestadores e 359.388 pacientes que, entre janeiro e dezembro de 2013, apresentaram atendimentos de consulta com valor total de $\mathrm{R} \$$ 
66.134.441,02. Esse total representou, nesse período, cerca de metade de todas as despesas relacionadas aos prestadores do tipo "pessoa física".

Dois tipos específicos de consulta (consultas em consultório e consultas em pronto socorro) foram escolhidas para análise, pois além de representarem $99 \%$ das despesas envolvidas, são também procedimentos com características semelhantes de atendimento, o que facilita estimar o tempo médio de atendimento para cada evento.

No total, as despesas ligadas às consultas no período avaliado foram três vezes maiores do que a soma dos demais procedimentos (psicoterapia, fonoaudiologia e acupuntura, respectivamente), para os prestadores do tipo "pessoa física".

Os registros foram extraídos da base Oracle da instituição por meio de um script elaborado em SQL, e inseridos no software RStudio [92] para manipulação inicial. De 23 atributos iniciais, apresentados a seguir na Tabela 6.1, seis foram escolhidos para análise: Códigos identificadores dos participantes e prestadores, códigos da guia de cobrança, data de atendimento, quantidades e o valor pago.

\begin{tabular}{|c|c|c|}
\hline $\begin{array}{l}\text { Descrição } \\
\text { do atributo }\end{array}$ & $\begin{array}{l}\text { Escolhido } \\
(\mathrm{S} / \mathrm{N})\end{array}$ & Motivos para escolha (ou não) \\
\hline Código do participante & $\mathrm{S}$ & Necessário para identificação do participante \\
\hline Nome do participante & $\mathrm{N}$ & Identificação pode ser por meio do código \\
\hline Código do prestador & $\mathrm{S}$ & Necessário para identificação do prestador \\
\hline Nome do prestador & $\mathrm{N}$ & Identificação pode ser por meio do código \\
\hline Código de autorização & $\mathrm{N}$ & \multirow{3}{*}{ Podem ser localizados pelo código da guia } \\
\hline \# da carga de cobranças & $\mathrm{N}$ & \\
\hline \# do grupo de guias & $\mathrm{N}$ & \\
\hline Código da guia & $\mathrm{S}$ & Necessário para identificação da guia de cobrança \\
\hline Código de especialidade & $\mathrm{N}$ & \multirow{2}{*}{$\begin{array}{l}\text { Tipos e especialidades dos prestadores foram filtrados } \\
\text { na extração }\end{array}$} \\
\hline Tipo de prestador & $\mathrm{N}$ & \\
\hline Data de atendimento & $\mathrm{S}$ & Necessário para cálculo das qtdes. por dia \\
\hline Data de recebimento & $\mathrm{N}$ & \multirow{2}{*}{ Não foram consideradas no escopo da análise } \\
\hline Data de pagamento & $\mathrm{N}$ & \\
\hline Código do procedimento & $\mathrm{N}$ & \multirow{2}{*}{ Procedimentos foram filtrados na extração } \\
\hline Descr. do procedimento & $\mathrm{N}$ & \\
\hline Cód. do item de custo & $\mathrm{N}$ & \multirow{2}{*}{$\begin{array}{l}\text { Itens de custo são padronizados em procedimentos de } \\
\text { consulta }\end{array}$} \\
\hline Desc. do item de custo & $\mathrm{N}$ & \\
\hline Valor cobrado & $\mathrm{N}$ & \multirow{4}{*}{$\begin{array}{c}\text { A avaliação abordou apenas as quantidades e valores } \\
\text { pagos. }\end{array}$} \\
\hline Quantidade cobrada & $\mathrm{N}$ & \\
\hline Valor glosado & $\mathrm{N}$ & \\
\hline Quantidade glosada & $\mathrm{N}$ & \\
\hline Valor pago & $\mathrm{S}$ & \multirow{2}{*}{ Necessário para cálculo de quantidades envolvidas } \\
\hline Quantidade paga & $S$ & \\
\hline
\end{tabular}

Tabela 6.1: Atributos considerados na análise

Inicialmente, para a definição da quantidade de atendimentos por prestador, por dia, todos os registros de cobrança foram agrupados pelo código do prestador e 
data de atendimento, somando, em cada grupo, os totais de quantidade de serviço e valor pago.

Em seguida, foi desconsiderado o valor pago, pois constatou-se que o valor individual das consultas encontrava-se contratualmente padronizada para quase todos os prestadores, apresentando o mesmo valor unitário, com poucos desvios. Os registros foram então agrupados por prestador, código de procedimento e datas de atendimento, somando os totais das quantidades de atendimento em cada data. Este resultado inicial resultou em um conjunto de 623.931 registros.

Uma análise estatística preliminar neste conjunto, considerando o campo "atendimentos por dia", revelou uma distribuição relativamente distorcida, conforme a Tabela 6.2 .

\begin{tabular}{c|c}
\hline $\begin{array}{c}\text { Intervalos } \\
\text { (Atendimentos por dia) }\end{array}$ & $\begin{array}{c}\text { Qtde. de registros de } \\
\text { cobrança }\end{array}$ \\
\hline$[0,10)$ & $\mathbf{6 2 0 . 9 7 5}$ \\
\hline$[10,20)$ & $\mathbf{2 . 6 4 2}$ \\
\hline$[20,30)$ & $\mathbf{2 5 7}$ \\
\hline$[30,40)$ & $\mathbf{5 1}$ \\
\hline$[40,50)$ & $\mathbf{7}$ \\
\hline$[50,60)$ & $\mathbf{5}$ \\
\hline$[60,70)$ & $\mathbf{2}$ \\
\hline$[70,80)$ & $\mathbf{1}$ \\
\hline$[80,90)$ & $\mathbf{0}$ \\
\hline$[90,100)$ & $\mathbf{1}$ \\
\hline TOTAL & $\mathbf{6 2 3 . 9 3 1}$ \\
\hline
\end{tabular}

Tabela 6.2: Distribuição do campo "Atendimentos por dia" dos prestadores

Conforme a Tabela 6.2, foram verificadas quantidades de consulta por dia superiores a 50 para alguns prestadores, sendo que um dos casos envolveu o total de 93 consultas por dia.

Uma hipótese inicial seria que, quanto maior o número de consultas em um único dia, maior o risco de existirem cobranças suspeitas. Neste caso, seria necessário definir um limite preliminar, mesmo que subjetivo, para uma investigação mais aprofundada. 


\subsection{Entendimento do Negócio - análise do conjunto inicial}

Após entrevistas com médicos especialistas, chegou-se a alguns padrões simples, como uma jornada de 8 horas e intervalo de 15 minutos entre as consultas, o que resultou em uma quantidade máxima de 32 atendimentos por dia.

Evidentemente que, nesta estimativa, não seriam consideradas folgas ou o simples fato de que os profissionais médicos geralmente destinam menos de 8 horas por dia para consultas médicas.

De qualquer forma, foram analisados os registros de autorização eletrônica referentes a algumas das maiores cobranças. De fato, como mostra a Figura 6.2, havia motivos para suspeitar da existência de práticas abusivas. Para um dos prestadores, conforme registrado pelo sistema no $\log$ do autorizador eletrônico externo, em uma data específica 55 cobranças foram submetidas entre $10 \mathrm{~h} 33 \mathrm{~m}$ e $11 \mathrm{~h} 29 \mathrm{~m}$. O intervalo médio entre as cobranças foi de aproximadamente 30 segundos.

\begin{tabular}{|l|c|}
\multicolumn{1}{c|}{ Data da cobrança: } & $13 / 12 / 2013$ \\
\cline { 2 - 2 } \multicolumn{1}{c|}{} & Horário \\
\hline Atendimento 01 & $11: 28: 38$ \\
\hline Atendimento 02 & $11: 29: 00$ \\
\hline Atendimento 03 & $11: 29: 25$ \\
\hline
\end{tabular}

Figura 6.2: Exemplo de registro de cobrança suspeita

Inicialmente, verificou-se que 18 dos 12.758 prestadores ultrapassaram o limite de 32 consultas por dia. Seus registros foram encaminhados para uma investigação mais aprofundada, que envolveu a análise das guias físicas de cobrança, verificando se havia a existência de assinaturas do participante e rasuras nos campos do formulário. Os supostos motivos para as consultas também foram verificados, assim como aquelas que ocorrem em feriados ou fins de semana.

Após a avaliação, constatou-se que em 11 dos 18 prestadores inicialmente suspeitos, as cobranças excessivas foram submetidas aparentemente sem justificativas. Os resultados da análise inicial são apresentados na Tabela 6.3. 


\begin{tabular}{c|c|c|c}
\hline & $\begin{array}{c}\text { Qtde. } \\
\text { Prestadores }\end{array}$ & Qtde. Registros & Valor Pago \\
\hline $\begin{array}{c}\text { Conjunto de dados } \\
\text { iniciais }\end{array}$ & 12.758 & 1.098 .693 & $66.134 .441,02$ \\
\hline $\begin{array}{c}\text { Acima do limite de } \\
\text { 32/dia }\end{array}$ & 18 & 39 (acima do limite) & $\begin{array}{c}103.588,00 \\
\text { (nos registros acima do limite) }\end{array}$ \\
\hline $\begin{array}{c}\text { Suspeitos } \\
\text { confirmados }\end{array}$ & 11 & 1.289 (total envolvido) & $\begin{array}{c}596.641,50 \\
\text { (total envolvido) }\end{array}$ \\
\hline
\end{tabular}

Tabela 6.3: Resultados da Análise Inicial - Cobranças excessivas em consultas

O valor total envolvido nos 11 prestadores com inconsistências confirmadas, de $\mathrm{R} \$ 303,687,50$, representa cerca de $50 \%$ do total pago para o conjunto de 18 prestadores separados para análise.

Contudo, a avaliação de todas as incidências de pagamentos acima da média tornou-se muito ineficiente, por dois motivos. Em primeiro lugar, a natureza relativamente subjetiva utilizada para definir o intervalo máximo diário significou que todos os fornecedores que apresentaram quantidades de pagamentos por dia abaixo do limite inicial de 32 por dia seriam excluídos da análise. Em contrapartida, o grupo de suspeitos confirmados contou com apenas 11 dos 18 prestadores apontados inicialmente.

Adicionalmente, a avaliação inicial dos registros de cobranças físicas revelou uma série de possíveis justificativas para a cobrança de quantidades elevadas de procedimentos por dia. Como exemplo, devido a falhas operacionais ou mera conveniência, as cobranças mensais ou semanais poderiam estar sendo cobradas apenas no final de cada período, sendo o campo "data de atendimento", em todas as guias, preenchido com uma única data. Embora tecnicamente incorreta, esta prática não seria considerada abusiva, pois de fato os serviços teriam sido prestados.

Outra possibilidade, sugerida pelos especialistas da área de saúde, seria a existência de programas assistenciais oferecidos pela OPS (como exames periódicos para os funcionários da empresa) em que um prestador de fato seria contratado para atender vários participantes em um único dia.

Em ambos os cenários, o comportamento padrão em um determinado período seria de trechos de cobrança "normais" pontuados por "picos" anormais de atendimentos.

Sendo assim, definiu-se por acrescentar novas variáveis no conjunto inicial de dados, a fim de se construir um modelo multivariado, capaz de definir, de forma 
automática e objetiva, o ponto de corte para análise, reduzindo a incidência de falsospositivos e falsos-negativos.

\subsection{Preparação dos dados}

Somada à variável existente de "quantidade de participantes atendidos no dia específico" (QTE_POR_DIA), considerou-se também as variáveis "número de participantes atendidos no mês do registro" (QTE_POR_MES), e "quantidade de dias com cobranças no mês" (DIAS_POR_MES). As novas variáveis serviriam para ponderar cada registro, de forma a priorizar os prestadores que apresentassem uma combinação de:

a) grande número de consultas em uma data específica;

b) maior frequência de atendimentos no mesmo mês e

c) elevado número de participantes distintos atendidos no período.

Conforme a análise da distribuição dos atendimentos, verificado anteriormente na Tabela 10, cerca de 99,6\% dos registros estavam relacionados a quantidades de 10 ou menos participantes por dia, para cada prestador de serviço. Para o campo QTE_POR_DIA, foram calculadas a média $(1,73)$ e o desvio padrão $(1,48)$. Considerando estes parâmetros, foram calculados os valores de três e seis desviospadrão da média, que poderiam servir como limites para redução do conjunto de dados, de forma a se considerar apenas os valores mais distantes da média (e, por consequência, mais prováveis de estarem ligados a cobranças excessivas).

Verificado o valor de seis desvios-padrão do atributo, de 10,6, este parâmetro foi utilizado como limite para estabelecer um ponto de corte para a análise, de 10 consultas por dia. Foram consideradas as seguintes justificativas para este limite:

a) O fato de que uma quantidade de 10 consultas por dia ainda estaria dentro do aceitável para um prestador do tipo "pessoa física", e o novo subconjunto ainda contemplaria todos os valores acima deste ponto de corte; e

b) Redução do tempo de processamento associado ao número de registros, pois o novo subconjunto continha apenas 2.147 registros, ou aproximadamente $0,3 \%$ dos cerca de 635.000 iniciais.

Iniciou-se então um estudo mais aprofundado deste subgrupo, por meio da análise de clusters utilizando o algoritmo K-means, descrito anteriormente. 


\subsection{Modelagem}

$\mathrm{Na}$ fase de modelagem, o número de clusters foi determinado por meio da soma dos quadrados, ou método de "cotovelo" [110]. Este método consiste em avaliar, para diferentes quantidades de clusters, a soma dos quadrados em cada agrupamento. É escolhido o ponto de maior variação na soma de cada cluster.

No caso avaliado, a maior "queda" utilizando os dados normalizados é vista após 4 clusters, conforme a Figura 6.3. Consequentemente, este foi o número de clusters escolhido para construção do modelo.

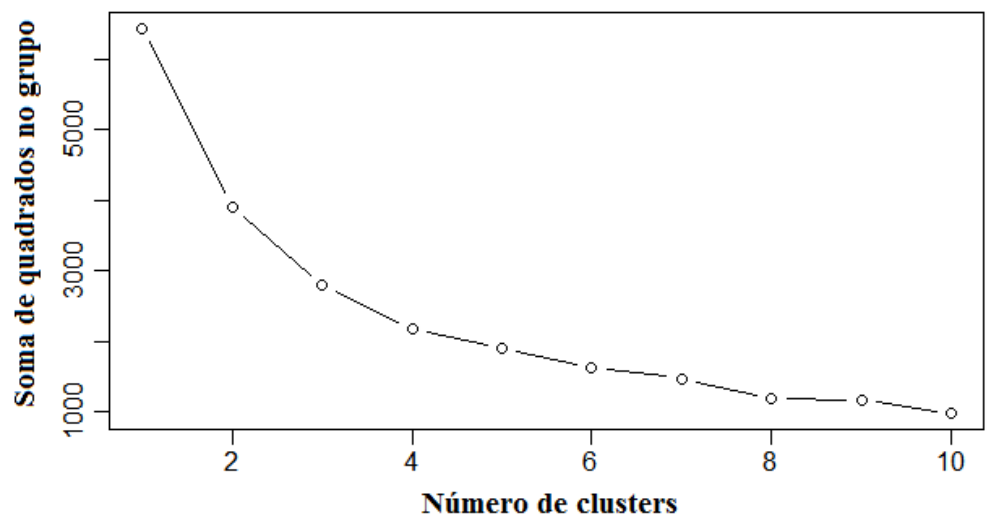

Figura 6.3: Número de clusters (4) definido por meio da técnica do "cotovelo"

A análise de clusters resultou em quatro grupos, subdividindo o conjunto de análise, que inicialmente continha 2.147 elementos, em clusters de 741, 944, 178 e 284 registros, respectivamente.

A Figura 6.4 apresenta a visão de cada cluster no conjunto de dados, considerando inicialmente a comparação entre as variáveis "quantidade de participantes atendidos no dia específico" (QTE_POR_DIA) e "quantidade de dias com cobranças no mês" (DIAS_POR_MES). 


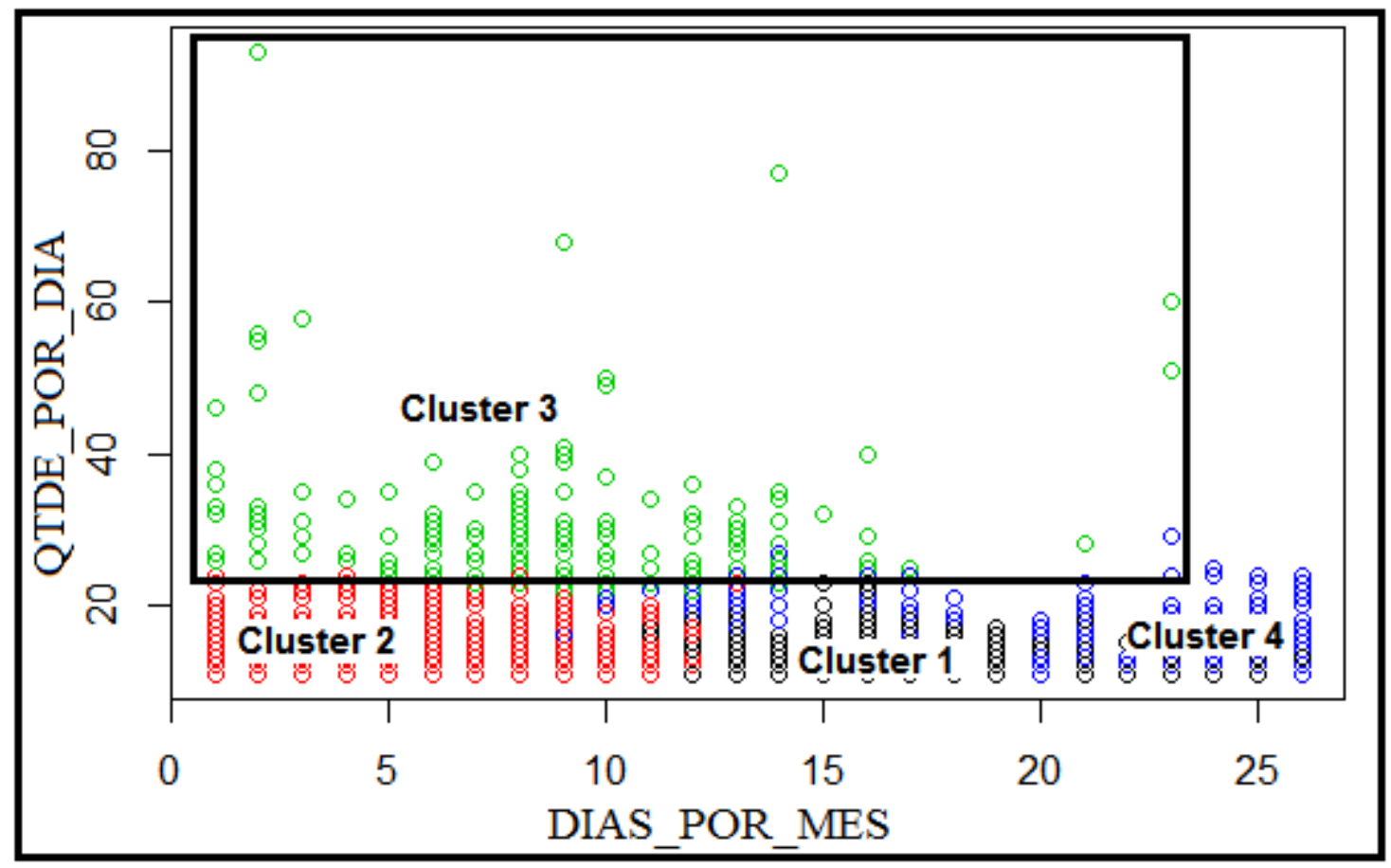

Figura 6.4: Resultados da análise de clusters: QTDE_POR_DIA x DIAS_POR_MES

Visualmente, é evidente que o terceiro cluster agrupou os valores extremos relacionados à variável QTE_POR_DIA, predominantemente envolvendo registros com 20 ou mais atendimentos por dia. Neste cluster houve também a preponderância de registros cuja quantidade de dias com atendimentos, no mês, é de até 15 . Os demais clusters 1,2 e 4 possuem agrupamentos distintos de registros referentes à variável DIAS_POR_MES, porém todos concentram registros com 20 ou menos atendimentos por dia.

Na Figura 6.5, visualiza-se os agrupamentos dos registros quando consideradas as variáveis "quantidade de participantes atendidos no dia específico" (QTE_POR_DIA) e "número de participantes atendidos no mês do registro" (QTE_PACIENTES_POR_MES). 


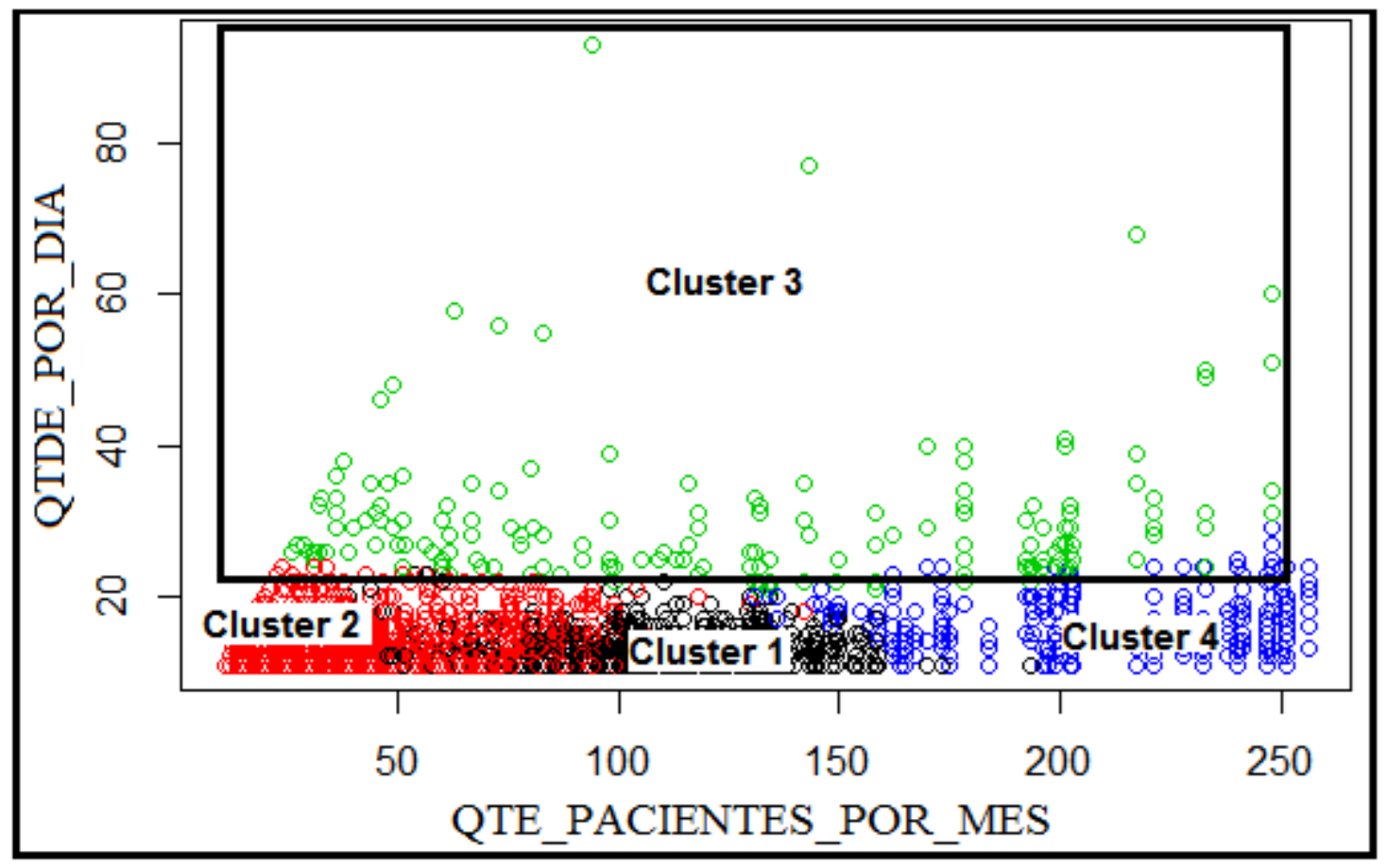

Figura 6.5: Resultados da análise de clusters: QTDE_POR_DIA x QTDE_PACIENTES_OR_MES

Assim como na Figura 39, verifica-se que o cluster 03 agrupou registros que, na sua maioria, possuem 20 ou mais atendimentos por dia. Entretanto, há uma maior dispersão em relação aos registros referentes à variável "número de participantes atendidos no mês do registro" (QTE_POR_MES). O cluster 02 concentra registros com 100 ou menos pacientes por mês e o cluster 04, na sua maioria, registros com mais de 150 pacientes, sendo que os registros entre estes intervalos foram agrupados pelo cluster 01 .

A relação entre as variáveis no conjunto inicial em ambos os clusters é discutida detalhadamente na fase de Avaliação, a seguir. 


\subsection{Avaliação - Validação de Clusters}

A primeira etapa no procedimento de validação foi verificar o desempenho do algoritmo, em termos da capacidade de detectar corretamente os registros inicialmente identificados como suspeitos.

A Tabela 6.4, a seguir, mostra que foi possível atribuir ao Cluster 03 todos os registros inicialmente rotulados como suspeitos, ligados aos 18 prestadores investigados no modelo anterior.

\begin{tabular}{|c|c|c|c|c|}
\hline Cluster & $\begin{array}{c}\text { Qtde. } \\
\text { Registros }\end{array}$ & Classe inicial & $\begin{array}{c}\text { Qtde. registros } \\
\text { por classe }\end{array}$ & $\begin{array}{c}\text { Qtde. de } \\
\text { prestadores }\end{array}$ \\
\hline Cluster 1 & 741 & \multirow{2}{*}{$\begin{array}{c}\text { Abaixo do limite } \\
\text { de 32/dia }\end{array}$} & 741 & 121 \\
\hline Cluster 2 & 944 & & 944 & 273 \\
\hline \multirow[t]{2}{*}{ Cluster 3} & \multirow[t]{2}{*}{178} & $\begin{array}{l}\text { Acima do limite } \\
\text { de 32/dia }\end{array}$ & 39 & $\begin{array}{c}18 \text { (todos os } \\
\text { suspeitos } \\
\text { iniciais) }\end{array}$ \\
\hline & & \multirow{2}{*}{$\begin{array}{l}\text { Abaixo do limite } \\
\text { de } 32 / \text { dia }\end{array}$} & 139 & 36 \\
\hline Cluster 4 & 284 & & 284 & 18 \\
\hline
\end{tabular}

Tabela 6.4: Qtde. de registros e prestadores em cada cluster

Adicionalmente, foram atribuídos ao mesmo cluster os registros de outros 36 prestadores que não haviam sido encaminhados para investigação, pois suas cobranças não haviam ultrapassado o limite de 32 atendimentos por dia.

Pelo fato da análise ser realizada a nível de registro, alguns prestadores poderiam estar relacionados a mais de um cluster. Contudo, nenhum registro dos 18 prestadores suspeitos foi localizado nos demais agrupamentos, além do Cluster 03.

Para cada agrupamento, o grau de dispersão das variáveis pode ser verificado por meio do seu desvio padrão. Quanto menor o desvio, melhor o desempenho do modelo em agrupar as variáveis semelhantes em grupos distintos. Um alto desvio padrão pode significar que o agrupamento contém uma quantidade maior de outliers.

Esta medida foi calculada para as variáveis de cada cluster, juntamente com os suas médias, como uma forma de medir tanto a dispersão dos pontos quanto o número de fatores de risco em cada cluster (Tabela 6.5), sendo este modelo aplicado também por [54]. 


\begin{tabular}{c|c|c|c|c|c|c}
\hline & \multicolumn{2}{|c|}{$\begin{array}{c}\text { Qtde. de pacientes } \\
\text { no dia }\end{array}$} & \multicolumn{2}{c|}{$\begin{array}{c}\text { Qtde. de dias } \\
\text { com atendimentos } \\
\text { (no mês) }\end{array}$} & \multicolumn{2}{c}{$\begin{array}{c}\text { Qtde. de pacientes } \\
\text { atendidos no mês }\end{array}$} \\
\cline { 2 - 7 } & média & desv. pad. & média & desv. pad. & média & desv. pad. \\
\hline Inicial & 15.14 & 6.07 & 11.77 & 6.23 & 98.02 & 61.53 \\
\hline Cluster 1 & 12.81 & 2.16 & 16.05 & 3.08 & 108.37 & 27.06 \\
\hline Cluster 2 & 13.81 & 3.06 & 6.64 & 3.10 & 50.93 & 25.81 \\
\hline Cluster 3 & 30.12 & 9.64 & 8.86 & 4.27 & 127.37 & 65.87 \\
\hline Cluster 4 & 16.27 & 3.90 & 19.48 & 5.00 & 209.18 & 35.31 \\
\hline
\end{tabular}

Tabela 6.5: resultados da clusterização: média e desvio padrão

Conforme destacado na Tabela 13, os resultados revelaram que o terceiro cluster, com 178 registros ( $8 \%$ dos 2.147 registros do conjunto total), continha o maior fator de risco (média) na variável de "quantidade de dias por mês". No mesmo agrupamento, o alto desvio padrão denota a presença de um maior número de outliers.

Também é de interesse que o Cluster 04, contendo a segunda maior média na mesma variável, também apresenta as maiores médias nas variáveis de dias e participantes por mês.

Com base nestes resultados preliminares, seria possível sugerir uma abordagem investigativa que priorizasse a análise de registros presentes nos agrupamentos com os maiores valores de risco (neste caso, justamente os Clusters 03 e 04).

Uma análise semelhante considerou a correlação entre cada variável, tanto no grupo "não-clusterizado" quanto em cada um dos clusters, conforme a Tabela 6.6. O cálculo da correlação é realizada por meio da função cor() do R, onde o coeficiente tau de Kendall é usado para estimar as medidas baseadas no grau de associação entre as variáveis [18].

\begin{tabular}{|c|c|c|c|}
\hline & & QTE_POR_DIA & DIAS_POR_MES \\
\hline \multirow{3}{*}{ Inicial } & QTE_POR_DIA & 1.0 & -0.12 \\
\hline & DIAS_POR_MES & -0.12 & 1.0 \\
\hline & QTE_PACIENTES_POR_MES & 0.21 & 0.71 \\
\hline \multirow{3}{*}{$\begin{array}{c}\text { Cluster } \\
1\end{array}$} & QTE_POR_DIA & 1.0 & -0.16 \\
\hline & DIAS_POR_MES & -0.16 & 1.0 \\
\hline & QTE_PACIENTES_POR_MES & 0.01 & 0.15 \\
\hline \multirow{3}{*}{$\begin{array}{c}\text { Cluster } \\
2\end{array}$} & QTE_POR_DIA & 1.0 & -0.08 \\
\hline & DIAS_POR_MES & -0.08 & 1.0 \\
\hline & QTE_PACIENTES_POR_MES & $\mathbf{0 . 0 3}$ & 0.44 \\
\hline \multirow{3}{*}{$\begin{array}{c}\text { Cluster } \\
3\end{array}$} & QTE_POR_DIA & 1.0 & -0.09 \\
\hline & DIAS_POR_MES & -0.09 & 1.0 \\
\hline & QTE_PACIENTES_POR_MES & 0.04 & 0.65 \\
\hline \multirow{3}{*}{$\begin{array}{c}\text { Cluster } \\
4\end{array}$} & QTE_POR_DIA & 1.0 & -0.20 \\
\hline & DIAS_POR_MES & -0.20 & 1.0 \\
\hline & QTE_PACIENTES_POR_MES & 0.11 & 0.35 \\
\hline
\end{tabular}

Tabela 6.6: matriz de correlação entre as variáveis clusterizadas 
No resultado desta análise, verifica-se uma correlação mais forte entre as variáveis DIAS_POR MES e QTE_PACIENTES_POR MES. Este resultado faz sentido, considerando que um número maior de pacientes tende a corresponder a uma maior quantidade de consultas. Neste caso, o Cluster 03 apresenta a maior pontuação entre as demais.

A correlação negativa entre as variáveis QTE_POR_DIA e DIAS_POR_MES sugere que as maiores quantidades de atendimento então distribuídas em um pequeno número de dias por mês. Em todos os casos, verificou-se uma correlação fraca entre as variáveis QTE_POR_DIA e QTE_PACIENTES_POR_MES.

Por fim, o comando pnorm da ferramenta $\mathrm{R}$ foi usado para a construção de uma função de distribuição cumulativa, a fim de descobrir a probabilidade de que um valor médio de uma variável no Cluster 03, que apresenta os maiores valores da variável QTE_POR_DIA, poderia pertencer aos demais agrupamentos. Nesse caso, define-se "pertencer" no sentido de apresentar parâmetros semelhantes aos dos outros conjuntos. Uma probabilidade baixa poderia sugerir um melhor agrupamento dos valores neste conjunto, confirmando a eficiência do algoritmo. A Tabela 6.6 apresenta o resultado desta análise.

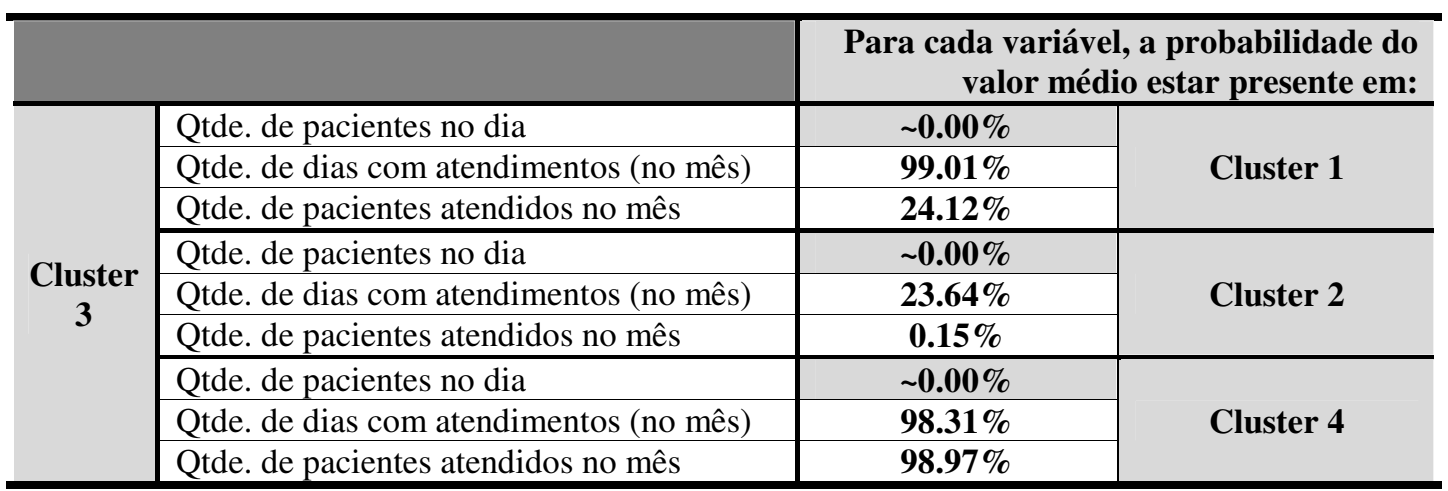

Tabela 6.6: matriz de probabilidade - probabilidade de que as variáveis do cluster 03 poderiam existir nos demais clusters

Conforme as células destacadas na Tabela 15, os valores da variável "Qtde. de pacientes no dia" do Cluster 03 (que possui, neste cluster, uma média de 30,12 e desvio padrão de 3,06 ) possuem $0 \%$ de probabilidade de estarem presentes nos demais grupos.

Quanto às variáveis "Qtde. de dias com atendimentos (no mês)" e "Qtde. de pacientes atendidos no mês", o Cluster 03 se assemelha ao Cluster 04, o que é 
evidenciado pela alta probabilidade de elementos com as mesmas características existirem naquele agrupamento.

\subsection{Implementação e Resultados}

Após avaliar os resultados do modelo de agrupamento, foi possível sugerir a priorização da análise dos registros pertencentes aos Clusters 03 e 04, pois demonstraram incidências maiores de fatores de risco e uma baixa probabilidade de serem confundidos com registros "normais" de atendimento, em comparação com o agrupamento dos outros clusters.

Como resultado da avaliação inicial das cobranças, houve a identificação de um conjunto de 11 prestadores cuja análise documental revelou inconsistências nas quantidades cobradas no decorrer do ano de 2013.

A carência de profissionais em suas respectivas regiões não permitiu a definição de medidas adicionais além do acompanhamento de suas cobranças. Entretanto, foi sugerido à área gestora que o efeito das investigações realizadas, que envolveram inclusive o contato aos prestadores para solicitação de comprovantes de atendimento, fosse verificado nas cobranças subsequentes.

Para fins de monitoramento, foi sugerida a avaliação semestral dos registros de cobrança deste tipo de procedimento, de forma a identificar novas entidades suspeitas e avaliar a comportamento dos prestadores já avaliados - tanto aqueles que foram investigados e cuja suspeita for confirmada, quanto os que apresentaram justificativas plausíveis para as quantidades solicitadas.

\subsection{Discussão dos Resultados}

Alguns resultados promissores foram obtidos por meio da análise de clusters, fornecendo uma direção para um estudo mais aprofundado dos dados de cobrança, permitindo uma melhor alocação dos escassos recursos humanos e tempo disponíveis para a auditoria de registros suspeitos. Os novos casos apontados nos Clusters 03 e 04 foram encaminhados para auditoria preliminar. Espera-se utilizar casos confirmados de abuso como pontos de partida para uma abordagem supervisionada [101] do conjunto de dados. 
No sentido de evoluir com esta análise, foram determinados os próximos passos como sendo o teste das variáveis criadas com outros algoritmos de clusterização, assim como a extração de um novo conjunto de dados, a fim de avaliar o desempenho do novo modelo de análise proposto. 


\section{Capítulo 7}

\section{Modelo para Identificação de Cobranças}

\section{Excessivas em Terapias Seriadas}

No decorrer das análises realizadas nos atendimentos ligados a procedimentos de consulta, foi levantada a hipótese da existência de cobranças excessivas também em atendimentos relacionados a procedimentos de tratamento seriado, como psicoterapias, fisioterapias, acupunturas e outros.

Estes tipos de procedimento, conforme exposto anteriormente no item 4.2.1, compõem o segundo maior grupo de despesas relacionadas aos prestadores classificados como "pessoa física", objetos do estudo.

Desta forma, este grupo de atendimentos foi escolhido para análise, por diversos motivos. Primeiramente, este estudo permitiria validar a eficiência da aplicação do modelo de clusterização em um segundo grupo de procedimentos, que possuem características distintas, como a necessidade de autorização prévia para realização e o fato de serem de natureza contínua (um tratamento típico envolve múltiplas sessões). Em segundo lugar, a recorrência dos atendimentos envolvendo o mesmo participante e prestador permitiria também a sua análise sobre outro aspecto: a avaliação da qualidade e frequência efetiva dos atendimentos baseada em entrevistas diretas junto aos participantes. Finalmente, as sessões de tratamento seriado tipicamente possuem duração mais longa do que uma simples consulta em consultório, o que facilitaria apontar casos de anomalias relacionadas a quantidades diárias de atendimentos. 
Com base nestas características, o modelo de análise necessitou de alguns ajustes, destacados na Figura 7.1.

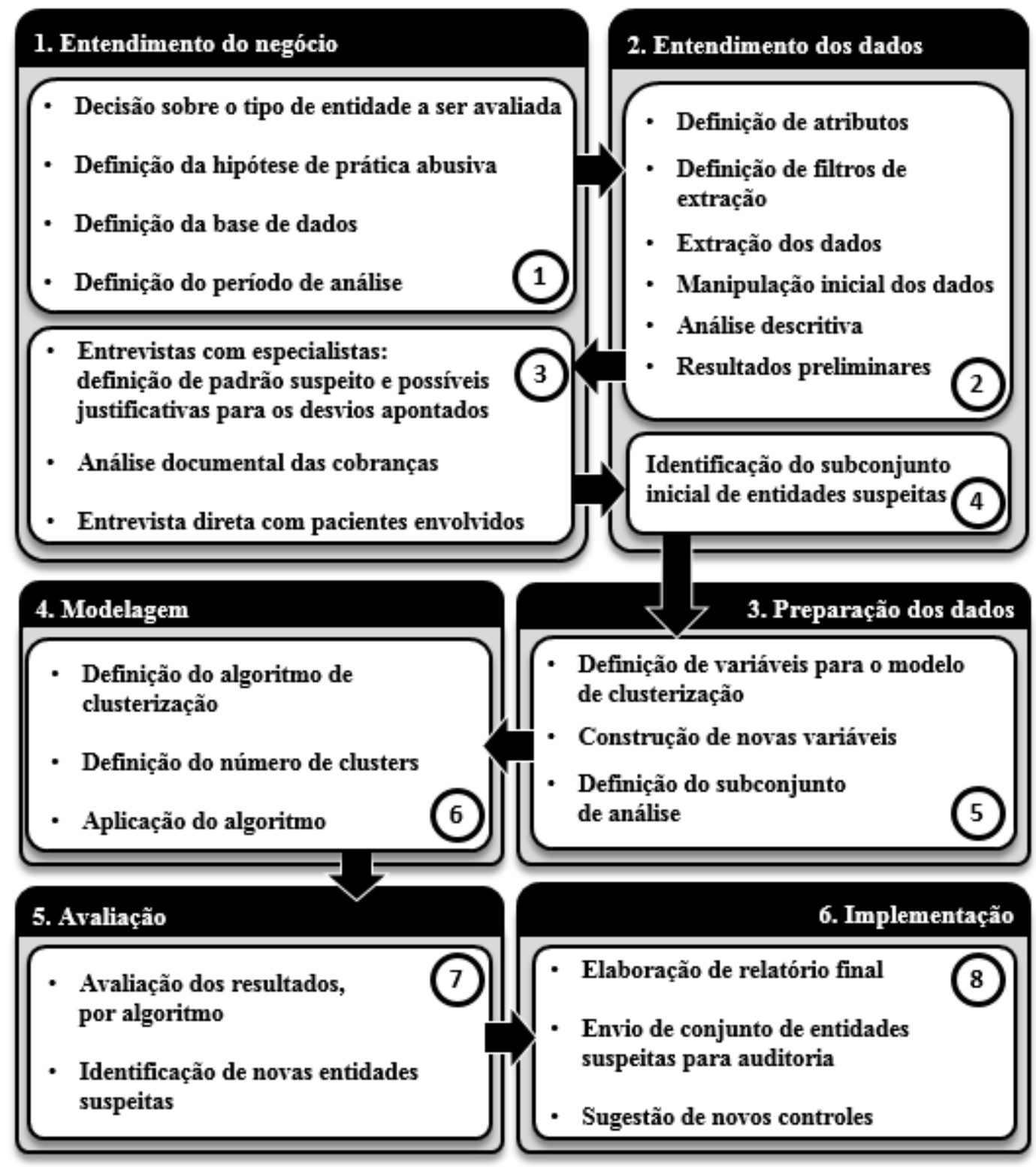

Figura 7.1: Modelo de análise, por clusterização, de terapias seriadas

A primeira alteração proposta no modelo, conforme (3), é a inclusão da atividade de entrevista direta juntos aos pacientes envolvidos, na etapa de Entendimento do Negócio. Pelo fato de tipicamente ocorrerem várias sessões entre um paciente e o prestador de serviços, a consulta direta junto aos pacientes possibilitaria verificar diversos fatores ligados a entidades suspeitas, como a frequência efetiva dos atendimentos (informação que serviria para confirmar - ou não - as datas de atendimento informadas na cobranças eletrônicas) e a duração média dos atendimentos, assim como a qualidade dos serviços prestados. 
Em seguida, propõe-se, na etapa de Modelagem, a aplicação de outros algoritmos de clusterização, além do K-Means (6). Esta alteração serviu principalmente pela possibilidade de testar a eficiência do algoritmo inicialmente utilizado em comparação com outros já utilizados em estudos anteriores para detecção de anomalias, e verificar a viabilidade de se incluir a comparação entre diversos algoritmos no fluxo de análise proposto pelo modelo. Esta análise da eficiência é então realizada no decorrer da etapa de Avaliação (7), onde é verificada a capacidade de cada algoritmo em detectar corretamente os casos indicados como suspeitos no decorrer da aplicação do modelo.

\subsection{Entendimento do Negócio}

De forma geral, as despesas oriundas de tratamentos seriados costumam ser de baixo valor individual. Novamente, a escassez de recursos humanos para análise individual de guias de cobrança resulta na criação de regras que determinem a auditoria de apenas aquelas cobranças que ultrapassam um limite pré-estabelecido (como, por exemplo, $\mathrm{R} \$ 1.000,00$ por guia), o que ainda seria superior ao valor individual cobrado por sessão.

Para as cobranças de procedimentos deste tipo, pode-se verificar os mesmos fatores que resultariam em pagamentos indevidos em cobranças de consulta, como a ausência de alertas de sistema que verifiquem a quantidade de sessões diárias por prestadores do tipo "Pessoa Física". Da mesma forma, seria lógico considerar que para estes prestadores, haveria um limite máximo de atendimentos passíveis de serem realizados em um período de 24 horas.

Diferentemente de guias de cobrança de consultas, os formulários utilizados para registro de atendimentos seriados possuem campos de data que, teoricamente, seriam preenchidos individualmente pelos participantes ao final de cada sessão. Contudo, existe a possibilidade de que o participante (ou até mesmo o prestador) preencha todos os campos de data de uma só vez, com a posterior inclusão da assinatura do participante no formulário. 


\subsection{Entendimento dos Dados - análise inicial}

Quanto ao tipo específico de procedimento, optou-se por avaliar os atendimentos relacionados a sessões de psicoterapia. Conforme o item 4.2.1, este subgrupo representou a maior despesa entre os eventos de tratamento seriado, com o total de aproximadamente $\mathrm{R} \$ 13$ milhões em 2013.

A extração dos dados da base de despesas assistenciais envolveu os registros de atendimentos de psicoterapia referentes ao período de janeiro a dezembro de 2013. Neste conjunto, a maior representatividade em termos de volume financeiro foi visto no subgrupo de procedimentos ligados a sessões de psicoterapia individual. Este subgrupo de procedimentos foi então escolhido para análise, considerando não apenas sua maior representatividade, como também a facilidade em estimar atendimentos excessivos para esta categoria (diferentemente de sessões de psicoterapia em grupo, de casal ou familiar).

As despesas corresponderam, no período avaliado, ao montante de aproximadamente $\mathrm{R} \$ 13$ milhões, distribuídos em 599.251 registros de cobranças de procedimentos de psicoterapia, originados de 20.282 participantes e 2.005 prestadores de serviço.

De 23 atributos iniciais, apresentados a seguir na Tabela 7.1, seis foram escolhidos para análise: Códigos identificadores dos participantes e prestadores, códigos da guia de cobrança, data de atendimento, quantidades e o valor pago. 


\begin{tabular}{|c|c|c|}
\hline $\begin{array}{l}\text { Descrição } \\
\text { do atributo }\end{array}$ & $\begin{array}{l}\text { Escolhido } \\
(\mathrm{S} / \mathrm{N})\end{array}$ & Motivos para escolha (ou não) \\
\hline Código do participante & $\mathbf{S}$ & Necessário para identificação do participante \\
\hline Nome do participante & $\mathrm{N}$ & Identificação pode ser por meio do código \\
\hline Código do prestador & $\mathbf{S}$ & Necessário para identificação do prestador \\
\hline Nome do prestador & $\mathrm{N}$ & Identificação pode ser por meio do código \\
\hline Código de autorização & $\mathrm{N}$ & \multirow{3}{*}{ Podem ser localizados pelo código da guia } \\
\hline \# da carga de cobranças & $\mathrm{N}$ & \\
\hline \# do grupo de guias & $\mathrm{N}$ & \\
\hline Código da guia & $\mathbf{S}$ & Necessário para identificação da guia de cobrança \\
\hline Código de especialidade & $\mathrm{N}$ & \multirow{2}{*}{$\begin{array}{c}\text { Tipos e especialidades dos prestadores foram filtrados } \\
\text { na extração }\end{array}$} \\
\hline Tipo de prestador & $\mathrm{N}$ & \\
\hline Data de atendimento & $\mathbf{S}$ & Necessário para cálculo das qtdes. por dia \\
\hline Data de recebimento & $\mathrm{N}$ & \multirow{2}{*}{ Não foram consideradas no escopo da análise } \\
\hline Data de pagamento & $\mathrm{N}$ & \\
\hline Código do procedimento & $\mathrm{N}$ & \multirow{2}{*}{ Procedimentos foram filtrados na extração } \\
\hline Descr. do procedimento & $\mathrm{N}$ & \\
\hline Cód. do item de custo & $\mathrm{N}$ & \multirow{2}{*}{$\begin{array}{l}\text { Itens de custo são padronizados em procedimentos de } \\
\text { consulta }\end{array}$} \\
\hline Desc. do item de custo & $\mathrm{N}$ & \\
\hline Valor cobrado & $\mathrm{N}$ & \multirow{4}{*}{$\begin{array}{l}\text { A avaliação abordou apenas as quantidades e valores } \\
\text { pagos. }\end{array}$} \\
\hline Quantidade cobrada & $\mathrm{N}$ & \\
\hline Valor glosado & $\mathrm{N}$ & \\
\hline Quantidade glosada & $\mathrm{N}$ & \\
\hline Valor pago & $\mathbf{S}$ & \multirow{2}{*}{ Necessário para cálculo de quantidades envolvidas } \\
\hline Quantidade paga & $\mathbf{S}$ & \\
\hline
\end{tabular}

Tabela 7.1: Atributos considerados na análise

Foram agrupadas as variáveis "código do prestador", "data de atendimento" "valor pago" e "quantidade paga", de forma a se obter o atributo derivado de "quantidade paga por dia" para cada prestador.

O agrupamento resultou em um novo conjunto de 188.639 registros, com a quantidade de atendimentos por dia variando entre menos de 10 (correspondendo a cerca de $99 \%$ dos registros) e até 45 sessões por dia.

\subsection{Entendimento do Negócio}

Realizou-se uma nova consulta com os especialistas médicos, que indicaram um limite máximo de 12 horas de atendimento por dia, com tempo médio de 45 minutos por atendimento. Esta quantidade resultou em um limite de 16 atendimentos por dia. Novamente, vale ressaltar que este foi apenas utilizado como ponto de partida, pois desprezou, de forma conservadora, a possibilidade de que os prestadores poderiam, num mesmo dia, prestador atendimentos para outras operadoras (ou até mesmo em caráter particular).

Tendo em vista os parâmetros estabelecidos com base na expertise dos profissionais da área de saúde, verificamos todos os registros de pagamento que 
ultrapassaram o limite indicado. Abaixo, a Tabela 7.2 apresenta um exemplo de prestador com uma quantidade de particularmente excessiva de atendimentos por dia:

\begin{tabular}{c|c|c|c}
\hline $\begin{array}{c}\text { ID do } \\
\text { Prestador }\end{array}$ & Dt. Atendimento & Qtde. Paga & Valor Pago \\
\hline \multirow{3}{*}{01} & $12 / 07 / 2013$ & 20 & 580,00 \\
\cline { 2 - 4 } & $07 / 06 / 2013$ & 19 & 551,00 \\
\cline { 2 - 4 } & $18 / 11 / 2013$ & 18 & 522,00 \\
\hline
\end{tabular}

Tabela 7.2: Exemplo de possíveis cobranças excessivas em sessões de psicoterapia

Tomando como exemplo a data do dia 12/07, se for considerado o limite de 45 minutos por sessão, o prestador necessitaria de 15 horas ininterruptas para atender a todos os 20 participantes. Todavia, os registros eletrônicos dos atendimentos deste prestador, na data verificada, mostraram um intervalo de menos de um minuto entre as solicitações de autorização.

Sendo assim, partiu-se para a análise mais aprofundada. Inicialmente, 13 prestadores, correspondendo a 19.540 registros de cobrança e com o valor envolvido de $\mathrm{R} \$ 534.170,31$, apresentaram quantidades de atendimento diárias acima do limite de 16 sessões por dia. O total corresponde a 3,26\% dos registros de cobrança, e 4,1\% do total pago no período. Nestes casos, foram recolhidas para análise as guias físicas de cobrança, contendo os campos de data de atendimento preenchidos manualmente, assim como as assinaturas dos participantes.

A análise documental realizada pela área de pagamento de contas apontou novas irregularidades, como rasuras e preenchimentos em série das datas de atendimento. Em alguns casos, foram verificadas inconsistências entre assinaturas do mesmo participante, e uso de corretivo nos campos da guia de cobrança.

Foi sugerido à área gestora realizar contato com uma amostra de participantes ligados aos prestadores suspeitos, de forma a verificar a efetiva prestação dos serviços e as características dos atendimentos de cada prestador, como a duração média de cada sessão, a frequência e intervalos de atendimento, e o grau de satisfação com os serviços prestados. A Tabela 7.3 detalha o resultado das respostas obtidas de cada um dos 13 prestadores avaliados. Para cada entidade, uma amostra de 05 participantes foi escolhida para a entrevista, realizada por telefone pelas Unidades jurisdicionantes. 


\begin{tabular}{|c|c|c|c|c|c|c|}
\hline Prestador & $\begin{array}{l}\text { \# médio } \\
\text { de } \\
\text { sessões } \\
\text { por } \\
\text { semana } \\
\end{array}$ & $\begin{array}{c}\text { Prestador com } \\
\text { facilidade para } \\
\text { marcação de } \\
\text { atendimentos? }\end{array}$ & $\begin{array}{c}\text { Prestador realiza } \\
\text { atendimentos em } \\
\text { feriados e datas } \\
\text { comemorativas? }\end{array}$ & $\begin{array}{c}\text { Duração } \\
\text { media da } \\
\text { sessão } \\
\text { (mins.) }\end{array}$ & $\begin{array}{c}\text { Grau de } \\
\text { satisfação } \\
\text { com o } \\
\text { atendiment } \\
\text { o } \\
\end{array}$ & Reclamações e Observações \\
\hline Prestador 01 & $1-2$ & Sim & Sim & $20-40$ & Médio & $\begin{array}{llr}\text { Participantes } & \text { foram } \\
\text { induzidos à assinar o } \\
\text { formulário de } \\
\text { duas vezes }\end{array}$ \\
\hline Prestador 02 & 1 & Variável & Não & $\sim 50$ & Alto & $\begin{array}{l}\text { Registros encaminhados } \\
\text { para análise, devido às } \\
\text { cobranças excessivas. }\end{array}$ \\
\hline Prestador 03 & 1 & Variável & Variável & $50-60$ & Alto & $\begin{array}{l}\text { Participantes } \quad \text { foram } \\
\text { induzidos à acrescentar } \\
\text { cobranças adicionais no } \\
\text { formulário. }\end{array}$ \\
\hline Prestador 04 & 1 & Sim & Sim & $\sim 50$ & Médio & $\begin{array}{l}\text { Erros de cobrança. Data de } \\
\text { atendimento agrupadas. }\end{array}$ \\
\hline Prestador 05 & $1-3$ & Sim & Sim & $30-45$ & Alto & \multirow{3}{*}{ 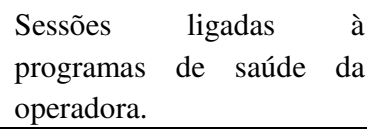 } \\
\hline Prestador 06 & $<1$ & Sim & Não & $50-60$ & Alto & \\
\hline Prestador 07 & $<1$ & Sim & Não & $50-60$ & Alto & \\
\hline Prestador 08 & $1-2$ & Sim & Sim & $30-50$ & Alto & $\begin{array}{l}\text { Atendimentos confirmados, } \\
\text { provável erro de cobrança. }\end{array}$ \\
\hline Prestador 09 & $<1$ & Sim & Sim & $\sim 50$ & Alto & \multirow{4}{*}{ 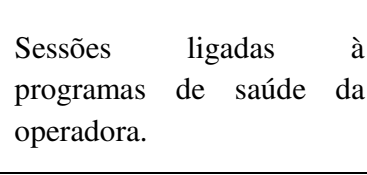 } \\
\hline Prestador 10 & $<1$ & Sim & Não & $\sim 50$ & Alto & \\
\hline Prestador 11 & 1 & Sim & Variável & 50 & Alto & \\
\hline Prestador 12 & $<1$ & Sim & Não & $>50$ & Médio & \\
\hline Prestador 13 & 1 & Sim & Variável & 50 & Alto & $\begin{array}{l}\text { Atendimentos confirmados, } \\
\text { provável erro de cobrança. }\end{array}$ \\
\hline
\end{tabular}

Tabela 7.3: Resultados dos questionários aplicados aos participantes atendidos por prestadores suspeitos

A elaboração das perguntas específicas, escalas de resposta e formato de entrevista foram de responsabilidade da área gestora das Unidades responsáveis por cada prestador, considerando as limitações de tempo e disponibilidade de funcionários para aplicação da entrevista. No entanto, foi sugerido, para análises futuras, o uso de questionários padronizados, com perguntas estruturadas de forma mais objetiva, considerando o uso de amostras definidas estatisticamente e uma escala de Likert [64] para registro das respostas. 


\subsection{Entendimento dos Dados - identificação do subconjunto de entidades suspeitas}

Não obstante sua estrutura relativamente subjetiva, a aplicação do questionários revelou algumas características referentes às práticas de cobrança e de prestação de serviços. Em primeiro lugar, as reclamações dos participantes ligadas aos Prestadores 01 e 03, referentes à solicitação de assinaturas para quantidades de serviço acima do que foi efetivamente prestado, poderia servir como base para um possível descredenciamento. Por sinal, nenhum prestador informou quantidades completamente fictícias de atendimento, indicando que, em casos de abuso, haveria apenas o acréscimo de quantidades de procedimento aos serviços efetivamente prestados. Em termos de características de atendimento, apenas o primeiro prestador possuiu a duração média de sessões abaixo de 30 minutos, sendo que a maioria das sessões ocorreu em intervalos semanais. Estes fatores poderiam servir como parâmetros de análise da frequência de atendimento.

Os resultados da investigação inicial estão apresentados na Tabela 7.4.

\begin{tabular}{|c|c|c|c|}
\hline Prestador & Conclusão & $\begin{array}{c}\text { Qtde de registros de cobrança } \\
(2013)\end{array}$ & $\begin{array}{c}\text { Vlr. pago para sessões de psicoterapia } \\
(2013)\end{array}$ \\
\hline Prestador 01 & \multirow{4}{*}{$\begin{array}{l}\text { Encaminhados para } \\
\text { investigação, devido à } \\
\text { denúncias e práticas de } \\
\text { cobranças excessivas }\end{array}$} & 1.025 & $27.216,00$ \\
\hline Prestador 02 & & 3.997 & $106.760,91$ \\
\hline Prestador 03 & & 3.754 & $100.413,00$ \\
\hline Prestador 04 & & 1.545 & $42.432,40$ \\
\hline \multicolumn{2}{|r|}{ TOTAL - Suspeitos confirmados } & 10.321 & $276.822,31$ \\
\hline Prestador 05 & \multirow{9}{*}{$\begin{array}{c}\text { Quantidades cobradas } \\
\text { justificadas, e/ou relacionadas a } \\
\text { programas específicos da } \\
\text { operadora }\end{array}$} & 2.860 & $74.601,00$ \\
\hline Prestador 06 & & 312 & $9.333,00$ \\
\hline Prestador 07 & & 34 & $2.720,00$ \\
\hline Prestador 08 & & 2.371 & $68.440,00$ \\
\hline Prestador 09 & & 42 & $2.100,00$ \\
\hline Prestador 10 & & 154 & $4.347,00$ \\
\hline Prestador 11 & & 1.208 & $34.525,00$ \\
\hline Prestador 12 & & 131 & $3.456,00$ \\
\hline Prestador 13 & & 2.107 & $57.826,00$ \\
\hline \multicolumn{2}{|c|}{ TOTAL - Cobranças com justificativas } & 9.219 & $257.348,00$ \\
\hline \multicolumn{2}{|c|}{ Registros ñ avaliados ( < 16 sess./dia) } & 579.711 & 13.708.574,30 \\
\hline \multicolumn{2}{|r|}{ TOTAL DE REGISTROS - 2013} & 599.251 & $14.242 .744,61$ \\
\hline
\end{tabular}

Tabela 7.4: Resultados da análise inicial

Embora os resultados iniciais terem sido reveladores em alguns aspectos, mesmo havendo a confirmação de que todos os quatro prestadores iniciais fossem, de fato, abusivos, ainda restariam outros 9 prestadores a serem investigados desnecessariamente. 
Assim como ocorreu na análise de consultas, o estudo revelou que a existência de cobranças de sessões de psicoterapia aparentemente excessivas poderia, em muitos casos, ser justificada. Como exemplo, a operadora de saúde possui programas de saúde específicos para atendimento a vítimas de assalto e sequestro que venham a ocorrer em agências da instituição financeira (IF) patrocinadora. Nestes casos, um prestador de serviços atenderia a todos os envolvidos em uma única sessão de psicoterapia em grupo. Contudo, a cobrança dos atendimentos para cada participante poderia ocorrer no código de psicoterapia individual, gerando um alto volume de atendimentos na respectiva data.

Além disso, o fato de ocorrer o acréscimo de cobranças adicionais torna difícil estimar o real volume de sessões fictícias, mesmo nas entidades suspeitas. Uma preocupação também existe pelo fato de que, mesmo quando cobranças individuais pudessem ser glosadas (negadas), a natureza deste tipo de procedimento significa que o descredenciamento de um prestador invariavelmente resultaria na interrupção no tratamento atual de vários participantes. Esta realidade valida o empenho na análise minuciosa das cobranças de cada entidade suspeita, ao mesmo tempo que realça o impacto humano associado às práticas abusivas no âmbito dos serviços de saúde.

Além dos custos associados à investigação dos falsos-positivos, deparou-se novamente com a possibilidade de existirem também falsos-negativos no conjunto de dados, devido à subjetividade do limite de 16 sessões por dia. Como exemplo, mesmo os prestadores que submetessem cobranças de 15 sessões por dia não seriam contemplados na análise, não obstante o fato de que até mesmo esta quantidade, se fosse parte de um padrão de cobranças recorrente, seria passível de investigação.

Novamente, verificou-se a necessidade de se construir um modelo que reduzisse os índices de apontamentos relacionados a falsos positivos e negativos. Seria necessário contemplar não somente a quantidade de sessões por dia, mas também o volume de atendimentos mensais e a quantidade de participantes em cada prestador no mesmo intervalo, sem um limite preestabelecido por especialistas. 


\subsection{Preparação dos dados e Modelagem}

Conforme verificado na Tabela 18, o grupo de prestadores suspeitos apresentou o maior índice médio de atendimentos por dia, assim como número de participantes e dias de atendimento por mês. Optou-se então por avaliar novamente estas variáveis como forma de isolar os registros suspeitos.

A escolha da técnica de análise foi influenciada pelos resultados obtidos com o uso do algoritmo K-Means, mas também na possibilidade de comparar o seu desempenho com outros métodos de clusterização. Esta forma de comparação havia sido realizada anteriormente por [1]. Sendo assim, foram escolhidos os algoritmos PAM [56], e Clustering Hierárquico [110], a fim de se avaliar as suas eficiências no agrupamento de prestadores com base nas variáveis escolhidas.

Conforme a análise da distribuição dos atendimentos, verificou-se que quase todos os registros inicialmente avaliados continham menos de 10 sessões por dia, para cada prestador de serviço.

Para a variável de "quantidade de atendimentos por dia", foram calculadas a média e o desvio padrão. Considerando estes parâmetros, foi calculado o valor de três desvios-padrão da média para o conjunto, de 9.04 sessões por dia, de forma a estabelecer um limite para redução do conjunto de dados. Esta escolha foi justificada pelo fato de que, além de possibilitar a restrição da análise aos valores mais distantes da média (e, por consequência, mais prováveis de estarem ligados a cobranças excessivas), as cobranças abaixo desta quantidade ainda se encontrariam dentro de um patamar aceitável de atendimento (pois até mesmo para sessões de 45 minutos, corresponderiam a uma jornada de trabalho de menos de 7 horas por dia). Com a análise apenas dos atendimentos com 9 ou mais sessões por dia, o novo conjunto de dados incluiu 2.400 registros, aproximadamente $1 \%$ do conjunto inicial.

Para os três algoritmos de clusterização escolhidos, houve a necessidade de definir a quantidade de clusters. A técnica de soma dos quadrados foi novamente utilizada para definir esta quantidade, apontando uma solução de quatro clusters como sendo a ideal.

No caso da clusterização hierárquica, todos os valores são inicialmente considerados como sendo parte de "clusters" individuais. As distâncias de cada ponto são utilizadas como referência para os subsequentes agrupamentos, sendo que o resultado final é um único cluster com todos os registros. 
A quantidade de clusters pode ser definida pela "poda" da estrutura em formato de árvore criada pelo algoritmo (denominado "dendrograma"). A métrica utilizada, neste caso, foi da distância relativa entre os "galhos", conforme descrito por [109], resultando na indicação de três clusters.

A Figura 7.2 apresenta a visão de cada cluster no conjunto de dados, considerando inicialmente o agrupamento pelo algoritmo K-Means. São comparados os registros das variáveis "quantidade de dias com cobranças no mês" (DIAS_POR_MES) e "número de participantes atendidos no mês do registro" (QTE_PACIENTES_POR_MES) em relação à variável "quantidade de participantes atendidos no dia específico" (QTE_POR_DIA).

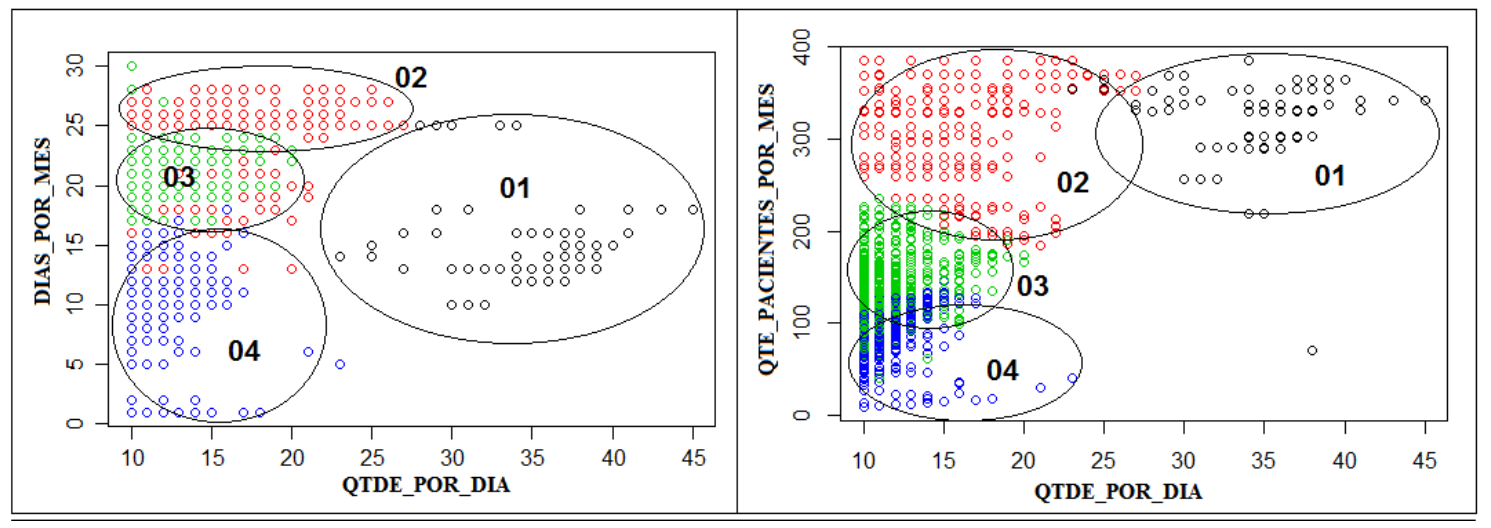

Figura 7.2: Resultados da clusterização em dados de psicoterapia - algoritmo K-Means

Neste conjunto, verifica-se que o primeiro cluster (1) agrupou os valores extremos relacionados à variável QTE_POR_DIA, predominantemente envolvendo registros com 25 ou mais atendimentos por dia. Neste cluster houve também a preponderância de registros cuja quantidade de dias com atendimentos, no mês, é maior a 10. Da mesma forma, o agrupamento contém registros relacionados a uma quantidade mensal de pacientes atendidos superior a 200. Os demais clusters 2, 3 e 4 possuem agrupamentos distintos de registros referentes às variáveis de DIAS_POR_MES e QTE_PACIENTES_POR_MES, porém todos concentram registros com 25 ou menos atendimentos por dia.

A aplicação do algoritmo PAM, apresentada na Figura 7.3, mostra que o comportamento em relação ao agrupamento dos registros foi semelhante ao visto com o algoritmo K-Means. 


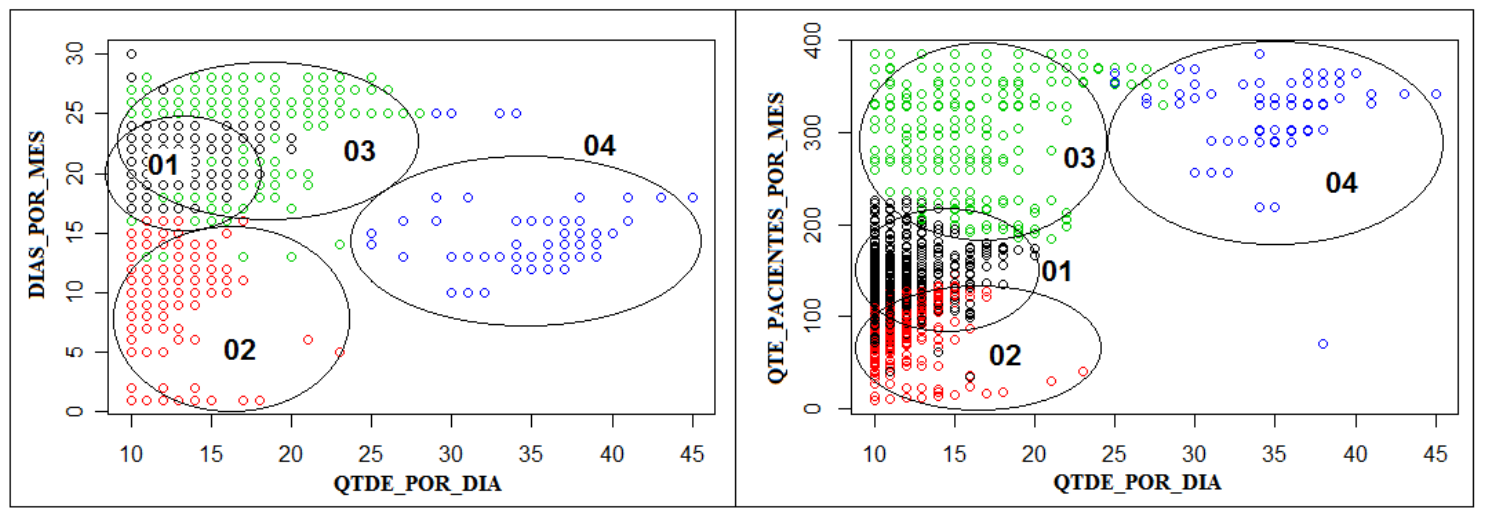

Figura 7.3: Resultados da clusterização em dados de psicoterapia - algoritmo PAM

No agrupamento por meio do algoritmo PAM, o cluster 04 consolida os registros com as maiores quantidades da variável "quantidade de participantes atendidos no dia específico" (QTE_POR_DIA) e nas demais variáveis, DIAS_POR_MES e QTE_PACIENTES_POR_MES, registros com quantidades maiores que 10 e 200, respectivamente. Sendo assim, agrupa os registros com altas quantidades de atendimentos por dia, em meses onde foram vistos também altas quantidades de pacientes atendidos e maior frequência de atendimento.

Por fim, a Figura 7.4 demonstra a aplicação do algoritmo HClust no mesmo conjunto de dados.

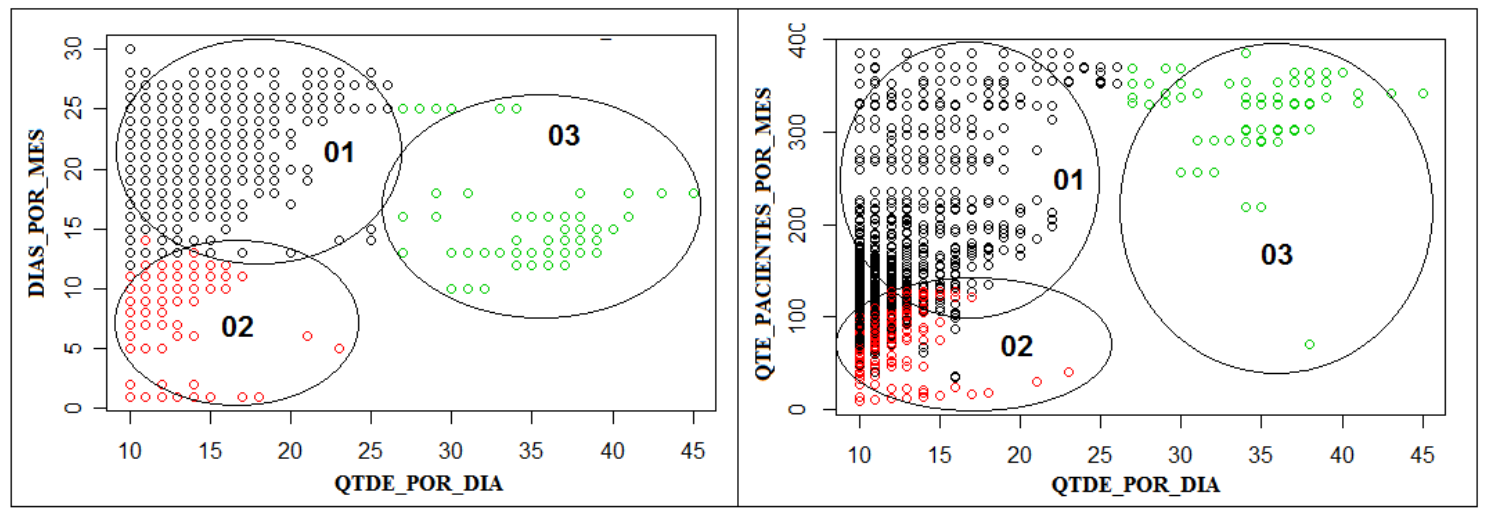

Figura 7.4: Resultados da clusterização em dados de psicoterapia - algoritmo HClust

Com este algoritmo, verifica-se que, devido à menor quantidade de clusters, há um agrupamento mais consolidado dos registros. Todavia, um único cluster, de número 03, novamente é criado com os registros com maiores quantidades da variável QTE_POR_DIA, com valores acima de 25 atendimentos. O cluster 01 contempla os 
registros com quantidade inferior a 25 atendimentos por dia, e com quantidades das variáveis DIAS_POR_MES e QTE_PACIENTES_POR_MES superiores aos do cluster 02.

Na etapa de Avaliação, o desempenho de cada algoritmo é definido pela capacidade de corretamente agrupar os registros suspeitos, e de desconsiderar aqueles definidos como falsos positivos detalhados anteriormente.

\subsection{Avaliação - Validação de Clusters}

A Tabela 20 apresenta a quantidade de registros por cluster, em cada um dos algoritmos utilizados. É avaliado se os registros agrupados pertencem a prestadores já identificados como suspeitos, não suspeitos, ou novos prestadores, que ainda não foram avaliados pelo modelo inicial.

\begin{tabular}{c|c|c|c|c|c|c|c|c|c|c|c|c}
\hline & & \multicolumn{3}{|c|}{ K-Means } & \multicolumn{3}{c|}{ PAM } & \multicolumn{3}{c}{ Hierárquico } \\
\hline & $\begin{array}{c}\text { Classe / } \\
\text { Cluster }\end{array}$ & 01 & 02 & 03 & 04 & 01 & 02 & 03 & 04 & 01 & 02 & 03 \\
\hline $\begin{array}{c}\text { Suspeitos } \\
\text { confirmados }\end{array}$ & 105 & 191 & 45 & 41 & 43 & 41 & 196 & 102 & 244 & 32 & 106 \\
\cline { 2 - 13 } & $\begin{array}{c}\text { Prestadores } \\
\text { \# de } \\
\text { com } \\
\text { Registros, } \\
\text { pobranças Classe } \\
\text { justificáveis }\end{array}$ & 1 & 157 & 199 & 27 & 183 & 23 & 177 & 1 & 374 & 9 & 1 \\
\hline $\begin{array}{c}\text { Novos } \\
\text { prestadores, } \\
\text { não } \\
\text { avaliados }\end{array}$ & 0 & 0 & 918 & 752 & 978 & 691 & 1 & 0 & 1272 & 398 & 0 \\
\hline $\begin{array}{c}\text { Total de registros, por } \\
\text { cluster }\end{array}$ & 106 & 348 & 1162 & 820 & 1204 & 755 & 374 & 103 & 1890 & 439 & 107 \\
\hline $\begin{array}{c}\text { Proporção: registros de } \\
\text { entidades suspeitas/ } \\
\text { total de registros no } \\
\text { cluster } \\
\text { (em \%) }\end{array}$ & 99,05 & 54,88 & 3,87 & 5,00 & 3,57 & 5,43 & 52,40 & 99,02 & 12,91 & 7,28 & 99,06 \\
\hline
\end{tabular}

Tabela 7.5: Entidades identificadas em cada cluster, por algoritmo

$\mathrm{Na}$ Tabela 7.5, é realizada a análise da proporção, em cada cluster de cada algoritmo, entre a quantidade de registros ligados a prestadores suspeitos confirmados e o total de registros agrupados no cluster. Quanto a esta métrica, verifica-se que o Cluster 01 do K-Means, o Cluster 04 do PAM e o Cluster 03 do algoritmo HClust tiveram o melhor desempenho. Nestes três casos, mais de $99 \%$ dos registros estão 
relacionados a entidades cuja suspeita de cobranças excessivas foi confirmada. Ou seja, caso os registros destes clusters tiverem sido priorizados para análise, haveria uma maior chance de identificar os casos suspeitos, sem o gasto de recursos para investigação de outras entidades.

A Tabela 7.6, por sua vez, identifica os prestadores presentes em cada cluster, com base nos registros presentes em cada agrupamento. Desta forma, vale ressaltar que um mesmo prestador pode estar presente em mais de um cluster.

\begin{tabular}{|c|c|c|c|c|c|c|c|c|c|c|c|c|}
\hline & \multirow[b]{2}{*}{ Classe / Cluster } & \multicolumn{4}{|c|}{ K-Means } & \multicolumn{4}{|c|}{ PAM } & \multicolumn{3}{|c|}{ Hierárquico } \\
\hline & & 01 & 02 & 03 & 04 & 01 & 02 & 03 & 04 & 01 & 02 & 03 \\
\hline \multirow{4}{*}{$\begin{array}{l}\text { Entidades } \\
\text { suspeitas, } \\
\text { confirmadas }\end{array}$} & Prestador 01 & & & & & & & & & & & \\
\hline & Prestador 02 & & & & & & & & & & & \\
\hline & Prestador 03 & & & & & & & & & & & \\
\hline & Prestador 04 & & & & & & & & & & & \\
\hline & TOTAL & 02 & $\mathbf{0 3}$ & 02 & 01 & 02 & 01 & $\mathbf{0 3}$ & 02 & 04 & 01 & 02 \\
\hline \multirow{5}{*}{$\begin{array}{c}\text { Entidades } \\
\text { inicialmente } \\
\text { avaliadas, mas } \\
\text { que possuem } \\
\text { justificativas }\end{array}$} & Prestador 05 & & & & & & & & & & & \\
\hline & Prestador 06 & & & & & & & & & & & \\
\hline & Prestador 07 & & & & & & & & & & & \\
\hline & Prestador 08 & & & & & & & & & & & \\
\hline & Prestador 09 & & & & & & & & & & & \\
\hline \multirow{4}{*}{$\begin{array}{c}\text { para as } \\
\text { cobranças } \\
\text { suspeitas }\end{array}$} & Prestador 10 & & & & & & & & & & & \\
\hline & Prestador 11 & & & & & & & & & & & \\
\hline & Prestador 12 & & & & & & & & & & & \\
\hline & Prestador 13 & & & & & & & & & & & \\
\hline & TOTAL & 01 & 03 & 05 & 06 & 05 & 06 & 03 & 01 & 05 & 05 & 01 \\
\hline \multicolumn{2}{|c|}{$\begin{array}{c}\text { Novas entidades apontadas } \\
\text { pelos clusters }\end{array}$} & $\mathbf{0}$ & $\mathbf{0}$ & 101 & 90 & 105 & 83 & 1 & $\mathbf{0}$ & 121 & 57 & $\mathbf{0}$ \\
\hline
\end{tabular}

Tabela 7.6: Entidades identificadas em cada cluster, por algoritmo

No algoritmo K-Means, o Cluster 02 identificou três dos quatro prestadores suspeitos investigados inicialmente (Prestadores 02, 03 e 04). Neste agrupamento, foram apontados apenas três dos nove prestadores com cobranças justificáveis (Prestadores 05, 08 e 13).

Uma eficiência semelhante é observada no Cluster 03 do algoritmo PAM, que além de agrupar registros de três prestadores suspeitos, também identificou registros de um novo prestador, que não havia sido avaliado anteriormente.

Verifica-se que o Cluster 01 gerado pelo algoritmo de Clusterização Hierárquica identificou corretamente todos os prestadores suspeitos, porém com o agrupamento de 05 dos 09 prestadores com cobranças justificáveis. Neste cluster, foram agrupados também registros de outras 121 entidades não avaliadas. Este fato pode ser interpretado como uma desvantagem, pois seria necessário um esforço adicional para análise destes novos prestadores pela equipe de auditoria. Por outro lado, caso a 
análise fosse iniciada pelo estudo dos registros dos Clusters 01 ou 02 do K-Means, ou 03 ou 04 do PAM, haveria um melhor direcionamento e uso dos recursos disponíveis para investigação.

\subsection{Implementação}

Considerando estes resultados e os valores envolvidos nas entidades investigadas, pode-se concluir que, caso a análise fosse iniciada pelo agrupamento dos registros, tanto com o uso do algoritmo K-Means quanto pelo PAM, teria resultado na identificação de $90 \%$ dos registros de pagamento ligados aos prestadores suspeitos, e com dispêndio de recursos na análise de apenas quatro dos nove prestadores classificados como falsos positivos. Isto significaria uma redução de esforços em termos de tempo e dinheiro, relacionados à consulta de especialistas para definição do limite diário de atendimento, à análise de guias físicas pela área de pagamento de contas, e à aplicação dos questionários aos participantes, pelas Unidades jurisdicionantes.

Quanto aos procedimentos de psicoterapia, a investigação inicial, aliada à confirmação dos casos suspeitos pela análise de clusters, resultou do descredenciamento de 03 dos 13 prestadores iniciais, assim como a decisão pelo acompanhamento das cobranças futuras oriundas do Prestador 04, conforme o detalhamento da Tabela 7.7:

\begin{tabular}{c|c|c|c}
\hline \multirow{2}{*}{ Provider } & Resultado & $\begin{array}{c}\text { \# Registros } \\
(\mathbf{2 0 1 3})\end{array}$ & $\begin{array}{c}\text { Valor Pago } \\
(\mathbf{2 0 1 3})\end{array}$ \\
\cline { 1 - 3 } Prestador 01 & \multirow{2}{*}{$\begin{array}{c}\text { Descredenciados, devido à práticas de } \\
\text { cobranças abusivas. }\end{array}$} & 1.025 & $27.216,00$ \\
\cline { 1 - 3 } \cline { 3 - 4 } Prestador 02 & 3.997 & $106.760,91$ \\
\hline Prestador 03 & Prestador indicado para acompanhamento. & 3.754 & $100.413,00$ \\
\hline Prestador 04 & TOTAL - Verdadeiros Positivos & $\mathbf{1 0 . 3 2 1}$ & $\mathbf{2 7 6 . 8 2 2 , 3 1}$ \\
\hline
\end{tabular}

Tabela 7.7: Resultados finais da análise de sessões de psicoterapia

Como resultado adicional, pode-se ressaltar novamente o apontamento de outras entidades passíveis de investigação, cujos registros não haviam sido apontados (pois estavam abaixo do limite definido), mas que apresentam comportamento semelhante às entidades suspeitas. Os esforços gastos na investigação de falsos positivos seriam, desta forma, aplicados na investigação destes novos prestadores. 


\section{Capítulo 8}

\section{Priorização das Investigações com o}

\section{Método AHP}

Nos Capítulos 6 e 7, verificou-se a aplicação de algoritmos de clusterização para a detecção de cobranças suspeitas, em dois conjuntos distintos de procedimentos consultas em consultório e sessões de psicoterapia. A identificação inicial destas entidades por meio do modelo de clusterização pôde ser realizada de forma semelhante para ambos os tipos de procedimentos.

Por um lado, a confirmação das inconsistências existentes nas cobranças de eventos de consulta em consultório mostrou ser mais direta do que a análise de sessões de psicoterapia, pois envolveu apenas a análise das guias físicas de cobrança. Para procedimentos de natureza mais complexa, como tratamentos seriados (como foi o caso das sessões de psicoterapia), seria necessário complementar a investigação com o uso de abordagens mais onerosas (em termos de tempo e utilização de esforços de análise), envolvendo a revisão dos dados de pagamento, a análise das cobranças físicas e a realização de entrevistas junto aos pacientes e prestadores de serviço.

Embora o primeiro modelo tenha identificado um conjunto inicial de prestadores suspeitos, verificou-se que a aplicação dos algoritmos de clusterização pode resultar no apontamento de várias outras entidades. Caso estes prestadores estejam localizados em uma mesma região geográfica, é provável que a equipe de análise da Unidade jurisdicionante necessite priorizar certas entidades, o que normalmente é feito com base no faturamento do prestador no decorrer do período avaliado. Contudo, conforme apontado no modelo inicial, nem sempre haverá uma correlação entre o total cobrado para um determinado prestador e a chance da entidade estar envolvida em práticas abusivas de cobrança. 
Da mesma forma, pode ser de interesse da OPS avaliar todo o conjunto de prestadores inclusos em clusters com os maiores fatores de risco, não se limitando apenas ao único cluster que se destaca em comparação aos demais. Neste cenário, também haverá a necessidade de criar um modelo de priorização que contemple métricas mais objetivas para a escolha de entidades a serem investigadas, de forma a evitar críticas quanto à possível subjetividade na definição do grupo de análise. Sendo assim, a escolha do método AHP foi definida como sendo a mais adequada, pois o método permite que sejam verificados, para a escolha das entidades a serem avaliadas, fatores qualitativos e quantitativos.

A construção deste modelo seguiu as etapas descritas na Figura 8.1, obedecendo às recomendações de [94].

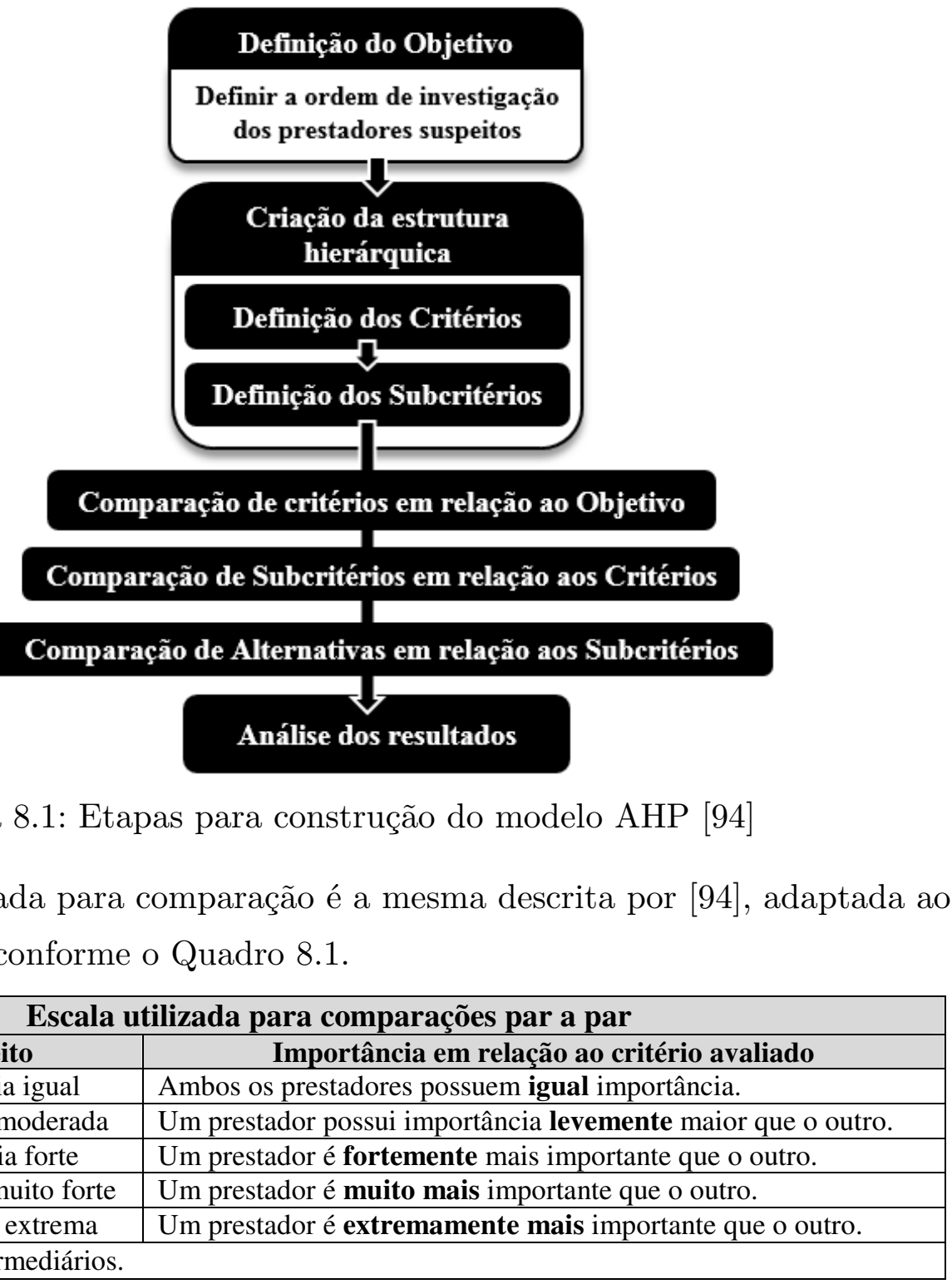

Quadro 8.1: Escala Saaty para comparações par a par 
A escala utiliza os valores de 1 a 9 para atribuição do grau de importância para as alternativas em análise. Caso ocorra uma discrepância muito significativa entre duas entidades, optou-se por utilizar os valores intermediários pares, de 2 a 8 , no intuito de evitar possíveis inconsistências.

\subsection{Definição dos Critérios}

A fim de priorizar a análise dos fornecedores suspeitos identificados pelos métodos anteriores, foram considerados fatores de risco levantados anteriormente por estudos na área de saúde e gestão de riscos, assim como aqueles identificados no decorrer da criação do modelo de clusterização.

Para os fatores de risco relacionados a atendimentos médico-hospitalares, entre os fatores já identificados previamente cabe ressaltar a possibilidade de ocorrência de tratamentos em datas improváveis e inconsistências entre o relato de participantes e os registros médicos [72], procedimentos incompatíveis com as necessidades dos participantes [83], quantidade excessiva de atendimentos [2] e irregularidades na documentação de cobrança [112].

Com base nas pesquisas de [58], foram verificados fatores de risco normalmente utilizados em autoavaliações organizacionais. Entre eles estão a frequência de ocorrência de eventos suspeitos, alterações na estrutura da entidade avaliada, e valores envolvidos. Outros fatores descritos anteriormente por Deshmukh e Millet (1999) e [29] também foram considerados.

Optou-se por agrupar os fatores de risco a serem avaliados em três subgrupos específicos, conforme a Figura 8.2.

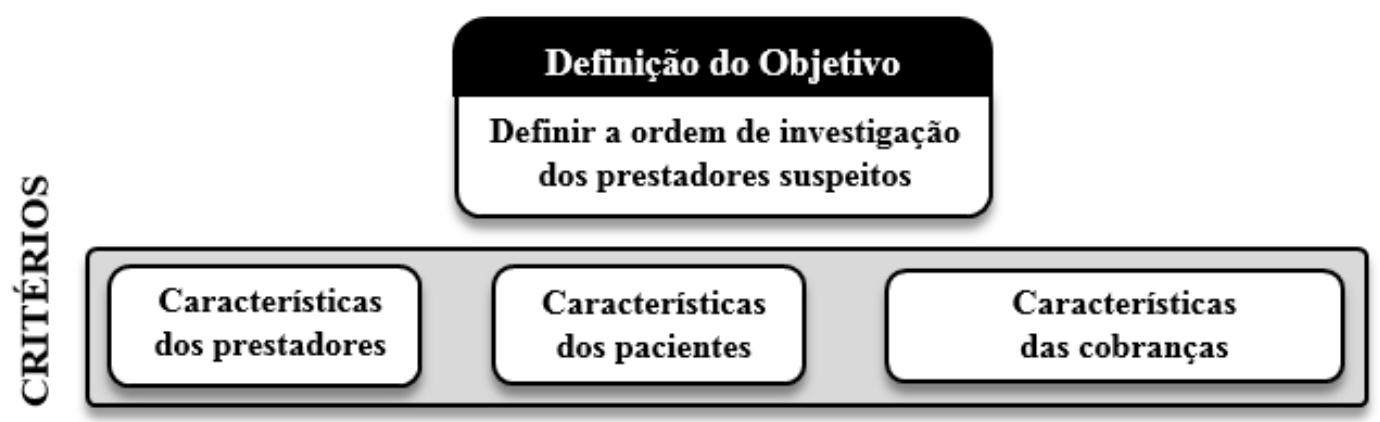

Figura 8.2: Estrutura do modelo AHP - Objetivo e Critérios 
Esta divisão contempla os três principais elementos envolvidos na investigação de cobranças assistenciais: as características dos prestadores de serviço, dos participantes envolvidos e das cobranças dos serviços prestados. O objetivo final foi de definir a ordem de investigação dos prestadores suspeitos.

O grupo de critérios "Características dos prestadores" considerou, principalmente, os fatores relacionados ao histórico do prestador de serviços envolvido, priorizando informações que poderiam ser extraídas do banco de dados do sistema de pagamentos da OPS. Entre estes, foram escolhidas a taxa de crescimento das despesas do prestador, o tempo de credenciamento junto à OPS e se a entidade já esteve envolvida em investigações anteriores. Para este último critério, foi considerado também se o prestador já foi alvo de alguma reclamação oriunda de seus participantes, conforme registros em canais de Ouvidoria da OPS ou mensagens encaminhadas à Unidade jurisdicionante.

O grupo de critérios "Características dos Participantes" abordou os fatores de risco associados aos participantes atendidos por um determinado prestador, avaliando as ocorrência de atendimentos de pacientes que residem fora da região, e a faixa etária dos participantes atendidos.

Por fim, o último grupo, de "Características de Cobrança" levou em consideração os fatores relacionados às práticas de cobrança dos prestadores. $\mathrm{O}$ primeiro subcritério escolhido foi o percentual de cobranças, em cada prestador, relacionados a valores anteriormente identificados como indevidos. Em seguida, foi avaliada a frequência semanal dos atendimentos cobrados por cada prestador, e a existência de cobranças em datas comemorativas e finais de semana. 


\subsection{Definição dos Subcritérios}

Os itens a seguir descrevem detalhadamente os subcritérios considerados em cada critério descrito no item 8.1. A visão geral do modelo, considerando estes critérios e seus respectivos subcritérios, pode ser verificada na Figura 8.3.

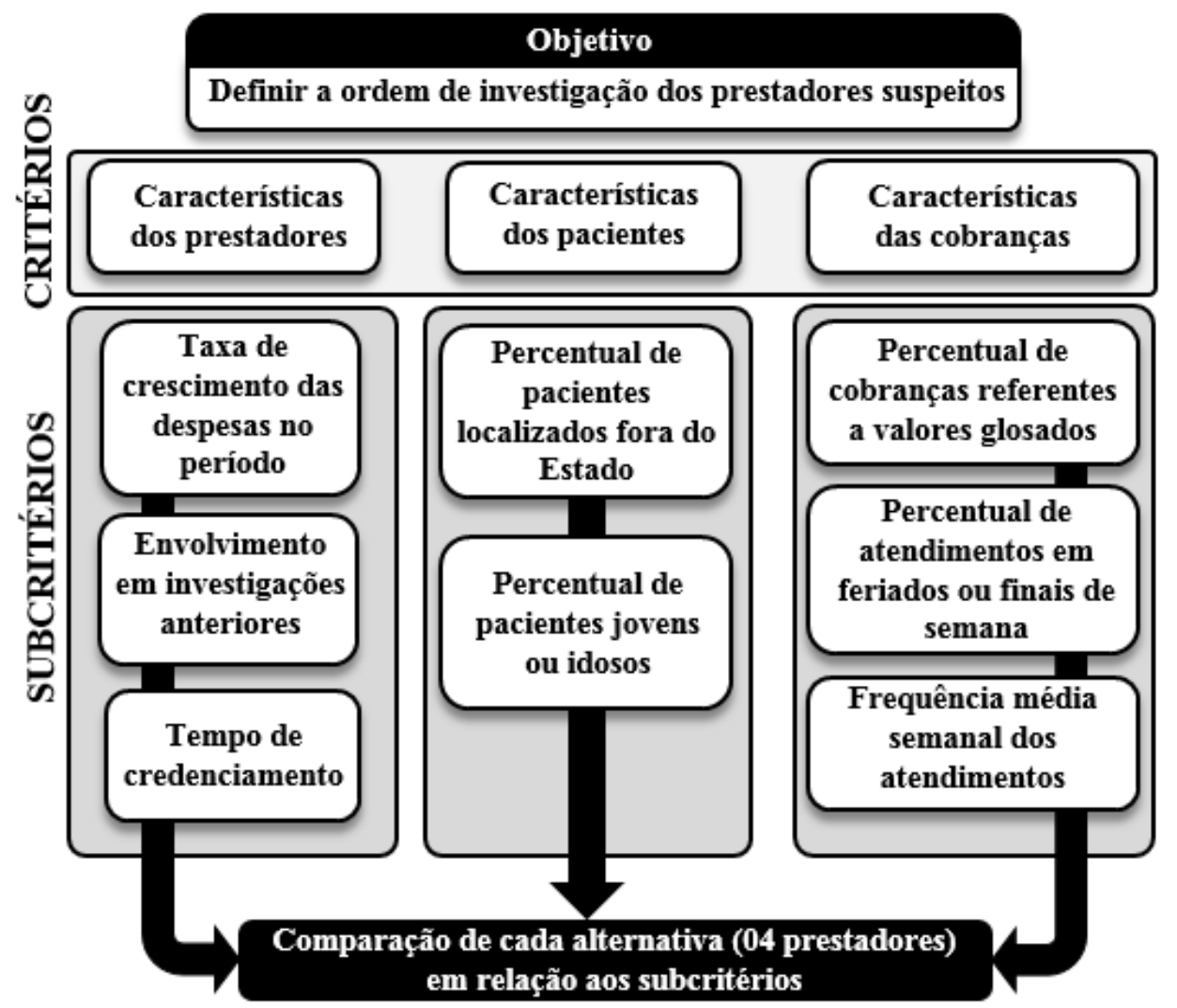

Figura 8.3: Modelo geral AHP

Cada um dos Critérios iniciais foi subdividido em subcritérios, que serão comparados entre si para determinar sua importância em relação ao nível superior da hierarquia. Adicionalmente, também haverá uma comparação entre as quatro alternativas (prestadores), em relação ao seus respectivos subcritérios.

Ao todo, o modelo propõe que sejam realizadas 58 comparações. Em primeiro lugar, são necessárias 10 comparações para a estrutura inicial (03 comparações para se avaliar os critérios em relação ao objetivo, e outras 07 comparações para avaliar os subcritérios em relação aos critérios). Estas comparações iniciais são realizadas apenas uma vez, na construção do modelo. Em seguida, para avaliar as 04 alternativas em relação aos subcritérios, são necessários outros 48 julgamentos. Considerando que esta quantidade de comparações tende a aumentar conforme a quantidade de entidades envolvidas, buscou-se a elaboração de subcritérios com base em informações 
disponíveis na mesma base de dados utilizada para a extração dos pagamentos das entidades envolvidas. Indicadores como a taxa de crescimento de despesas, tempo de credenciamento e frequência de atendimento podem ser calculados automaticamente por meio de consultas em um sistema gerenciador de bancos de dados (como o Microsoft Access), gerando automaticamente os valores de intensidade entre cada alternativa. Em seguida, estes valores são impostados no software Expert Choice [39], que calcula os pesos com base na formulação teórica do AHP, descrito anteriormente no item 2.3.1.

\subsubsection{Características dos Prestadores}

Para o subcritério de "Taxa de crescimento das despesas no período", é avaliada a tendência do crescimento das despesas de cada prestador (crescente, estável ou decrescente) dentro do período avaliado. Nas comparações par a par, caso ambos os prestadores demonstrassem crescimento nas despesas, é dada mais importância ao que apresentasse a maior taxa.

No subcritério de "Envolvimento em investigações anteriores", é considerado que, caso um determinado prestador tenha sido alvo de investigações ou reclamações, teria de ser priorizado para análise. Uma ênfase maior foi dada a casos de investigação, principalmente se já tivesse envolvido o estorno de valores pagos previamente.

Já no subcritério de "Tempo de credenciamento", considera-se a hipótese de que prestadores com menos tempo de vínculo junto a instituição estariam mais propícios a iniciarem práticas abusivas. Dentre o grupo de características dos prestadores, esta foi a análise mais objetiva, pois considerou apenas a data de credenciamento de cada prestador. 


\subsubsection{Características dos Pacientes}

Para o subcritério de "Percentual de pacientes localizados fora do Estado", avalia-se o envio de cobranças oriundas de pacientes que não são residentes do mesmo Estado onde se localiza o prestador de serviços. Para um procedimento que normalmente envolve várias sessões ao longo de um período de meses, julga-se importante avaliar se os prestadores suspeitos possuem percentuais expressivos de pacientes nesta condição.

O subcritério de "Percentual de pacientes jovens ou idosos" abrange dois extremos verificados no decorrer das análises: Prestadores que atendem uma preponderância de pacientes jovens (abaixo de 18 anos) ou idosos (com idade igual ou superior a 65 anos). A análise deste fator foi considerada importante, em função do senso crítico de participantes nestas faixas etárias, o que poderia influenciar na probabilidade de questionarem as possíveis solicitações de assinaturas de quantidades adicionais em cada guia de cobrança. Sendo assim, seria dada uma maior ênfase nos prestadores com um percentual maior de pacientes nestas faixas etárias.

\subsubsection{Características das Cobranças}

Dentre as características de cobrança, o subcritério de "Percentual de cobranças referentes a valores glosados", serve para avaliar as cobranças do prestador no período em análise, no intuito de verificar se houveram glosas (montantes referentes a negativas de pagamento), e qual a proporção destes valores em relação ao total pago no período. Um alto índice de glosas pode significar uma maior tendência do prestador em submeter cobranças incorretas, e também refletir em um grau de insatisfação maior da entidade perante à operadora de planos.

Quanto ao subcritério "Frequência média semanal dos atendimentos", é considerada a frequência dos atendimentos cobrados por prestador. Conforme consulta realizada junto aos especialistas da área de saúde da OPS, uma frequência considerada razoável para este tipo de atendimento seria de entre uma e duas vezes por semana. Desta forma, foram apuradas as frequências semanais de atendimento, por paciente, em cada prestador. Em seguida, a comparação considerou a média dos atendimentos semanais por prestador. 
O subcritério "Percentual de atendimentos em feriados ou finais de semana" está relacionado a um dos fatores levantados no decorrer da análise inicial das guias de cobrança pela área de pagamento de contas. Para esta análise, é considerada a proporção de atendimentos em feriados ou finais de semana para cada prestador, em relação a todos os atendimentos realizados no período. Em seguida, foi comparada a proporção de cada prestador.

\subsection{Resultados dos julgamentos, por nível hierárquico}

Nos itens a seguir, apresenta-se o resultado das análises par a par realizadas entre os critérios, subcritérios e alternativas. A proposta do modelo inclui a participação de 02 analistas e 02 gestores da área responsável pela análise dos dados, de um analista da área responsável pela análise documental das cobranças e um analista da área responsável pela posterior investigação direta junto aos prestadores de serviço e participantes. O resultado das comparações é então validada pelos gestores das áreas intervenientes.

Para que não houvesse influência nas respostas fornecidas, foi proposta a análise entre subcritérios e alternativas separadamente, sem a apresentação, aos participantes, do impacto dos julgamentos na pontuação geral do modelo, de forma semelhante à adotada por [7]

\subsubsection{Resultados dos julgamentos - Critérios em relação ao Objetivo}

A análise por meio do modelo AHP inicia-se pela comparação dos critérios principais, par a par, a fim de determinar sua importância para os investigadores. A proposta foi que este julgamento inicial seria baseado no consenso entre integrantes da área de Riscos da OPS, considerando a expertise adquirida pelos gestores e analistas da área em investigações anteriores. 
Neste primeiro conjunto, foram necessárias três comparações: entre as características dos prestadores e dos pacientes, entre as características dos prestadores e das cobranças, e entre as características dos pacientes e das cobranças. O Quadro 8.2 apresenta o resultado das comparações (destacando, em cada uma, a alternativa escolhida), incluindo as justificativas apresentadas para cada uma delas.

\begin{tabular}{|c|c|c|c|}
\hline \multicolumn{2}{|c|}{ Comparação - Critérios } & Intensidade & Justificativa \\
\hline $\bar{A}$ & $\bar{B}$ & & \\
\hline $\begin{array}{c}\text { C. dos } \\
\text { Prestadores }\end{array}$ & $\begin{array}{c}\text { C. dos } \\
\text { Pacientes }\end{array}$ & 3 & $\begin{array}{l}\text { As inconsistências relacionadas aos prestadores são } \\
\text { ligeiramente mais importantes, pois são um } \\
\text { indicativo mais forte de práticas abusivas. }\end{array}$ \\
\hline $\begin{array}{c}\text { C. dos } \\
\text { Prestadores }\end{array}$ & $\begin{array}{c}\text { C. das } \\
\text { Cobranças }\end{array}$ & 3 & $\begin{array}{l}\text { As inconsistências relacionadas às cobranças foram } \\
\text { julgadas mais importantes, pois estão relacionadas a } \\
\text { desvios de comportamento mais objetivos e mais } \\
\text { facilmente verificáveis. }\end{array}$ \\
\hline $\begin{array}{c}\text { C. dos } \\
\text { Pacientes }\end{array}$ & $\begin{array}{c}\text { C. das } \\
\text { Cobranças }\end{array}$ & 4 & $\begin{array}{l}\text { Pelos mesmos motivos descritos acima, as } \\
\text { inconsistências verificadas nas cobranças são } \\
\text { indicadores mais fortes de práticas abusivas. }\end{array}$ \\
\hline
\end{tabular}

Quadro 8.2: Comparações entre Critérios

O resultado dos cálculos dos pesos de cada critério, de acordo com os julgamentos do Quadro 8.2, são descritos na Tabela 8.1, a seguir.

\begin{tabular}{l|c|c}
\hline \multicolumn{1}{c|}{ Critérios } & Peso em relação ao objetivo (Peso =1,00) & Índice de inconsistência \\
\hline C. dos Prestadores & $\mathbf{0 , 2 6 8}$ & \multirow{2}{*}{0,07} \\
\hline C. dos Pacientes & $\mathbf{0 , 1 1 7}$ & \\
\hline C. das Cobranças & $\mathbf{0 , 6 1 4}$ & \\
\hline
\end{tabular}

Tabela 8.1: Pesos resultantes das comparações entre Critérios

A representação visual do resultado acima pode ser verificada na Figura 8.4:

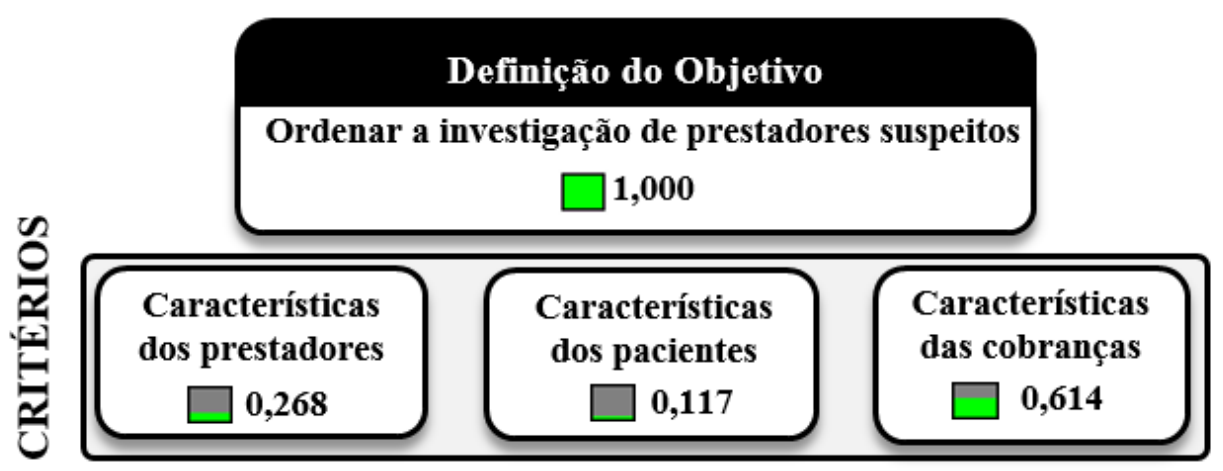

Figura 8.4: Representação gráfica dos pesos do Objetivo e Critérios 
Desta forma, é possível visualizar que as características de cobrança contribuem com o maior peso $(0,614)$ para definição do objetivo, seguidas pelas características dos prestadores (peso 0,268$)$ e dos pacientes $(0,117)$.

\subsubsection{Resultados dos julgamentos - Subcritérios em relação}

\section{aos Critérios}

O modelo AHP determina que, dentro de cada critério, haja a comparação par a par entre os subcritérios. Assim como realizado nos julgamentos anteriores, cada subcritério foi avaliado em termos de sua importância para o apontamento de práticas abusivas. O Quadro 8.3 apresenta os resultados. Em cada comparação, é destacada a alternativa escolhida.

\begin{tabular}{|c|c|c|c|c|}
\hline Critérios & \multicolumn{2}{|c|}{ Comparação - Subcritérios } & Intensidade & Justificativa \\
\hline \multirow{3}{*}{$\begin{array}{c}\text { C. dos } \\
\text { Prestadores }\end{array}$} & $\begin{array}{l}\text { Tx. de } \\
\text { crescimento } \\
\text { das despesas }\end{array}$ & $\begin{array}{l}\text { Envolvimento } \\
\text { em } \\
\text { investigações } \\
\text { anteriores }\end{array}$ & 5 & $\begin{array}{l}\mathrm{O} \text { envolvimento em investigações } \\
\text { anteriores é um forte indício de que o } \\
\text { prestador esteja envolvido em práticas } \\
\text { abusivas. }\end{array}$ \\
\hline & $\begin{array}{c}\text { Tx. de } \\
\text { crescimento } \\
\text { das despesas }\end{array}$ & $\begin{array}{c}\text { Tempo de } \\
\text { credenciamento }\end{array}$ & 4 & $\begin{array}{l}\text { Um prestador com crescimento repentino } \\
\text { em suas despesas torna-se mais suspeito } \\
\text { do que aquele com pouco tempo de } \\
\text { credenciamento. }\end{array}$ \\
\hline & $\begin{array}{l}\text { Envolvimento } \\
\text { em } \\
\text { investigações } \\
\text { anteriores }\end{array}$ & $\begin{array}{c}\text { Tempo de } \\
\text { credenciamento }\end{array}$ & 9 & $\begin{array}{l}\text { Conforme a lógica acima, indícios de } \\
\text { investigações anteriores pesam mais do } \\
\text { que o tempo de credenciamento. }\end{array}$ \\
\hline $\begin{array}{c}\text { C. dos } \\
\text { Pacientes }\end{array}$ & $\begin{array}{l}\text { Percentual de } \\
\text { pacientes } \\
\text { localizados } \\
\text { fora do Estado }\end{array}$ & $\begin{array}{l}\text { Percentual de } \\
\text { pacientes jovens } \\
\text { ou idosos }\end{array}$ & 9 & $\begin{array}{l}\text { Foi dada uma importância maior na } \\
\text { análise de prestadores com pacientes } \\
\text { extremamente jovens ou idosos. }\end{array}$ \\
\hline \multirow{3}{*}{$\begin{array}{c}\text { C. das } \\
\text { Cobranças }\end{array}$} & $\begin{array}{c}\% \text { de } \\
\text { cobranças } \\
\text { referentes a } \\
\text { valores } \\
\text { glosados }\end{array}$ & $\begin{array}{l}\text { Frequência } \\
\text { média semanal } \\
\text { dos } \\
\text { atendimentos }\end{array}$ & 6 & $\begin{array}{l}\text { Apesar da quantidade glosada ser um } \\
\text { fator importante a ser avaliado, seria } \\
\text { mais interessante priorizar os casos com } \\
\text { alta frequência semanal de atendimentos. }\end{array}$ \\
\hline & $\begin{array}{c}\% \text { de } \\
\text { cobranças } \\
\text { referentes a } \\
\text { valores } \\
\text { glosados }\end{array}$ & $\begin{array}{c}\% \text { de } \\
\text { atendimentos } \\
\text { em feriados ou } \\
\text { finais de semana }\end{array}$ & 4 & $\begin{array}{l}\text { Entre estes dois fatores, decidiu-se por } \\
\text { priorizar casos com alto índice de glosas, } \\
\text { pois cobranças em dias não úteis } \\
\text { poderiam ser justificáveis. }\end{array}$ \\
\hline & $\begin{array}{l}\text { Frequência } \\
\text { média } \\
\text { semanal dos } \\
\text { atendimentos }\end{array}$ & $\begin{array}{c}\% \text { de } \\
\text { atendimentos } \\
\text { em feriados ou } \\
\text { finais de semana }\end{array}$ & 9 & $\begin{array}{l}\text { Seguindo a mesma lógica anterior, a } \\
\text { análise da frequência dos atendimentos } \\
\text { deve ser priorizada, pois cobranças em } \\
\text { dias não úteis poderiam ser justificáveis. }\end{array}$ \\
\hline
\end{tabular}

Quadro 8.3: Comparação de subcritérios em relação aos Critérios 
Após a atribuição dos valores em cada subcritério, e conforme a formulação do método AHP descrita anteriormente, gerou-se os resultados descritos na Tabela 8.2, em termos de pesos para cada subcritério em relação aos critérios iniciais.

\begin{tabular}{|c|c|c|c|}
\hline Critérios & Subcritérios & $\begin{array}{c}\text { Peso- } \\
\text { Subcritérios } \\
\text { em relação } \\
\text { aos Critérios }\end{array}$ & $\begin{array}{c}\text { Índice de } \\
\text { inconsistência }\end{array}$ \\
\hline \multirow{3}{*}{$\begin{array}{c}\text { C. dos } \\
\text { Prestadores }\end{array}$} & Tx. de crescimento das despesas & 0,052 & \multirow{3}{*}{0,07} \\
\hline & Envolvimento em investigações anteriores & 0,199 & \\
\hline & Tempo de credenciamento & 0,017 & \\
\hline \multirow{2}{*}{$\begin{array}{c}\text { C. dos } \\
\text { Pacientes }\end{array}$} & Percentual de pacientes localizados fora da UF & 0,012 & \multirow{2}{*}{0,07} \\
\hline & Percentual de pacientes jovens ou idosos & 0,105 & \\
\hline \multirow{3}{*}{$\begin{array}{c}\text { C. das } \\
\text { Cobranças }\end{array}$} & $\%$ de cobranças referentes a valores glosados & 0,108 & \multirow{3}{*}{0,10} \\
\hline & Frequência média semanal dos atendimentos & 0,469 & \\
\hline & $\%$ de atendimentos em feriados / finais de semana & 0,038 & \\
\hline
\end{tabular}

Tabela 8.2: Pesos atribuídos aos subcritérios

Esta análise inicial revelou que os subcritérios de "envolvimento em investigações anteriores", "percentual de pacientes jovens ou idosos", e "frequência média semanal dos atendimentos" são aqueles que receberam os maiores pesos dentro de seus respectivos Critérios. A Figura 8.5 descreve a visão do modelo, com a atribuição dos pesos dos critérios e subcritérios.

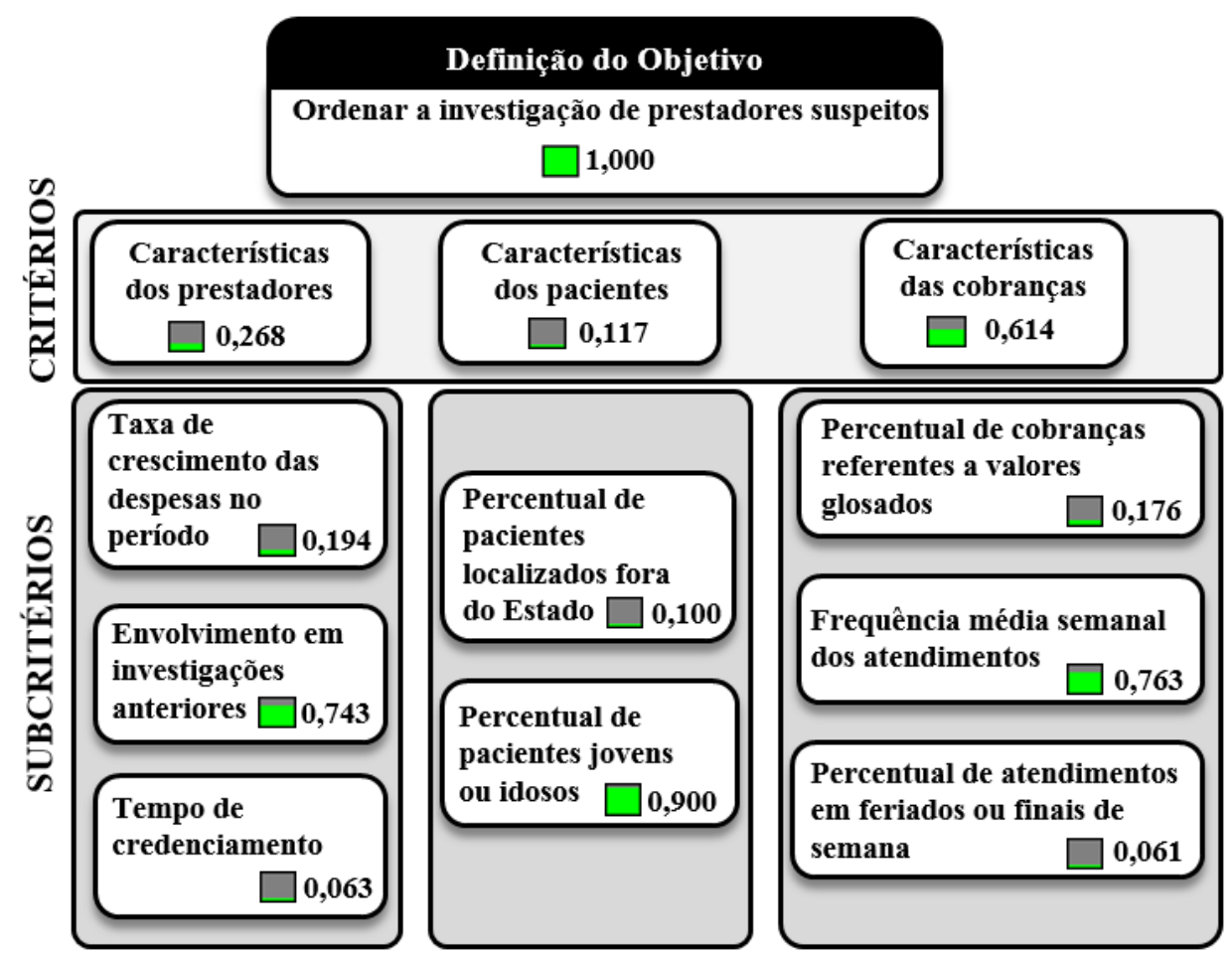

Figura 8.5: Modelo AHP - pesos atribuídos ao Objetivo, Critérios e Subcritérios 
Os valores da Figura 8.5 demonstram a prioridade local, ou seja, a importância de cada elemento em relação à hierarquia imediatamente superior.

A etapa final da aplicação do AHP é a comparação, em relação aos subcritérios, de cada alternativa (neste caso, os próprios prestadores de serviço identificados como suspeitos no modelo de clusterização). Os itens a seguir detalham como esta atividade foi realizada.

\subsubsection{Resultados dos julgamentos - Alternativas por Subcritério}

\subsubsection{Características dos Prestadores - Taxa de crescimento das despesas no período}

O cálculo da taxa de crescimento das despesas foi realizada pela análise da média aritmética das despesas mensais de cada prestador ao longo do período avaliado, de janeiro a dezembro de 2013. A fonte para este cálculo foi a mesma base de dados utilizada para construção do modelo de clusterização. A Tabela 8.3 apresenta os resultados, por prestador.

\begin{tabular}{c|c|c}
\hline Prestadores & Total Pago & $\begin{array}{c}\text { Tx. De crescimento das despesas } \\
\text { (jan-dez 2013) }\end{array}$ \\
\hline Prestador 01 & $\mathbf{2 7 . 2 1 6 , 0 0}$ & $\mathbf{7 , 0 3 \%}$ \\
\hline Prestador 02 & $\mathbf{1 0 6 . 7 6 0 , 9 1}$ & $\mathbf{8 , 8 4 \%}$ \\
\hline Prestador 03 & $\mathbf{1 0 0 . 4 1 3 , 0 0}$ & $\mathbf{- 2 , 5 2 \%}$ \\
\hline Prestador 04 & $\mathbf{4 2 . 4 3 2 , 4 0}$ & $\mathbf{1 4 , 2 4 \%}$ \\
\hline
\end{tabular}

Tabela 8.3: Taxa de crescimento das despesas, por prestador

A análise do histórico de cobranças revelou que entre as quatro entidades, o Prestador 04 possui o maior índice de crescimento, de 14,24\%. Os prestadores 02 e 01 possuem taxas de 8,84\% e 7,03\%, respectivamente. Já o Prestador 03 apresentou taxa decrescente, de $-2,52 \%$.

Para esta análise, decidiu-se por comparar o percentual de crescimento de cada alternativa em comparação com as demais. A Tabela 8.4 detalha os valores de intensidade, conforme a diferença do percentual de crescimento entre duas alternativas. 


\begin{tabular}{|c|c|c|c|}
\hline $\begin{array}{c}\text { Percentual de } \\
\text { diferença }\end{array}$ & Intensidade & $\begin{array}{c}\text { Percentual de } \\
\text { diferença }\end{array}$ & Intensidade \\
\hline $1 \%-50 \%$ & 1 & $251 \%-300 \%$ & 6 \\
\hline $51 \%-100 \%$ & 2 & $301 \%-350 \%$ & 7 \\
\hline $101 \%-150 \%$ & 3 & $351 \%-400 \%$ & 8 \\
\hline $151 \%-200 \%$ & 4 & $>400 \%$ & 9 \\
\hline $201 \%-250 \%$ & 5 & & \\
\hline
\end{tabular}

Tabela 8.4: Tx. de crescimento das despesas - valores de intensidade por $\%$ de diferença

A escala acima propõe que percentuais de diferença inferiores a $50 \%$ podem ser considerados, para efeitos práticos, iguais. Também são utilizados os valores intermediários da escala de Saaty $(2,4,6$, e 8). Percentuais de diferença acima de 400\% recebem o valor máximo, que também é atribuído aos casos em que é necessária a comparação entre uma alternativa que sofreu crescimento de despesas, enquanto outra evidenciou uma redução nessa taxa. Com base na escala acima, a Tabela 8.5 apresenta os julgamentos realizados para as quatro alternativas nesse subcritério. Novamente são destacadas as alternativas escolhidas em cada comparação.

\begin{tabular}{c|c|c|c|c|c}
\hline \multicolumn{2}{c|}{ Comparação - Alternativas } & \multicolumn{2}{c|}{$\begin{array}{c}\text { Taxas de crescimento } \\
\text { das despesas }\end{array}$} & $\begin{array}{c}\text { \% Diferença } \\
\text { (Vlr. Absoluto) }\end{array}$ & Intensidade \\
\hline A & $\boldsymbol{B}$ & $\boldsymbol{A}$ & $\boldsymbol{B}$ & & 1 \\
\hline Prestador 01 & Prestador 02 & $\mathbf{7 , 0 3 \%}$ & $\mathbf{8 , 8 4 \%}$ & $25,75 \%$ & 9 \\
\hline Prestador 01 & Prestador 03 & $\mathbf{7 , 0 3 \%}$ & $\mathbf{- 2 , 5 2 \%}$ & $378,97 \%$ & 3 \\
\hline Prestador 01 & Prestador 04 & $\mathbf{7 , 0 3 \%}$ & $\mathbf{1 4 , 2 4 \%}$ & $102,56 \%$ & 9 \\
\hline Prestador 02 & Prestador 03 & $\mathbf{8 , 8 4 \%}$ & $\mathbf{- 2 , 5 2 \%}$ & $450,79 \%$ & 2 \\
\hline Prestador 02 & Prestador 04 & $\mathbf{8 , 8 4 \%}$ & $\mathbf{1 4 , 2 4 \%}$ & $61,09 \%$ & 9 \\
\hline Prestador 03 & Prestador 04 & $\mathbf{- 2 , 5 2 \%}$ & $\mathbf{1 4 , 2 4 \%}$ & $665,08 \%$ & \\
\hline
\end{tabular}

Tabela 8.5: Tx. de crescimento das despesas - Comparação de alternativas em relação ao subcritério

Como resultado das atribuições acima, a Tabela 8.6 descreve os pesos atribuídos a cada alternativa em relação ao subcritério, calculados pela ferramenta Expert Choice [39] com base na formulação do AHP.

\begin{tabular}{|c|c|c}
\hline Alternativas & $\begin{array}{c}\text { Peso em relação ao subcritério } \\
\text { "Taxa de crescimento das despesas" }\end{array}$ & $\begin{array}{c}\text { Índice de } \\
\text { inconsistência }\end{array}$ \\
\hline Prestador 01 & $\mathbf{0 , 2 3 1}$ & \multirow{2}{*}{0,04} \\
\hline Prestador 02 & $\mathbf{0 , 2 5 1}$ & \\
\hline Prestador 03 & $\mathbf{0 , 0 3 4}$ & \\
\hline Prestador 04 & $\mathbf{0 , 4 8 3}$ & \\
\hline
\end{tabular}

Tabela 8.6: Tx. de crescimento das despesas - pontuação das alternativas 
Conforme a Tabela 8.6, o Prestador 04 recebeu o maior peso entre as quatro alternativas, de 0,483, seguido pelos Prestadores 02 e 01. O Prestador 03, único a apresentar redução na taxa de crescimento das despesas, recebeu a menor pontuação.

\subsubsection{Características dos Prestadores - Envolvimento em}

\section{investigações anteriores}

A análise das alternativas em relação a este subcritério necessitou a criação de métricas específicas para a atribuição dos valores de intensidade para cada comparação. Foram considerados os seguintes fatores, em ordem crescente de importância:

a) Prestador com registro de reclamações de participantes: É verificado o histórico do prestador, registrado no seu cadastro no sistema de pagamentos da OPS, no intuito de identificar se a entidade já foi alvo de alguma crítica ou reclamação por parte de seus pacientes.

b) Prestador já envolvido em investigações anteriores: Quanto a esta métrica, é feito um levantamento no histórico de investigações realizadas anteriormente pela área de riscos e controles internos da OPS, verificando se o prestador já esteve envolvido anteriormente em estudos com foco na identificação de práticas abusivas de cobrança.

Com base nestes critérios, foram levantadas as informações sobre cada prestador, e registrados os julgamentos, conforme a Tabela 8.7.

\begin{tabular}{|c|c|c|c|}
\hline \multicolumn{2}{|c|}{$\begin{array}{l}\text { Comparações } \\
(P=\text { Prestador })\end{array}$} & Intensidade & \multirow[t]{2}{*}{ Justificativa } \\
\hline$A$ & $B$ & & \\
\hline P01 & P02 & 9 & $\begin{array}{l}\text { O Prestador } 01 \text { apresentou registros de reclamações anteriores, } \\
\text { envolvendo cobranças de procedimentos não realizados. Não } \\
\text { foram identificadas anomalias referentes ao Prestador } 02 \text {. }\end{array}$ \\
\hline P01 & P03 & 1 & $\begin{array}{l}\text { Ambos os Prestadores apresentaram registros de reclamações } \\
\text { anteriores. }\end{array}$ \\
\hline P01 & P04 & 9 & $\begin{array}{l}\text { O Prestador } 01 \text { apresentou registros de reclamações anteriores. } \\
\text { Não foram identificadas anomalias referentes ao Prestador } 04 .\end{array}$ \\
\hline P02 & P03 & 9 & $\begin{array}{l}\text { O Prestador } 03 \text { apresentou registros de reclamações anteriores, } \\
\text { envolvendo erros no envio de cobranças. Não foram identificadas } \\
\text { anomalias referentes ao Prestador } 02 \text {. }\end{array}$ \\
\hline P02 & P04 & 1 & Nenhum dos dois prestadores apresentou anomalias. \\
\hline P03 & P04 & 9 & $\begin{array}{l}\text { O Prestador } 03 \text { apresentou registros de reclamações anteriores. } \\
\text { Não foram identificadas anomalias referentes ao Prestador } 04 .\end{array}$ \\
\hline
\end{tabular}

Tabela 8.7: Envolvimento em investigações anteriores - comparação de alternativas 
Considerando os registros de reclamação direcionados aos os Prestadores 01 e 03, ambos foram subsequentemente priorizados nesta análise específica. Verifica-se na Tabela 8.8 o cálculo final desta comparação.

\begin{tabular}{l|c|c}
\hline Alternativas & $\begin{array}{c}\text { Peso em relação ao subcritério } \\
\text { "Envolvimento em investigações anteriores” }\end{array}$ & Índice de inconsistência \\
\hline Prestador 01 & $\mathbf{0 , 4 5 0}$ & \multirow{2}{*}{0} \\
\hline Prestador 02 & $\mathbf{0 , 0 5 0}$ & $\mathbf{0 , 0 0}$ \\
\hline Prestador 03 & $\mathbf{0 , 4 5 0}$ & \\
\hline Prestador 04 & $\mathbf{0 , 0 5 0}$ & \\
\hline
\end{tabular}

Tabela 8.8: Envolvimento em investigações anteriores - pontuação das alternativas

A pontuação espelha o resultado das comparações, tendo em vista que apenas os Prestadores 01 e 03 apresentaram reclamações anteriores, e nenhum dos prestadores esteve envolvido em investigações anteriores.

\subsubsection{Características dos Prestadores - Tempo de credenciamento}

A análise do tempo de credenciamento de cada prestador considerou a hipótese de que, quanto mais recente fosse o cadastro do prestador junto à OPS, maiores as chances de existirem inconsistências em seus registros de cobrança. O cálculo considerou a diferença de meses completos entre a data inicial de cadastro do prestador e o dia 31/12/2013. Conforme a Tabela 8.9, criou-se um conjunto de medidas para a comparação entre dois prestadores, considerando a diferença do tempo de credenciamento entre eles.

\begin{tabular}{c|c}
\hline Meses de diferença & Intensidade \\
\hline 1 a 12 & 1 \\
\hline 13 a 24 & 3 \\
\hline 25 a 36 & 5 \\
\hline 37 a 48 & 7 \\
\hline$>48$ & 9 \\
\hline
\end{tabular}

Tabela 8.9: Tempo de credenciamento - tabela de intensidades para comparação 
A Tabela 8.10 apresenta o resultado das comparações realizadas entre as alternativas.

\begin{tabular}{c|c|c|c|c|l}
\hline \multicolumn{2}{c|}{$\begin{array}{c}\text { Comparações } \\
(\boldsymbol{P}=\text { Prestador })\end{array}$} & \multicolumn{2}{c|}{$\begin{array}{c}\text { Tempo de } \\
\text { credenciamento } \\
(\text { em meses })\end{array}$} & Intensidade & Justificativa \\
\hline $\boldsymbol{A}$ & $\boldsymbol{B}$ & $\boldsymbol{A}$ & $\boldsymbol{B}$ & & \\
\hline P01 & $\mathbf{P 0 2}$ & $\mathbf{3 7}$ & $\mathbf{3 0}$ & $\mathbf{1}$ & Prestador 02 é 7 meses mais novo. \\
\hline P01 & $\mathbf{P 0 3}$ & $\mathbf{3 7}$ & $\mathbf{1 5}$ & $\mathbf{3}$ & Prestador 03 é 22 meses mais novo. \\
\hline P01 & $\mathbf{P 0 4}$ & $\mathbf{3 7}$ & $\mathbf{8 2}$ & $\mathbf{7}$ & Prestador 01 é 45 meses mais novo. \\
\hline P02 & P03 & $\mathbf{3 0}$ & $\mathbf{1 5}$ & $\mathbf{3}$ & Prestador 03 é 15 meses mais novo. \\
\hline P02 & $\mathbf{P 0 4}$ & $\mathbf{3 0}$ & $\mathbf{8 2}$ & $\mathbf{9}$ & Prestador 02 é 52 meses mais novo. \\
\hline P03 & $\mathbf{P 0 4}$ & $\mathbf{1 5}$ & $\mathbf{8 2}$ & $\mathbf{9}$ & Prestador 03 é 67 meses mais novo. \\
\hline
\end{tabular}

Tabela 8.10: Tempo de credenciamento - comparação entre alternativas

A pontuação reflete o fato de que o Prestador 04, por ser mais antigo do que os demais, deve receber uma pontuação relativa mais alta. A Tabela 8.11 apresenta o resultado dos cálculos da ferramenta Expert Choice, considerando as intensidades atribuídas na comparação anterior.

\begin{tabular}{|c|c|c}
\hline Alternativas & $\begin{array}{c}\text { Peso em relação ao subcritério } \\
\text { "Tempo de credenciamento" }\end{array}$ & $\begin{array}{c}\text { Índice de } \\
\text { inconsistência }\end{array}$ \\
\hline Prestador 01 & $\mathbf{0 , 2 1 0}$ & \multirow{2}{*}{0,05} \\
\hline Prestador 02 & $\mathbf{0 , 2 2 8}$ & \\
\hline Prestador 03 & $\mathbf{0 , 5 2 5}$ & \\
\hline Prestador 04 & $\mathbf{0 , 0 3 6}$ & \\
\hline
\end{tabular}

Tabela 8.11: Tempo de credenciamento - pesos das alternativas

Com o peso de 0,525 , o Prestador 03 é a alternativa que recebeu a maior importância neste subcritério. Estes julgamentos finais permitem avaliar a importância de cada alternativa para a composição do Critério "Característica dos prestadores", conforme a Figura 8.6: 


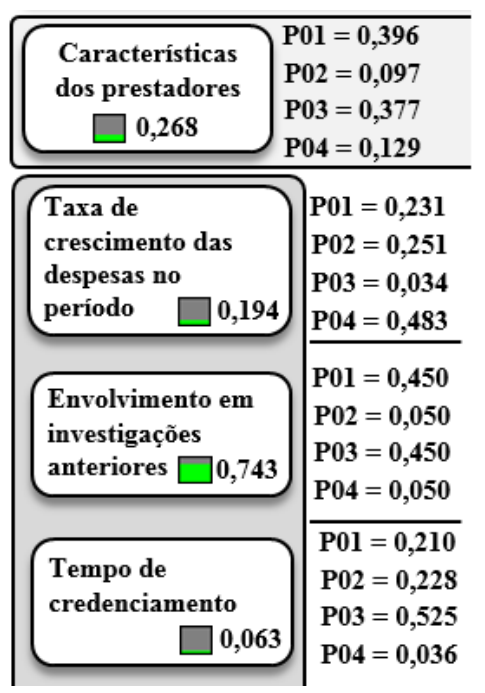

Figura 8.6: Visualização dos pesos para o critério "Característica dos prestadores"

Além dos pesos já descritos para cada subcritério (taxa de crescimento das despesas, envolvimento em investigações e tempo de credenciamento), verifica-se a importância das alternativas também para o Critério como um todo. Neste caso, o Prestador 01 apresenta a maior importância, com peso de 0,396, seguido pelo Prestador 03, com peso de 0,377.

\subsubsection{Características dos Pacientes - Percentual de pacientes \\ localizados fora da UF}

Esta análise específica partiu da hipótese de que um alto índice de atendimentos, por um prestador, de pacientes fora do seu Estado, poderia ser um indicativo de cobranças inexistentes. A fonte dos dados foi a mesma utilizada para o modelo de clusterização, onde foi avaliada a UF registrada na tabela de endereço dos pacientes envolvidos. No decorrer da análise, foi verificado que diversos participantes possuíam cadastrados incompletos, sem esta informação. Estes casos foram desconsiderados. A Tabela 8.12 apresenta o resultado da análise, por prestador.

\begin{tabular}{c|c|c}
\hline Prestadores & \% de pacientes do mesmo Estado & \% de pacientes fora do Estado \\
\hline Prestador 01 & $\mathbf{9 4 , 7 4 \%}$ & $\mathbf{5 , 2 6 \%}$ \\
\hline Prestador 02 & $93,33 \%$ & $\mathbf{6 , 6 7 \%}$ \\
\hline Prestador 03 & $\mathbf{1 0 0 , 0 0 \%}$ & $\mathbf{0 , 0 0 \%}$ \\
\hline Prestador 04 & $\mathbf{1 0 0 , 0 0 \%}$ & $\mathbf{0 , 0 0 \%}$ \\
\hline
\end{tabular}

Tabela 8.12: Percentual de pacientes localizados dentro e fora do Estado - por prestador 
Devido à proximidade entre os percentuais de atendimentos fora do Estado por prestador, a atribuição dos valores de intensidade em cada comparação foi realizada de forma mais subjetiva. A Tabela 8.13 apresenta este resultado.

\begin{tabular}{|c|c|c|c|c|c|}
\hline \multicolumn{2}{|c|}{$\begin{array}{c}\text { Comparações } \\
(P=\text { Prestador })\end{array}$} & \multicolumn{2}{|c|}{$\begin{array}{l}\text { \% de pacientes } \\
\text { fora do Estado }\end{array}$} & \multirow[t]{2}{*}{ Intensidade } & \multirow[t]{2}{*}{ Justificativa } \\
\hline $\boldsymbol{A}$ & $\boldsymbol{B}$ & $A$ & $\boldsymbol{B}$ & & \\
\hline P01 & P02 & $5,26 \%$ & $6,67 \%$ & 3 & $\begin{array}{l}\mathrm{O} \text { Prestador } 02 \text { apresentou percentual } \\
\text { ligeiramente mais alto que o Prestador } 01 \text {. }\end{array}$ \\
\hline P01 & P03 & $5,26 \%$ & $0,00 \%$ & 9 & \multirow{4}{*}{$\begin{array}{l}\text { Os Prestadores } 01 \text { e } 02 \text { receberam pontuação } \\
\text { máxima, considerando que consta o } \\
\text { percentual de } 0 \% \text { para os Prestadores } 03 \text { e } 04 .\end{array}$} \\
\hline P01 & P04 & $5,26 \%$ & $\mathbf{0 , 0 0 \%}$ & 9 & \\
\hline P02 & P03 & $6,67 \%$ & $\mathbf{0 , 0 0 \%}$ & 9 & \\
\hline P02 & P04 & $6,67 \%$ & $0,00 \%$ & 9 & \\
\hline P03 & P04 & $0,00 \%$ & $0,00 \%$ & 1 & $\begin{array}{l}\text { Ambos os Prestadores possuem percentual de } \\
0 \% \text {. }\end{array}$ \\
\hline
\end{tabular}

Tabela 8.13: Percentual de pacientes localizados fora do Estado - comparações por prestador

Conforme estes julgamentos, apenas os Prestadores 01 e 02 receberam valores de intensidade significativos, por serem os únicos a apresentarem percentuais de pacientes atendidos fora do Estado da entidade. O cálculo da ferramenta AHP, registrado na Tabela 8.14, reflete este resultado.

\begin{tabular}{l|c|c}
\hline Alternativas & $\begin{array}{c}\text { Peso em relação ao subcritério } \\
\text { “\% de pacientes fora do Estado" }\end{array}$ & $\begin{array}{c}\text { Índice de } \\
\text { inconsistência }\end{array}$ \\
\hline Prestador 01 & $\mathbf{0 , 3 2 8}$ & \multirow{2}{*}{0,06} \\
\hline Prestador 02 & $\mathbf{0 , 5 7 9}$ & \\
\hline Prestador 03 & $\mathbf{0 , 0 4 7}$ & \\
\hline Prestador 04 & $\mathbf{0 , 0 4 7}$ & \\
\hline
\end{tabular}

Tabela 8.14: Percentual de pacientes localizados fora do Estado - pesos por prestador

Os Prestadores 01 e 02 receberam as maiores pontuação, com pesos em relação ao subcritério de 0,328 e 0,579, respectivamente. Já os Prestadores 03 e 04, por não apresentarem percentuais significativos nesta categoria, receberam a pontuação mínima como resultado da comparação par a par. 


\subsubsection{Características dos Pacientes - Percentual de pacientes jovens ou idosos}

A análise do percentual de pacientes jovens ou idosos, por prestador, foi baseada no pressuposto, já verificado em estudos anteriores realizados pela OPS, de que indivíduos nestas faixas etárias muitas vezes transferem a responsabilidade pelo acompanhamento de suas terapias a familiares ou representantes legais. Desta forma, não haveria um controle direto, pelo próprio paciente atendido, em relação às quantidades ou valores cobrados.

Desta forma, a análise do percentual de pacientes idosos ou jovens envolveu o cálculo, por entidade, da quantidade de pacientes atendidos dentro do período de análise. Foi então calculada a proporção de pacientes com menos de 18 ou mais de 65 anos, para cada prestador, conforma a Tabela 8.15.

\begin{tabular}{l|c}
\hline Alternativas & $\begin{array}{c}\text { \% de pacientes jovens ou idosos } \\
\text { atendidos em 2013 }\end{array}$ \\
\hline Prestador 01 & $\mathbf{2 6 , 3 2 \%}$ \\
\hline Prestador 02 & $\mathbf{2 4 , 4 4 \%}$ \\
\hline Prestador 03 & $\mathbf{5 4 , 5 5 \%}$ \\
\hline Prestador 04 & $\mathbf{1 8 , 1 8 \%}$ \\
\hline
\end{tabular}

Tabela 8.15: Percentual de pacientes jovens ou idosos - por prestador

A diferença significativa entre os percentuais verificados em cada prestador resultou na necessidade de se criar parâmetros específicos para a atribuição dos valores de intensidade, para a realização das comparações entre as entidades. Conforme a Tabela 8.16, quanto maior a diferença entre dois percentuais comparados, maior será o valor de intensidade atribuído. Como exemplo, caso um prestador apresente um percentual de 30\%, e outro de 15\% (15\% de diferença) o primeiro prestador receberá um valor de intensidade de ' 3 '.

\begin{tabular}{c|c}
\hline Diferença entre percentuais & Intensidade \\
\hline $1 \%-10 \%$ & 1 \\
\hline $11 \%-20 \%$ & 3 \\
\hline $21 \%-30 \%$ & 5 \\
\hline $31 \%-40 \%$ & 7 \\
\hline$>40 \%$ & 9
\end{tabular}

Tabela 8.16: Percentual de pacientes jovens ou idosos - intensidades por faixa de diferença 
Na Tabela 8.17, verifica-se o resultado em cada comparação, com base nos valores definidos acima e a diferença entre cada entidade em relação às demais.

\begin{tabular}{c|c|c|c|c|c}
\hline \multicolumn{2}{c|}{ Comparação - Alternativas } & \multicolumn{2}{c|}{$\begin{array}{c}\text { \% de pacientes } \\
\text { jovens ou idosos }\end{array}$} & $\begin{array}{c}\text { \% Diferença } \\
\text { (Vlr. Absoluto) }\end{array}$ & \multirow{2}{*}{ Intensidade } \\
\hline A & $\boldsymbol{B}$ & $\boldsymbol{A}$ & $\boldsymbol{B}$ & & 1 \\
\hline Prestador 01 & Prestador 02 & $\mathbf{2 6 , 3 2 \%}$ & $\mathbf{2 4 , 4 4 \%}$ & $1,88 \%$ & 5 \\
\hline Prestador 01 & Prestador 03 & $\mathbf{2 6 , 3 2 \%}$ & $\mathbf{5 4 , 5 5 \%}$ & $28,23 \%$ & 1 \\
\hline Prestador 01 & Prestador 04 & $\mathbf{2 6 , 3 2 \%}$ & $\mathbf{1 8 , 1 8 \%}$ & $8,14 \%$ & 7 \\
\hline Prestador 02 & Prestador 03 & $\mathbf{2 4 , 4 4 \%}$ & $\mathbf{5 4 , 5 5 \%}$ & $30,11 \%$ & 1 \\
\hline Prestador 02 & Prestador 04 & $\mathbf{2 4 , 4 4 \%}$ & $\mathbf{1 8 , 1 8 \%}$ & $6,26 \%$ & 7 \\
\hline Prestador 03 & Prestador 04 & $\mathbf{5 4 , 5 5 \%}$ & $\mathbf{1 8 , 1 8 \%}$ & $36,37 \%$ & \\
\hline
\end{tabular}

Tabela 8.17: Percentual de pacientes jovens ou idosos - comparações por

prestador

A comparação entre os Prestadores 01 e 02, 01 e 04, e 02 e 04, resultaram no valor de intensidade ' 1 ', pois de acordo com a escala definida anteriormente, as diferenças entre seus respectivos percentuais os torna praticamente iguais em termos de importância.

Novamente os julgamentos foram inseridos no sistema Expert Choice, e o resultado é descrito na Tabela 8.18.

\begin{tabular}{|c|c|c}
\hline Alternativas & $\begin{array}{c}\text { Peso em relação ao subcritério } \\
\text { “\% de pacientes jovens ou idosos" }\end{array}$ & $\begin{array}{c}\text { Índice de } \\
\text { inconsistência }\end{array}$ \\
\hline Prestador 01 & $\mathbf{0 , 1 1 4}$ & \multirow{2}{*}{0,01} \\
\hline Prestador 02 & $\mathbf{0 , 1 0 5}$ & \\
\hline Prestador 03 & $\mathbf{0 , 6 7 6}$ & \\
\hline Prestador 04 & $\mathbf{0 , 1 0 5}$ & \\
\hline
\end{tabular}

Tabela 8.18: Percentual de pacientes jovens ou idosos - pesos por prestador

O resultado final demonstra que, devido ao seu alto percentual de pacientes jovens ou idosos, o Prestador 03 se destaca em relação aos seus pares, devendo consequentemente receber maior atenção no tocante a este subcritério específico.

Novamente os julgamentos finais permitem avaliar a importância de cada alternativa para a composição do Critério como um todo, conforme a Figura 8.7. 


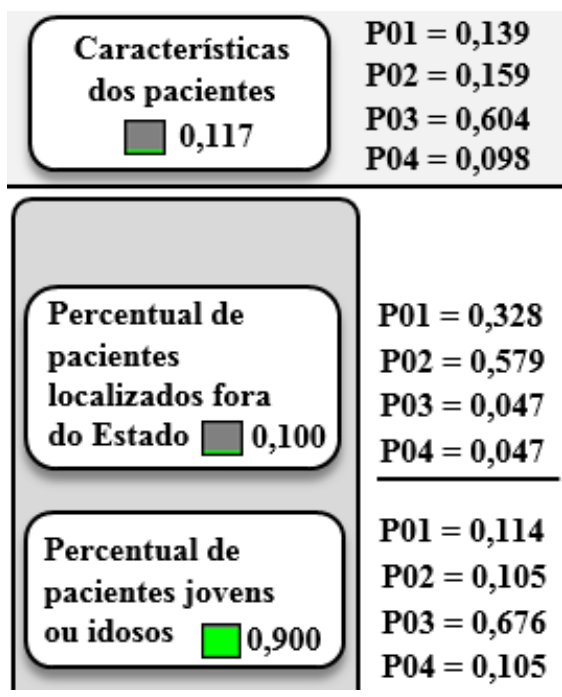

Figura 8.7: Visualização dos pesos para o critério "Característica dos pacientes"

Conforme a Figura 8.7, no Critério "Características dos Pacientes" o Prestador 03 se destaca claramente, com o peso de 0,604. Os outros prestadores 01, 02 e 04, por sua vez, recebem pesos semelhantes $(0,139,0,159$ e 0,098, respectivamente).

\subsubsection{Características das Cobranças - Percentual de cobranças referentes a valores glosados}

A métrica de "percentual de cobranças referentes a valores glosados" busca avaliar a proporção entre os valores cobrados pelos prestadores e os que foram efetivamente pagos. Vale ressaltar que o termo "glosa" se refere a alguma negativa de pagamento, registrada (manual ou automaticamente) no decorrer no fluxo de análise de contas médico-hospitalares para um determinada cobrança, o que resulta no pagamento parcial (ou recusa total) da guia encaminhada pelo prestador.

Já é de conhecimento dos gestores da OPS que um alto índice de glosas reflete diretamente no relacionamento entre a operadora e um prestador de serviços, podendo ser resultado de diversos fatores, entre eles o envio de cobranças em desacordo com parâmetros regulatórios do procedimento envolvido.

Para o cálculo deste subcritério, foi realizada a divisão do valor glosado no período avaliado, por prestador, pelo total pago no mesmo período, conforme a Tabela 8.19. 


\begin{tabular}{c|c|c|c}
\hline Prestadores & Valor Pago & Valor glosado & $\begin{array}{c}\text { \% do valor glosado em } \\
\text { relação ao total }\end{array}$ \\
\hline Prestador 01 & $\mathbf{R} \$ 27.216,00$ & $\mathbf{R} \$ 459,00$ & $1,69 \%$ \\
\hline Prestador 02 & $\mathrm{R} \$ 106.760,91$ & $\mathbf{R} \$ 3.024,67$ & $\mathbf{2 , 8 3 \%}$ \\
\hline Prestador 03 & $\mathbf{R} \$ 100.413,00$ & $\mathbf{R} \$ 945,00$ & $\mathbf{0 , 9 4 \%}$ \\
\hline Prestador 04 & $\mathbf{R} \$ 42.432,40$ & $\mathbf{R} \$ 1.061,40$ & $\mathbf{2 , 5 0 \%}$ \\
\hline
\end{tabular}

Tabela 8.19: Percentual de cobranças referentes a valores glosados - por prestador

O resultado da análise revelou que tanto os valores quanto os percentuais de glosa não se mostraram expressivos quanto ao total pago no período. Entre o conjunto total de guias avaliadas mensalmente pelo área de pagamento de contas, o índice médio de glosa gira em torno de 10\%. Contudo, nenhum dos prestadores avaliados apresentou percentual de glosa superior a $3 \%$.

Desta forma, julgou-se suficiente a análise subjetiva para atribuição dos valores de intensidade, na comparação de cada prestador. A Tabela 8.20 apresenta o resultado das comparações par a par, destacando a alternativa escolhida em cada comparação.

\begin{tabular}{c|c|c|c|c}
\hline \multicolumn{2}{c|}{ Comparação - Alternativas } & \multicolumn{2}{c|}{$\begin{array}{c}\text { \% de valores } \\
\text { glosados }\end{array}$} & \multirow{2}{*}{ Intensidade } \\
\cline { 1 - 4 } & $\boldsymbol{B}$ & $\boldsymbol{A}$ & $\boldsymbol{B}$ & \\
\hline Prestador 01 & Prestador 02 & $\mathbf{1 , 6 9 \%}$ & $\mathbf{2 , 8 3 \%}$ & 3 \\
\hline Prestador 01 & Prestador 03 & $\mathbf{1 , 6 9 \%}$ & $\mathbf{0 , 9 4 \%}$ & 3 \\
\hline Prestador 01 & Prestador 04 & $\mathbf{1 , 6 9 \%}$ & $\mathbf{2 , 5 0 \%}$ & 3 \\
\hline Prestador 02 & Prestador 03 & $\mathbf{2 , 8 3 \%}$ & $\mathbf{0 , 9 4 \%}$ & 5 \\
\hline Prestador 02 & Prestador 04 & $\mathbf{2 , 8 3 \%}$ & $\mathbf{2 , 5 0 \%}$ & 1 \\
\hline Prestador 03 & Prestador 04 & $\mathbf{0 , 9 4 \%}$ & $\mathbf{2 , 5 0 \%}$ & 5 \\
\hline
\end{tabular}

Tabela 8.20: Percentual de cobranças referentes a valores glosados julgamentos por prestador

Verifica-se que as maiores intensidades são atribuídas aos prestadores que são comparados com o Prestador 03, que apresenta o menor índice de glosa do conjunto avaliado. A Tabela 8.21 detalha o cálculo final dos pesos por prestador.

\begin{tabular}{l|c|c}
\hline Alternativas & $\begin{array}{c}\text { Peso em relação ao subcritério } \\
\text { “\% de cobranças } \text { glosadas” }\end{array}$ & $\begin{array}{c}\text { Índice de } \\
\text { inconsistência }\end{array}$ \\
\hline Prestador 01 & $\mathbf{0 , 1 5 2}$ & \multirow{2}{*}{0,02} \\
\hline Prestador 02 & $\mathbf{0 , 3 9 0}$ & \\
\hline Prestador 03 & $\mathbf{0 , 0 6 8}$ & \\
\hline Prestador 04 & $\mathbf{0 , 3 9 0}$ & \\
\hline
\end{tabular}

Tabela 8.21: Percentual de cobranças referentes a valores glosados - pesos por prestador 
Como consequência de possuírem o maior percentual de glosas, com percentual semelhante, os Prestadores 02 e 04 receberam o maior peso do conjunto avaliado, ambos com 0,390 .

\subsubsection{Características das Cobranças - Frequência média semanal dos atendimentos}

Este subcritério específico busca avaliar os prestadores sob a ótica de frequência de atendimentos. Para cada prestador, são somadas as quantidades cobradas por mês, dentro dos 12 meses no período avaliado. A média semanal é uma estimativa aproximada, obtida pela divisão das quantidades mensais por 4 . O objetivo da análise é identificar os prestadores com frequências de atendimento muito acima de seus pares, atribuindo uma maior importância para estes casos. A Tabela 8.22 detalha as frequências de atendimento para cada um dos prestadores avaliados.

\begin{tabular}{c|c|c}
\hline Prestadores & $\begin{array}{c}\text { Qtde. atendimentos } \\
\text { em 2013 }\end{array}$ & Qtde. média de atendimentos por semana \\
\hline Prestador 01 & 1.008 & $\mathbf{2 1 , 0 0}$ \\
\hline Prestador 02 & 3.887 & $\mathbf{8 0 , 9 8}$ \\
\hline Prestador 03 & 3.719 & $\mathbf{7 7 , 4 8}$ \\
\hline Prestador 04 & 1.516 & $\mathbf{3 1 , 5 8}$ \\
\hline
\end{tabular}

Tabela 8.22: Frequência média semanal dos atendimentos - por prestador

Considerando a discrepância considerável entre as quantidades verificadas, e no intuito de utilizar um parâmetro objetivo de análise e diminuir a possibilidade de inconsistências nas comparações, foi definida uma escala específica para a atribuição de valores de intensidade neste subcritério. Conforme a Tabela 8.23, o percentual de diferença entre duas quantidades avaliadas par a par determina a intensidade atribuída à alternativa escolhida.

\begin{tabular}{c|c}
\hline $\begin{array}{c}\text { Percentual de } \\
\text { diferença }\end{array}$ & Intensidade \\
\hline $\mathbf{1 \%}-\mathbf{5 0 \%}$ & $\mathbf{1}$ \\
\hline $\mathbf{5 1 \%}-\mathbf{1 0 0 \%}$ & $\mathbf{3}$ \\
\hline $\mathbf{1 0 1 \%}-\mathbf{1 5 0 \%}$ & $\mathbf{5}$ \\
\hline $\mathbf{1 5 1 \% - 2 0 0 \%}$ & $\mathbf{7}$ \\
\hline$>\mathbf{2 0 0 \%}$ & 9 \\
\hline
\end{tabular}

Tabela 8.23: Frequência média semanal dos atendimentos - intensidades por percentual de diferença 
Em seguida, na Tabela 8.24 é descrita a visão geral das comparações realizadas entre cada prestador, com base nas quantidades médias de atendimento por semana.

\begin{tabular}{c|c|c|c|c|c}
\hline \multicolumn{2}{c|}{ Comparação - Alternativas } & \multicolumn{2}{c|}{$\begin{array}{c}\text { Qtde. média de } \\
\text { atends. por semana }\end{array}$} & \multirow{2}{*}{$\begin{array}{c}\% \\
\text { Diferença }\end{array}$} & \multirow{2}{*}{ Intensidade } \\
\cline { 1 - 4 } $\boldsymbol{A}$ & $\boldsymbol{B}$ & $\boldsymbol{A}$ & $\boldsymbol{B}$ & & \\
\hline Prestador 01 & Prestador 02 & $\mathbf{2 1 , 0 0}$ & $\mathbf{8 0 , 9 8}$ & $285,62 \%$ & 9 \\
\hline Prestador 01 & Prestador 03 & $\mathbf{2 1 , 0 0}$ & $\mathbf{7 7 , 4 8}$ & $268,95 \%$ & 9 \\
\hline Prestador 01 & Prestador 04 & $\mathbf{2 1 , 0 0}$ & $\mathbf{3 1 , 5 8}$ & $50,38 \%$ & 3 \\
\hline Prestador 02 & Prestador 03 & $\mathbf{8 0 , 9 8}$ & $\mathbf{7 7 , 4 8}$ & $4,32 \%$ & 1 \\
\hline Prestador 02 & Prestador 04 & $\mathbf{8 0 , 9 8}$ & $\mathbf{3 1 , 5 8}$ & $61,00 \%$ & 3 \\
\hline Prestador 03 & Prestador 04 & $\mathbf{7 7 , 4 8}$ & $\mathbf{3 1 , 5 8}$ & $59,24 \%$ & 3 \\
\hline
\end{tabular}

Tabela 8.24: Frequência média semanal dos atendimentos - comparações entre as alternativas

A intensidade atribuída nas comparações acima reflete a diferença entre as frequências dos prestadores 02 e 03 quantos aos demais. Por conseguinte, estas duas entidades receberam o maior peso após o cálculo das prioridades pela ferramenta de AHP, conforme a Tabela 8.25.

\begin{tabular}{l|c|c}
\hline Alternativas & $\begin{array}{c}\text { Peso em relação ao subcritério } \\
\text { “Qtde. média de atendimentos por } \\
\text { semana" }\end{array}$ & $\begin{array}{c}\text { Índice de } \\
\text { inconsistência }\end{array}$ \\
\hline Prestador 01 & $\mathbf{0 , 0 4 5}$ & \multirow{2}{*}{0,00} \\
\hline Prestador 02 & $\mathbf{0 , 4 0 9}$ & \\
\hline Prestador 03 & $\mathbf{0 , 4 0 9}$ & \\
\hline Prestador 04 & $\mathbf{0 , 1 3 6}$ & \\
\hline
\end{tabular}

Tabela 8.25: Frequência média semanal dos atendimentos - pesos das alternativas

Como resultado da análise, foi possível definir que os Prestadores 02 e 03 possuem o peso mais expressivo em relação ao subcritério, com pontuação de 0,409 cada. São seguidos pelos Prestadores 04 e 01, com pontuações de 0,136 e 0,045, respectivamente. 


\subsubsection{Características das Cobranças - Percentual de atendimentos em feriados ou finais de semana}

Por fim, este último subcritério busca apontar quantidades possivelmente excessivas de atendimentos ocorridos em feriados ou finais de semana, por prestador. Embora a ocorrência de procedimentos realizados em dias não úteis não seja, por si só, um indicativo de comportamento suspeito, foram definidos como passíveis de análise aqueles casos em que um prestador apresente cobranças desta natureza em quantidades fora do padrão verificado no grupo de entidades como um todo.

Sendo assim, foram avaliadas individualmente todas as datas de atendimento apresentadas pelos prestadores envolvidos, considerando a base de dados utilizada no modelo de clusterização. Tendo em vista que as informações estão armazenadas em um banco de dados no formato Microsoft Access, foi criada uma consulta ligada à tabela de dados de pagamento, utilizando a função weekday para definir em qual dia da semana ocorreu o atendimento (esta função converte cada data em seu respectivo dia da semana, atribuindo valores de 1 a 7). As datas foram cruzadas com uma tabela auxiliar contendo os feriados nacionais para o período em análise (janeiro a dezembro de 2013).

Cada registro de atendimento recebeu então um rótulo, apontando se ocorreu em dia não útil ou em data comemorativa. Para cada prestador, conforme a Tabela 8.26, foi calculado o percentual de atendimento referentes a estas datas, em relação ao total de dias com cobranças.

\begin{tabular}{c|c|c}
\hline Prestadores & $\begin{array}{c}\text { Qtde. atendimentos } \\
\text { em } 2013\end{array}$ & \% de atendimentos em finais de semana \\
\hline Prestador 01 & 1.008 & $\mathbf{0 , 9 9 \%}$ \\
\hline Prestador 02 & 3.887 & $\mathbf{1 1 , 8 6 \%}$ \\
\hline Prestador 03 & 3.719 & $\mathbf{0 , 7 8 \%}$ \\
\hline Prestador 04 & 1.516 & $\mathbf{0 , 0 7 \%}$ \\
\hline
\end{tabular}

Tabela 8.26 - Percentual de atendimentos em feriados ou finais de semana por prestador

A análise revelou que dos quatro prestadores, apenas o Prestador 02 apresentou um percentual significativo de atendimentos em dias não úteis, muito acima dos demais. Sendo assim, optou-se por avaliar as quatro entidades diretamente, conforme a Tabela 8.27. 


\begin{tabular}{c|c|c|c|c|l}
\hline \multicolumn{2}{c|}{$\begin{array}{c}\text { Comparações } \\
(\boldsymbol{P}=\text { Prestador })\end{array}$} & $\begin{array}{c}\text { \% de atendimentos em } \\
\text { dias não uteis }\end{array}$ & Intensidade & \multicolumn{1}{c}{ Justificativa } \\
\hline $\boldsymbol{A}$ & $\boldsymbol{B}$ & $\boldsymbol{A}$ & $\boldsymbol{B}$ & & \\
\hline P01 & $\mathbf{P 0 2}$ & $\mathbf{0 , 9 9 \%}$ & $\mathbf{1 1 , 8 6 \%}$ & $\mathbf{9}$ & P02 possui percentual muito acima de P01 \\
\hline P01 & $\mathbf{P 0 3}$ & $\mathbf{0 , 9 9 \%}$ & $\mathbf{0 , 7 8 \%}$ & $\mathbf{1}$ & Percentuais aproximadamente iguais \\
\hline P01 & $\mathbf{P 0 4}$ & $\mathbf{0 , 9 9 \%}$ & $\mathbf{0 , 0 7 \%}$ & $\mathbf{3}$ & Percentual de P01 superior a de P04 \\
\hline P02 & $\mathbf{P 0 3}$ & $\mathbf{1 1 , 8 6 \%}$ & $\mathbf{0 , 7 8 \%}$ & $\mathbf{9}$ & P02 possui percentual muito acima de P03 \\
\hline P02 & $\mathbf{P 0 4}$ & $\mathbf{1 1 , 8 6 \%}$ & $\mathbf{0 , 0 7 \%}$ & $\mathbf{9}$ & P02 possui percentual muito acima de P04 \\
\hline P03 & $\mathbf{P 0 4}$ & $\mathbf{0 , 7 8 \%}$ & $\mathbf{0 , 0 7 \%}$ & $\mathbf{3}$ & Percentual de P03 superior a de P04 \\
\hline
\end{tabular}

Tabela 8.27: Percentual de atendimentos em feriados ou finais de semana comparações entre alternativas

Novamente os julgamentos foram calculados conforme a formulação do método AHP. Os resultados são apresentados na Tabela 8.28.

\begin{tabular}{|c|c|c}
\hline Alternativas & $\begin{array}{c}\text { Peso em relação ao subcritério } \\
\text { “\% de atendimentos em dias não uteis” }\end{array}$ & $\begin{array}{c}\text { Índice de } \\
\text { inconsistência }\end{array}$ \\
\hline Prestador 01 & $\mathbf{0 , 1 0 6}$ & \multirow{2}{*}{0,06} \\
\hline Prestador 02 & $\mathbf{0 , 7 4 0}$ & \\
\hline Prestador 03 & $\mathbf{0 , 1 0 6}$ & \\
\hline Prestador 04 & $\mathbf{0 , 0 4 8}$ & \\
\hline
\end{tabular}

Tabela 8.28: Percentual de atendimentos em feriados ou finais de semana pesos por alternativa

O peso atribuído ao Prestador 02 reflete a importância que possui dentro os demais prestadores neste subcritério específico.

Em termos do Critério "Características das Cobranças", a Figura 8.8 demonstra a importância de cada alternativa, em decorrência das avaliações realizadas em cada subcritério. 


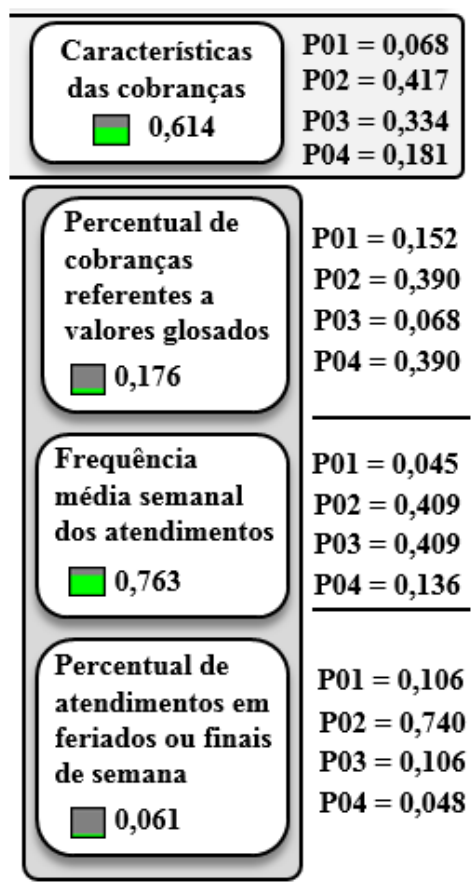

Figura 8.8: Visualização dos pesos para o critério "Característica das cobranças"

Os Prestadores 02 e 03 são os que mais contribuem para o resultado geral do Critério, com pesos de 0,417 e 0,334. Os demais prestadores recebem importâncias menos expressivas (O Prestador 04 possui peso de 0,181 e o Prestador 01, apenas 0,068). A análise revela que, no Critério mais importante do modelo, duas alternativas são claramente preferidas, o que deve se refletir no resultado final.

Sendo assim, o cálculo do último subcritério possibilita verificar o cálculo final do modelo, descrito no próximo item.

\subsection{Resultados do Método AHP}

A Tabela 8.29 apresenta o resultado da aplicação do método AHP construído com base na pesquisa, com todos os valores correspondentes calculados para cada um dos critérios, subcritérios e alternativas.

Entre os Critérios, verifica-se que as Características de Cobrança foram julgadas como as mais importantes, e dentro deste conjunto, foi definida a análise das frequências semanais de cobrança como fator decisivo para a escolha dos prestadores.

Os valores finais representam o cálculo do software de AHP, definindo a prioridade global (ou seja, importância em relação ao objetivo) de cada alternativa. O 
modelo define que, com seus respectivos pesos de 0,367 e 0,313, os Prestadores 03 e 02 devem ser priorizados para análise, seguidos pelos Prestadores 04 e 01.

Em termos de direcionamento de esforços de auditoria, esta ordenação serve para auxiliar nas escolhas de diversas etapas do processo, como a definição de quais cobranças fisicas serão solicitadas primeiro, qual o conjunto de participantes deverá ser priorizado para as entrevistas, e em que ordem deverão ser agendadas as visitas presenciais nos estabelecimentos investigados.

No decorrer da aplicação do modelo de priorização das investigações por meio do AHP, foram identificadas algumas vantagens em relação ao método atual, de priorização apenas com base nos valores envolvidos de cada prestador. Os ganhos são decorrentes da rapidez na identificação das prioridades, do uso mais eficiente dos recursos disponíveis para investigação e maior probabilidade de impedir a continuação dos comportamentos abusivos, caso confirmados

As informações necessárias para o cálculo das métricas utilizadas neste modelo podem ser extraídas da mesma base de dados inicialmente utilizada no modelo de identificação de cobranças abusivas, e os cálculos podem ser realizados automaticamente após a parametrização inicial das queries no banco de dados utilizado para armazenar as informações de cobrança. Desta forma, não há a expectativa de que as comparaçãos par a par consumam um tempo excessivo de análise pelos avaliadores.

Ademais, considerando as atividades envolvidas no fluxo de investigação, como a análise documental, a elaboração de questionários e contato com prestadores e participantes, além das auditorias in loco, o ganho em termos de eficiência na escolha correta das entidades a serem investigadas significa um menor intervalo entre a identificação das inconsistências e a interrupção das práticas abusivas, caso confirmadas. 


\begin{tabular}{|c|c|c|c|c|c|c|c|c|c|}
\hline \multicolumn{10}{|c|}{ Objetivo: Ordenar a investigação de prestadores suspeitos } \\
\hline \multirow[b]{2}{*}{ Alternativas } & \multicolumn{3}{|c|}{ Características dos Prestadores } & \multicolumn{2}{|c|}{$\begin{array}{c}\text { Características dos } \\
\text { Pacientes }\end{array}$} & \multicolumn{3}{|c|}{ Características das Cobranças } & \multirow[b]{2}{*}{ TOTAIS } \\
\hline & $\begin{array}{c}\text { Taxa de } \\
\text { crescimento } \\
\text { das despesas } \\
\text { no periodo }\end{array}$ & $\begin{array}{c}\text { Envolvimento } \\
\text { em } \\
\text { investigações } \\
\text { anteriores }\end{array}$ & $\begin{array}{c}\text { Tempo de } \\
\text { credenciamento }\end{array}$ & $\begin{array}{c}\% \text { de } \\
\text { pacientes } \\
\text { localizados } \\
\text { fora do } \\
\text { Estado }\end{array}$ & $\begin{array}{c}\% \text { de } \\
\text { pacientes } \\
\text { jovens } \\
\text { ou idosos }\end{array}$ & $\begin{array}{c}\text { \% de } \\
\text { cobranças } \\
\text { referentes } \\
\text { a valores } \\
\text { glosados } \\
\end{array}$ & $\begin{array}{c}\text { Frequência } \\
\text { média } \\
\text { semanal dos } \\
\text { atendimentos }\end{array}$ & $\begin{array}{c}\% \text { de } \\
\text { atendimentos } \\
\text { em feriados } \\
\text { ou finais de } \\
\text { semana }\end{array}$ & \\
\hline Prestador 01 & 0,011 & 0,089 & 0,003 & 0,003 & 0,008 & 0,019 & 0,023 & 0,002 & 0,159 \\
\hline Prestador 02 & 0,012 & 0,010 & 0,003 & 0,005 & 0,007 & 0,048 & 0,210 & 0,017 & $\mathbf{0 , 3 1 3}$ \\
\hline Prestador 03 & 0,002 & 0,089 & 0,008 & 0,000 & 0,047 & 0,008 & 0,210 & 0,002 & 0,367 \\
\hline Prestador 04 & 0,023 & 0,010 & 0,001 & 0,000 & 0,007 & 0,048 & 0,070 & 0,001 & 0,161 \\
\hline \multirow{3}{*}{ TOTAIS } & 0,052 & 0,199 & 0,017 & 0,012 & 0,105 & 0,108 & 0,469 & 0,038 & 1,000 \\
\hline & & 0,268 & & \multicolumn{2}{|c|}{0,117} & \multicolumn{3}{|c|}{0,614} & 1,000 \\
\hline & \multicolumn{9}{|c|}{1,000} \\
\hline
\end{tabular}

Tabela 8.29: Resultados finais do modelo AHP 


\section{Parte III}




\section{Capitulo 9}

\section{Conclusões}

Este capítulo aborda alguns dos principais resultados obtidos com a construção dos modelos descritos ao longo do estudo, e finaliza-se com as propostas de trabalhos futuros, visando melhorias adicionais com outras aplicações das ferramentas e métodos introduzidos nesta pesquisa.

\subsection{Resultados Obtidos}

Este estudo teve como objetivo principal a apresentação de medidas para o aprimoramento da gestão de riscos operacionais no processo de pagamento de contas médicas de uma operadora de planos de saúde, por meio da integração de técnicas de detecção de anomalias e métodos de análise multicritério à sua metodologia atual de avaliação de riscos.

Para atingir este objetivo geral, foi necessária a identificação das melhores práticas referentes à gestão de riscos, por meio do estudo de metodologias, padrões, normas e tecnologias. O cumprimento desta tarefa se deu pelo levantamento de arcabouços, técnicas e ferramentas para a avaliação de riscos em ambientes corporativos.

Os próximos passos contemplaram o diagnóstico da metodologia atual de gestão de riscos da organização, e a proposta de uma nova metodologia de gestão de riscos, por meio da combinação entre a metodologia existente e as técnicas identificadas por meio do levantamento bibliográfico. Como resultados, verifica-se a descrição da metodologia atual da organização no item 4.3.1, e as propostas de alterações conforme, o Capítulo 05. 
A aplicação da nova metodologia de autoavaliação de riscos e controles no processo de pagamento de contas médicas da organização resultou em um conjunto de 52 riscos identificados, sendo entre estes, 15 indicados para tratamento. Entre os riscos mais críticos, optou-se por avaliar aquele relacionado a possíveis cobranças excessivas em procedimentos médicohospitalares.

Desta forma, a próxima etapa de pesquisa foi a proposta de um modelo quantitativo para tratamento deste risco. O fluxo apresentado, baseado em técnicas de detecção de anomalias, foi aplicado em dois conjuntos de dados distintos, referentes a cobranças de consultas e sessões de psicoterapia. Estes conjuntos abrangeram os principais grupos de despesas no tipo de prestador "pessoa física", a classe de entidades escolhida para análise por possuir a maior representatividade na rede credenciada da operadora. Como resultado da construção do modelo inicial e aplicação dos algoritmos de clusterização, foi possível identificar um conjunto de prestadores de serviços suspeitos. Para estas entidades, a análise documental comprovou a existência de irregularidades nas cobranças recebidas no decorrer do ano de 2013, o que levou, em alguns casos, ao seu descredenciamento da rede da operadora.

O último passo foi a criação de um modelo para priorizar as investigações referentes às entidades suspeitas, apontadas pelo modelo de análise quantitativa. Elaborado com base no método AHP, o modelo proposto envolveu a análise par a par de critérios relacionados às características de cada prestador, de seus participantes e de suas práticas de cobrança. Como resultado, houve a indicação da ordem em que as entidades deveriam ser avaliadas pela equipe de auditoria da organização, conforme o peso atribuído aos diversos fatores de risco contemplados no modelo.

\subsection{Trabalhos Futuros}

Conforme descrito anteriormente, foram ainda identificadas diversas oportunidades de melhoria no modelo de gestão de riscos empregado pela organização.

Em termos da análise de riscos por atividade do processo, sugere-se a elaboração de métricas para avaliar a dependência entre os riscos, de forma a 
melhor priorizar o seu tratamento, pois uma possível perda poderia ser evitada caso fosse consequência de riscos não mitigados em atividades anteriores. Quanto à avaliação de controles, seria útil estabelecer critérios adicionais de mensuração dos níveis de controle, contemplando, por exemplo, análises estatísticas de falhas e custos de implementação baseados em dados históricos.

Quanto ao modelo quantitativo de investigação de cobranças de entidades suspeitas, o próximo passo seria ampliar a análise para os demais procedimentos de maior custo para o tipo de prestador "pessoa física". Além da alteração do escopo de procedimentos, outras variáveis poderiam ser acrescentadas ao modelo. A título de exemplo, um dos resultados do estudo foi a sugestão, encaminhada à área gestora do processo de pagamento de contas, de avaliar o número de vezes em que um participante foi atendido no mesmo dia (ou seja, a frequência de consultas por participante), assim como a quantidade de medicamentos e exames prescritos por consulta, e a incidência de abusos por Estado. Foi sugerida também a criação de outros controles para avaliação de práticas de cobrança possivelmente suspeitas, como a prestação de serviços por pessoas físicas em finais de semana e feriados. Podem ser verificados, inclusive, casos de prestadores cuja cobrança estava relacionada a serviços prestados a si próprios (neste caso, serão avaliadas coincidências entre o nome do participante e nome do prestador). Existe também a possibilidade de aplicar este modelo aos procedimentos realizados por prestadores do tipo "pessoa jurídica", ampliando substancialmente o escopo dos valores potencialmente envolvidos. Neste caso, seria necessário um levantamento, junto às dependências gestoras de cada prestador, do corpo clínico disponível para cada entidade apontada como suspeita. A comparação entre os serviços cobrados e a capacidade produtiva seria realizada pela análise da relação entre a quantidade cobrada e o número de profissionais disponíveis para realização do procedimento em uma determinada data.

A aplicação de técnicas de detecção de anomalias também poderia ser aplicada para o estudo do uso de materiais e medicamentos em excesso, tanto em regimes ambulatoriais quanto, principalmente, de internação. Para isso, o estudo das quantidades excessivas seria feito não com base nas quantidades de procedimentos, mas de itens de custo utilizados por episódio de atendimento. Os dados apresentam várias possibilidades, incentivando a construção de uma estrutura mais robusta para investigações futuras. 


\section{Referências}

[1] Abbas, O. A. Comparisons Between Data Clustering Algorithms. International Arab Journal of Information Technology, v. 5, n. 3, p. 320-325, 7 jul. 2008.

[2] Aliferis, L.; Dembosky, A.; Pickoff-White, L. California Doctors Among Those Charging Medicare the Most for Office Visits | State of Health | KQED News.

[3] Alpaydin, E. Introduction to machine learning. 2a ed. Cambridge, Mass.: MIT Press, 2010.

[4] Aon Hewitt. Aon Hewitt 2015 Global Medical Trend Rate. Disponível em: http://www.aon.com/attachments/human-capitalconsulting/2015_Global_Medical_Trend_Rate_Survey_Report_2015_01. pdf. Acesso em: 20 de jun. 2015.

[5] Aral, K. D. et al. A prescription fraud detection model. Computer Methods and Programs in Biomedicine, v. 106, n. 1, p. 37-46, abr. 2012.

[6] Araújo, L. C. G.; Garcia, A. A.; Martines, S. Gestão de Processos: Melhores resultados e excelência organizacional. 1a.ed. São Paulo: Atlas, 2011.

[7] Araújo, M. S. Análise de maturidade da gestão de riscos de TI na Fiocruz: definição e aplicação de instrumento de avaliação e especificação de requisitos para um sistema computacional. Brasília: Universidade de Brasília - UnB, 2014.

[8] Arena, M.; Arnaboldi, M.; Azzone, G. The organizational dynamics of Enterprise Risk Management. Accounting, Organizations and Society, v. 35, n. 7, p. 659-675, out. 2010.

[9] Associação Brasileira De Normas Técnicas. NBR ISO 31.010: gestão de riscos: técnicas de avaliação de riscos. Rio de Janeiro, 2012. 
[10] Associação Brasileira De Normas Técnicas. NBR ISO 31.000: Gestão de Riscos. Rio de Janeiro, 2009.

[11] Badea, A. et al. Assessing Risk Factors in Collaborative Supply Chain with the Analytic Hierarchy Process (AHP). Procedia - Social and Behavioral Sciences, v. 124, p. 114-123, mar. 2014.

[12] Bahia, L. Planos privados de saúde: luzes e sombras no debate setorial dos anos 90. Ciência ES saúde coletiva, v. 6, n. 2, p. 329-339, 2001.

[13] Barros, Daniel. A doença do custo. EXAME, São Paulo, v. 1090, p. 34-46, maio 2015.

[14] Banco Central Do Brasil. Resolução 3.380, de 29 de junho de 2006. Dispõe sobre a implementação de estrutura de gerenciamento do risco operacional.

[15] Baranoff, E.; Brockett, P. L.; Kahane, Y. Risk Management for Enterprises and Individuals. S.l.: Flat World Knowledge, Inc., 2009.

[16] Bastos, A. L. A. et al. Modelo multicritério de apoio a decisão para seleção de fornecedores. VII Congresso Nacional de Excelência em Gestão, p. 17,12 ago. 2011.

[17] Beasley, M. S.; Clune, R.; Hermanson, D. R. Enterprise risk management: An empirical analysis of factors associated with the extent of implementation. Journal of Accounting and Public Policy, v. 24, n. 6, p. 521-531, nov. 2005.

[18] Becker, R. A.; Chambers, J. M.; Wilks, A. R. The New S Language. Wadsworth \& Brooks/Cole, 1988.

[19] Becker, D. J., Kessler, D. P. And Mcclellan, M. B.. Detecting Medicare Abuse. Social Science Research Network, Rochester, NY, SSRN Scholarly Paper ID 579820, Aug. 2004.

[20] Berbicz, R. B. Fraudes em Planos de Saúde e seus Reflexos na Manutenção do Sistema e Beneficiários. Curitiba: Pontifícia Universidade Católica do Paraná, 2007. 
[21] Bhushan, N.; Rai, K. Strategic decision making: applying the analytic hierarchy process. Springer Science $\&$ Business Media, 2004.

[22] Bloomberg. Most efficient health care 2014: countries. Bloomberg, 2014. Disponível em: http://www.bloomberg.com/visual-data/best-andworst/most-efficient-health-care-2014-countries. Acesso em 11 dez. 2014.

[23] Brasil. Lei no 9.656, de 03 de junho de 1998. Dispõe sobre os planos e seguros privados de assistência à saúde. Diário Oficial [da República Federativa do Brasil], Brasília, DF, 04 jun. 1998, P.1.

[24] Brasil. Lei n⿳⺈ 9.961, de 28 de janeiro de 2000. Cria a Agência Nacional de Saúde Suplementar - ANS e dá outras providências. Diário Oficial [da República Federativa do Brasil], Brasília, DF, 29 jan. 2000, P.5.

[25] Brasil. Instrução Normativa $\mathrm{n}^{\mathrm{o}}$ 14, de 27 de dezembro de 2007. Regulamenta os critérios e diretrizes para substituição da formulação de cálculo da Margem de Solvência constante do caput do art. $8^{\mathrm{o}}$ da Resolução Normativa $\mathrm{n}^{\mathrm{O}} 160$, de 03 de julho de 2007, com a utilização de modelo próprio baseado nos riscos das Operadoras de Planos de Saúde.

[26] Brennan, M.; Clark, R.; Vine, M. What May Cause Insurance Companies To Fail - And How This Influences Our Criteria. Standard and Poor's Rating Services, 13 jun. 2013.

[27] Caixeiro, F. T. Aplicação do FMEA para prospecção de riscos de cuidados hospitalares no Brasil. Rio de Janeiro: Escola Nacional de Saúde Pública, 2011. 86 f. Dissertação (Mestrado) - Escola Nacional de Saúde Pública, Rio de Janeiro, 2011.

[28] Carbone, T. A.; Tippett, D. D. Project risk management using the project risk FMEA. Engineering Management Journal, v. 16, n. 4, p. 28-35, 2004 .

[29] Carroll, J.; Mu, E. Development of a Decision Model to Prioritizing Potential Fraud Cases for Internal Investigative Purposes. International Journal of the Analytic Hierarchy Process, 7 fev. 2014.

[30] Champlain, J. J. Auditing Information Systems. 2nd ed. Hoboken, NJ: John Wiley, 2003. 
[31] Chandola, V.; Sukumar, S. R.; Schryver, J. C. Knowledge discovery from massive healthcare claims data. Proceedings of the 19th ACM SIGKDD international conference on Knowledge discovery and data mining. ACM, 2013.

[32] Chapman, P. et al. CRISP-DM 1.0 Step-by-step data mining guides. 2000.

[33] Chen, S.; Gangopadhyay, A. A Novel Approach to Uncover Health Care Frauds through Spectral Analysis IEEE, set. 2013.

[34] COSO. Gerenciamento de Riscos Corporativos - Estrutura Integrada. Edição brasileira patrocinada pela PriceWaterhouseCoopers e Audibra. 2006.

[35] Costa, Mariana. Operadoras: como gerenciar os riscos? Revista RH, 2011.

[36] Derosier, J. et al. Using health care failure mode and effect analysis: the VA National Center for Patient Safety's prospective risk analysis system. Joint Commission Journal on Quality and Patient Safety, v. 28, n. 5, p. 248267, 2002.

[37] Deshmukh, A.; Millet, I. An Analytic Hierarchy Process Approach to Assessing the Risk of Management Fraud. The Journal of Applied Business Research, v. 15, n. 1, p. 87-102, 1999.

[38] Disantostefano, J. Medicare Fraud and Abuse Issues. The Journal for Nurse Practitioners, v. 9, n. 1, p. 61-63, 2013.

[39] Expert Choice. Expert Choice - For Collaborative Decision Making. Disponível em: <http://expertchoice.com/>. Acesso em: 1 jun. 2014.

[40] Gee, J. et al. The financial cost of healthcare fraud. University of Portsmouth, 2010.

[41] Georgieva, P.; Mihaylova, L.; Jain, L. C. (Eds.). Advances in Intelligent Signal Processing and Data Mining. Berlin, Heidelberg: Springer Berlin Heidelberg, 2013. v. 410.

[42] Gil, Antônio Carlos. Como elaborar projetos de pesquisa. 5a ed., São Paulo: Atlas, 2010. 
[43] Hampton, J. J. Fundamentals of enterprise risk management: how top companies assess risk, manage exposures, and seize opportunities. New York: American Management Association, 2009.

[44] Han, J.; Kamber, M.; Pei, J. Data mining: concepts and techniques. 3.ed. Amsterdam: Elsevier/Morgan Kaufmann, 2012.

[45] Hartigan, J.A. Clustering algorithms. John Wiley ES Sons, Inc., 1975.

[46] $\mathrm{Hu}$, J. et al. A healthcare utilization analysis framework for hot spotting and contextual anomaly detection. AMIA Annual Symposium Proceedings. American Medical Informatics Association, 2012.

[47] IBGC - Instituto Brasileiro De Governança Corporativa. Guia de orientação para o gerenciamento de riscos corporativos. Instituto Brasileiro de Governança Corporativa; coordenação: Eduarda La Rocque. São Paulo, SP: IBGC, 2007.

[48] IIA. Professional Practice Pamphlet 98-2 A Perspective on Control SelfAssessment. Institute of Internal Auditing, 1998.

[49] IOR. Institute of Operational Risk - Risk Control Self-Assessment. Institute of OpRisk, 2010.

[50] Ishizaka, A.; Nemery, P. Multi-criteria decision analysis: methods and software. Chichester, West Sussex, United Kingdom: Wiley, 2013.

[51] International Organization For Standardization. ISO 31000 - Risk management.

[52] Jacobus, D. New Paradigm of Managing Risks: Risk and Control Selfassessment. Agriculture and Agricultural Science Procedia, v. 3, p. 3234,2015 .

[53] Jamshidi, A. et al. A comprehensive fuzzy risk-based maintenance framework for prioritization of medical devices. Applied Soft Computing, v. 32, p. 322-334, jul. 2015.

[54] Jans, M., Lybaert, N., E Vanhoof K. Internal fraud risk reduction: Results of a data mining case study. International Journal of Accounting Information Systems, vol. 11, no. 1, pp. 17-41, Mar. 2010. 
[55] Joudaki, H. et al. Using Data Mining to Detect Health Care Fraud and Abuse: A Review of Literature. Global Journal of Health Science, v. 7, n. 1,31 ago. 2014 .

[56] Kaufman, L.; Rousseeuw, P. J. Finding groups in data: An introduction to cluster analysis. New York: Wiley, 1990.

[57] Kobler, Daniel et al. Management of Operational Risks in Insurance. Deloitte e Institute of Insurance Economics of the University of St. Gallen., 2007.

[58] Kruger, H. A.; Hattingh, J. M. A combined AHP-GP model to allocate internal auditing time to projects. ORiON, v. 22, n. 1, p. 59-76, 2006.

[59] Keršulienè, V.; Turskis, Z. An Integrated Multi-criteria Group Decision Making Process: Selection of the Chief Accountant. Procedia - Social and Behavioral Sciences, v. 110, p. 897-904, jan. 2014.

[60] Kodinariya, T. M.; Makwana, P. R. Review on determining number of Cluster in K-Means Clustering. International Journal of Advance Research in Computer Science and Management Studies, v. 1, n. 6, 2013.

[61] Lai, P. et al. Evaluating the efficiency performance of airports using an integrated AHP/DEA-AR technique. Transport Policy, v. 42, p. 75-85, ago. 2015 .

[62] LAKATOS, Eva Maria \& MARCONI, Marina De Andrade. Fundamentos de metodologia científica. São Paulo: Atlas, 2003.

[63] Lemos, Lilian Correia. A judicialização da saúde: O posicionamento do Poder Judiciário ante a relação contratual entre as operadoras e os beneficiários dos planos de saúde anteriores à Lei n⿳0 9.656/98. In: Âmbito Jurídico, Rio Grande, XI, n. 58, out 2008.

[64] Likert, Rensis. A Technique for the Measurement of Attitudes. Archives of Psychology 140: 1-55, 1932.

[65] Liu, Q. E Vasarhelvi, M. Healthcare fraud detection: A survey and a clustering model incorporating Geo-location information. 
[66] Lowrey, Annie. Study of U.S. Health Care System Finds Both Waste and Opportunity to Improve. The New York Times, set. 2012.

[67] Mango, D. Applying actuarial techniques in operational risk modeling. ERM Symposium. 2006.

[68] Marsland, Stephen. Machine Learning - An Algorithmic Perspective. 2.ed. Chapman and Hall/CRC, 2009.

[69] Matesco, V. Sinistros e fraudes: maus companheiros. Revista Conjuntura Econômica, v. 57, n. 8, p. 126-127, agosto de 2003.

[70] Mcdermott, R.; Mikulak, R.; Beauregard, M. The Basics of FMEA. 2nd ed. New York: Taylor \& Francis Group, 2009.

[71] Michel, Maria Helena. Metodologia e pesquisa científica em ciências sociais. São Paulo: Atlas, 2005.

[72] Moon, C.; Matsiga, C. 7 Red Flags for Fraud in Medical Records. Disponível em: <http://healthinformation.advanceweb.com/Features/Articles/7-Red-Flags-for-Fraud-inMedical-Records.aspx>. Acesso em: 5 jul. 2015.

[73] Musal, R. M. Two models to investigate Medicare fraud within unsupervised databases. Expert Systems with Applications, vol. 37, no. 12, pp. 8628-8633, Dec. 2010.

[74] NHCAA. The Challenge of Health Care Fraud. Disponível em: $<$ http://www.nhcaa.org/resources/health-care-anti-fraud-resources/thechallenge-of-health-care-fraud.aspx>. Acesso em: 28 nov. 2015.

[75] Olmstead, J. Medicare Fraud and Abuse: Turn Up the HEAT. The Journal for Nurse Practitioners, vol. 8, no. 7, p. 504, Jul. 2012.

[76] Ortega, P. A.; Figueroa, C. J.; Ruz, G. A. A Medical Claim Fraud/Abuse Detection System based on Data Mining: A Case Study in Chile. DMIN, v. 6, p. 26-29, 2006.

[77] Ostrom, L. T.; Wilhelmsen, C. A. Risk assessment: tools, techniques, and their applications. Hoboken, New Jersey: Wiley, 2012. 
[78] Paim, J. S. Modelos assistenciais: reformulando o pensamento e incorporando a proteção e a promoção da saúde. ANVISA-Seminários Temáticos Permanentes. Brasília, v. 28, 2002.

[79] Peng, Y. et al. Application of clustering methods to health insurance fraud detection. 2006 International Conference on Service Systems and Service Management. Anais. IEEE, 2006.

[80] Pickett, K. H. S. The Internal Auditing Handbook, 3rd Edition. Ed. Chichester, West Sussex, U.K: Wiley, 2010.

[81] Pickett, K. H. S. The Essential Guide to Internal Auditing. 2nd ed. Chichester: Wiley, 2011.

[82] Pietrobon, L.; Prado, M. L. Do; Caetano, J. C. Suplemental health in Brazil: the role of the National Agency of Suplemental Health in the sector's regulation. Physis: Revista de Saúde Coletiva, v. 18, n. 4, p. 767-783, 2008.

[83] Piper, C. 10 popular health care provider fraud schemes. Disponível em: $<$ http://www.acfe.com/article.aspx?id=4294976280>. Acesso em: 5 jun. 2015 .

[84] Project Management Institute. PMBOK - A guide to the project management body of knowledge. Fifth edition. Newtown Square, Pennsylvania: Project Management Institute, Inc, 2013.

[85] Pricewaterhousecoopers. The Healthcare Market in Brazil. PricewaterhouseCoopers, 2013.

[86] Pritchard, C. Risk Management - Concepts and Guidance. 5th ed. Boca Raton, Florida, EUA: CRC Press, 2015.

[87] Rimes. Solvency II - The Data Challenge. RIMES White Paper, p. 4, 2014.

[88] Rosenblatt, Alice; Segal, Sim. Risks \& Mitigation for Health Insurance Companies. Society of Actuaries, 2012.

[89] Roy, B. Decision-aid and decision-making. European Journal of Operational Research, v. 45, n. 2-3, p. 324-331, 1990. 
[90] Roy, B. Multicriteria Methodology for Decision Aiding. Nonconvex Optimization and Its Applications, v. 12, 1996.

[91] Rudolph, Max. Enterprise Risk Management Practice as applied to Health Insurers, Self-Insured Plans, and Health Finance Professionals. Society of Actuaries Health Section, 2009.

[92] Rstudio. RStudio - Open source and enterprise-ready professional software for R. Disponível em: <https://www.rstudio.com/>. Acesso em: 1 jun. 2015.

[93] Saaty, T.L. The Analytic Hierarchy Process. McGraw-Hill, New York, 1980.

[94] Saaty, T.L. Decision making with the analytic hierarchy process. International journal of services sciences, v. 1, n. 1, p. 83-98, 2008.

[95] Sammut, C.; Webb, G. I. Encyclopedia of machine learning. [s.l.] Springer Science \& Business Media, 2011.

[96] Sampiere, R. H. Collado, C. F. Lucio, P. B. Metodologia de Pesquisa. São Paulo: Ed. Mc-Graw-Hill, $3^{\text {a }}$ Edição, 2006.

[97] SCOR Sustainable development policy. Enterprise Risk Management (ERM) - A driving force for the insurance industry. Focus, outubro 2009.

[98] Society Of Actuaries, Session 24PD. Risk Management for Health Insurance, 30., 19-21 de maio 2004, Anaheim, CA. Anais. 2004.

[99] Stamatis, D. H. Failure Mode and Effect Analysis: FMEA from Theory to Execution. 2nd ed. Milwaukee, Wisconsin: ASQC Quality Press, 2003.

[100] Sueyoshi, T.; Shang, J.; Chiang, W.-C. A decision support framework for internal audit prioritization in a rental car company: A combined use between DEA and AHP. European Journal of Operational Research, v. 199, n. 1, p. 219-231, nov. 2009.

[101] Tan, P.-N.; Steinbach, M.; Kumar, V. Introduction to Data Mining, 1st edition. Boston: Addison-Wesley, 2005.

[102] The Economist. The $\$ 272$ billion swindle: Why thieves love America's health-care system. The Economist, 2014. 
[103] Theodoridis, S.; Koutroumbas, K. Pattern recognition. 4. ed. Amsterdam: Elsevier Acad. Press, 2009.

[104] Thornton, D., Mueller, R. M., Schoutsen, P., Hillegersberg. Predicting Healthcare Fraud in Medicaid: A Multidimensional Data Model and Analysis Techniques for Fraud Detection. Procedia Technology, vol. 9, pp. 1252-1264, 2013.

[105] Tibshirani, R.; Walther, G.; Hastie, T. Estimating the number of clusters in a data set via the gap statistic. J. R. Statist. Soc. B, v. 63 (2), p. 411-423, 2001.

[106] Torre-Enciso, M. I. M.; Barros, R. H. Operational Risk Management for Insurers. International Business Research, v. 6, n. 1, 7 dez. 2012.

[107] Towers Watson. 2014 Global Medical Trends - Survey Report.

[108] Trucco, P.; Cavallin, M. A quantitative approach to clinical risk assessment: The CREA method. Safety Science, v. 44, n. 6, p. 491-513, jul. 2006.

[109] Vogler, R. Hierarchical Clustering with R (feat. D3.js and Shiny) joy of data, 2014. Disponível em: <http://www.joyofdata.de/blog/hierarchicalclustering-with-r/>. Acesso em: 4 jul. 2015

[110] Witten, I. H.; Frank, E.; Hall, M. A. Data mining: practical machine learning tools and techniques. 3rd ed. Burlington, MA: Morgan Kaufmann, 2011 .

[111] $\mathrm{Wu}, \mathrm{X}$. et al. Top 10 algorithms in data mining. Knowledge and Information Systems, v. 14, n. 1, p. 1-37, jan. 2008.

[112] Zalma, B. Insurance Fraud -- Red Flags. Disponível em: $<$ http://www.lexisnexis.com/legalnewsroom/insurance/b/insurance-lawblog/archive/2008/05/16/insurance-fraud-_2d002d00_-red-flags.aspx > . Acesso em: 5 jun. 2015.

[113] Zeydan, M.; Çolpan, C.; Çobanoğlu, C. A combined methodology for supplier selection and performance evaluation. Expert Systems with Applications, v. 38, n. 3, p. 2741-2751, mar. 2011. 


\section{APÊNDICE I - FLUXOGRAMA DO PROCESSO DE PAGAMENTO DE CONTAS MÉDICAS}

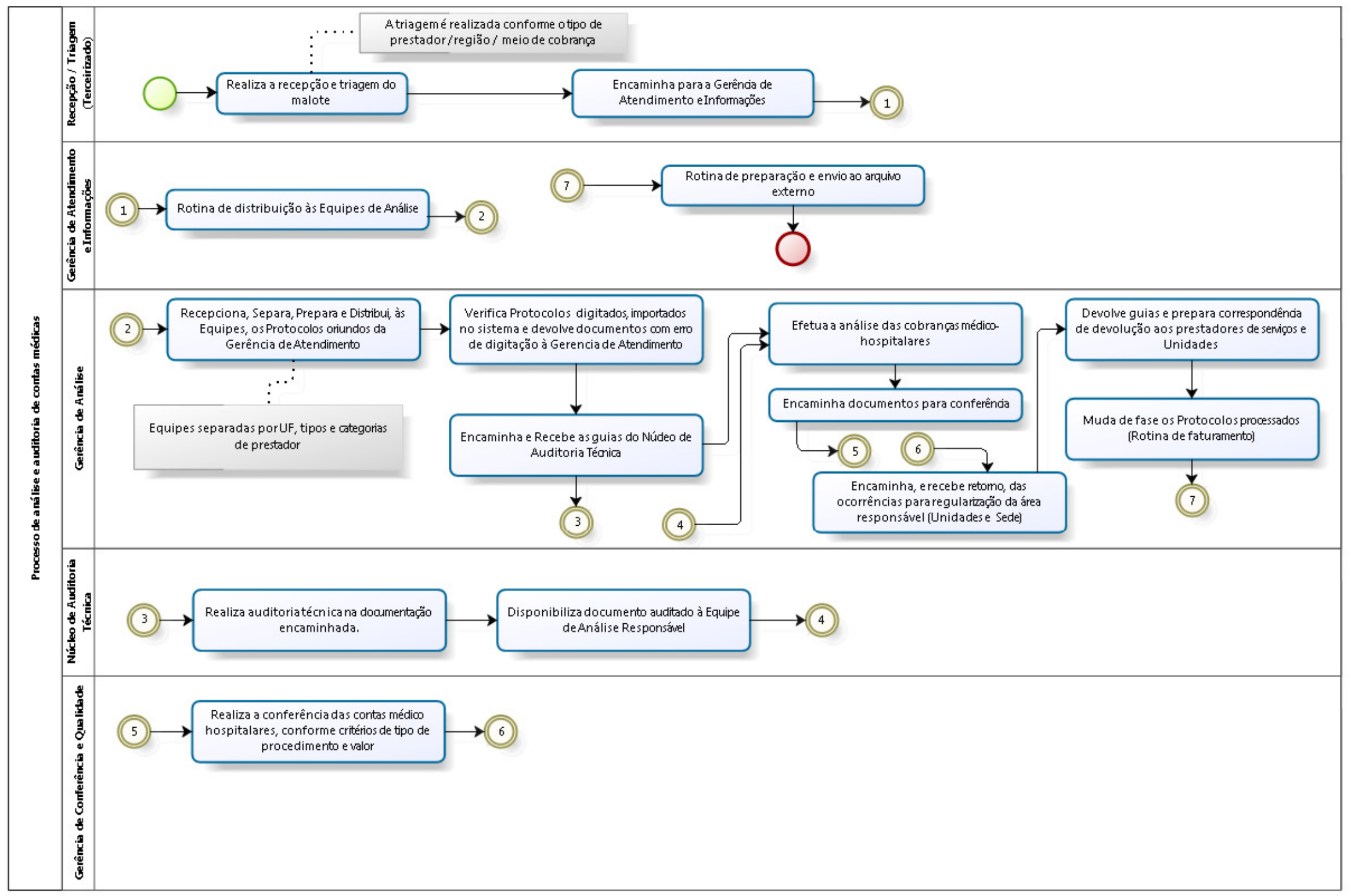


APÊNDICE II - RISCOS IDENTIFICADOS NO PROCESSO DE PAGAMENTO DE CONTAS MÉDICAS - SUBPROCESSO DE ANÁLISE DE CONTAS MÉDICO-HOSPITALARES

\begin{tabular}{|c|c|c|c|c|c|c|c|c|c|c|c|}
\hline ATIVIDADE & RISCO & SUBCATEGORIA & Probabilidade & Impacto & $\begin{array}{l}\text { Risco } \\
\text { Bruto }\end{array}$ & CONTROLE & CAT_CONTROLE & NC & RR & D & RPN \\
\hline $\begin{array}{l}\text { 1. Recepcionar, Separarar, Preparar } \\
\text { e Distribuir os Protocolos oriundos da } \\
\text { Gerência de Atendimento. }\end{array}$ & $\begin{array}{l}\text { Interpretação normativa referente ao } \\
\text { processo de mudança de fase } \\
\text { (devolução desnecessária do } \\
\text { Protocolo à Gerência de } \\
\text { Atendimento). }\end{array}$ & $\begin{array}{l}\text { Processos - } \\
\text { Modelagem }\end{array}$ & 5 & 1 & 5 & $\begin{array}{l}\text { Avaliação periódica } \\
\text { dos normativos. }\end{array}$ & $\begin{array}{l}\text { Controle Básico - } \\
\text { Administrativo e } \\
\text { Organizacionais - } \\
\text { Normas e } \\
\text { Procedimentos Internos }\end{array}$ & 3 & 2 & 3 & 6 \\
\hline $\begin{array}{l}\text { 1. Recepcionar, Separarar, Preparar } \\
\text { e Distribuir os Protocolos oriundos da } \\
\text { Gerência de Atendimento. }\end{array}$ & $\begin{array}{l}\text { Recebimento de documento físico } \\
\text { fracionado, recebimento indevido } \\
\text { (trânsito indevido), não recebimento e } \\
\text { não importação do arquivo eletrônico } \\
\text { para o Sistema de Pagamentos, pela } \\
\text { Gerência de Atendimento. }\end{array}$ & $\begin{array}{l}\text { Pessoas - Falha } \\
\text { Humana / } \\
\text { Tecnologia - } \\
\text { Sistemas }\end{array}$ & 3 & 1 & 3 & $\begin{array}{l}\text { Verificação do } \\
\text { analista de contas ou } \\
\text { coordenador de } \\
\text { equipe no processo } \\
\text { de análise }\end{array}$ & Controle Direto & 2 & 1 & 5 & 5 \\
\hline $\begin{array}{l}\text { 1. Recepcionar, Separarar, Preparar } \\
\text { e Distribuir os Protocolos oriundos da } \\
\text { Gerência de Atendimento. }\end{array}$ & $\begin{array}{l}\text { Sobrecarga do analista no volume de } \\
\text { guias processadas. }\end{array}$ & $\begin{array}{l}\text { Pessoas - Falha } \\
\text { Humana }\end{array}$ & 3 & 1 & 3 & $\begin{array}{l}\text { Distribuição por } \\
\text { demanda dos } \\
\text { Protocolos aos } \\
\text { analistas pelo (a) } \\
\text { coordenador (a). } \\
\end{array}$ & Controle Direto & 2 & 1 & 3 & 3 \\
\hline $\begin{array}{l}\text { 1. Recepcionar, Separarar, Preparar } \\
\text { e Distribuir os Protocolos oriundos da } \\
\text { Gerência de Atendimento. }\end{array}$ & $\begin{array}{l}\text { Recebimento dos Protocolos por } \\
\text { equipes não responsáveis pelo } \\
\text { processamento. }\end{array}$ & $\begin{array}{l}\text { Pessoas - Falha } \\
\text { Humana }\end{array}$ & 3 & 1 & 3 & $\begin{array}{l}\text { Critérios de } \\
\text { separação e } \\
\text { sinalização nas } \\
\text { caixas }\end{array}$ & Controle Direto & 2 & 1 & 2 & 2 \\
\hline $\begin{array}{l}\text { 1. Recepcionar, Separarar, Preparar } \\
\text { e Distribuir os Protocolos oriundos da } \\
\text { Gerência de Atendimento. }\end{array}$ & $\begin{array}{l}\text { Inclusão/alteração de guias, eventos } \\
\text { e graus pela equipe de análise nos } \\
\text { Protocolos em status de análise, } \\
\text { ocasionando perda de produção ou } \\
\text { pagamento indevido ou fraude. }\end{array}$ & $\begin{array}{l}\text { Pessoas - Falha } \\
\text { Humana / } \\
\text { Pessoas - } \\
\text { Fraude / } \\
\text { Processos - } \\
\text { Modelagem } \\
\end{array}$ & 3 & 5 & 15 & $\begin{array}{l}\text { Gravação do registro } \\
\text { da alteração pela } \\
\text { auditoria do sistema. }\end{array}$ & Controle Direto & 2 & 13 & 7 & 91 \\
\hline $\begin{array}{l}\text { 1. Recepcionar, Separarar, Preparar } \\
\text { e Distribuir os Protocolos oriundos da } \\
\text { Gerência de Atendimento. }\end{array}$ & $\begin{array}{l}\text { Recebimento de guias digitadas de } \\
\text { forma incorreta. }\end{array}$ & $\begin{array}{l}\text { Pessoas - Falha } \\
\text { Humana }\end{array}$ & 5 & 2 & 10 & $\begin{array}{l}\text { Detecção pelo } \\
\text { analista no ato da } \\
\text { análise' }\end{array}$ & $\begin{array}{l}\text { Controle Básico - } \\
\text { Conferências e } \\
\text { Autorizações }\end{array}$ & 2 & 8 & 8 & 64 \\
\hline $\begin{array}{l}\text { 1. Recepcionar, Separarar, Preparar } \\
\text { e Distribuir os Protocolos oriundos da } \\
\text { Gerência de Atendimento. }\end{array}$ & $\begin{array}{l}\text { Inclusão/alteração de guias ou } \\
\text { eventos e graus pela equipe de } \\
\text { análise nos Protocolos em status de } \\
\text { digitação. }\end{array}$ & $\begin{array}{l}\text { Pessoas - Falha } \\
\text { Humana / } \\
\text { Pessoas - } \\
\text { Fraude / } \\
\text { Processos - } \\
\text { Modelagem }\end{array}$ & 3 & 4 & 12 & $\begin{array}{l}\text { Critérios definidos } \\
\text { nos grupos de } \\
\text { segurança dos } \\
\text { colaboradores. }\end{array}$ & $\begin{array}{l}\text { Controle Básico - } \\
\text { Segregação de Função }\end{array}$ & 3 & 9 & 7 & 63 \\
\hline $\begin{array}{l}\text { 1. Recepcionar, Separarar, Preparar } \\
\text { e Distribuir os Protocolos oriundos da } \\
\text { Gerência de Atendimento. }\end{array}$ & $\begin{array}{l}\text { Acondicionamento dos Protocolos } \\
\text { oriundos da Gerência de Atendimento } \\
\text { com protocolos diversos e tipos de } \\
\text { guias na mesma caixa para } \\
\text { distribuição aos analistas. }\end{array}$ & $\begin{array}{l}\text { Pessoas - Falha } \\
\text { Humana }\end{array}$ & 5 & 2 & 10 & $\begin{array}{l}\text { Critérios de } \\
\text { separação e } \\
\text { sinalização nas } \\
\text { caixas }\end{array}$ & Controle Direto & 2 & 8 & 6 & 48 \\
\hline
\end{tabular}




\begin{tabular}{|c|c|c|c|c|c|c|c|c|c|c|c|}
\hline ATIVIDADE & RISCO & SUBCATEGORIA & Probabilidade & Impacto & \begin{tabular}{|l|} 
Risco \\
Bruto \\
\end{tabular} & CONTROLE & CAT_CONTROLE & NC & RR & D & RPN \\
\hline $\begin{array}{l}\text { 1. Recepcionar, Separarar, Preparar } \\
\text { e Distribuir os Protocolos oriundos da } \\
\text { Gerência de Atendimento. }\end{array}$ & $\begin{array}{l}\text { Perfil inadequado do analista para } \\
\text { análise de determinado tipo de guia. }\end{array}$ & $\begin{array}{l}\text { Pessoas - Falha } \\
\text { Humana }\end{array}$ & 3 & 4 & 12 & $\begin{array}{l}\text { Critérios de } \\
\text { separação de guias } \\
\text { pelo Coordenador de } \\
\text { equipe. } \\
\text { Treinamento de } \\
\text { reciclagem. } \\
\end{array}$ & $\begin{array}{l}\text { Controle Direto / } \\
\text { Controle Básico - } \\
\text { Capacitação - } \\
\text { Aprendizagem } \\
\text { Continua }\end{array}$ & 2 & 10 & 2 & 20 \\
\hline $\begin{array}{l}\text { 2. Verificar Protocolos digitados, } \\
\text { importados no sistema e devolver } \\
\text { Protocolos com erro de digitação à } \\
\text { Gerência de Atendimento. } \\
\end{array}$ & $\begin{array}{l}\text { Extravio das guias devolvidas para a } \\
\text { Gerência de Atendimento. }\end{array}$ & $\begin{array}{l}\text { Pessoas - Falha } \\
\text { Humana }\end{array}$ & 5 & 3 & 15 & $\begin{array}{l}\text { Critérios de } \\
\text { reconstituição de } \\
\text { guias }\end{array}$ & Controle Direto & 2 & 13 & 2 & 26 \\
\hline $\begin{array}{l}\text { 2. Verificar Protocolos digitados, } \\
\text { importados no sistema e devolver } \\
\text { Protocolos com erro de digitação à } \\
\text { Gerência de Atendimento. }\end{array}$ & $\begin{array}{l}\text { Devolução das guias para } \\
\text { redigitação, interrompendo, dessa } \\
\text { forma, a continuidade da análise. }\end{array}$ & $\begin{array}{l}\text { Pessoas - Falha } \\
\text { Humana }\end{array}$ & 5 & 2 & 10 & $\begin{array}{l}\text { Detecção pelo } \\
\text { analista no ato da } \\
\text { análise }\end{array}$ & $\begin{array}{l}\text { Controle Básico - } \\
\text { Conferências e } \\
\text { Autorizações }\end{array}$ & 2 & 8 & 2 & 16 \\
\hline $\begin{array}{l}\text { 3. Encaminhar e Receber as guias do } \\
\text { Núcleo de Auditoria Técnica }\end{array}$ & $\begin{array}{l}\text { Não recebimento das guias auditadas } \\
\text { pela análise. }\end{array}$ & $\begin{array}{l}\text { Pessoas - Falha } \\
\text { Humana }\end{array}$ & 3 & 1 & 3 & $\begin{array}{l}\text { Email de } \\
\text { encaminhamento dos } \\
\text { Protocolos.' }\end{array}$ & Controle Direto & 2 & 1 & 2 & 2 \\
\hline $\begin{array}{l}\text { 3. Encaminhar e Receber as guias do } \\
\text { Núcleo de Auditoria Técnica }\end{array}$ & $\begin{array}{l}\text { Processamento de Protocolos } \\
\text { recebidos da Auditoria sem registro } \\
\text { da critica do auditor. }\end{array}$ & $\begin{array}{l}\text { Pessoas - Falha } \\
\text { Humana }\end{array}$ & 3 & 4 & 12 & $\begin{array}{l}\text { Verificação do } \\
\text { parecer do médico } \\
\text { auditor pelo analista } \\
\text { de contas }\end{array}$ & $\begin{array}{l}\text { Controle Básico - } \\
\text { Conferências e } \\
\text { Autorizações }\end{array}$ & 2 & 10 & 2 & 20 \\
\hline $\begin{array}{l}\text { 4. Efetuar análise das cobranças } \\
\text { médico-hospitalares }\end{array}$ & $\begin{array}{l}\text { Processamento das guias sem a } \\
\text { crítica da auditoria in loco. }\end{array}$ & $\begin{array}{l}\text { Pessoas - Falha } \\
\text { Humana }\end{array}$ & 2 & 4 & 8 & $\begin{array}{l}\text { Atividade de } \\
\text { conferência de } \\
\text { contas médicas }\end{array}$ & $\begin{array}{l}\text { Controle Básico - } \\
\text { Conferências e } \\
\text { Autorizações }\end{array}$ & 2 & 6 & 9 & 54 \\
\hline $\begin{array}{l}\text { 4. Efetuar análise das cobranças } \\
\text { médico-hospitalares }\end{array}$ & $\begin{array}{l}\text { Não observância pelo analista de } \\
\text { contas dos tipos de atendimentos a } \\
\text { serem encaminhadas para avaliação } \\
\text { do núcleo de auditoria técnica. }\end{array}$ & $\begin{array}{l}\text { Pessoas - Falha } \\
\text { Humana }\end{array}$ & 2 & 4 & 8 & $\begin{array}{l}\text { Critérios para } \\
\text { avaliação dos tipos } \\
\text { de atendimentos pelo } \\
\text { núcleo de auditoria } \\
\text { técnica }\end{array}$ & Controle Direto & 2 & 6 & 9 & 54 \\
\hline $\begin{array}{l}\text { 4. Efetuar análise das cobranças } \\
\text { médico-hospitalares }\end{array}$ & $\begin{array}{l}\text { Processamento indevido quando da } \\
\text { divergência entre os itens } \\
\text { (eventos/graus) autorizados e as } \\
\text { anotações no campo observações da } \\
\text { autorização. }\end{array}$ & $\begin{array}{l}\text { Pessoas - Falha } \\
\text { Humana }\end{array}$ & 2 & 3 & 6 & $\begin{array}{l}\text { Alerta no Sistema; } \\
\text { Vinculação do evento } \\
\text { principal e senha. }\end{array}$ & Controle Direto & 2 & 4 & 8 & 32 \\
\hline $\begin{array}{l}\text { 4. Efetuar análise das cobranças } \\
\text { médico-hospitalares }\end{array}$ & $\begin{array}{l}\text { Alteração do tipo de guia de } \\
\text { SP/SADT para internação, quando } \\
\text { pagamento de valores superiores a } \\
110.000 \text {, alterando dessa forma as } \\
\text { informações originais encaminhadas } \\
\text { pelo prestador. }\end{array}$ & $\begin{array}{l}\text { Pessoas - Falha } \\
\text { Humana / } \\
\text { Tecnologia - } \\
\text { Sistemas }\end{array}$ & 2 & 2 & 4 & $\begin{array}{l}\text { Parametrização do } \\
\text { Sistema de } \\
\text { Pagamentos }\end{array}$ & Controle Direto & 2 & 2 & 3 & 6 \\
\hline $\begin{array}{l}\text { 4. Efetuar análise das cobranças } \\
\text { médico-hospitalares }\end{array}$ & $\begin{array}{l}\text { Falha do analista de contas no } \\
\text { processamento de contas médicas, } \\
\text { oriunda da falta de qualificação, } \\
\text { gerando pagamento indevido. }\end{array}$ & $\begin{array}{l}\text { Pessoas - Falha } \\
\text { Humana }\end{array}$ & 5 & 5 & 25 & $\begin{array}{l}\text { Atividade de } \\
\text { conferência de } \\
\text { contas médicas / } \\
\text { Treinamentos de } \\
\text { reciclagem. }\end{array}$ & $\begin{array}{l}\text { Controle Básico - } \\
\text { Conferências e } \\
\text { Autorizações / } \\
\text { Capacitação - } \\
\text { Aprendizagem } \\
\text { Continua }\end{array}$ & 3 & 22 & 9 & 198 \\
\hline
\end{tabular}




\begin{tabular}{|c|c|c|c|c|c|c|c|c|c|c|c|}
\hline ATIVIDADE & RISCO & SUBCATEGORIA & Probabilidade & Impacto & \begin{tabular}{|l|} 
Risco \\
Bruto
\end{tabular} & CONTROLE & CAT_CONTROLE & NC & $\mathbf{R R}$ & D & RPN \\
\hline $\begin{array}{l}\text { 4. Efetuar análise das cobranças } \\
\text { médico-hospitalares }\end{array}$ & $\begin{array}{l}\text { Não detecção de práticas abusivas } \\
\text { de cobrança de serviços médico- } \\
\text { hospitalares }\end{array}$ & $\begin{array}{l}\text { Pessoas - Falha } \\
\text { Humana / } \\
\text { Tecnologia - } \\
\text { Sistemas }\end{array}$ & 5 & 5 & 25 & $\begin{array}{l}\text { Relatórios } \\
\text { parametrizados e } \\
\text { apontamentos de } \\
\text { sistema }\end{array}$ & Controle Direto & 5 & 20 & 9 & 180 \\
\hline $\begin{array}{l}\text { 4. Efetuar análise das cobranças } \\
\text { médico-hospitalares }\end{array}$ & $\begin{array}{l}\text { Pagamento de procedimentos na } \\
\text { mesma guia e contemplados em } \\
\text { senhas distintas, ocasionando na não } \\
\text { sensibilização da autorização. }\end{array}$ & $\begin{array}{l}\text { Pessoas - Falha } \\
\text { Humana }\end{array}$ & 5 & 4 & 20 & $\begin{array}{l}\text { Apontamento de } \\
\text { glosa pelo sistema. }\end{array}$ & Controle Direto & 2 & 18 & 7 & 126 \\
\hline $\begin{array}{l}\text { 4. Efetuar análise das cobranças } \\
\text { médico-hospitalares }\end{array}$ & $\begin{array}{l}\text { Processamento das contas médicas } \\
\text { com código de evento curinga } \\
\text { (genérico), sem vinculação de } \\
\text { autorização. }\end{array}$ & $\begin{array}{l}\text { Pessoas - Falha } \\
\text { Humana / } \\
\text { Tecnologia - } \\
\text { Sistemas }\end{array}$ & 5 & 4 & 20 & $\begin{array}{l}\text { Alerta no Sistema; } \\
\text { Vinculação do evento } \\
\text { principal e senha. }\end{array}$ & Controle Direto & 2 & 18 & 7 & 126 \\
\hline $\begin{array}{l}\text { 4. Efetuar análise das cobranças } \\
\text { médico-hospitalares }\end{array}$ & $\begin{array}{l}\text { Interpretação do analista nas } \\
\text { informações provenientes da } \\
\text { auditoria. }\end{array}$ & $\begin{array}{l}\text { Pessoas - Falha } \\
\text { Humana }\end{array}$ & 3 & 4 & 12 & $\begin{array}{l}\text { Atividade de } \\
\text { conferência de } \\
\text { contas médicas }\end{array}$ & $\begin{array}{l}\text { Controle Básico - } \\
\text { Conferências e } \\
\text { Autorizações } \\
\end{array}$ & 2 & 10 & 9 & 90 \\
\hline $\begin{array}{l}\text { 4. Efetuar análise das cobranças } \\
\text { médico-hospitalares }\end{array}$ & $\begin{array}{l}\text { Recebimento de notas fiscais } \\
\text { provenientes das Unidades sem a } \\
\text { checagem para pertinência do } \\
\text { pagamento, gerando processamento } \\
\text { indevido, atraso e retrabalho. }\end{array}$ & $\begin{array}{l}\text { Pessoas - Falha } \\
\text { Humana / } \\
\text { Tecnologia - } \\
\text { Sistemas }\end{array}$ & 3 & 4 & 12 & $\begin{array}{l}\text { Assinatura do Gestor } \\
\text { da Unidade na nota } \\
\text { fiscal / Atividade de } \\
\text { conferência de } \\
\text { contas médicas }\end{array}$ & $\begin{array}{l}\text { Controle Básico - } \\
\text { Conferências e } \\
\text { Autorizações / Alçadas }\end{array}$ & 2 & 10 & 8 & 80 \\
\hline $\begin{array}{l}\text { 4. Efetuar análise das cobranças } \\
\text { médico-hospitalares }\end{array}$ & $\begin{array}{l}\text { Processamento indevido por } \\
\text { ausência de impostação e } \\
\text { atualização dos dados cadastrais dos } \\
\text { prestadores e participantes, como: } \\
\text { especialidade, pacotes, tabela } \\
\text { negocial, alertas, inclusão nos } \\
\text { módulos específicos dos } \\
\text { participantes, autorizações, } \\
\text { conversão de graus. }\end{array}$ & $\begin{array}{l}\text { Pessoas - Falha } \\
\text { Humana }\end{array}$ & 5 & 3 & 15 & $\begin{array}{l}\text { Parametrização e } \\
\text { impostação de dados } \\
\text { no Sistema de } \\
\text { Pagamentos pela } \\
\text { Sede e Unidades. }\end{array}$ & Controle Direto & 4 & 11 & 7 & 77 \\
\hline $\begin{array}{l}\text { 4. Efetuar análise das cobranças } \\
\text { médico-hospitalares }\end{array}$ & $\begin{array}{l}\text { Ausência de informativos ou } \\
\text { informações incorretas que subsidiem } \\
\text { o pagamento diferenciado para } \\
\text { determinado participante ou } \\
\text { prestadores. }\end{array}$ & $\begin{array}{l}\text { Pessoas - Falha } \\
\text { Humana }\end{array}$ & 3 & 4 & 12 & $\begin{array}{l}\text { Impostação de } \\
\text { alertas no sistema }\end{array}$ & Controle Direto & 2 & 10 & 7 & 70 \\
\hline $\begin{array}{l}\text { 4. Efetuar análise das cobranças } \\
\text { médico-hospitalares }\end{array}$ & $\begin{array}{l}\text { Processamento indevido, mediante } \\
\text { autorizações com status de } \\
\text { cancelado no SOC. }\end{array}$ & $\begin{array}{l}\text { Pessoas - Falha } \\
\text { Humana }\end{array}$ & 3 & 4 & 12 & $\begin{array}{l}\text { Glosas do sistema / } \\
\text { Atividade de } \\
\text { conferência de } \\
\text { contas médicas }\end{array}$ & $\begin{array}{l}\text { Controle Direto / } \\
\text { Controle Básico - } \\
\text { Conferências e } \\
\text { Autorizações }\end{array}$ & 2 & 10 & 7 & 70 \\
\hline $\begin{array}{l}\text { 4. Efetuar análise das cobranças } \\
\text { médico-hospitalares }\end{array}$ & $\begin{array}{l}\text { Processamento indevido de OPME } \\
\text { quando da impostação incorreta, } \\
\text { ausência de detalhamento, na } \\
\text { autorização, dos materiais/ } \\
\text { medicamentos a serem abonados. }\end{array}$ & $\begin{array}{l}\text { Pessoas - Falha } \\
\text { Humana }\end{array}$ & 3 & 4 & 12 & $\begin{array}{l}\text { Atividade de } \\
\text { conferência de } \\
\text { contas médicas }\end{array}$ & $\begin{array}{l}\text { Controle Básico - } \\
\text { Conferências e } \\
\text { Autorizações }\end{array}$ & 2 & 10 & 7 & 70 \\
\hline $\begin{array}{l}\text { 4. Efetuar análise das cobranças } \\
\text { médico-hospitalares }\end{array}$ & $\begin{array}{l}\text { Pagamento indevido/duplicado de } \\
\text { honorários médicos cobrados pelo } \\
\text { hospital e pela equipe médica. }\end{array}$ & $\begin{array}{l}\text { Pessoas - Falha } \\
\text { Humana }\end{array}$ & 3 & 4 & 12 & $\begin{array}{l}\text { Apontamento de } \\
\text { glosa pelo sistema. }\end{array}$ & Controle Direto & 2 & 10 & 5 & 50 \\
\hline
\end{tabular}




\begin{tabular}{|c|c|c|c|c|c|c|c|c|c|c|c|}
\hline ATIVIDADE & RISCO & SUBCATEGORIA & Probabilidade & Impacto & $\begin{array}{l}\text { Risco } \\
\text { Bruto } \\
\end{array}$ & CONTROLE & CAT_CONTROLE & NC & RR & D & RPN \\
\hline $\begin{array}{l}\text { 4. Efetuar análise das cobranças } \\
\text { médico-hospitalares }\end{array}$ & $\begin{array}{l}\text { Verificação desnecessária de alertas } \\
\text { repetitivos para os eventos da } \\
\text { mesma guia, do mesmo Protocolo. }\end{array}$ & $\begin{array}{l}\text { Pessoas - Falha } \\
\text { Humana / } \\
\text { Tecnologia - } \\
\text { Sistemas } \\
\end{array}$ & 5 & 4 & 20 & $\begin{array}{l}\text { Apontamentos dos } \\
\text { alertas inconsistentes } \\
\text { à área gestora }\end{array}$ & Controle Direto & 2 & 18 & 2 & 36 \\
\hline $\begin{array}{l}\text { 4. Efetuar análise das cobranças } \\
\text { médico-hospitalares }\end{array}$ & $\begin{array}{l}\text { Ausência de impostações do plano } \\
\text { terapêutico nas autorizações do PAD, } \\
\text { gerando atraso de processamento e } \\
\text { perda de produtividade. }\end{array}$ & $\begin{array}{l}\text { Pessoas - Falha } \\
\text { Humana }\end{array}$ & 3 & 4 & 12 & $\begin{array}{l}\text { Conferência do } \\
\text { núcleo de auditoria } \\
\text { técnica de contas } \\
\text { médicas } \\
\end{array}$ & $\begin{array}{l}\text { Controle Básico - } \\
\text { Conferências e } \\
\text { Autorizações }\end{array}$ & 2 & 10 & 3 & 30 \\
\hline $\begin{array}{l}\text { 4. Efetuar análise das cobranças } \\
\text { médico-hospitalares }\end{array}$ & $\begin{array}{l}\text { Pagamento indevido/duplicado de } \\
\text { arquivos importados com } \\
\text { atendimentos idênticos. }\end{array}$ & $\begin{array}{l}\text { Pessoas - Falha } \\
\text { Humana }\end{array}$ & 3 & 4 & 12 & $\begin{array}{l}\text { Apontamento de } \\
\text { glosa pelo sistema / } \\
\text { Checagem de } \\
\text { parâmetros no } \\
\text { momento da } \\
\text { importação do } \\
\text { arquivo eletrônico } \\
\end{array}$ & Controle Direto & 2 & 10 & 2 & 20 \\
\hline $\begin{array}{l}\text { 4. Efetuar análise das cobranças } \\
\text { médico-hospitalares }\end{array}$ & $\begin{array}{l}\text { Pagamento indevido/duplicado de } \\
\text { itens já inclusos nos pacotes } \\
\text { negociados com os prestadores de } \\
\text { serviços. }\end{array}$ & $\begin{array}{l}\text { Pessoas - Falha } \\
\text { Humana / } \\
\text { Tecnologia - } \\
\text { Sistemas } \\
\end{array}$ & 3 & 4 & 12 & $\begin{array}{l}\text { Atividade de } \\
\text { conferência de } \\
\text { contas médicas }\end{array}$ & $\begin{array}{l}\text { Controle Básico - } \\
\text { Conferências e } \\
\text { Autorizações }\end{array}$ & 2 & 10 & 1 & 10 \\
\hline $\begin{array}{l}\text { 5. Encaminhar ocorrência para } \\
\text { regularização da área responsável } \\
\text { (Unidades / Sede). }\end{array}$ & $\begin{array}{l}\text { Apontamento incompleto e/ou } \\
\text { incorreto da necessidade de } \\
\text { intervenção da área responsável. }\end{array}$ & $\begin{array}{l}\text { Pessoas - Falha } \\
\text { Humana }\end{array}$ & 3 & 3 & 9 & $\begin{array}{l}\text { Avaliação prévia da } \\
\text { inconsistência pelo } \\
\text { coordenador de } \\
\text { equipe via e-mail. }\end{array}$ & Controle Direto & 3 & 6 & 2 & 12 \\
\hline $\begin{array}{l}\text { 5. Encaminhar ocorrência para } \\
\text { regularização da área responsável } \\
\text { (Unidades / Sede). }\end{array}$ & $\begin{array}{l}\text { Ausência de encaminhamento das } \\
\text { inconsistências às áreas } \\
\text { responsáveis para devida } \\
\text { regularização. }\end{array}$ & $\begin{array}{l}\text { Pessoas - Falha } \\
\text { Humana }\end{array}$ & 3 & 3 & 9 & Não há controle. & Sem Controle & 0 & 9 & 3 & 27 \\
\hline $\begin{array}{l}\text { 6. Receber retorno de inconsistências } \\
\text { sinalizadas às áreas responsáveis. }\end{array}$ & $\begin{array}{l}\text { Morosidade no recebimento da } \\
\text { resolução dos apontamentos ou não } \\
\text { recebimento de resposta em relação } \\
\text { a: cadastro de prestadores e } \\
\text { participantes / autorização / } \\
\text { parametrização / alertas / tabelas de } \\
\text { preços. }\end{array}$ & $\begin{array}{l}\text { Pessoas - Falha } \\
\text { Humana }\end{array}$ & 3 & 4 & 12 & $\begin{array}{l}\text { Compilação de } \\
\text { inconsistências e } \\
\text { acompanhamento por } \\
\text { e-mail. }\end{array}$ & Controle Direto & 2 & 10 & 2 & 20 \\
\hline $\begin{array}{l}\text { 7. Devolver guias e preparar } \\
\text { correspondência de devolução aos } \\
\text { prestadores de serviços e Unidades. }\end{array}$ & $\begin{array}{l}\text { Não efetivação da devolução da } \\
\text { documentação física, efetuada } \\
\text { somente no sistema. }\end{array}$ & $\begin{array}{l}\text { Pessoas - Falha } \\
\text { Humana }\end{array}$ & 3 & 3 & 9 & $\begin{array}{l}\text { Apontamento do } \\
\text { sistema no momento } \\
\text { do arquivamento }\end{array}$ & Controle Direto & 3 & 6 & 3 & 18 \\
\hline $\begin{array}{l}\text { 7. Devolver guias e preparar } \\
\text { correspondência de devolução aos } \\
\text { prestadores de serviços e Unidades. }\end{array}$ & Extravio das guias devolvidas. & $\begin{array}{l}\text { Pessoas - Falha } \\
\text { Humana }\end{array}$ & 2 & 4 & 8 & $\begin{array}{l}\text { Critérios de } \\
\text { reconstituição das } \\
\text { guias }\end{array}$ & Controle Direto & 2 & 6 & 3 & 18 \\
\hline $\begin{array}{l}\text { 7. Devolver guias e preparar } \\
\text { correspondência de devolução aos } \\
\text { prestadores de serviços e Unidades. }\end{array}$ & Devolução improcedente das guias. & $\begin{array}{l}\text { Pessoas - Falha } \\
\text { Humana }\end{array}$ & 3 & 3 & 9 & \begin{tabular}{|l|} 
Avaliação da carta de \\
devolução pelo \\
coordenador de \\
equipe
\end{tabular} & Controle Direto & 2 & 7 & 2 & 14 \\
\hline
\end{tabular}




\begin{tabular}{|c|c|c|c|c|c|c|c|c|c|c|c|}
\hline ATIVIDADE & RISCO & SUBCATEGORIA & Probabilidade & Impacto & $\begin{array}{l}\text { Risco } \\
\text { Bruto } \\
\end{array}$ & CONTROLE & CAT_CONTROLE & NC & RR & D & RPN \\
\hline $\begin{array}{l}\text { 7. Devolver guias e preparar } \\
\text { correspondência de devolução aos } \\
\text { prestadores de serviços e Unidades. }\end{array}$ & $\begin{array}{l}\text { Direcionamento incorreto das } \\
\text { devoluções, para os prestadores de } \\
\text { serviços ou Unidades. }\end{array}$ & $\begin{array}{l}\text { Pessoas - Falha } \\
\text { Humana }\end{array}$ & 3 & 3 & 9 & \begin{tabular}{|l|} 
Avaliação prévia pelo \\
coordenador de \\
equipe e equipe da \\
Gerência de \\
Atendimento. \\
\end{tabular} & Controle Direto & 2 & 7 & 1 & 7 \\
\hline $\begin{array}{l}\text { 7. Devolver guias e preparar } \\
\text { correspondência de devolução aos } \\
\text { prestadores de serviços e Unidades. }\end{array}$ & $\begin{array}{l}\text { Exclusão dos registros no Sistema de } \\
\text { Pagamentos dos atendimentos } \\
\text { originais extraviados, após a } \\
\text { devolução. }\end{array}$ & $\begin{array}{l}\text { Pessoas - Falha } \\
\text { Humana / } \\
\text { Tecnologia - } \\
\text { Sistemas }\end{array}$ & 3 & 4 & 12 & $\begin{array}{l}\text { Critérios de } \\
\text { reconstituição das } \\
\text { guias }\end{array}$ & Controle Direto & 2 & 10 & 5 & 50 \\
\hline $\begin{array}{l}\text { 7. Devolver guias e preparar } \\
\text { correspondência de devolução aos } \\
\text { prestadores de serviços e Unidades. }\end{array}$ & $\begin{array}{l}\text { Agrupamento dos registros de } \\
\text { devoluções na impressão do relatório } \\
\text { para diferentes Protocolos } \\
\text { devolvidos, do mesmo prestador, } \\
\text { geradas na mesma data. }\end{array}$ & $\begin{array}{l}\text { Pessoas - Falha } \\
\text { Humana / } \\
\text { Tecnologia - } \\
\text { Sistemas }\end{array}$ & 3 & 4 & 12 & $\begin{array}{l}\text { Ajuste manual do } \\
\text { analista de contas }\end{array}$ & Controle Direto & 2 & 10 & 2 & 20 \\
\hline $\begin{array}{l}\text { 7. Devolver guias e preparar } \\
\text { correspondência de devolução aos } \\
\text { prestadores de serviços e Unidades. }\end{array}$ & $\begin{array}{l}\text { Devolução inconsistente aos } \\
\text { prestadores e Unidades, devido à } \\
\text { replicação do motivo de devolução } \\
\text { específico de uma guia em todas. }\end{array}$ & $\begin{array}{l}\text { Pessoas - Falha } \\
\text { Humana / } \\
\text { Tecnologia - } \\
\text { Sistemas }\end{array}$ & 3 & 4 & 12 & $\begin{array}{l}\text { Ajuste manual do } \\
\text { analista de contas }\end{array}$ & Controle Direto & 2 & 10 & 2 & 20 \\
\hline $\begin{array}{l}\text { 8. Mudar de fase os Protocolos } \\
\text { processados. }\end{array}$ & $\begin{array}{l}\text { Envio de Protocolos à equipe de } \\
\text { conferência sem a devida realização } \\
\text { da mudança de fase, ocasionando } \\
\text { atraso no processamento. }\end{array}$ & $\begin{array}{l}\text { Pessoas - Falha } \\
\text { Humana }\end{array}$ & 3 & 2 & 6 & $\begin{array}{l}\text { Atividade de } \\
\text { conferência de } \\
\text { contas médicas e } \\
\text { apontamento do } \\
\text { sistema no ato do } \\
\text { arquivamento } \\
\end{array}$ & $\begin{array}{l}\text { Controle Direto / } \\
\text { Controle Básico - } \\
\text { Conferências e } \\
\text { Autorizações }\end{array}$ & 3 & 3 & 2 & 6 \\
\hline $\begin{array}{l}\text { 8. Mudar de fase os Protocolos } \\
\text { processados. }\end{array}$ & $\begin{array}{l}\text { Não encaminhamento das guias } \\
\text { físicas indispensáveis para o } \\
\text { processo de conferência. }\end{array}$ & $\begin{array}{l}\text { Pessoas - Falha } \\
\text { Humana }\end{array}$ & 2 & 2 & 4 & \begin{tabular}{|l|} 
Atividade de \\
conferência de \\
contas médicas
\end{tabular} & $\begin{array}{l}\text { Controle Básico - } \\
\text { Conferências e } \\
\text { Autorizações } \\
\end{array}$ & 2 & 2 & 1 & 2 \\
\hline $\begin{array}{l}\text { 8. Mudar de fase os Protocolos } \\
\text { processados. }\end{array}$ & $\begin{array}{l}\text { Inobservância de todas as } \\
\text { pendências de processamento antes } \\
\text { da liberação da alçada } \\
\text { (incompatibilidades). }\end{array}$ & $\begin{array}{l}\text { Pessoas - Falha } \\
\text { Humana / } \\
\text { Tecnologia - } \\
\text { Sistemas }\end{array}$ & 5 & 4 & 20 & $\begin{array}{l}\text { Apontamentos do } \\
\text { sistema }\end{array}$ & Controle Direto & 2 & 18 & 2 & 36 \\
\hline $\begin{array}{l}\text { 8. Mudar de fase os Protocolos } \\
\text { processados. }\end{array}$ & $\begin{array}{l}\text { Não observância pelo analista de } \\
\text { contas das pendências de análise } \\
\text { antes da mudança de fase. }\end{array}$ & $\begin{array}{l}\text { Pessoas - Falha } \\
\text { Humana / } \\
\text { Tecnologia - } \\
\text { Sistemas } \\
\end{array}$ & 3 & 4 & 12 & $\begin{array}{l}\text { Apontamentos do } \\
\text { Sistema de } \\
\text { Pagamentos }\end{array}$ & Controle Direto & 3 & 9 & 2 & 18 \\
\hline $\begin{array}{l}\text { 9. Receber ocorrências e encaminhar } \\
\text { contas processadas à Equipe de } \\
\text { Conferência. }\end{array}$ & $\begin{array}{l}\text { Não recebimento/devolução de } \\
\text { ocorrências provenientes da } \\
\text { conferência. }\end{array}$ & $\begin{array}{l}\text { Pessoas - Falha } \\
\text { Humana }\end{array}$ & 3 & 3 & 9 & $\begin{array}{l}\text { Acompanhamento } \\
\text { das ocorrências pela } \\
\text { equipe de } \\
\text { conferência por meio } \\
\text { de planilha }\end{array}$ & Controle Direto & 3 & 6 & 2 & 12 \\
\hline $\begin{array}{l}\text { 9. Receber ocorrências e encaminhar } \\
\text { contas processadas à Equipe de } \\
\text { Conferência. }\end{array}$ & $\begin{array}{l}\text { Não regularização da ocorrência, } \\
\text { recepcionada e devolvida à equipe de } \\
\text { conferência. }\end{array}$ & $\begin{array}{l}\text { Pessoas - Falha } \\
\text { Humana }\end{array}$ & 2 & 3 & 6 & $\begin{array}{l}\text { Atividade de } \\
\text { conferência de } \\
\text { contas médicas }\end{array}$ & $\begin{array}{l}\text { Controle Básico - } \\
\text { Conferências e } \\
\text { Autorizações }\end{array}$ & 3 & 3 & 2 & 6 \\
\hline
\end{tabular}




\begin{tabular}{|c|c|c|c|c|c|c|c|c|c|c|c|}
\hline ATIVIDADE & RISCO & SUBCATEGORIA & Probabilidade & Impacto & \begin{tabular}{|l|} 
Risco \\
Bruto \\
\end{tabular} & CONTROLE & CAT_CONTROLE & NC & $\mathbf{R R}$ & D & RPN \\
\hline $\begin{array}{l}\text { 9. Receber ocorrências e encaminhar } \\
\text { contas processadas à Equipe de } \\
\text { Conferência. }\end{array}$ & $\begin{array}{l}\text { Não efetivação da mudança de fase } \\
\text { do status de análise para conferência } \\
\text { das ocorrências regularizadas. }\end{array}$ & $\begin{array}{l}\text { Pessoas - Falha } \\
\text { Humana }\end{array}$ & 3 & 2 & 6 & $\begin{array}{l}\text { Atividade de } \\
\text { conferência de } \\
\text { contas médicas }\end{array}$ & $\begin{array}{l}\text { Controle Básico - } \\
\text { Conferências e } \\
\text { Autorizações }\end{array}$ & 3 & 3 & 2 & 6 \\
\hline $\begin{array}{l}\text { 9. Receber ocorrências e encaminhar } \\
\text { contas processadas à Equipe de } \\
\text { Conferência. }\end{array}$ & $\begin{array}{l}\text { Não recebimento das ocorrências em } \\
\text { tempo hábil para regularização dentro } \\
\text { do prazo do protocolo. }\end{array}$ & $\begin{array}{l}\text { Pessoas - Falha } \\
\text { Humana }\end{array}$ & 2 & 2 & 4 & $\begin{array}{l}\text { Priorização das } \\
\text { ocorrências } \\
\text { solicitadas pelo } \\
\text { coordenador de } \\
\text { equipe }\end{array}$ & Controle Direto & 2 & 2 & 2 & 4 \\
\hline $\begin{array}{l}\text { 9. Receber ocorrências e encaminhar } \\
\text { contas processadas à Equipe de } \\
\text { Conferência. }\end{array}$ & $\begin{array}{l}\text { Recebimento da ocorrência pela } \\
\text { equipe indevida. }\end{array}$ & $\begin{array}{l}\text { Pessoas - Falha } \\
\text { Humana }\end{array}$ & 2 & 2 & 4 & $\begin{array}{l}\text { Identificação da } \\
\text { equipe responsável } \\
\text { por meio do Tipo de } \\
\text { guia/UF/prestador }\end{array}$ & Controle Direto & 2 & 2 & 1 & 2 \\
\hline $\begin{array}{l}\text { 9. Receber ocorrências e encaminhar } \\
\text { contas processadas à Equipe de } \\
\text { Conferência. }\end{array}$ & $\begin{array}{l}\text { Não regularização da ocorrência em } \\
\text { tempo hábil do protocolo em questão. }\end{array}$ & $\begin{array}{l}\text { Pessoas - Falha } \\
\text { Humana }\end{array}$ & 2 & 2 & 4 & $\begin{array}{l}\text { Priorização das } \\
\text { ocorrências } \\
\text { solicitadas pelo } \\
\text { coordenador de } \\
\text { equipe }\end{array}$ & Controle Direto & 2 & 2 & 1 & 2 \\
\hline
\end{tabular}




\section{APÊNDICE III - Formulário de Levantamento de Riscos}

Área Gestora:

Data:

\section{Processo Avaliado:}

Prezado (a),

Conforme descrito no normativo PO-14.0005 - Metodologia de Autoavaliação de Riscos e Controles, a Gerência de Riscos e Controles Internos (GRCI) está realizando a análise do processo acima, sob a ótica de riscos e suficiência de controles.

A equipe de autoavaliação, composta por facilitadores da GRCI em conjunto com representantes dessa dependência, realizou o mapeamento das atividades do processo e identificação do conjunto inicial de riscos em cada atividade do macrofluxo, que foi encaminhado em anexo juntamente com este formulário.

Considerando os riscos identificados pela equipe, e a sua experiência em relação ao processo avaliado, solicitamos que atribua a cada um dos riscos identificados a seguir os valores de Probabilidade e Impacto.

Para atribuição dos valores, considere as variáveis descritas no quadro a seguir.

\begin{tabular}{|c|c|c|c|}
\hline \multirow{6}{*}{ Probabilidade } & Valor & \multicolumn{2}{|c|}{ Conceito } \\
\hline & 5 & \multicolumn{2}{|c|}{$\begin{array}{l}\text { Quase certa - Com histórico de ocorrências anteriores, e fortes indícios de que } \\
\text { o evento voltará a ocorrer }\end{array}$} \\
\hline & 4 & \multicolumn{2}{|c|}{$\begin{array}{l}\text { Provável - Sem histórico de ocorrências anteriores, porém com Fortes indícios } \\
\text { de que o evento ocorrerá. }\end{array}$} \\
\hline & 3 & \multicolumn{2}{|c|}{$\begin{array}{l}\text { Moderada - Com ou sem histórico de ocorrências anteriores, e apenas alguns } \\
\text { indícios de que o evento ocorrerá. }\end{array}$} \\
\hline & 2 & \multicolumn{2}{|c|}{$\begin{array}{l}\text { Eventual - Com ou sem histórico de ocorrências anteriores, e indícios de que o } \\
\text { evento só ocorrerá em circunstâncias excepcionais. }\end{array}$} \\
\hline & 1 & \multicolumn{2}{|c|}{$\begin{array}{l}\text { Improvável - Sem histórico de ocorrências anteriores, e sem indícios de que o } \\
\text { evento ocorrerá. }\end{array}$} \\
\hline \multirow{5}{*}{ Impacto } & 5 & Extremo & \multirow{5}{*}{$\begin{array}{l}\text { Resulta da combinação entre as perdas } \\
\text { Financeiras e o desgaste da imagem da } \\
\text { organização. }\end{array}$} \\
\hline & 4 & Alto & \\
\hline & 3 & Médio & \\
\hline & 2 & Baixo & \\
\hline & 1 & Irrelevante & \\
\hline
\end{tabular}

Ao final da análise, caso identifique algum outro risco não apontado pela equipe de autoavaliação, gentileza registre-os no campo "Sugestão de riscos adicionais a serem avaliados". 


\section{APÊNDICE III - Formulário de Levantamento de Riscos}

\begin{tabular}{|c|c|c|c|}
\hline \multirow{2}{*}{ RISCOS IDENTIFICADOS PELA EQUIPE DE AUTOAVALIAÇÃO } & \multicolumn{3}{|c|}{ PROBABILIDADE X IMPACTO } \\
\hline & $\mathbf{P}$ & $\mathbf{I}$ & CONCEITO (P X I) \\
\hline \multicolumn{4}{|l|}{ <Descrição dos riscos preenchida pela equipe de autoavaliação > } \\
\hline & & & \\
\hline & & & \\
\hline & & & \\
\hline & & & \\
\hline & & & \\
\hline & & & \\
\hline (2) & & & \\
\hline
\end{tabular}

\begin{tabular}{|c|c|c|c|}
\hline \multirow{2}{*}{ SUGESTÃO DE RISCOS ADICIONAIS A SEREM AVALIADOS } & \multicolumn{3}{|c|}{ PROBABILIDADE X IMPACTO } \\
\hline & $\mathbf{P}$ & I & CONCEITO (P X I) \\
\hline \multicolumn{4}{|l|}{ <Descrição dos riscos preenchida pelo colaborador da área gestora> } \\
\hline & & & \\
\hline & & & \\
\hline & & & \\
\hline & & & \\
\hline & & & \\
\hline & & & \\
\hline 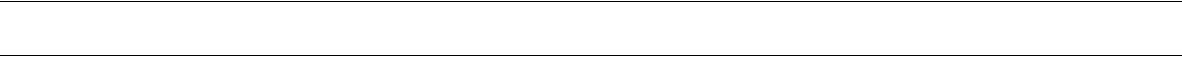 & & & \\
\hline
\end{tabular}

